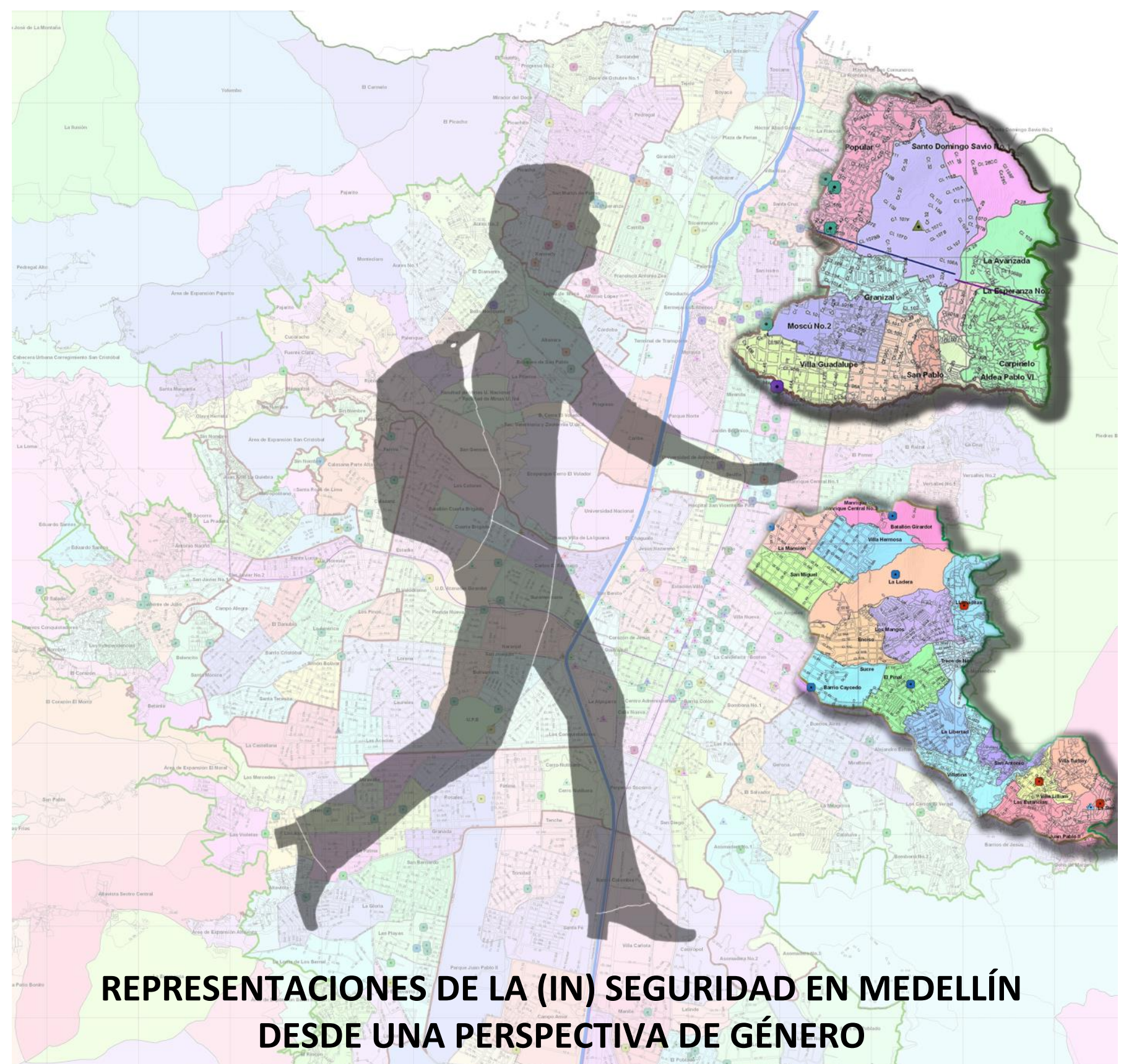

Heidy Cristina Gómez Ramírez

Tesis de Maestría para optar al título de

Magister en Ciencias Sociales UNLP - Argentina 2015 


\title{
Representaciones de la (in) seguridad en Medellín desde una perspectiva de género
}

\author{
Heidy Cristina Gómez Ramírez \\ Tesis de Maestría para optar al título de \\ Magister en Ciencias Sociales
}

\author{
Director \\ Esteban Rodríguez Alzueta, Mg en Ciencias Sociales \\ Co directora \\ Ruth López Loseira, Ph en Historia
}

Universidad Nacional de la Plata

Facultad de Humanidades y Ciencias de la Educación

2015 


\section{Agradecimientos}

A las mujeres de las comunas que abrieron un espacio para compartir conmigo esa parte de sus vidas, que abrieron su corazón y por un momento me entregaron sus miedos pero también sus certezas.

A ese ser que ya no está, pero que siempre me acompaña con su luz.

A las mujeres de mi vida, mi madre y hermana que siempre están allí incondicionales en el amor. A mi compañero de vida, paciente y noble que llena de fortaleza y esperanza cada paso de mi vida. 


\section{TABLA DE CONTENIDO}

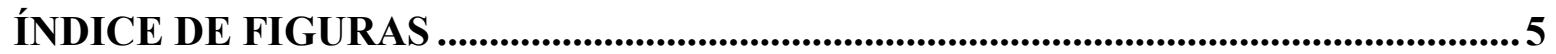

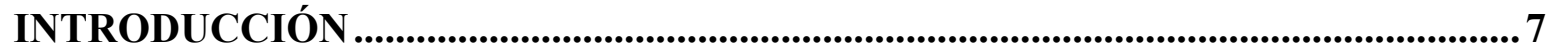

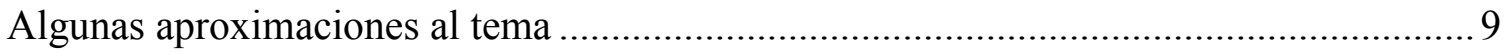

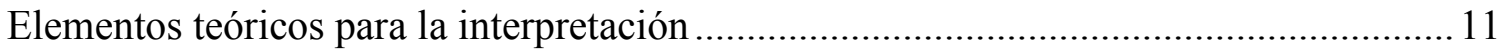

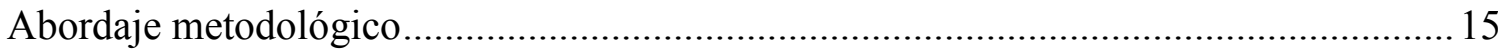

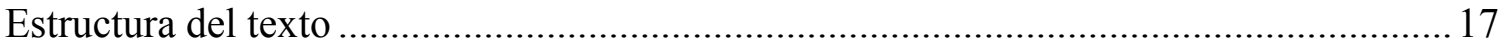

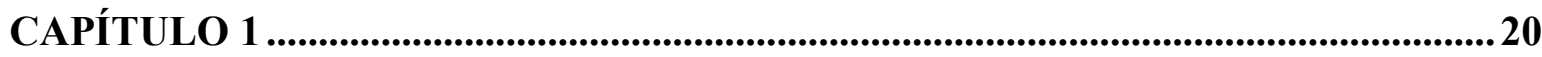

LAS MUJERES EN MEDELLÍN, UN CAMPO HOSTIL............................................20

DE VIOLENCIAS E INSEGURIDADES ......................................................................20

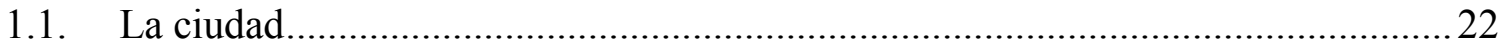

1.1.1. Una historia marcada por las violencias ........................................................25



1.2. Comunas 1 - Popular (C1P) y 8 - Villa Hermosa (C8VH) ......................................... 41

1.2.1. Contexto espacial y social ............................................................................... 41

1.2.2. Caracterización del conflicto armado urbano en las $\mathrm{C} 1 \mathrm{P}$ y $\mathrm{C} 8 \mathrm{VH}$........................50

1.2.3. Otros detonantes de la violencia y la inseguridad en las comunas........................56

1.3. Un enfoque diferenciado desde las políticas públicas de seguridad ..........................59

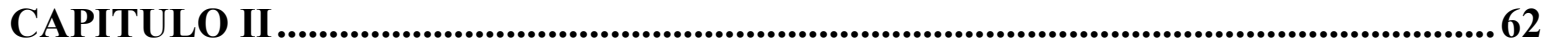

ESTRUCTURAS RELACIONALES DEL MIEDO ……...............................................62

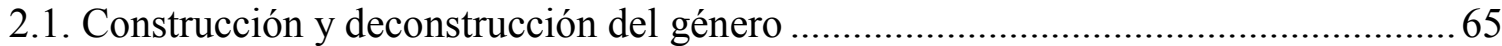

2.2. Escenarios de dominación, responsabilidad o búsqueda de libertad ..........................77

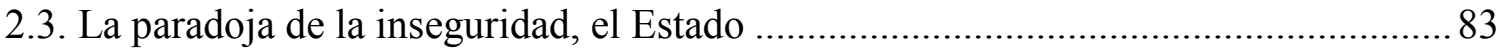

2.4. Control social y territorial en el marco de la ilegalidad............................................... 88

2.5. Capital Social y Problemáticas Sociales ¿construyen representaciones? ...................98

CAPITULO III ........................................................................................................................... 105

ESPACIOS DE INSEGURIDAD Y MIEDO _........................................................105

3.1 La ciudad, lo urbano, el centro... lo ajeno, lo extraño... lo distante ...........................111

3.1.1. Un asunto de segregación espacial.................................................................116

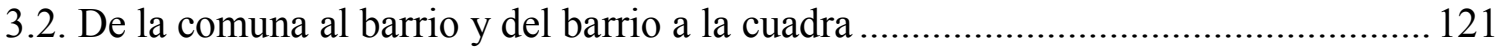

3.2.1 Puntos de referencia en la representación del barrio y la comuna ....................... 124 
3.2.2 ¿"Fronteras invisibles"?, urdimbre de las representaciones ................................. 126

3.3. La casa ¿espacio seguro por excelencia? .......................................................... 133

3.4. Los medios de comunicación median las representaciones ..................................... 136

3.4.1. Una aproximación al análisis de medios ......................................................... 137

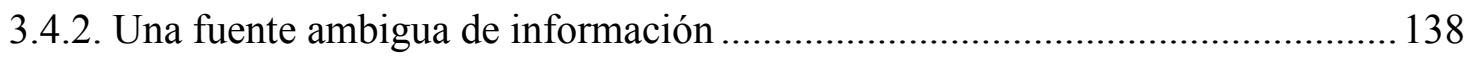

3.4.3. Otros recursos, otros medios de información..................................................... 141

CONSIDERACIONES FINALES ….....................................................................143

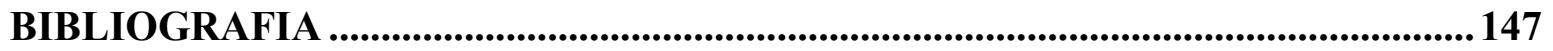

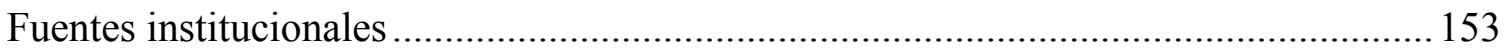

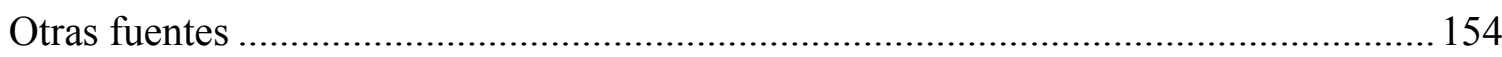

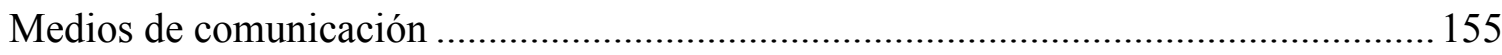

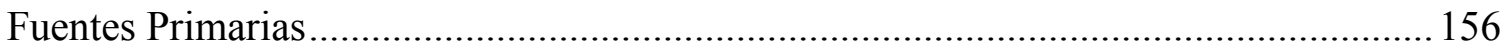

\section{ÍNDICE DE FIGURAS}

Figura 1. Población en Medellín según sexo........................................................................... 22

Figura 2. Países con tasa promedio anual de muertes violentas................................................... 25

Figura 3. Homicidios Principales ciudades de Colombia................................................................. 26

Figura 4. Homicidios en Medellín según sexo............................................................................... 31

Figura 5. Delitos sexuales en las principales ciudades del país. ................................................... 34

Figura 6. Número de desplazados en Medellín. ............................................................................ 35

Figura 7. Desplazados intraurbanos en Medellín según sexo......................................................... 36

Figura 8. Violencia intrafamiliar en Medellín según sexo 2005-2011 ......................................... 40

Figura 9. Delitos en Medellín según sexo - 2011 ...................................................................... 41

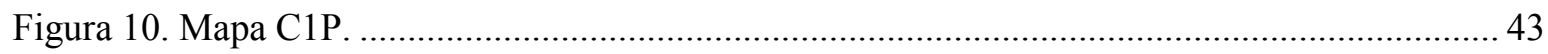

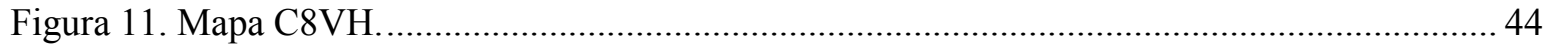

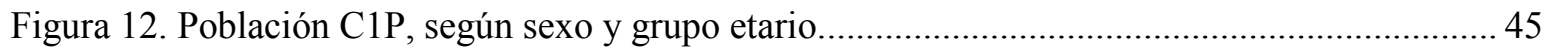

Figura 13. Población C8VH, según sexo y grupo etario ............................................................... 48

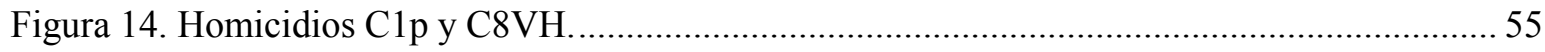

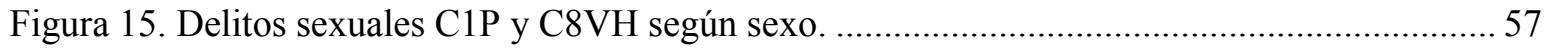

Figura 16. Violencia Intrafamiliar, C1P y C8VH según sexo............ ¡Error! Marcador no definido.

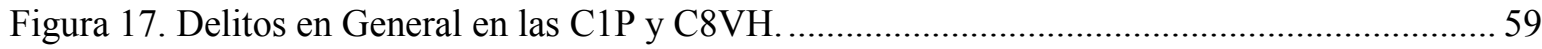

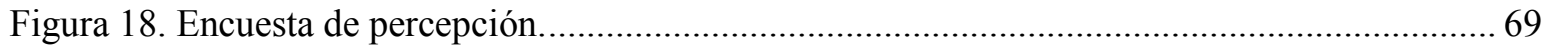


Figura 19. Usos del espacio.......

\section{ÍNDICE DE TABLAS}

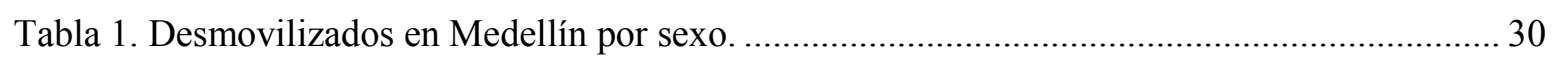

Tabla 2. Número de desmovilizados por comuna. ...................................................................... 52

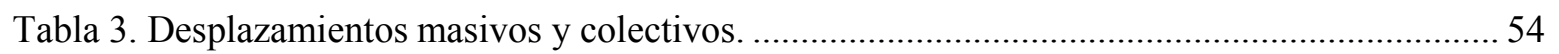

Tabla 4. Percepción de riesgos con enfoque diferenciado por comuna. ...........................................56

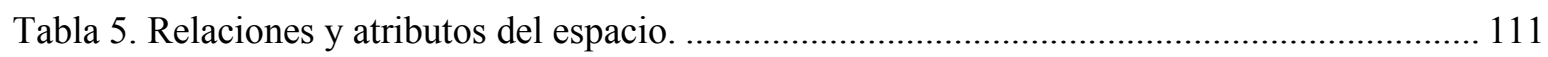

Tabla 6. Variables y atributos en la representación de la seguridad en la ciudad......................... 115

Tabla 7. Representaciones de inseguridad en el barrio y la comuna............................................ 133 


\section{INTRODUCCIÓN}

La situación de violencia en la ciudad de Medellín es un tema de preocupación constante que incide de manera directa en los modos de habitar la ciudad y en la formulación de las políticas públicas en materia de seguridad y convivencia. Sin embargo las políticas de seguridad existentes para enfrentar la criminalidad y a su vez generar confianza y tranquilidad a la ciudadanía, parecen no ser lo suficientemente eficaces, mucho menos para las mujeres, quienes cada vez se ven afectadas por diferentes hechos que se instauran en el campo de las múltiples violencias, sin una efectiva solución. El tema de la violencia y la (in) seguridad se complementan para hacer de la ciudad un caos en el que perviven los miedos de distinta naturaleza, ya sea por razones de orden público, delincuencia común, necesidades básicas insatisfechas y/o conflicto armado urbano.

A la hora de analizar los miedos es posible percibir que las masculinidades vertebran sus interpretaciones. Una masculinización que subordina las interpretaciones de las mujeres a los modos de sentir, percibir y pensar del hombre, dejando de lado las experiencias de las mujeres, sus vivencias, puntos de vista, que propician una sensación y percepción distintas, únicas e inexploradas porque no se encuentran en el sentido común, tan sólo en el de ellas mismas. De esa manera las mujeres, víctimas de la violencia, acaban siendo victimizadas otra vez cuando se las niega del relato o estudios sobre las violencias.

Es así como las formas de victimización y violencia contra las mujeres terminan siendo invisibilizadas ante la falta de un enfoque de género existente para cuantificar y analizar las violencias, podría decirse que solo en los últimos años, se ha dado un poco de relevancia al asunto y se realizan informes de victimización, de manera diferenciada, pues ha prevalecido el ideario de que los problemas de violencia física y sicológica no deben ser abordados como problemas públicos y generales sino como problemas privados y particulares.

Los elementos que inciden en la inseguridad de las mujeres no quedan reflejados en las estadísticas oficiales que tradicionalmente se emplean para indicar las tasas de criminalidad. Una razón de ello podría estar considerada dentro de lo que se denomina las "cifras negras de la criminalidad" (CAFSU, 2002 citado en Massolo, 2007: 136) que se traducen en los actos de violencia que por no existir en el sistema penal no son objeto de consideración en la denuncia oficial, y es evidente en 
tanto el urdimbre de las violencias por el cual atraviesan las mujeres pasa más por el componente subjetivo que objetivo que hacen parte de la seguridad.

En este sentido el tema de la violencia contra las mujeres como también la relación de seguridad y mujer, va delimitando enfoques que contribuyen a la construcción y de-construcción de las representaciones sociales que las mujeres tienen sobre la seguridad y la inseguridad. Esas precisiones conceptuales han ayudado a argumentar las condiciones de desigualdad, demandados por el movimiento de mujeres, expresadas en distintos instrumentos de incidencia jurídica y política que han tomado fuerza en las últimas décadas, creando una serie de mecanismos internacionales que buscan proteger los derechos humanos de las mujeres, además de aportar elementos para leer los temas relacionados con la seguridad de hombres y mujeres con un enfoque diferencial, los cuales se han ido incorporando en la jurisprudencia nacional como la Convención sobre la eliminación de todas las formas de discriminación establecida por la CEDAW en 1979, la Declaración para la eliminación de la violencia contra la mujer en 1994 creada por la Asamblea General de la ONU en su Resolución 48/104 y la Convención Interamericana para prevenir, sancionar y erradicar la violencia contra la mujer conocida como "convención de Belém Do Pará" y que a nivel Nacional se materializan en la Ley 1257 de 2008 donde se establecen normas de sensibilización, prevención y sanción de formas de violencia y discriminación contra las mujeres.

La inseguridad es diferente para las mujeres, no solo por su relación con el cuerpo que es donde afectan las principales violencias, sino por otros factores en los que inciden los diferentes tipos de violencias como causas, lugares, horarios y victimarios. Todo esto asociado a patrones culturales como la socialización del espacio público, la transmisión cultural de peligro y los roles de género, la concepción de sí mismas construida históricamente en una alteridad de subordinación y negación de derechos.

Esta investigación busca dar cuenta de las representaciones sociales que tienen las mujeres de la (in) seguridad, en dos comunas de la ciudad que se caracterizan por contextos de violencia urbana, pero que tienen unas connotaciones específicas que conllevan a unas representaciones particulares dadas las relaciones con el entorno, los/as otras, el espacio físico y los grupos armados legales e ilegales ${ }^{1}$,

\footnotetext{
${ }^{1}$ En esta investigación al hacer referencia de los grupos armados legales se hace alusión a la Fuerza Pública especialmente a la policía, quienes son los encargados en la ciudad y para este caso en los barrios y comunas de garantizar la seguridad y la protección de la ciudadanía. De otra parte los grupos armados ilegales de los
} 
pues se hace necesario "escudriñar a través de las representaciones, las ideologías, los discursos acuñados por las culturas y las prácticas de género para acceder a la economía simbólica que instala el régimen jerárquico y lo reproduce" (Segato: 2003: 14), y que no solo se reproducen en la violencia urbana en relación a un conflicto armado urbano sino a ese orden social que establece el comportamiento de hombres y mujeres en la sociedad.

En estas representaciones aparecen las violencias visibles que acontecen en la esfera doméstica, la casa, que dicho sea de paso es el lugar donde más ocurren los delitos sexuales, y que han sido tema de disputa y controversia por los movimientos sociales para hacer visible que lo privado también es público al igual que las violencias sexuales que siempre serán un tema recurrente cuando se aborda el tema de las violencias contra las mujeres. Pero en particular son el principal foco de interés de ésta investigación, las violencias que son invisibilizadas que hacen parte de lo cotidiano y que por estar insertas allí pasan desapercibidas, pero están limitando el goce de los espacios de ciudad, coartando las libertadas e imponiéndose en comportamientos normalizados.

\section{Algunas aproximaciones al tema}

En los últimos años el miedo, la violencia y la inseguridad han sido objeto de investigaciones en ciencias sociales, que buscan analizar su incidencia en la sociedad desde diversos enfoques y perspectivas. Igualmente la necesidad por explicar los fenómenos que acontecen en sociedades específicas ha conllevado a que se delimiten los espacios de indagación, con el fin de obtener un profundo análisis -que además de visibilizar algunas causas estructurales-, ayude a comprender y explicar los factores que irrumpen en la vida cotidiana de las personas alterando prácticas y formas de convivencia.

El miedo es un tema central y relevante para estudiar la inseguridad, en tanto que en relación a la delincuencia que es una de las principales problemáticas que enfrentan las ciudades, desencadena comportamientos tanto en hombres como en mujeres que de alguna manera contribuyen especialmente al control social de las mujeres, limitando el ejercicio de sus derechos e incrementando las brechas de desigualdad de género ya existentes. Situación que se expresa a partir de la conjugación de la perspectiva objetivista (datos estadísticos) y que es además el enfoque más

cuales se habla durante el texto hacen referencia a los combos y bandas ligadas en su mayoría al narcotráfico y que operan en los sectores donde se realizó la investigación. 
tradicional con la perspectiva construccionista social que permite entender el problema de la delincuencia como un fenómeno mucho más complejo (Madriz: 2001)

En cuanto al tema de seguridad, violencia y género, estos han sido el centro de interés de algunos países, especialmente en Latinoamérica, donde se ha visto con gran preocupación cómo los índices de violencia contra las mujeres han ido aumentando de una manera alarmante en las últimas décadas. Igualmente se vienen realizando importantes aportes que analizan la violencia que viven las mujeres especialmente en el espacio público. Estos estudios ponen de manifiesto los problemas que tienen las ciudades tanto en su infraestructura como en los modelos de planeación, que excluyen y niegan las dificultades que tienen las mujeres para un real acceso y ejercicio de sus derechos como son los casos concretos de Chile, España y Perú (Saborido: 2009; Duran:2008;), pero además la manera como estas formas de exclusión del espacio público inciden en las múltiples violencias que se ejercen contra las mujeres (Falú: 2009; Vargas: 2007).

Actualmente, en Colombia, los estudios sobre seguridad con enfoque de género no son muchos. Algunas de las investigaciones existentes centran y delimitan su estudio en el ámbito de la esfera doméstica, visibilizando y analizando el feminicidio como una consecuencia final y fatal de la violencia intrafamiliar (Castillo: 2007). Otras analizan las implicaciones y consecuencias en la seguridad de las mujeres por causa del conflicto armado interno que vive el país desde los lugares que ocupan dentro del mismo (Londoño: 2008) y algunas se centran en analizar la inseguridad en los entornos urbanos (Caicedo: 2013). Finalmente hay una interpretación sobre la legislación existente en materia de no violencia contra las mujeres orientada a que trascienda y se aplique adecuadamente (Ramírez: 2010).

Por su parte las investigaciones sobre la violencia de género en la ciudad de Medellín se quedan en informes y diagnósticos, algunos centrados en el tema de las violencias sexuales (Mujeres que crean: 2002 al 2013; Roldán: 2010; Gómez: 2007 y Gómez: 2009), los cuales responden más bien a requerimientos urgentes y manifiestos de la política pública que, aun siendo necesarios, toda vez que contribuyen a visibilizar el problema y a ponerlo en el centro del debate público, no trascienden el campo de análisis y la discusión teórica, pese a esto algunos avances ponen en la discusión el concepto de feminicidio desde el ámbito doméstico hasta el contexto urbano como visibilizando las realidades concretas y particulares que rodean estos casos (Vélez-Guzmán: 2012). 
Incluso algunos de estos diagnósticos son promovidos a partir de la asignación de recursos del presupuesto participativo por las organizaciones de base de mujeres y ejecutados por organizaciones sociales (IKALA: 2013a, IKALA: 2013b). Estos estudios constituyen un importante aporte no solo al conocimiento -en tanto que surgen de reflexiones y análisis de las mujeres que viven en los territorios-, sino que también constituyen insumos importantes para el diseño e implementación de políticas públicas que mejoren las condiciones de vida de las mujeres en sus territorios.

Este panorama vislumbra un amplio camino por recorrer en relación a los estudios de seguridad de las mujeres, que vaya más allá del hecho de que las mujeres se sientan seguras en el espacio público, tal como lo plantea la Corporación Humanas. Hay unos mínimos claros establecidos como el reconocimiento de los derechos humanos de las mujeres como un marco general, la seguridad económica para la autodeterminación de las mujeres, la no violencia contra las mujeres que garantiza la no discriminación, el goce de los derechos sexuales y reproductivos y la igualdad en la participación (Humanas: 2007).

Desde la academia el trabajo sobre las mujeres se ha abordado de una manera muy general haciendo énfasis en el tema de las múltiples violencias, sin embargo hay acercamientos en la lectura desde el enfoque de la seguridad humana donde se cuestionan asuntos como el ámbito doméstico, la pobreza, los feminicidios y la seguridad de la ciudad para las mujeres (Henao: 2012). La seguridad para las mujeres es una dimensión emergente que aparece desde este enfoque, concibiéndola, incluso, como uno de los asuntos prioritarios a trabajar en la ciudad (Sierra: 2010).

\section{Elementos teóricos para la interpretación}

Plantear el concepto de (in) seguridad en esta investigación ha llevado a atender otras categorías de análisis para poder abordar la problemática desde una perspectiva de género, es decir, para que tenga en cuenta las especificidades que fueron dejadas de lado en los estudios sobre la (in) seguridad y la violencia citados arriba. Es así como, conceptos como los de seguridad, violencia y miedo que se encuentran articulados entre sí, al mismo tiempo serán vertebrados desde la perspectiva de género. Nos interesa explorar cómo viven las mujeres el delito y la violencia, qué entienden por inseguridad, qué sienten. Averiguar y analizar las representaciones sociales que tienen sobre todos estos temas. La necesidad de contar con una perspectiva de género se justifica no solo para entender las diferencias entre hombres y mujeres, sino para ensayar políticas públicas que puedan atender las especificidades. 
La seguridad es un concepto que tiene diversos enfoques. Algunos, desde una perspectiva restringida o tradicional, en la cual prevalece el concepto clásico de Estado soberano en la protección y soberanía del territorio ante amenazas externas de los países (Kaminsky, 2005: 27). Otros hacen hincapié en la defensa de la propiedad privada y los bienes, incluyendo espacios y vivienda (Vargas: 2007: 28); y finalmente están los enfoques más amplios que consideran los diversos factores (salud, educación, alimentación, medio ambiente) que intervienen para que las personas se sientan seguras como también las condiciones reales con que cuentan para lograrlo, para ello se concibe desde un modelo más integral que articule varias dimensiones (PNUD, 1994).

Ahora bien, todos estos conceptos coinciden en hacer la distinción entre la seguridad objetiva y la seguridad subjetiva. Dos categorías relacionadas entre sí, pero nunca de una manera mecánica. La seguridad objetiva, se refiere a datos concretos y estadísticas reales que dan cuenta de la situación de seguridad; y la subjetiva, se relaciona con las experiencias y las vivencias desde las cuales las personas construyen sus percepciones y representaciones sobre la seguridad (Angarita: 2006; Palencia, 2002; Massolo, 2005). Es importante reconocer que si bien ambas se articulan de una manera indisociable, desde un análisis concreto sobre la in seguridad es la amenaza a la integridad física más que a los bienes lo que predomina (Kessler, 2009: 97), dejando en evidencia que en este caso la subjetividad opera como un elemento predominante en la manifestación de inseguridad.

Si bien la transformación del concepto seguridad ha tenido un importante avance en la medida en que se ha logrado trascender desde la visión militarista predominante a una más integral y centrada en las personas, ésta aún no es suficientemente inclusiva para que las mujeres se encuentren plenamente identificadas. Para ello hace falta entender varios factores, a saber: la política criminal no es lo mismo que la política de seguridad; las violencias existentes son vividas de forma diferente según el sexo, la edad o el estrato social; y las violencias que afectan a las mujeres van más allá de su concepción como grupo vulnerable (Laub, 2007: 60).

De allí que desde la perspectiva del género se hace necesario analizar la construcción cultural e histórica de la diferencia de los sexos, para que haya una real interpretación de lo que implica ser y estar seguro para hombres y mujeres y en algunos sentidos feminizar el concepto con el fin de que las conductas que no son tipificadas penalmente y a las cuales no se les hace ningún tipo de seguimiento sean reconocidas como generadoras de inseguridad (Fernández, 2004; PNUD, 2005;). 
Pero comprender estos temas desde la perspectiva de género implica, además, un análisis sobre las diferencias que subyacen a las relaciones que se establecen entre hombres y mujeres, y que encuentra unas importantes reflexiones acerca de la división de los sexos y la construcción social del género (Buttler: 1990; Lamas: 1986; De Lauretis: 2000; Scott: 2003), pero especialmente porque en él se establecen unas relaciones de poder que dan lugar a una serie de abusos que históricamente han predominado sobre las mujeres y que se materializan en las distintas formas de violencia que contra ellas se ejercen.

De acuerdo a cada cultura se establecen las creencias y valores que tienen el ser hombre y ser mujer delimitando comportamientos, pensamientos y emociones. Esta dicotomía masculino-femenino establece estereotipos, que por lo general son rígidos y condicionan los comportamientos (Lamas: 1986; Castellanos: 2006).

En el estereotipo de la cultura occidental moderna, durante mucho tiempo se sugirió que las mujeres son "inseguras por naturaleza", esta inseguridad ha sido asumida por las propias mujeres y justificada socialmente al atribuirles la debilidad, insensatez, pasividad, sentimentalismo y victimización como rasgos que las identifican. Estos han sido los argumentos recurrentes a través de los cuales se ha justificado la discriminación que, por mucho tiempo, ha existido hacia ellas, y que ha propiciado unas formas de violencia difícilmente percibidas, dado que se instauran en el plano de lo simbólico o sicológico / moral (Segato, 2003; Femenías, 2006).

En consecuencia, la perspectiva de género aplicada al concepto de seguridad, conlleva a entender a las violencias contra las mujeres, en su sentido más amplio, pues la errada concepción de que la violencia que ocurría en el espacio doméstico era un asunto de interés privado ha ido transformándose, por lo que hoy es posible que sea considerado no sólo como un problema de salud pública, sino también como una violación a los derechos humanos. Así mismo ha dado lugar a que se pueda analizar el contexto general de dichas violencias como también sus factores de riesgo.

La violencia contra las mujeres debe considerarse como un continuo entre los ámbitos privado y público (Fraser, 1997; Moser, 2004), En dicho continuo, en el que las mujeres y las niñas son sometidas a diferentes tipos de violencia: violencia sexual, abuso, prostitución forzada, tráfico sexual o trata de personas, reclutamiento forzado para ejercer servicios domésticos y sexuales, asesinatos, torturas y control social de los actores armados y que tienen distintas implicaciones. 
En este sentido se trasciende el escenario doméstico y se reconoce el espacio público carente de neutralidad ante las atribuciones y usos de sus espacios y la forma en que se constituyen los lugares como apuestas y prácticas que surgen desde los individuos y grupos colectivos (Auge, 2000: 57; Sennett: 1994). La connotación de lugar está dada por el equipamiento y contenido del mismo para realizar determinadas funciones o actividades, que representan un sistema de signos que son interpretados y aprendidos para hacer uso de los mismos (De Certeau, 2000: 129) bajo esquemas predominantemente masculinos.

El espacio público hace parte de lo que constituye la ciudad, concebido desde la antropología urbana, y en términos generales: la calle, el afuera, la exteriorización de los espacios que circundan la casa, son los que por antonomasia definen la ciudad en sí misma, allí donde se establecen de manera diferenciada técnicas, prácticas y símbolos que la organizan, se transforman espacial y temporalmente, en ella interactúan los seres humanos de acuerdo a las exigencias de cada situación (Delgado, 1999; 2007) y a las determinaciones que cada cultura establece.

Lo anterior incide drásticamente en los significados y representaciones que las mujeres tienen de la inseguridad que al igual que el miedo son un proceso individual que se construye y comparte socialmente y se aprende en la cultura que lo ratifica en la interpretación de una realidad común (Reguillo, 2006; Jodelet citado en Arruda, 2012: 329) y que en su propio sentido se vuelven funcionales en la vida diaria, elementos claves que constituyen las representaciones sociales.

Las representaciones sociales han tenido su nicho en la sociología desde las representaciones colectivas y la sociología del conocimiento (Durkheim, 1898; Berger y Luckman 1991), en ambas aparecen elementos que permiten analizar la manera en que las mujeres construyen sus representaciones. De una parte, por el soporte de la ideología y tradición que opera como un elemento ligado a la costumbre de lo que debe significar o implicar una situación de inseguridad, y por la otra porque en ella se establecen la relación de las mujeres con el entorno que les rodea, a partir de comportamientos y prácticas que establecen con los actores sociales (Berger y Lukman, 1991).

Las representaciones sociales de inseguridad se desarrollan de una manera más fuerte en las mujeres en tanto que, los asuntos que las afectan están entrelazados desde las condiciones objetivas mismas que no son tipificadas, hasta los procesos que devienen de su convivencia social situaciones que 
acontecen tanto dentro del espacio privado como el público, negando así cualquier posibilidad de sentirse segura en alguno de ellos.

\section{Abordaje metodológico}

Esta investigación es un estudio exploratorio de corte cualitativo en el cual se conjugaron distintas técnicas y herramientas para la recolección de información, que permitieron, a partir de la subjetividad de los agentes, indagar la realidad para obtener elementos de análisis desde los cuales se articulan los conceptos teóricos con los saberes y prácticas de los actores sociales y que se presentan como resultados. Desde este enfoque se privilegia la voz de las mujeres, se estudian sus narrativas, para luego analizar y comprender las concepciones desde las cuales construyen sus representaciones y prácticas.

El telón de fondo de esta investigación está constituido por unos intereses personales y políticos antecedidos por una aproximación al tema de la seguridad y las mujeres en una ciudad caracterizada por unas formas de violencia tan arraigadas en su historia que llevan a pasar de lado las violencias cotidianas que han marcado la vida de muchas mujeres.

Pero además, es reconocer en las otras mujeres con quienes se investiga esos aspectos que de alguna manera comparto en mi ser y en mi sentir como mujer, es quizás un principio de identidad que en estos cuatro años de aproximaciones, encuentros y des encuentros, en las relaciones que se crean no constituyen un problema de vigilancia epistemológica sino que por el contrario como lo plantea Mac Dowell:

\footnotetext{
"Las relaciones e interconexiones que se crean con el tiempo entre una entrevistadora y sus informantes no son ya un problema a evitar, sino una parte valiosa del proceso indagador. Lo que se busca en los estudios de casos feministas no es la objetividad, sino la intersubjetividad, que se acepta como parte del resultado de la investigación, y no se excluye del producto final” (Mc Dowell, 2000: $349)$.
}

Desde este punto de vista es posible reconocer las bondades que la metodología cualitativa ofrece para investigaciones con perspectiva de género, ya que permite una mayor profundidad con un menor número de casos. Así mismo, las relaciones que se construyen logran un acercamiento con las participantes que conlleva a que la entrevistadora no sea una agente extraña sino por el contrario 
cercana y confiable con quien se puede compartir un espacio de dialogo frente a la inseguridad que las apremia.

Si bien esta investigación plantea la perspectiva de género, se centra en las mujeres y no abarca la violencia sufrida por los hombres. De igual manera, el término mujeres, no incluye a niñas y adolescentes de rangos inferiores a los 16 años, ya que estas constituyen unas categorías etarias que demandan un abordaje diferente, pese a esto, algunos de los hallazgos exponen situaciones relacionadas con mujeres en edades aproximadas.

Esta metodología pese a un diseño inicial tuvo alteraciones debido a dificultades que se evidenciaron en la técnicas del grupo focal aplicada en un ejercicio piloto, cuyos resultados conllevaron a una serie de dudas, puesto que el pilotaje no arrojo elementos de contraste sino de uniformidad ante el liderazgo asumido al interior del grupo por algunas mujeres que llevaba a unos acuerdos unísonos del resto, es así como esta técnica propuestas inicialmente fue reemplazada por entrevistas a profundidad.

Se realizaron 13 entrevistas en total, las cuales fueron distribuidas en la unidad de análisis correspondiendo a 7 mujeres de la Comuna 1 - Popular (C1P) y 6 mujeres en la Comuna 8 Villahermosa $(\mathrm{C} 8 \mathrm{VH})$. Estas mujeres no respondían a un perfil definido, es así como algunas eran estudiantes universitarias, líderes sociales, amas de casa y profesionales, lo cual permitió identificar puntos en común y de contraste entre todas.

Inicialmente las entrevistas estaban diseñadas para dos momentos, sin embargo las dificultades en los tiempos de las mujeres y la incertidumbre de poder concretar la segunda parte, obligaron a hacer toda la entrevista en un solo momento. Esta estaba formulada en dos apartados el primero en relación al espacio público dentro de la comuna y en la ciudad, desde el cual se describían los contextos socio espaciales que pudieran llevar a determinar las representaciones. El segundo, indagaba las relaciones interpersonales desde las cuales se construyen las percepciones individuales y/o colectivas de las fuentes de inseguridad representadas en las personas bien sea a partir de una experiencia personal o cercana.

En esta técnica se utilizaron dibujos desde los cuales se realizó un análisis de correspondencias, es decir, la relación establecida en un mapa donde se esbozaba el esquema de relaciones espaciales y sociales, identificando con signos positivos y negativos su representación. Lo anterior complemento 
las respuestas construidas durante la entrevista en algunos casos marcando cierta contundencia en relación a lugares y personas.

Algunas de las respuestas obtenidas hacían alusión a la representación propia que difería del "sentido común" de las personas en general que habitaban o transitaban esos espacios o sostenían relaciones interpersonales, ejem: un lugar o los muchachos de la esquina considerados como peligrosos y que para ellas no lo fuera. Este ejercicio brindo elementos para identificar algunos de los criterios que conforman las representaciones la estructura, las emociones, lo que lo reactiva, así como las opiniones o comportamientos específicos (Alvarado, 2008: 53).

Con el fin de contrastar esta información se realizaron aleatoriamente 40 encuestas, 20 en cada comuna, las cuales estaban construidas con preguntas cerradas que indagaban de manera muy general algunas afirmaciones que se han ido construyendo en el tiempo y que aparecen como justificación o revictimización, cuando algún un hecho de violencia ocurre contra una mujer.

De igual manera se realizó una revisión de la prensa durante el año 2011 centrando el análisis en las noticias que daban cuenta de situaciones o hechos que afectaran la seguridad de las mujeres, especialmente en las Comunas de estudio y finalmente se hizo una revisión de fuentes secundarias o "literatura gris" de informes anuales de derechos humanos de las mujeres elaborados por organizaciones del movimiento social de mujeres e instituciones públicas como la Personería de Medellín.

La información obtenida mediante las técnicas descritas (entrevistas, encuestas, revisión documental) fueron trianguladas y analizadas bajo el software de análisis cualitativo Atlas Ti, allí se elaboraron las categorías y subcategorías, que permitieron identificar la interacción existente entre los distintos componentes que hicieron parte del proceso metodológico y que se encuentran entre los contenidos representacionales: fenómeno, contexto, antecedentes, acción e interacción de los y las actoras y las principales consecuencias (Araya: 2002: 72).

\section{Estructura del texto}

Este trabajo esta esbozado en tres capítulos: Las mujeres en Medellín, un campo hostil de violencias e inseguridades; Estructuras relacionales del miedo; Espacios y lugares escenarios de inseguridad y miedo y, finalmente las conclusiones. 
En el primer capítulo se contextualizan algunos aspectos importantes sobre el espacio de indagación. En primer lugar la ciudad, luego la comuna y el barrio y finalmente la casa dado que hay referentes que han marcado el devenir social de los y las habitantes y de muchas maneras han incidido en la representación que las mujeres tienen sobre la seguridad desde un enfoque multidimensional.

Aunque la investigación no busca explorar ni explicar las formas que asume la violencia, sus causas, manifestaciones, etc., hablar de la seguridad implica tener en cuenta algunos elementos históricos que han estado presentes en la cotidianidad de la ciudad, como por ejemplo el conflicto armado urbano entre grupos armados ilegales, sean estos combos o bandas delincuenciales, que se han reconfigurado en los últimos 30 años; el narcotráfico como fenómeno en el cual se ha sostenido gran parte de la economía; y la situación de exclusión y marginalización de las personas que habitan las periferias y que han sido el caldo de cultivo de la difícil situación de orden público que se vive actualmente.

En el segundo capítulo se describen y analizan las relaciones interpersonales que las mujeres de las Comunas 1 - Popular (C1P) y 8 - Villa Hermosa $(\mathrm{C} 8 \mathrm{VH})$ establecen, punto de partida para construir sus representaciones sobre la (in) seguridad. La manera cómo las mujeres construyen sus relaciones personales y de sociabilidad en los contextos de comuna y de ciudad. Aspectos como la cercanía y la proximidad son referentes importantes pero también la intuición frente al otro/a, y las formas de relacionamiento tradicionalmente establecidas desde el orden social están presentes.

El tercer capítulo describe y analiza la relación de las mujeres con los espacios públicos de comuna y de ciudad, a partir de un análisis del espacio, los lugares de re encuentros pero en ocasiones ajenos y extraños por las personas que transitan, los usos que se dan al espacio denominado como público y su disfrute y acceso a ellas. Territorios que ratifican la tradición que demarca un uso diferenciado de hombres y mujeres denotando tiempo, modo y lugar. Así mismo se analizan los entornos cercanos, casa, barrio y comuna y la manera como estos se configuran y re configuran en las trayectorias que la experiencia personal que cada una ha construido y a partir de las cuales se generan sus representaciones de (in) seguridad limitando o no su movilización en el territorio.

Finalmente, en el último punto, repasaremos algunas conclusiones principales de la investigación, puntos de consonancia y de contraste desde un espacio micro en el cual sin duda pese al tamaño de 
la muestra hay elementos que permiten vislumbrar que hay un sentido común que opera en las representaciones sociales no solo de las mujeres de las comunas de estudio sino en general. 


\section{CAPÍTULO 1}

\section{LAS MUJERES EN MEDELLÍN, UN CAMPO HOSTIL DE VIOLENCIAS E INSEGURIDADES}

"El tema de la seguridad de las mujeres en la ciudad

no está relacionado con la Fuerza Pública, no está relacionado solamente con que haya luces en calles oscuras, ni tampoco con que haya gamines o lugares solos. El problema de seguridad es la concepción que hay de la vida de las mujeres, que el cuerpo y la vida de las mujeres no es de nosotras, sino que le pertenece al Estado o a un hombre o al paraco, quien puede decidir sobre nosotras, y que es tan frágil que ellos pueden decidir sobre nosotras e incluso matarnos,

y que es tan frágil que puede ser el alcalde de Medellín, un indigente, el conductor de un taxi que se cree con el derecho de decirnos y hacernos cualquier cosa".

$(\mathrm{CO}, \mathrm{C} 1$, abril 10) 
En este capítulo se describe la situación de la ciudad enmarcada en las múltiples violencias y el contexto del conflicto armado urbano armado que hace parte de su historia reciente y que en los últimos diez años ha tenido hitos importantes en donde el factor del narcotráfico ha sido relevante al estar ligado a la existencia de los grupos armados ilegales que proliferan en distintos sectores y ejercen el control territorial.

Esta descripción, importante además para entender los elementos que intervienen en la representación de la (in) seguridad de las mujeres, parte de un panorama general de ciudad enfatizando algunos asuntos de su historia y de los actores que han incidido en ella, para posteriormente plantear otras situaciones que conllevan a violencias. Este primer análisis se realiza desde un enfoque comparativo para entender la dimensión de las violencias que afectan a hombres y mujeres discriminadamente.

La segunda parte del capítulo se centra en reconocer el contexto espacial y social de cada una de las comunas de estudio, para entender cómo el territorio configura ciertos escenarios de relacionamiento entre hombres y mujeres. Considera además la incidencia que el conflicto armado urbano ha tenido en estos sectores y cómo ha afectado las dinámicas barriales y el tejido social, pero reconoce a su vez que factores como la pobreza y la marginalidad hacen parte de los otros tipos de detonantes que generan violencia e inseguridad.

Finalmente, la seguridad/inseguridad de las mujeres en la ciudad no solo esta mediada en las relaciones sociales que establecen hombres y mujeres sino también por las apuestas que desde la institucionalidad se construyen para mediar las desigualdades a razón de género y desaparecer la violencia que contra las mujeres históricamente se ha ejercido. En ese sentido se abordan algunas políticas públicas que se han venido construyendo desde algunos años y que se han convertido en un referente nacional para abordar las problemáticas que afectan en particular a las mujeres.

Es importante destacar que gran parte de este capítulo se elabora a partir de datos estadísticos de fuentes institucionales, desde los cuales se realiza un análisis con enfoque diferenciado que ayuda a entender la relevancia del tema de la (in) seguridad de las mujeres. Igualmente se apoya en gráficos y tablas que permiten visualizar mejor los datos analizados y las situaciones que afectan a las mujeres. 


\subsection{La ciudad}

Medellín es la segunda ciudad en importancia de Colombia luego de Bogotá y la sigue Cali. Es la capital del departamento de Antioquia y forma parte del Área Metropolitana del Valle de Aburrá conformada por 10 municipios atravesados de sur a norte por el río Medellín. Es habitada por 2’368.282 personas, de las cuales el 52,92\% son mujeres y el 47,08\% son hombres (Encuesta de Calidad de Vida, 2011) $)^{2}$.

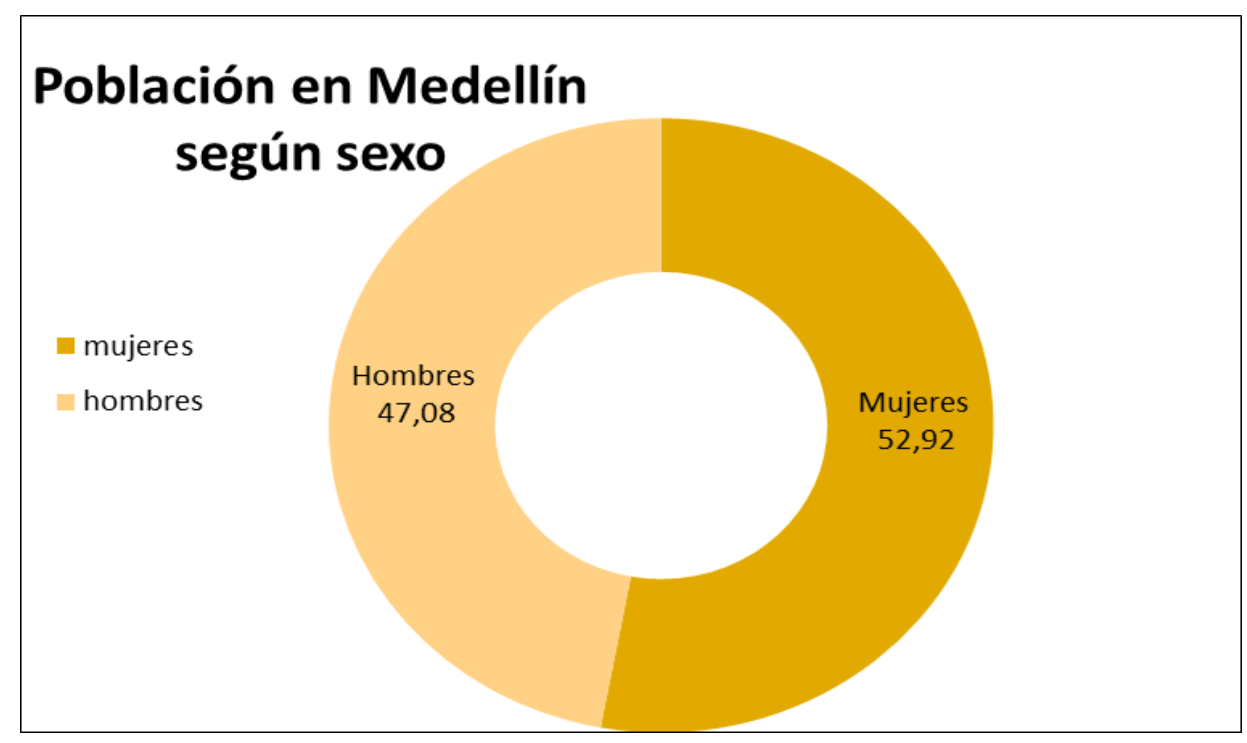

Figura 1. Población en Medellín según sexo. Fuente: Encuesta Calidad de Vida

Su división política está conformada administrativamente por seis zonas ${ }^{3}$, las cuales a su vez están subdivididas en 16 comunas ubicadas en el área urbana y 5 corregimientos en la zona rural las cuales se dividen en veredas. Sus unidades espaciales básicas son los 249 barrios reconocidos

\footnotetext{
${ }^{2}$ Este instrumento fue diseñado para realizar el seguimiento y la medición de las condiciones socioeconómicas de los habitantes de las 16 comunas y los 5 corregimientos que conforman el municipio de Medellín.

Ver: http://www.medellin.gov.co/irj/portal/ciudadanos?NavigationTarget=navurl://f4db57e77c5260dd195e9596 59c76ad7, citado el 4 de abril de 2012. Según el Departamento Administrativo de Planeación, DANE, que es la entidad encargada de la planeación, levantamiento, procesamiento, análisis y difusión de las estadísticas oficiales en Colombia, la ciudad presenta un crecimiento poblacional de 1,14\% anual promedio.

${ }^{3}$ Formalmente, las zonas no tienen un valor territorial, pero son el referente que agrupan las comunas de acuerdo con la ubicación en la ciudad.
} 
legalmente dentro del Plan de Ordenamiento Territorial ${ }^{4}$ que hacen parte del conglomerado de la ciudad.

En Colombia, el DANE establece una clasificación socioeconómica bajo criterios de estratificación, que representan el nivel de ingresos y la calidad de vida, determinados a su vez por las condiciones físicas de la vivienda y de su localización. Para el caso de Medellín predominan el estrato bajo-bajo (1), bajo (2) y medio-bajo (3), siendo el bajo el de mayor número de viviendas con 254.631, lo que constituye un $35,62 \%$, seguido del medio-bajo con 206.650 o sea un $28,91 \%$, el bajo-bajo con 85.793, un $12,00 \%$, y el medio con 78.514 , un $10,98 \%$. Solo aproximadamente el $13 \%$ de las viviendas se encuentran en estratos medio alto y alto (DANE, 2011). Adicional a esto, si bien en el periodo 2002-2010 la línea de pobreza disminuyó un 39\%, al igual que la línea de indigencia en un $29 \%$, estos dos aspectos continúan estando por encima del promedio de las trece principales áreas metropolitanas del país, lo cual está relacionado con el crecimiento de la economía y el comportamiento del mercado laboral ${ }^{5}$.

La tasa de desempleo en el 2010 fue de 13,9\%, con 1,8 puntos porcentuales menos que el año anterior. Por su parte, la tasa del subempleo se mantuvo estable en un $13 \%{ }^{6}$. Esta información comparada con las trece áreas metropolitanas del país da cuenta de un menor desempeño del mercado laboral en la ciudad, con una mayor afectación de desempleo sobre las mujeres, de 53,1\% frente a $46,9 \%$ de hombres, con una brecha porcentual de 6 para ellas. Así mismo, los ingresos laborales mensuales de las mujeres fueron $23,79 \%$ menos que los de los hombres ${ }^{7}$, lo que da cuenta que para las mujeres no solo es más difícil acceder al mercado laboral, sino también tener empleo en condiciones de igualdad.

La ciudad ha tenido un crecimiento del Producto Interno Bruto (PIB) de alrededor de 5,5\%, y una disminución del desempleo: de 17\% a 13\% aproximadamente. Sin embargo, en los últimos 8 años

\footnotetext{
${ }^{4}$ Sin embargo, es importante resaltar que en unos ejercicios recientes de planeación realizados por cada una de las comunas y corregimientos de la ciudad, las comunidades reconocieron la existencia de nuevos barrios que no son incluidos en el POT, pero que esperan sean considerados y legalizados como un proceso de inclusión y reconocimiento de quienes habitan en ellos.

${ }^{5}$ Medellín cómo vamos (2010). Informe de calidad de vida. "Pobreza y desigualdad". El programa Medellín cómo vamos es una alianza interinstitucional privada que tiene como principal objetivo hacer evaluación y seguimiento a la calidad de vida en la ciudad. Ver: www.medellincomovamos.org.

${ }^{6} \mathrm{El}$ dato de subempleo adquiere relevancia en la medida en que este indicador permite establecer la calidad del empleo que se genera en la ciudad en cuanto a proporción de tiempo trabajado, el tipo de remuneración y la competencia laboral.

7 Plan de Desarrollo de Medellín 2012-2015. "Medellín un hogar para la vida”, Aníbal Gaviria Correa, alcalde. Documento para el Consejo Territorial de Planeación, febrero 29 de 2012.
} 
ha habido una variación importante del PIB: tocó el pico más bajo en el 2009 con 0,51 y logró una reactivación de $3,97 \%$ en el 2010. Con respecto al coeficiente $\mathrm{GINI}^{8}$, aunque en Colombia hubo una mejoría al pasar de 0,573 en el 2002 a 0,560 en el 2010, en Medellín sucedió lo contrario, ya que en el 2010 se ubicó como la ciudad con mayor grado de desigualdad monetaria en relación con las principales ciudades del país, seguida por Cali, Bogotá y Montería ${ }^{9}$.

Esta situación de desigualdad contrasta con el Indicador de Desarrollo Humano ${ }^{10}$, debido a que ha tenido una mejora constante que se refleja en una variación anual del $1 \%$, siendo los componentes del ingreso y logro educativo los que más han incidido en su evolución. Entre los años 2004 y 2011 pasó de 81,11 a 86,32, con un incremento promedio más alto en las comunas que en los corregimientos, con 5,22\% y 1,05\% respectivamente (DANE. 2012).

Con respecto a su infraestructura, Medellín ha sufrido grandes transformaciones gracias a las intervenciones del llamado urbanismo social ${ }^{11}$, que se evidencian en la construcción de espacios como parques biblioteca, organización y adecuación de parques y zonas verdes, que buscan propiciar un mejor acceso de las y los ciudadanos a los espacios públicos. Sin embargo, la realidad es que a nivel social la apuesta de las autoridades locales en tal sentido ha sido deficitaria y ha generado situaciones de marginalización y segregación de la población que habita en asentamientos ilegales que generalmente se encuentran en la periferia. Estos cuentan de por sí con una alta densidad en la ocupación del territorio, llegando en algunos barrios a sobrepasar los 700 habitantes por hectárea y un índice crítico de espacio público de $1,35 \mathrm{~m}^{2} /$ habitante $^{12}$, mientras que el promedio de la ciudad se encuentra en $3,08 \mathrm{~m}^{2} /$ habitante. Este índice la ubica por encima del promedio

\footnotetext{
${ }^{8}$ Herramienta para medir el grado de desigualdad en la distribución de los ingresos (o del consumo) entre los individuos de un determinado país o ciudad. Los valores de medición oscilan entre 0 y 1 , donde 0 corresponde a la perfecta igualdad y 1 a la perfecta desigualdad. En Colombia estos resultados son generados por la Misión para el Empalme de las Series de Empleo, Pobreza y Desigualdad (MESEP) constituida en el año 2009.

${ }^{9}$ MESEP, con base en la Encuesta Continua de Hogares 2002-2005 y la Gran Encuesta Integrada de hogares 2008-2010. Departamento Administrativo de Planeación, con base en PIB 2005-2006.

${ }^{10} \mathrm{El}$ Indicador de Desarrollo Humano, IDH, clasifica los países a partir de variables que tengan en cuenta no solo el factor netamente económico como lo es el ingreso o el gasto monetarios de los hogares o individuos, sino también el factor de educación y salud. El IDH se calcula para Medellín de acuerdo con los criterios utilizados por las Naciones Unidas hasta el 2009, para el IDH de los países.

${ }^{11}$ Esta propuesta empezó a tener mucha más fuerza a partir del 2008 con el gobierno de Sergio Fajardo. Con ella se pretendía invertir en los sectores populares mediante intervenciones urbanísticas que buscaban mejorar la arquitectura y por ende la autoestima y el orgullo de la comunidad, como estrategias para una transformación social profunda.

${ }^{12}$ Alcaldía de Medellín (2008). Plan de Desarrollo 2008-2011, Medellín es solidaria y competitiva. Línea 3, Medellín un espacio para el encuentro.
} 
nacional que es de $3,6 \mathrm{~m}^{2}$, pero muy por debajo de lo propuesto por la agenda Hábitat de las Naciones Unidas para países en vía de desarrollo, que establece que las zonas verdes, y no solo de espacio público, deben ser equivalentes a $10 \mathrm{~m}^{2}$ por habitante (Medellín como vamos, 2010).

\subsubsection{Una historia marcada por las violencias ${ }^{13}$}

Una de las principales características que ha estado presente en el imaginario del país y del mundo ha sido el alto nivel de violencias que tiene la ciudad, desconociendo los factores estructurales existentes, como la situación de pobreza, la marginación y exclusión social que afecta una parte importante de la población. Sin duda alguna, el arraigo que ha tenido el narcotráfico y las secuelas que ha ido dejando en su camino son elementos importantes al momento de analizar el fenómeno de las violencias. Secuelas que han sido a su vez una de las razones principales para que en los dos últimos años haya ocupado el primer lugar en cuanto a mayor tasa de homicidios que se cometen en las ciudades de Colombia. Situación que incide para que el país se encuentre con una de las tasas comparativas más altas en relación con otros países, como lo muestra el siguiente gráfico:

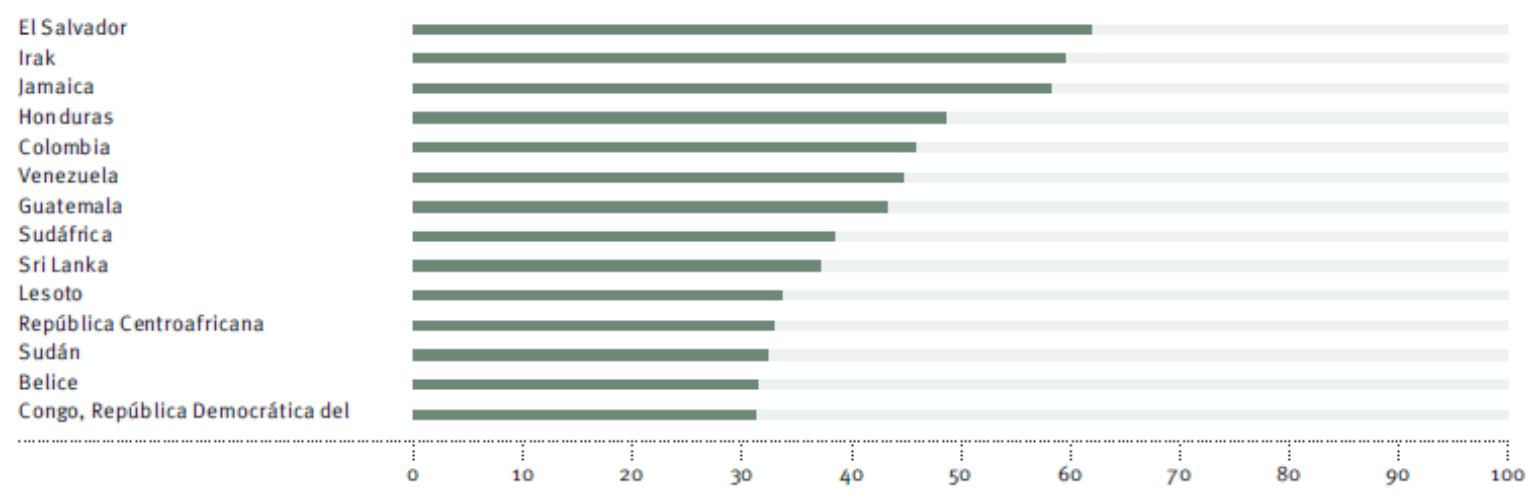

Figura 2. Países con tasa promedio anual de muertes violentas. Fuente: Base de datos CGVA 2011. Informe Carga Mundial de la Violencia Armada

\footnotetext{
${ }^{13}$ Es importante precisar que en Colombia el concepto de violencia ha tenido diversas interpretaciones. Algunas en unos contextos políticos específicos contenían una alusión directa a la violencia política proyectada como un elemento estructural de la evolución política y social del país (Sánchez, 1995: 30). Sin embargo, este concepto ha adquirido variadas características que hacen que hoy en día no pueda ser asociado a un fenómeno en particular, sino a la pluralidad de las violencias. "Al lado de la violencia política hay una violencia socioeconómica, hay una violencia sobre los territorios y hay finalmente una violencia sociocultural por la defensa del orden moral o social o por el derecho a la diferencia" (Sánchez, 1991: 226, citado en Blair, 2012: 21). Habría que agregar acá la violencia urbana, que ha tomado tanta fuerza que sobre ella pueden ubicarse la multiplicidad de violencias existentes en el marco de un contexto urbano, como es la ciudad de Medellín, sobre la cual se hace este análisis.
} 
Según este registro, Colombia se encuentra entre los primeros cinco países con tasas de más alto promedio anual de muertes violentas. Para alcanzar este puesto son determinantes los actos criminales ligados al negocio del narcotráfico y/o de productos ilícitos. Esto se articula al contexto de violencias que vive la ciudad de Medellín ante la proliferación de grupos armados ilegales que disputan el control territorial para la comercialización y distribución de la droga, como también las rentas ilegales soportadas en extorsiones a los comerciantes, transportadores y habitantes. De acuerdo con el análisis realizado por la Declaración de Ginebra sobre violencia armada y desarrollo, "los países con altas tasas de homicidios registran tasas de feminicidios que representan sólo una mínima parte de los homicidios en los que los hombres son las víctimas" (2012: 7), situación que si bien es acorde con los datos, en la ciudad de Medellín ha ido en aumento.

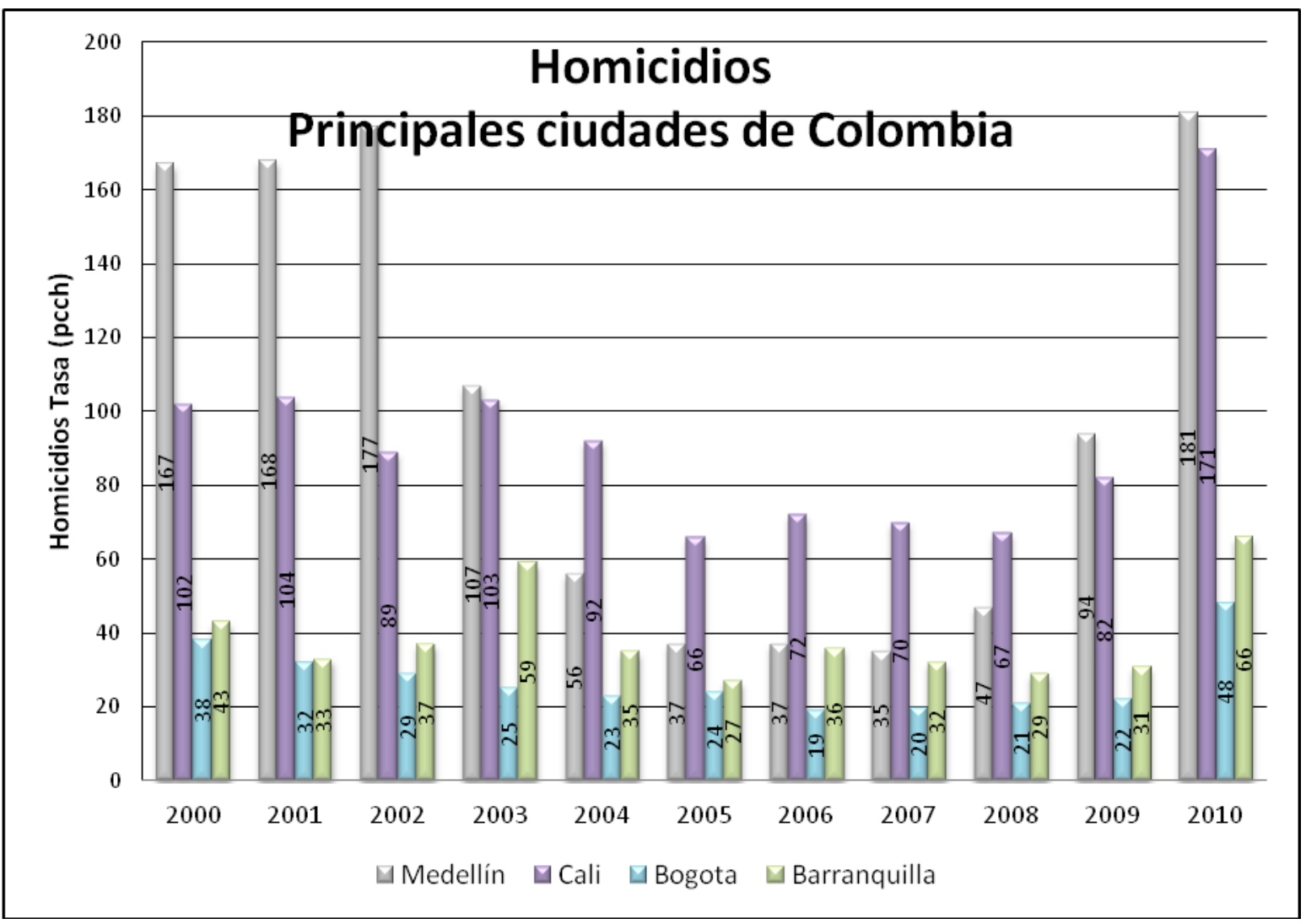

Figura 3. Homicidios Principales ciudades de Colombia. Fuente: Instituto de Medicina Legal

Tal como lo muestra esta figura, es posible identificar unos picos importantes en los que se incrementan las tasas de homicidio en la ciudad, por encima de las tres principales ciudades del país. Eso se da al inicio y al finalizar la década. En el 2010 se presenta casi el mismo número de homicidios que en el 2000, luego de un periodo de disminución notable que coincide con el auge 
del proceso de desmovilización y reinserción en el país ${ }^{14}$. Entre el 2003 y el 2008 se desmovilizó el mayor número de personas, en lo que fue un proceso experimental para la reinserción a la vida civil. Antes de entrar a hablar del proceso de desmovilización y reinserción de grupos paramilitares, es importante hacer una breve reconstrucción histórica que permita tener elementos para entender la dinámica de la violencia urbana que ha caracterizado la ciudad de Medellín.

Al respecto, diversos autores estudiosos del tema de violencia en la ciudad (Salazar y Jaramillo, 1992; Jaramillo, 1998; Medina, 2006; Blair, 2008) permiten identificar tres momentos: uno de antecedentes entre 1980-1994, otro de conflicto reciente, 1995-2005, y un de conflicto actual, 20052007 (Blair, 2008). El primero, caracterizado por la prevalencia de prácticas mafiosas que se instauran en la sociedad, ligadas al fenómeno del narcotráfico, el sicariato ${ }^{15}$ y la presencia de bandas o combos delincuenciales que operaron como el brazo armado del Cartel de Medellín liderado por Pablo Escobar. Economías ilegales que encuentran en la situación de desempleo y precariedad económica el mejor lugar para anidarse y crecer, generando la cultura de "dinero fácil".

Paralelo a este primer momento aparece en escena el fenómeno miliciano ${ }^{16}$ y las mal llamadas “«limpiezas sociales» contra «los viciosos» de la mano de «justicieros» que, a partir de la eliminación o el destierro, imponían la tranquilidad en los barrios" (Jaramillo et al, 1998). Estas milicias $^{17}$ fueron asociadas a procesos comunitarios y barriales que legitimaron sus acciones

\footnotetext{
${ }^{14}$ El proceso de desmovilización se presenta con personas que hacían parte de los grupos paramilitares. Un primer momento se da el 25 de noviembre del 2003 con 864 combatientes del Bloque Cacique Nutibara, quienes dejan las armas en un acto público que se consolida como un punto de partida en el proceso de negociación durante el gobierno de Álvaro Uribe Vélez. En el 2005 dejan las armas los integrantes del Bloque Héroes de Granada, quienes hacían parte de las estructuras delincuenciales de Medellín.

${ }^{15}$ El sicariato es una actividad delictiva que se caracteriza como el "asesinato por encargo" y que desde la década de los noventa ha tenido bastante incidencia en el número de homicidios ocurridos en la ciudad de Medellín como una consecuencia directa del narcotráfico que se ha valido del sicariato como su brazo armado. Esta actividad cuenta con unas particularidades que van desde el tipo de delito que se comete, explícitamente el homicidio, el nivel de violencia, el profesionalismo con el que se lleva a cabo y las relaciones sociales establecidas previas al hecho (Carrión, 2008).

${ }^{16} \mathrm{El}$ fenómeno miliciano alude a los diversos grupos armados que fueron apareciendo en la ciudad de Medellín durante de la década de los ochenta, inicialmente en la comuna nororiental de Medellín. En estos grupos confluyen tres elementos importantes para su caracterización durante la época: la dinámica de las bandas armadas de tipo delincuencial y con dominio de territorios; un elemento político revolucionario propiciado por las células disidentes de la guerrilla y de la izquierda armada como proceso de disgregación de los partidos de extrema izquierda como el Partido Comunista Marxista Leninista Maoísta; y las estrategias de protección y limpieza social que implementaron en los barrios y que en consecuencia terminaron legitimando muchas de sus acciones (Ceballos, 2000: 393).

${ }^{17}$ Como fue el caso de las Milicias Populares del Pueblo y para el Pueblo, MPP, que tuvieron su gran centro de acción en la zona nororiental, en los sectores del Popular, Granizal, Santo Domingo y Santa Inés, y luego
} 
mediante obras "sociales" con las personas más pobres de los barrios. En este escenario tuvieron incidencia las guerrillas del ELN y EPL, quienes aprovecharon la ausencia estatal en las zonas marginales de la ciudad para fortalecerse y legitimar su accionar (Alonso, 2007: 117).

Iniciando la década del 2000 se fue transformando el conflicto ante la incursión de otros actores catalogados como "actores políticos" por la relación directa con el conflicto político armado que

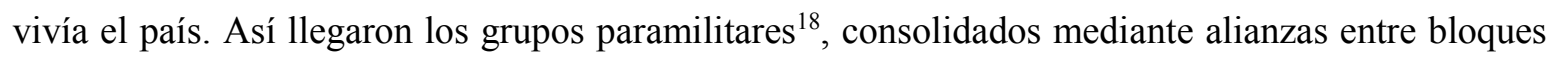
de autodefensa (Insuasty, 2010). Además se dio una recomposición de la delincuencia y las bandas de narcotraficantes, que se establecieron en grandes estructuras del crimen organizado, teniendo como estrategias de acción la denominada Oficina de Envigado y las bandas ya posicionadas en el negocio como La Terraza, La Cañada, Los Triana y la Banda de Frank en las comunas 1 - Popular, 3 - Manrique y 6 - Doce de Octubre. Esto fue en particular lo que caracterizó el segundo momento catalogado como conflicto reciente entre 1995-2005.

Luego del proceso de Desmovilización y Reinserción en el $2002^{19}$ y de la extradición de Diego Fernando Murillo, alias Don Berna en el 2008, se ha producido una proliferación de grupos armados ilegales que se encontraban bajo el mando de Maximiliano Bonilla, alias Valenciano y Erik Vargas, alias Sebastián, quienes hasta el 2011 se disputaron el negocio del narcotráfico y el

se fueron aproximando a otros sectores de la ciudad como Picachito y 12 de Octubre en la zona noroccidental y La Floresta y 20 de julio en la centro occidental. Posterior a esto fueron llegando las Milicias Populares del Valle de Aburrá, MPVA, que entraron a disputar el territorio en la zona nororiental, incluso con nuevos grupos de milicias que iban emergiendo en estos mismos sectores, como América Libre AL y las Brigadas de Resistencia Popular, BRP. Ver: Medina Franco, Gilberto (2006).

${ }^{18}$ Estos grupos paramilitares fueron el Bloque Metro, comandado por Carlos Mauricio García Fernández, alias Rodrigo o Doble Cero, quien era un exmilitar que combatía contra las milicias. En el 2001, compartió esta lucha con el Bloque Cacique Nutibara, al mando de Diego Fernando Murillo Bejarano alias Don Berna, quien ya venía con antecedentes en las estructuras del narcotráfico y quien con apoyo de las Autodefensas Unidas de Colombia en el 2002 comandó una fuerza de 4.000 hombres que entraron a las comunas de Medellín sembradas de milicianos del ELN y de las FARC. En pocos meses, y en coincidencia con la Operación Orión del Ejército que entró violentamente a la C1P, las arrasó. Entre el 2002 y el 2003 se enfrentó al Bloque Metro, ganando el control de la ciudad, poder que se hizo evidente incluso al momento de su desmovilización en el 2003, de su captura y detención en la cárcel de máxima seguridad en Cómbita, hasta su extradición en el 2008 acusado de narcotráfico. Ver informaciones de prensa y organismos no gubernamentales. http://www.verdadabierta.com/victimarios/715-perfil-diego-fernando-murillo-bejaranoalias-don-berna.

${ }^{19}$ Las primeras desmovilizaciones se dieron en Colombia en la década de los noventa con la desmovilización de nueve grupos guerrilleros, que dejaron 8.817 individuos acogidos al programa a través de la Oficina nacional de Reinserción, de ahí en adelante entre 1998 y 2002 en el Gobierno de Pastrana y bajo el nombre de la Dirección General para la reinserción se acogieron 2.502 personas y, posteriormente en el gobierno de Uribe se creó el Programa para la Reintegración a la Vida Civil que inició con desmovilizaciones individuales y luego con las colectivas y que finalmente se reestructura con la Ley de Justicia y Paz, Ley 975 de 2005, que establece los lineamientos jurídicos para el Proceso de Desarme, Desmovilización y Resocialización. 
control territorial de varias zonas de la ciudad, mediante el dominio de la denominada Oficina de Envigado. Sin embargo y luego de la detención de Valenciano en el 2011, entran en la escena del conflicto armado urbano nuevos actores que luego del desarme paramilitar habían tenido una fuerte incidencia en zonas rurales del país, como es el caso de los Urabeños ${ }^{20}$, quienes entran a reclutar las bandas y combos que operan en los territorios antes controlados por Valenciano para así adueñarse de los corredores estratégicos para el tráfico de armas y de drogas y combatir la Oficina de Envigado al mando de Sebastián. De esta manera y siguiendo a Blair, las dinámicas del conflicto actual permiten evidenciar que patrones de confrontación de hace 20 años no desaparecen, pero se revisten de nuevas formas, incluidos nuevos actores (Blair, 2008).

Las nuevas formas de accionar de los grupos paramilitares, "se comportan como un conjunto de relaciones resultantes de los complejos procesos de aniquilación, negociación, absorción, dominación y contratos derivados de las cuatro grandes rutas de la guerra en Medellín: la de las autodefensas, la del narcotráfico, la de las bandas y la paramilitar" (Espinal y Valencia, 2008: 26), hoy día denominadas Bacrim (Bandas Criminales Emergentes) u ODIN (Organizaciones Delincuenciales Integradas al Narcotráfico) por el Estado.

20 Después del desame paramilitar se conformaron nuevos grupos como los Rastrojos, los Paisas, los Urabeños, el Ejército Revolucionario Popular, ERPAC, los cuales siguieron generando violencia en las zonas que antes controlaban los paramilitares. Ver http://www.verdadabierta.com/index.php?option=com_content\&id=3727, revisado el 20 de marzo de 2012. Un informe del año 2011 realizado por el Instituto de Estudio para el Desarrollo y la Paz, Indepaz, da cuenta de que en la ciudad de Medellín se está consolidando una presencia permanente de estos grupos denominados "narcoparamilitares" por su vinculación al manejo del negocio del narcotráfico y mantenimiento de redes de parapolítica (vínculos de políticos y grupos de paramilitares), predominando la Oficina de Envigado, los Urabeños, los Rastrojos, los Paisas y las Águilas Negras (Indepaz, 2012). 


\begin{tabular}{|l|l|l|l|l|}
\hline Año & Estructura & Hombres & Mujeres & Total \\
\hline 2003 & Bloque Cacique Nutibara & 860 & 8 & 868 \\
\hline 2003 & Bloque Metro $^{21}$ & 21 & & 21 \\
\hline 2005 & Bloque Héroes de Granada & 1998 & 35 & 2033 \\
\hline
\end{tabular}

Tabla 1. Desmovilizados en Medellín por sexo. Fuente: MAPP OEA 2007 y Verdad Abierta.

A partir del año $2003^{22}$ los grupos paramilitares y desmovilizados se organizan como bandas delincuenciales ligadas al negocio del narcotráfico y generan un alto nivel de controversia por cuanto son consideradas por sectores políticos y de la sociedad civil como "la semilla posible de una 'tercera generación paramilitar'” (CNNR, 2007: 16).

Esta historia de transfiguración del conflicto armado urbano en la ciudad ha dejado como consecuencia unos intervalos de violencia ${ }^{23}$ que se reflejan en las estadísticas de homicidios ocurridos en los últimos años y que son además uno de los principales problemas de seguridad en la ciudad, tal como lo expone la siguiente figura:

\footnotetext{
${ }^{21}$ El proceso de desmovilización y reinserción solo reporta 21 personas del Bloque Metro debido a que antes de que se lograra concretar la desmovilización, muchos de sus miembros fueron cooptados por diversas estructuras de las autodefensas, como Cacique Nutibara, Héroes de Granada, Central Bolívar, Mineros, Calima y el Centauros, entre otros, siendo el Bloque Cacique Nutibara el que mayor número de personas logró ingresar a sus filas disidentes del Bloque Metro.

${ }^{22}$ En el proceso de negociación con las Autodefensas, Medellín es la primera ciudad del país en llevar a cabo el programa de Desarme, Desmovilización y Reinserción, DDR, y tenía además el mayor número de desmovilizados en todo el país, con una cifra de 2.885 excombatientes, correspondientes a 868 hombres del Bloque Cacique Nutibara, 1.617 del Bloque Héroes de Granada y 400 de los bloques Catatumbo, Pacífico, Bananero y otros.

${ }^{23}$ Estos intervalos de violencia guardan cierta relación con lo que Michel Misse denomina "Acumulación social de violencia", luego de estudiar el comportamiento delictivo y criminal y los contextos que producen ciertas prácticas extralegales delimitadas en los últimos 50 años en la ciudad de Río de Janeiro, donde se asocia un complejo de factores que se entrelazan en la construcción social del delito fuera o dentro del Estado (2010: 33).
} 


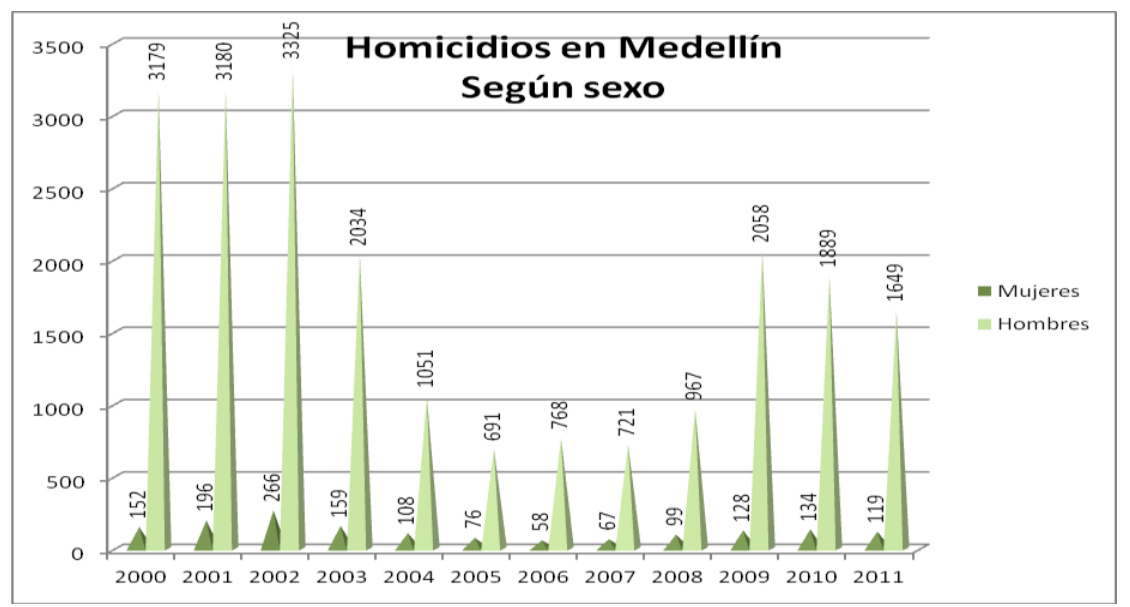

Figura 4. Homicidios en Medellín según sexo. Fuente Instituto de Medicina Legal. Secretaria de las Mujeres. Secretaria de Gobierno

Si bien es preocupante la oscilación en el número de homicidios ocurridos ${ }^{24}$ contra los hombres durante esta década, también lo es la situación de las mujeres. Al inicio y finalización del mismo periodo, estos incrementos de homicidios en ambos casos coinciden con momentos determinantes del conflicto armado urbano, como se expuso anteriormente, alcanzando unos picos más altos entre el 2000 y el 2003, época en la que los grupos de paramilitares venían consolidándose como actor hegemónico en la ciudad, mediante la cooptación de bandas y combos en la disputa del control territorial en la ciudad con las milicias urbanas. Ya en la mitad del periodo, con un proceso de desmovilización y reinserción en pleno auge y un conflicto menguado, disminuyen proporcionalmente los homicidios, tanto de hombres como de mujeres, hasta que se captura y extradita a Don Berna, momento en el que la ciudad nuevamente pierde el rumbo para resolver el conflicto y hay una diseminación de grupos armados ilegales sin un liderazgo visible. Se da entonces la consolidación de alias Valenciano y Sebastián como dos actores en disputa, hasta la llegada de los Urabeños como nuevo actor del conflicto.

En estos escenarios de violencia, los factores de riesgo que enfrentan hombres y mujeres difieren en cuanto al tipo de delitos a los que se ven expuestos, al trauma que estos generan y a la forma en como estos ocurren. Para las mujeres, el espacio donde generalmente son ejercidas las violencias, en particular aquellas en las que pierden la vida, es la vivienda. Es allí, en la esfera privada, donde un número importante de ellas son asesinadas, lo que en datos porcentuales representa más del

${ }^{24}$ Según el informe de la Personería de Medellín (2012), durante el 2011 el promedio de homicidios fue de 141 por mes, 32 por semana y 5 por día. Las principales víctimas continúan siendo los y las jóvenes en edades entre los 18 y 35 años, en su mayoría habitantes de barrios de estratos dos y tres. 
doble que para los hombres. Es decir, por cada hombre asesinado en su vivienda o lugar de residencia, hay tres mujeres muertas en esos espacios. Y a la inversa: por cada mujer asesinada en el espacio público, han sido asesinado tres hombres. Esto demuestra que hombres y mujeres terminan siendo víctimas de la violencia mortal en los espacios que tradicional y culturalmente les han sido asignados (Bedoya, 2008: 100).

En el caso de los homicidios es importante destacar el contexto de los casos, por un lado la mayor parte de los homicidios de hombres se da por arma de fuego durante enfrentamientos entre grupos armados ilegales o por ataques directos en el marco del conflicto armado urbano; en el caso de las mujeres, estudios del SISC $^{25}$ dan cuenta que más de la mitad de los casos son feminicidios, es decir asesinatos de mujeres por el hecho de ser mujeres, eliminando con ello toda alusión a "crímenes pasionales" como erróneamente se presenta en los medios de comunicación.

En las hipótesis de asesinatos de mujeres por el conflicto armado y/o por la violencia intrafamiliar aparece otro elemento importante: la edad de las víctimas. Otra dimensión que tampoco hay que perder de vista. Por ejemplo, la edad de las mujeres más afectadas por este delito oscila entre la población adolescente y joven entre los 11 y los 25 años, seguidas de mujeres adultas entre 35 y 45 años. Esto se agrava aún más con el incremento que en los últimos años viene teniendo en la ciudad el asesinato de mujeres, en algunos casos feminicidios ${ }^{26}$, que en el 2010 y el 2011 representaron respectivamente el $43 \%$ y el $48 \%$ de los ocurridos, según un análisis realizado por el Sistema de Información para la Seguridad y la Convivencia, SISC $^{27}$ - de la Secretaría de Gobierno de Medellín- y la Comisión Primera del Consejo de Seguridad Pública para las Mujeres de Medellín,

\footnotetext{
${ }^{25}$ Sistema para la Seguridad y la Convivencia.

${ }^{26}$ El concepto de feminicidio fue utilizado por primera vez por Diana Russell en el Tribunal de Crímenes contra Mujeres, en Bruselas en 1976. Sin embargo, según esta misma autora, este término ya había sido utilizado por primera vez en 1801 en Inglaterra para referirse al homicidio o asesinato de una mujer. La connotación política que le imprime Russell está dada por el asesinato de mujeres por el hecho de serlo. Actualmente en Medellín tiene vigencia la discusión sobre la forma como se denominan y analizan los asesinatos que ocurren contra mujeres. De una parte, se toman algunos elementos propuestos por Marcela Lagarde como es la definición de feminicidios íntimos y no íntimos, pero además se han agregado otros como feminicidios por conexión, de mujeres trasgresoras y relaciones desconocidas (Velez-Guzman, 2012: 17).

${ }^{27}$ El Sistema de Información para la Seguridad y la Convivencia, SISC, es la dependencia encargada de la generación de datos oficiales, construcción de conocimientos e insumos para la toma de decisiones y la formulación prospectiva de la política pública en materia de seguridad y convivencia ciudadana en Medellín, contextualizado con la dinámica del total de municipios que conforman el área metropolitana del Valle de Aburrá. El sistema hace parte integral de la Secretaría de Gobierno de Medellín y depende directamente del despacho.
} 
$\mathrm{CSPM}^{28}$. Estos datos aportan a que Colombia se encuentre entre los 10 primeros países con las más altas tasas de feminicidios, como lo reveló un estudio realizado en 83 países que examina las formas letales de violencia contra las mujeres (Nowak, 2012: 3).

El nivel de vulneración y afectación sobre el cuerpo de las mujeres, ya sea por causas de asesinato o violaciones, en particular por grupos armados ilegales, "deja entrever que las bandas delincuenciales que libran férreas disputas armadas por el control de los barrios de la ciudad están utilizando el cuerpo de la mujer como botín de guerra para demostrar poder y supremacía frente a sus enemigos" (Agencia de Prensa - Instituto Popular de Capacitación, 2010a). No en vano nuestra ciudad registra en los últimos años el segundo lugar (tasa por cien mil mujeres) de homicidios ${ }^{29}$ de mujeres, al igual que delitos sexuales ${ }^{30}$.

En este sentido, el cuerpo de las mujeres sigue siendo el lugar donde se inscriben las relaciones de poder que las subordinan y las violentan, con cuerpo es concebido como un espacio que se dispone para ser marcado. Se habla a través de los cuerpos de las mujeres. Un código de "la escritura en el cuerpo de las mujeres" (Segato: 2006). En una sociedad patriarcal, como luego veremos, los conflictos armados se encuentran impregnados de violencia de género, porque allí en sus cuerpos se escribe su derrota.

\footnotetext{
${ }^{28}$ El Consejo de Seguridad Pública de las Mujeres fue creado en el 2008 como la instancia interinstitucional que direcciona la implementación de la política de seguridad pública de las mujeres de la ciudad para promover acciones, planes, programas y proyectos que propendan por el goce efectivo de las mujeres de una vida libre de violencias. EI CSPM es coordinado por la Secretaría de las Mujeres y cuenta con la participación de instituciones del orden municipal, departamental y nacional (Policía, Fiscalía, Instituto Nacional de Medicina Legal y Ciencias Forenses, Personería de Medellín y Secretarías de Gobierno, Salud, Educación, Bienestar Social de la Alcaldía de Medellín y la Secretaría de Equidad de Género para las Mujeres del Departamento de Antioquia).

${ }^{29} \mathrm{Si}$ bien el concepto se vincula más con el de feminicidios, se maneja como homicidio teniendo en cuenta la información que maneja el Instituto de Medicina Legal, pero además para no incurrir en el error de denominarlos todos de la misma manera desconociendo las causas reales.

${ }^{30}$ Este dato se refiere al número de mujeres que establecieron la denuncia por abuso y/o asalto sexual.
} 


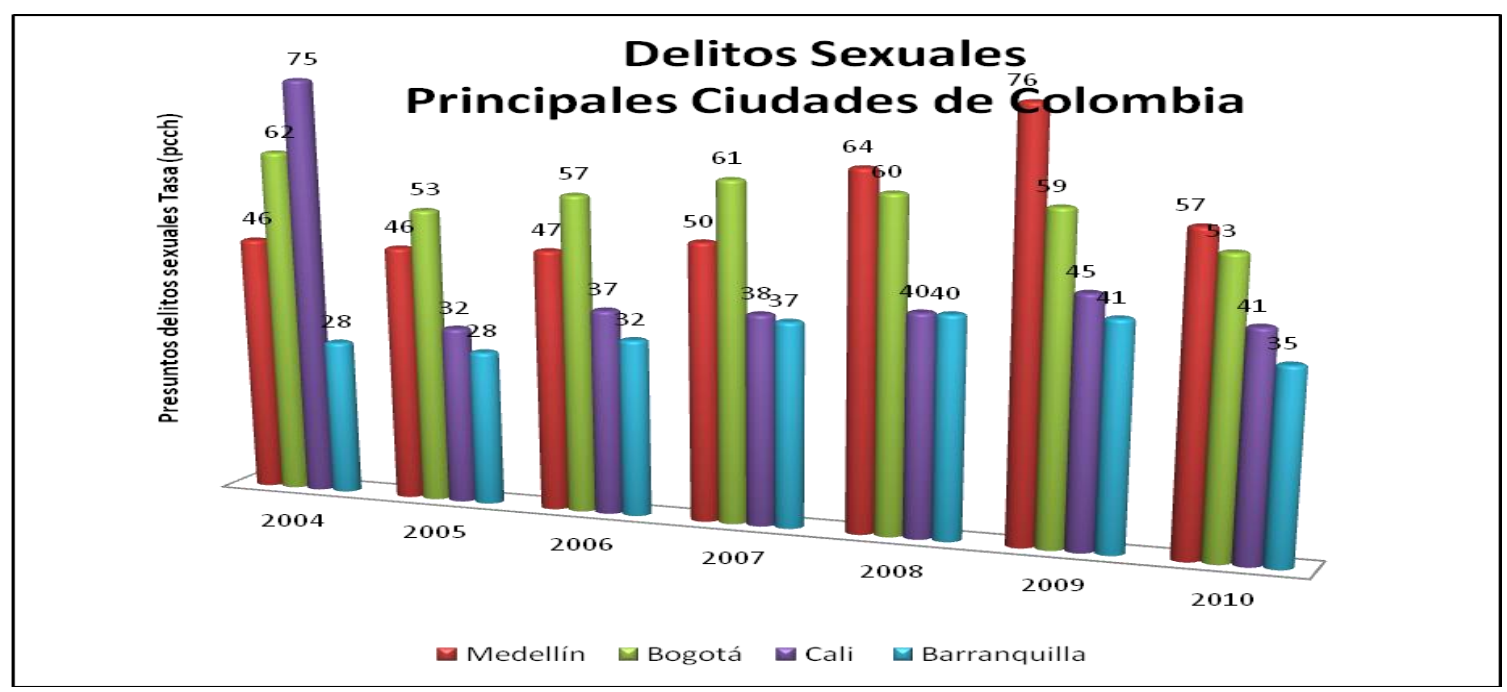

Figura 5. Delitos sexuales en las principales ciudades del país. Fuente Instituto de Medicina Legal.

A excepción del año 2004, Medellín ha registrado el primer y segundo lugar en cuanto a número de delitos sexuales cometidos contra las mujeres. Llama la atención el hecho de que estos delitos tengan su pico más alto durante los mismos años que el caso de los homicidios, al igual que como sucede con el tema del desplazamiento intraurbano. A esto último hay que agregar: "Es recurrente que por los riesgos de género, antes de desplazarse las mujeres ya han sufrido cualquier clase de amenazas y torturas contra su cuerpo, su sexualidad y su salud mental en el entorno social que habitan. Muestra de ello es que los barrios y las comunas que mayor índice de violencia y de desplazamiento forzado intraurbano presentan [...] por las disputas entre combos y bandas, coinciden con los que más reportan delitos sexuales" (Martínez, 2011: 51).

El nivel de afectación de la violencia se visibiliza en el tema de los homicidios y los delitos sexuales, incluso éstas manifestaciones de violencias, terminan convirtiéndose en detonantes de otros hechos victimizantes, como el fenómeno del desplazamiento forzado urbano que ya venía presentándose en la década de los noventa en la ciudad, toma relevancia nuevamente en el contexto de la ciudad a partir del año 2000, a raíz del incremento del desplazamiento masivo que se presenta en la ciudad, como consecuencia de la reconfiguración de las dinámicas de la violencia armada y la denominada "urbanización del conflicto", que dio lugar al reconocimiento del fenómeno en las ciudades como desplazamiento intraurbano ${ }^{31}$ y que ubica a la ciudad con los más altos índices de

${ }^{31}$ El desplazamiento forzado intraurbano es el traslado obligado de personas dentro de un mismo barrio o de un barrio a otro, dentro del perímetro urbano, ya sea por acciones de coacción o intimidación por parte de actores ilegales dentro de un contexto de violencia generalizada. 
desplazamiento forzado en comparación con otras ciudades capitales del país (Agencia Presidencial para la Acción Social y la Cooperación Internacional, 2009).

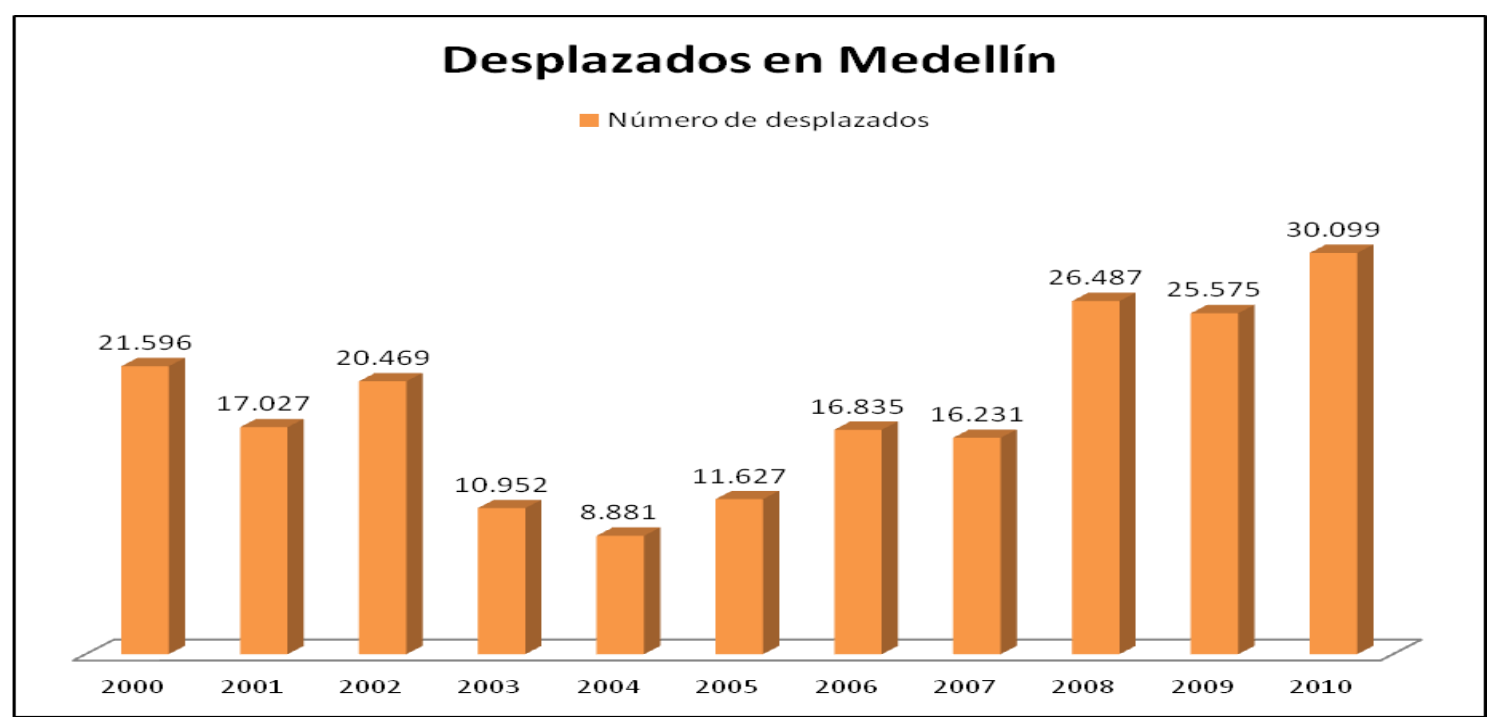

Figura 6. Número de desplazados en Medellín.

Fuente. Personería de Medellín.

La evolución de este fenómeno durante la primera década del siglo no ha sido nada uniforme. Ha presentado un mayor número de personas desplazadas en el 2000 y el 2002, pero ha llegado a un punto máximo entre el 2008 y 2010. Entre los años 1998 y 2011 hay 248.740 personas en situación de desplazamiento registradas por la Personería de Medellín (2011), lo que implica que por cada 100.000 habitantes hay 10.616 víctimas de desplazamiento forzado en la ciudad, provenientes de distintas regiones del país.

El problema del desplazamiento forzado es de tal magnitud que conllevó a la formulación de jurisprudencia con enfoque diferenciado y orientado específicamente a la población femenina. Tal es el caso del Auto 092 del $2008^{32}$, que establece diez factores de riesgo a los que están expuestas las mujeres por causa de su condición femenina, entre los cuales se aplican en el marco del contexto urbano: la violencia sexual, explotación sexual o abuso sexual; la explotación; el reclutamiento forzado de niños/as o de otro tipo de amenazas contra ellos/as; los riesgos derivados de las relaciones familiares o personales con integrantes de alguno de los grupos armados; su pertenencia a organizaciones sociales, comunitarias o políticas y labores de liderazgo y promoción de derechos humanos; persecución y asesinato por la estrategias de control del comportamiento público y

32 El auto 092 del 2008 establece un marco jurídico que busca proteger los derechos fundamentales de las mujeres afectadas por el desplazamiento forzado a causa del conflicto armado. 
privado y la pérdida o ausencia de su compañero o proveedor económico (Corte Constitucional, 2008), y que, tal como lo muestra la siguiente gráfica, ha venido afectando proporcionalmente a las mujeres en los últimos años:

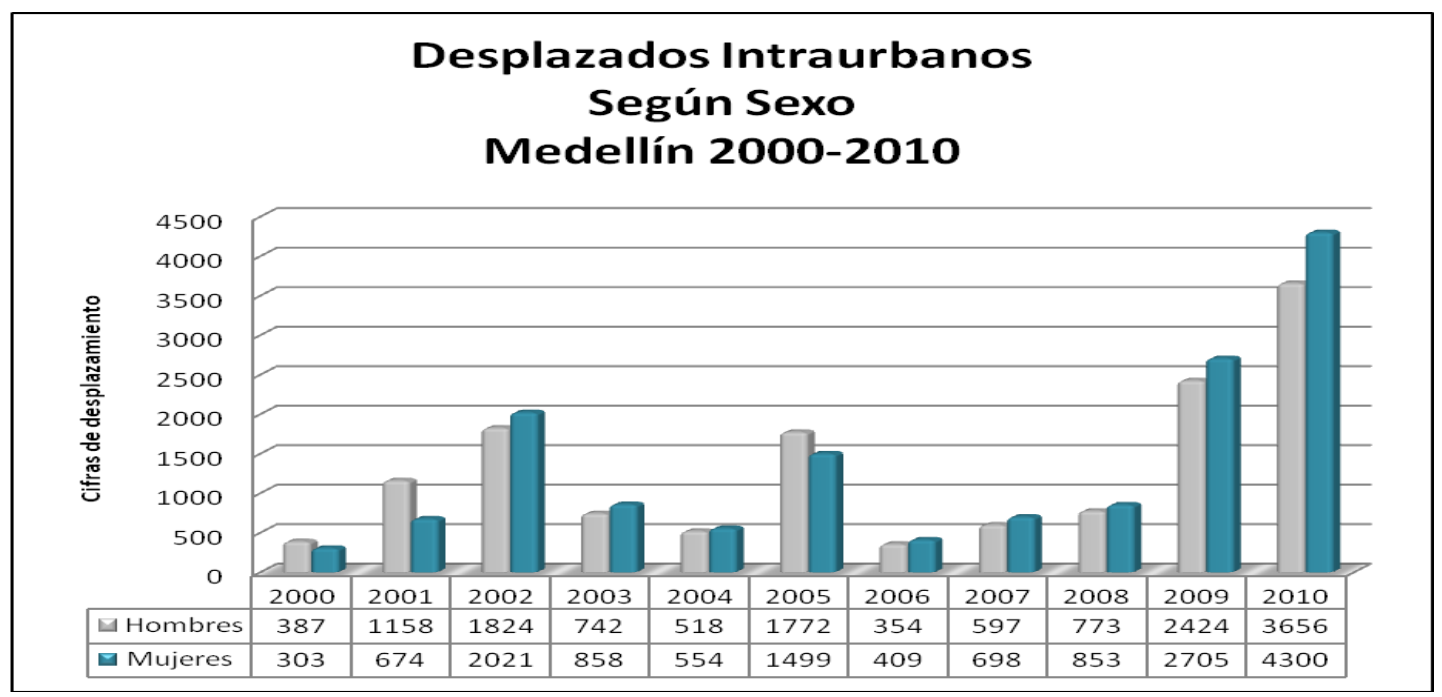

Figura 7. Desplazados intraurbanos en Medellín según sexo.

Fuente: Registro Único de población desplazada.

Específicamente el problema del desplazamiento forzado afecta a familias enteras en las que una de sus niñas o adolescentes se niega a involucrarse en el negocio de la trata de personas, bajo cualquiera de las modalidades que ofrece, como reclutante o para ofrecer su cuerpo (Agencia de Prensa - Instituto Popular de Capacitación, 2009b), y que se incrementa con la cultura de mujeres prepago en donde las mujeres se involucran en el comercio sexual para satisfacer necesidades de consumo (Mujeres que crean Corporación para la vida Mujeres que crean y Corporación Vamos mujer, 2010).

En este contexto, la trata de personas, constituye uno de los riesgos para las mujeres. Una práctica que viene de la mano de la venta de estupefacientes y armas que constituyen los negocios ilícitos más rentables en la actualidad, en tanto que constituye una de las expresiones contemporáneas de violencia sexual contra las niñas y adolescentes en donde esencialmente el mercadeo del cuerpo, cruza diversos ámbitos: la guerra, la calle, las familias (Corporación para la vida Mujeres que crean y Corporación Vamos mujer, 2010: 24). Este fenómeno trae consigo varios factores negativos para la vida de las mujeres, entre otros, la desaparición forzada de mujeres adolescentes y jóvenes que se ven sometidas por los grupos armados ilegales a ejercer la prostitución fuera del perímetro urbano en los municipios del departamento o en el peor de los casos fuera del país (Agencia de Prensa Instituto Popular de Capacitación, 2009a). 
El desplazamiento forzado constituye solo un eslabón más de la cadena de afectación que trae consigo la violencia asociada a otras expresiones del conflicto como el control territorial, social y económico que ejercen los grupos armados ilegales en casi todos los barrios de la ciudad. Igualmente, las amenazas y las desapariciones forzadas, que en los últimos años también han tenido datos significativos: han pasado de 87 casos en el 2008 a 454 en el 2009 y a 197 en el 2010, asociadas al enfrentamiento entre bandas delincuenciales y ajuste de cuentas (Personería de Medellín, 2011).

En Medellín una parte importante de las vulneraciones a la integridad física ocurren como consecuencia del conflicto armado y de la necesidad de los actores armados en disputa de imponer sus formas de control y de dominación, que llegan a incluir aspectos como las formas de vestir, sentir, hacer y desear. Esta situación se agrava en la medida en "que desconocen las subjetividades y borran las necesidades particulares" (Mujeres que crean, 2005), ya que éstas formas se instalan en la cotidianidad bajo las formas de relacionamiento hegemónicas y tradicionales que otorgan a las mujeres unos estereotipos que hacen que se justifiquen los tipos de agresión simbólica, manifestados en la cohibición, en el límite al libre desarrollo de su personalidad, llegando a ocasionar los embarazos en adolescentes, la afectación a su dignidad y la muerte sin unas circunstancias claras ante la ocurrencia del hecho.

Si bien es cierto "los hombres son más frecuentemente víctimas de ejecuciones sumarias y matanzas, la violencia contra la mujer, en particular la violencia sexual perpetrada por grupos armados, se ha hecho habitual en medio de un conflicto que se degenera paulatinamente" (Coomaraswamy, 2010: 42), pero además porque son violencias que no se visibilizan ante la falta de denuncias y el miedo a la estigmatización que producen este tipo de delitos sobre las mujeres.

\subsubsection{Situaciones asociadas a otras violencias}

En el contexto de Medellín es común asociar la violencia a las acciones implementadas por los grupos armados que operan en la ciudad. Sin embargo, las violencias han permeado la vida cotidiana, en la medida que están presentes en los distintos escenarios concatenados que se vinculan y responden unos a otros (Auyero-Berti, 2013: 94). Las otras violencias a las que se hace referencia en este apartado aluden a aquellas formas de violencia que no son una consecuencia directa del 
conflicto armado urbano, aunque en ocasiones haya elementos que puedan generar alguna asociación directa.

En este caso resulta pertinente traer la definición propuesta por la Convención de Belém do Para que fue aprobada por la Asamblea General de la Organización de los Estados Americanos en 1994, en la cual la violencia contra la mujer es "cualquier acto o conducta basada en el género que cause muerte, daño o sufrimiento físico, sexual o psicológico a la mujer, tanto en la esfera pública como en la privada". Estas violencias hacen parte de la cotidianidad de la ciudad, en la forma de relacionamientos sociales e institucionales existentes. En ellas se incluyen la violencia económica ${ }^{33}$, la violencia intrafamiliar, la violencia sexual y otras formas de violencias asociadas a los delitos no identificados como de alto impacto.

El factor económico representa una forma de violencia importante, dada la manera como las mujeres se insertan en el mercado laboral o se les niega su derecho a unas condiciones dignas y equitativas de trabajo. Generalmente, son ellas las que soportan el peso de la crisis económica, no solo por el mayor número de mujeres en condición de pobreza, sino porque son estas las que asumen la responsabilidad de sostener los/as hijos/as ${ }^{34}$. Las preocupaciones por el costo de vida o por la salud en un plano personal, estas tienen implicaciones en su grupo familiar, esto contribuye al debate acerca de la feminización de la pobreza, que denota el creciente empobrecimiento material de las mujeres, el empeoramiento de sus condiciones de vida, así como la vulneración de sus derechos fundamentales (Cobo, 2006).

Entre las principales vulneraciones ligadas al factor económico, y que constituye violencia económica, se encuentra la brecha salarial que se presenta en la ciudad. Las mujeres constituyen uno de los grupos poblacionales más afectados por ella. Mientras que en el 2010 el 45,93\% de las mujeres se ocupaba laboralmente, el $62,57 \%$ de los hombres lo hacía, situación que repercutió en que la tasa de desempleo estuviera un 2,98\% puntos porcentuales sobre la masculina (Alcaldía de

\footnotetext{
${ }^{33}$ El artículo 2 de la Ley 1257 de 2008 en la definición de violencia contra la mujer establece que la violencia económica es otra forma de violencia contra las mujeres que consiste en el (...) "abuso económico, el control abusivo de las finanzas, recompensas o castigos monetarios a las mujeres por razón de su condición social, económica o política. Esta forma de violencia puede consolidarse en las relaciones de pareja, familiares, en las laborales o en las económicas".

${ }^{34}$ Según información de la Secretaría de las Mujeres, el 43 por ciento de los hogares en Medellín tienen jefatura femenina, son madres cabeza de hogar que se encuentran en la pobreza. "En Medellín queremos mujeres libres" http://www.elmundo.com/portal/noticias/derechos_humanos/_en_medellin_queremos_mujeres_libres.ph p Tomado del periódico El Mundo, 29 de enero de 2012. [Consultado el 5 de abril de 2012].
} 
Medellín, 2011). Así mismo, dentro de las 153.206 personas desempleadas en el mismo periodo, el $53,1 \%$ correspondía al género femenino, y aunado a esto, sus ingresos mensuales fueron un 23,79\% menor que los de los hombres (Alcaldía de Medellín, 2012). No en vano estos datos objetivos se afirman con la autopercepción de pobreza que tienen las mujeres frente a los hombres un $23 \%$ y un $21 \%$ de mujeres e incluso son ellas quienes reportan mayores problemas económicos (Medellín como vamos, 2010).

De otra parte, los casos de violencia intrafamiliar ${ }^{35}$ en la ciudad no disminuyen. Según el sistema THETA $^{36}$, en las Comisarías de Familia de la ciudad se atendieron 5.225 casos en el año 2009, frente a 5.477 en el 2010 , de los cuales el $81 \%$ de las víctimas eran mujeres, principalmente entre los 18 y 35 años de edad. Entre los tipos de violencia que predominan, el 53\% de los casos corresponden a agresión física, casi el 22\% a la agresión verbal, el 2,7\% a agresión sicológica y el $21,6 \%$ a otras formas de violencia. De los 5.720 casos ocurridos en el 2011, el 83\% fueron mujeres y el 17\% hombres, datos que con respecto al 2006 presentaron un aumento de 2.766 (48\%) casos de violencia, que según las denuncias son físicas, psicológicas y sexuales. Entre las causas más comunes a las que se aduce la violencia intrafamiliar se encuentran los celos y las razones de índole económica.

35 La violencia intrafamiliar y la ocurrencia de este delito, ya sea en el espacio privado o público, son abordados ampliamente en la Ley 1257 de 2008, en la cual se penaliza su comisión en escenarios diferentes al familiar, ya que esto constituye una violación al derecho de las mujeres a una vida libre de violencias. ${ }^{36}$ Sistema Administrativo THETA de la subsecretaría de apoyo a la justicia, Secretaría de Gobierno de Medellín. 


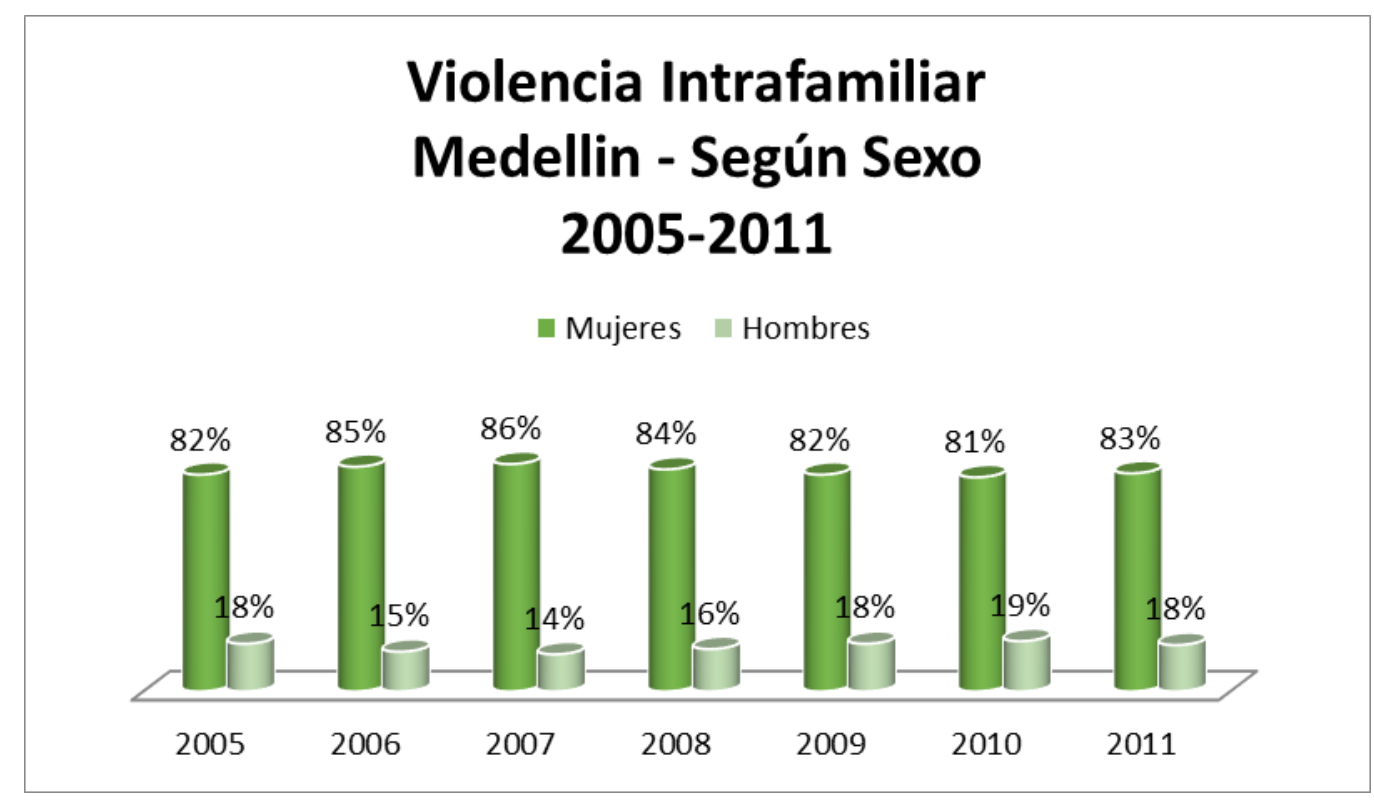

Figura 8. Violencia intrafamiliar en Medellín según sexo 2005-2011. Fuente Sistema Theta, Secretaria de Gobierno, Alcaldía de Medellín.

Ligada en ocasiones a la violencia intrafamiliar se encuentra la violencia sexual. Este delito representa para las mujeres el mayor grado de vulnerabilidad, ya que el nivel de afectación trasciende la agresión física contra su cuerpo y genera daños irreversibles en su estructura emocional y síquica. Históricamente, este tipo de violencia ha determinado las relaciones de poder y dominación del hombre sobre la mujer. "Pese a que las violencias sexuales constituyen un delito contra la vida, la integridad personal y la libertad sexual, aún sigue siendo un flagelo difícil de identificar y más aún de nombrar” (Personería de Medellín, 2010).

En el 2010 se reportaron 720 dictámenes sexológicos, de los cuales el 87,08\% fueron mujeres (627 casos) y el 12,92\%, hombres (93casos). En relación con el 2008, este dato representaba una disminución importante del 20,97\%, es decir, 191 casos. Sin embargo, no ocurrió lo mismo en el 2011 , cuando el número de casos se incrementó a 1.257, de los cuales el $89 \%$ de las víctimas fueron mujeres, siendo las niñas y adolescentes, como también las mujeres ente 18 y 30 años de edad, las más afectadas, $\mathrm{y}$, desconocidos, padres, padrastros y vecinos los principales perpetradores del delito $^{37}$.

En un estudio realizado en el 2008 acerca de la percepción de seguridad con perspectiva de género en Medellín, se encontró que el 73\% de las mujeres perciben mayores niveles de inseguridad, frente

${ }^{37}$ Casos recibidos en el Centro de Atención Integral a las Víctimas de Abuso Sexual. CAIVAS, 2011. 
a un $57 \%$ por parte de los hombres ${ }^{38}$, aunque la ocurrencia de delitos como los homicidios tienen una mayor difusión frente a delitos denominados de "menor impacto" como robos y atracos.

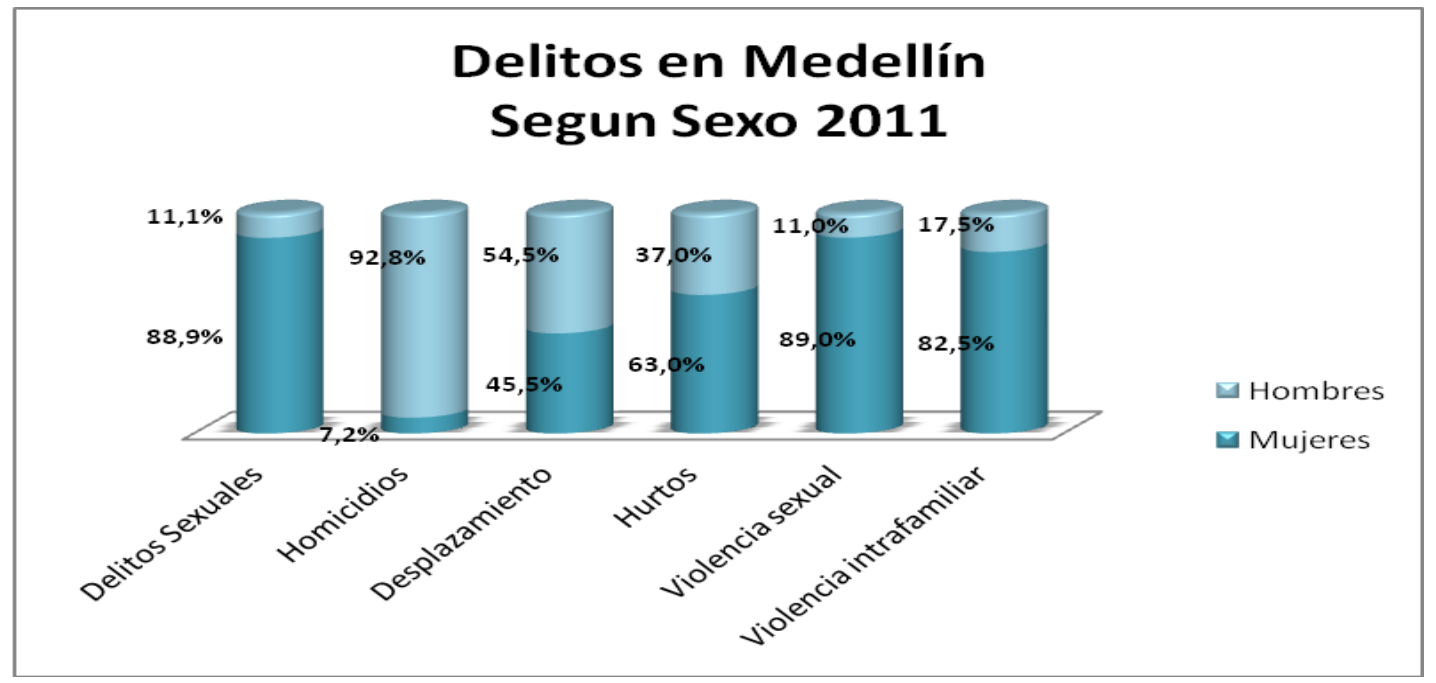

Figura 9. Delitos en Medellín según sexo - 2011.

Fuente: Sistema THETA, SISC - Secretaria de Gobierno.

Considerando las proporciones frente a la gravedad de los hechos y del riesgo al que expone cada uno de estos delitos, se logró establecer, tomando como datos de referencia el periodo 2011, que la violencia intrafamiliar les ocurre tres veces más a las mujeres, el homicidio les ocurre quince veces más a los hombres que a las mujeres. Sin embargo según algunos estudios pese a la seguridad tradicionalmente asociada a la casa, "las mujeres asesinadas tienen diez veces más probabilidades que los hombres de haber sido víctimas de violencia doméstica” (Madriz, 2001: 33). Así mismo los impactos que se generan producen traumas y consecuencias diferenciadas, pues las mujeres víctimas de violencia sexual deben vivir con un trauma que las acompañara durante toda la vida (Madriz, 2001: 81). En proporción similar que afecta los homicidios a los hombres, afecta la violencia sexual más a las mujeres y más de la mitad de las personas afectadas por el hurto y el desplazamiento ${ }^{39}$ son mujeres.

\subsection{Comunas 1 - Popular (C1P) y 8 - Villa Hermosa (C8VH)}

\subsubsection{Contexto espacial y social}

\footnotetext{
${ }^{38}$ Centro de Estudios de Opinión (2008). Percepción de seguridad con perspectiva de género, Universidad de Antioquia, documento inédito.

${ }^{39}$ Generalmente las causas que originan el desplazamiento están antecedidas por actos violentos, como la intimidación, amenaza, la extorsión o el asesinato de uno de los miembros de la familia.
} 
Las C1P y C8VH se encuentran ubicadas al oriente del río Medellín, la primera en la zona nororiental y la segunda en la zona centro oriental. Ambas comunas tienen una conformación barrial determinada por el Departamento de Planeación Municipal, pero se encuentran en la disputa por el reconocimiento legal de barrios que se han ido consolidando en los procesos de invasión, asentamiento $^{40}$ y ocupación informal que ha caracterizado estas zonas, y que han sido identificados por la comunidad ${ }^{41}$ por adscripción al entorno barrial que se denota en el tiempo de conformación, ubicación territorial y sentido de pertenencia, respectivamente.

La C1P limita por el norte con el municipio de Bello, por el oriente con el corregimiento de Santa Elena, por el sur con la Comuna 3 - Manrique, por el noroccidente con la Comuna 2 - Santa Cruz y por el suroccidente con la Comuna 4 - Aranjuez. Según datos del Departamento de Planeación Municipal se establece que en la $\mathrm{C} 1 \mathrm{P}$ se encuentran distribuidos 12 barrios, mientras que la comunidad identifica 9 barrios más, siendo en total 21 barrios que conforman este sector (Corporación Con-vivamos, 2009) ${ }^{42}$.

\footnotetext{
${ }^{40}$ En ambas comunas los procesos de invasión y asentamientos ilegales han sido en su mayoría generados por la población desplazada que llega a la ciudad y se instala en las zonas periféricas de ella.

${ }^{41}$ Estos nuevos barrios han sido identificados en la elaboración de los planes de desarrollo local que cada una de las comunas ha realizado mediante ejercicios comunitarios de reconocimiento y proyección espacial y social del entorno comunitario.

42 Santo Domingo 1, Santo Domingo 2, Granizal, Popular 1, Moscú 2, Villa Guadalupe, San Pablo, Carpinello, El Compromiso, Aldea Pablo VI, La Esperanza y La Avanzada. Barrios identificados por la comunidad: Santa María La Torre, Popular 2, Santa Cecilia 1, Santa Cecilia 2, Marco Fidel Suárez, Villa Guadalupe parte baja, San Pablo 2, Nuevo Horizonte y Nuestra Señora del Rocío.
} 


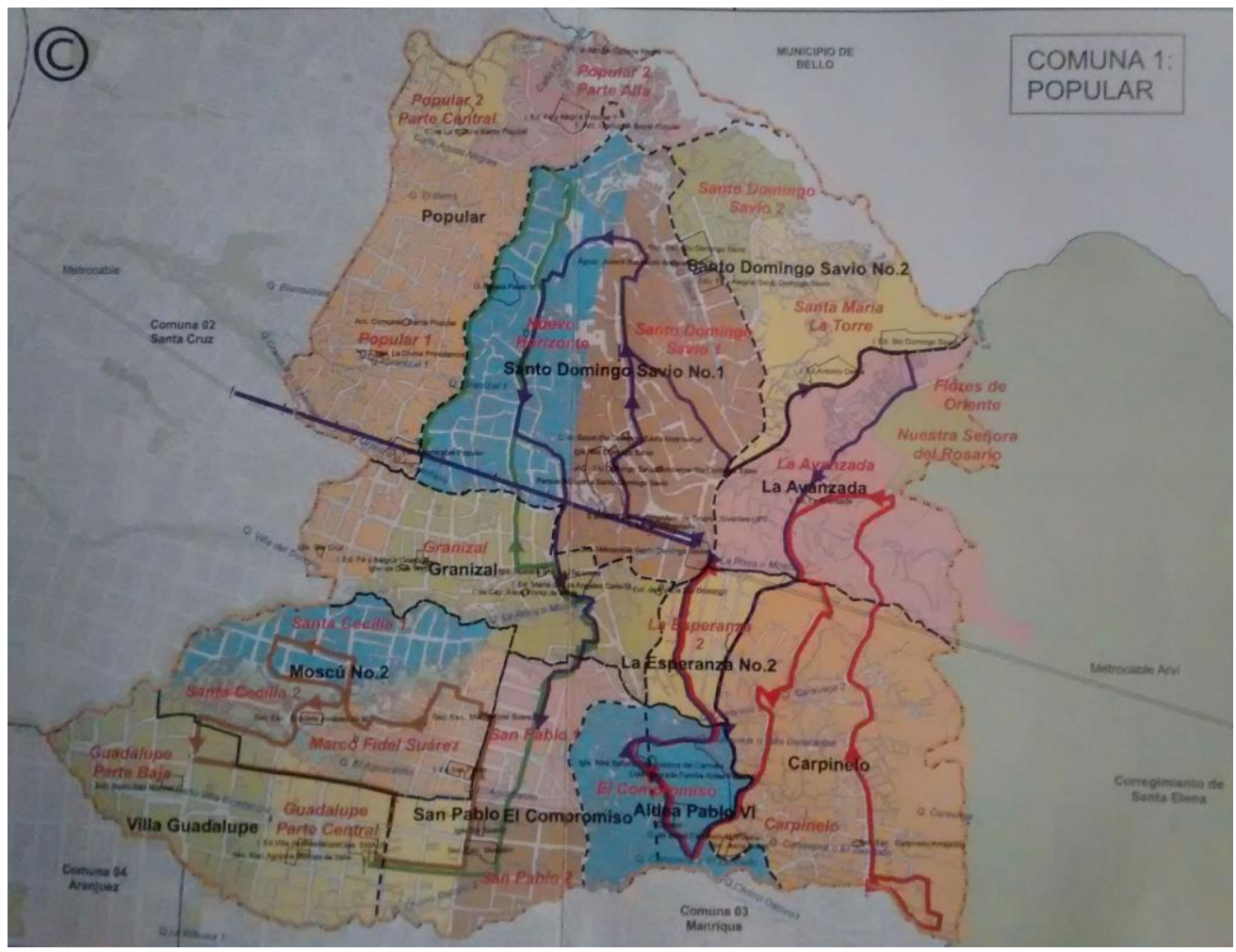

Figura 10. Mapa C1P.

Fuente: Universidad Nacional de Colombia. Proyecto Hábitat como construcción social (2010).

A principios de siglo el proceso de conformación y consolidación del territorio en la C1P se caracterizó por que los propietarios de las fincas allí ubicadas poseían una solvencia económica, lo que permitió que se definiera una sociedad urbanizadora que trazó calles, predios y se conformaron nuevos barrios. Ya en las décadas del 50 y 60 hay una transformación en este panorama: personas de estratos más bajos comenzaron los procesos de urbanización en los terrenos más difíciles de la zona debido a lo empinado y quebrado de su geografía. Estas con el tiempo fueron legalizando la tenencia de la propiedad, aunque no en su totalidad (Naranjo, 2009a). Se presentaron además dos procesos de poblamiento, cada uno de ellos marcado por algunas particularidades, entre las que están: el asentamiento como producto de urbanizadores particulares de conformación histórica más antigua y relación directa con el sector, y las modalidades de poblamiento ilegal como invasiones y loteo pirata (Naranjo, 1992).

Por su parte, la C8VH limita al oriente con el perímetro urbano y el corregimiento de Santa Elena, al occidente con la C1P, Comuna 10 - La Candelaria, al norte con la Comuna 3 - Manrique y al sur con la quebrada Santa Elena y la Comuna 9 - Buenos Aires. Según datos del Departamento 
Municipal de Planeación hay en este territorio 18 barrios $^{43}$, mientras que la comunidad identifica 12 barrios más ${ }^{44}$, siendo en total 30 barrios los que conforman este sector (Corpades, 2009).

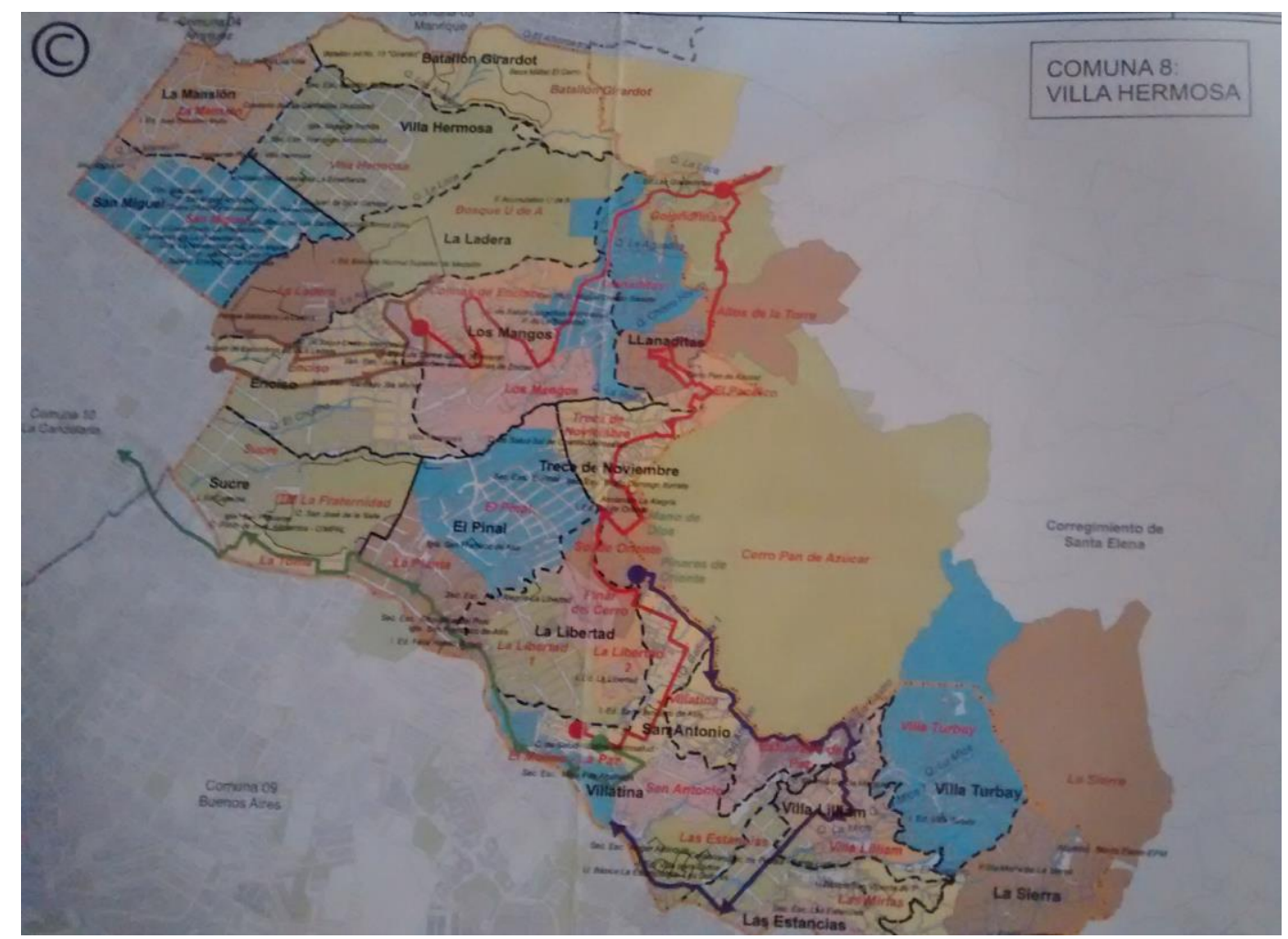

Figura 11. Mapa C8VH.

Fuente: Universidad Nacional de Colombia. Proyecto Hábitat como construcción social (2010).

La ubicación de esta comuna ha permitido en su proceso de urbanización una prolongación del centro hacia el oriente, que, al igual que la $\mathrm{C} 1 \mathrm{P}$, se desarrolla al margen de la ilegalidad, especialmente en las zonas periféricas, ya que los barrios con proximidad al centro de la ciudad se caracterizaron por una arquitectura impecable que daba además cuenta de un proceso de planificación que se fue diluyendo en la expansión hacia las laderas (Naranjo, 2009b).

El proceso de poblamiento de los asentamientos, al igual que otros sectores con las mismas características de "invasiones ilegales", tienen en común la falta de planeación física y social institucional, ya que se constituyeron debido a la migración de campesinos provenientes de

\footnotetext{
${ }^{43}$ Villa Hermosa, La Mansión, San Miguel, La Ladera, Enciso, Sucre, Los Mangos, Trece de Noviembre, El Pinal, La Libertad, Las Estancias (incluye Unión de Cristo), Villa Lilliam, San Antonio (incluye las Torres), Villatina (incluye La Esperanza), Sol de Oriente (incluye Pinares de Oriente), Villa Turbay, La Sierra y Esfuerzos de Paz.

${ }^{44}$ Colinas de Enciso, Golondrinas, Llanaditas, Pinar del Cerro, La Toma, La Planta (Incluye Las Perlas y Quintas de la Playa), El Molino - La Paz, Santa Lucía, La Libertad 2, Las Mirlas, Altos de la Torre y El Pacífico.
} 
diferentes partes de la zona rural de Antioquia, en procesos de desplazamiento y migración nacionales y regionales, centrado especialmente a la población afrodescendiente en las $\mathrm{C} 8 \mathrm{VH}$ y Comuna 13 - San Javier (Nieto, 2008).

En ambas comunas se continúan generando los procesos de invasión que tomaron fuerza en la década de los noventa y que hoy día se conocen como asentamientos nuevos de población desplazada como consecuencia del conflicto armado en algunas regiones del país y del departamento, los cuales dan nombre a los barrios aún no reconocidos en el Departamento Municipal de Planeación, y que con el paso del tiempo aumentan dado su crecimiento poblacional, lo cual repercute en la dimensión espacial del territorio haciendo que los barrios sean más pequeños.

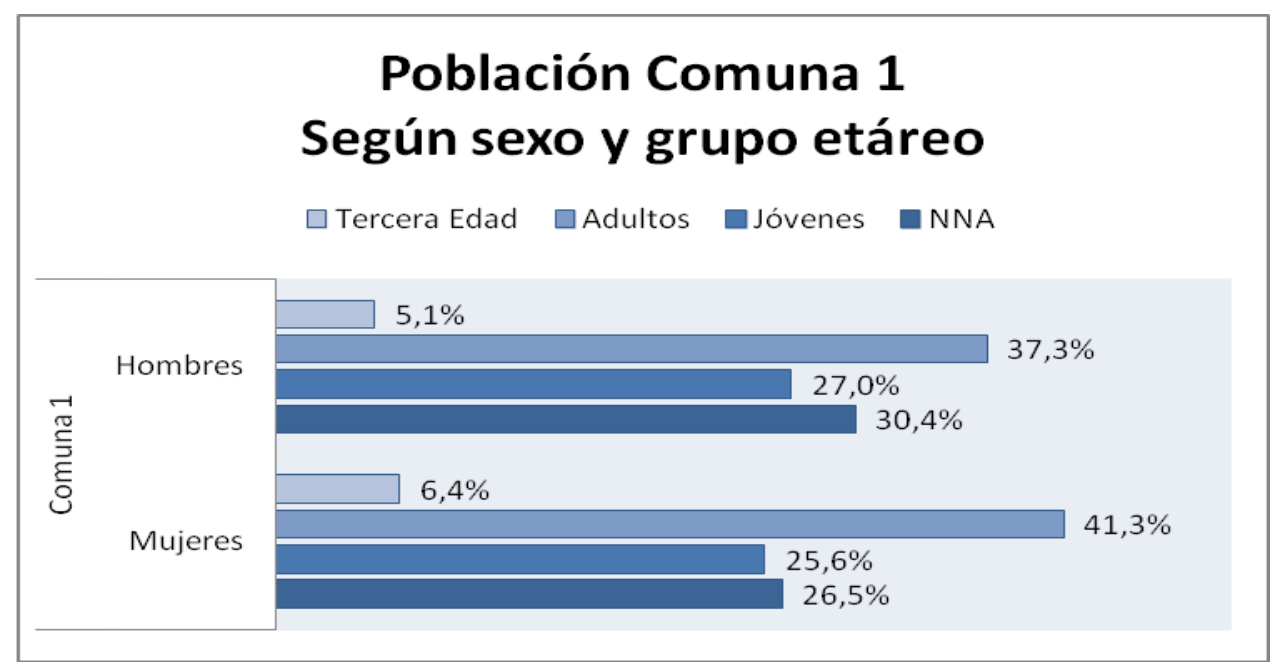

Figura 12. Población C1P, según sexo y grupo etario. Fuente: Encuesta Calidad de Vida 2011.

En relación con los datos demográficos ${ }^{45}$, ambas comunas cuentan con unas características algo similares en cuanto a la conformación por sexo, grupo etario y situación económica de sus pobladores. La C1P, por su parte, cuenta con 126.887 habitantes $^{46}$, de los cuales 60.173 (47,5\%) son hombres y $66.714(52,5 \%)$ son mujeres, que representan el 5,42\% del total de la población en Medellín. De este número de mujeres, el 26,5\% lo constituyen niñas y adolescentes, 25,6\% jóvenes; seguido de un $41,3 \%$ de adultas, y el 6,4\% pertenecientes a la tercera edad. En este panorama se puede establecer que las jóvenes, niñas y adolescentes son el grupo etario que predomina del total de las mujeres y es además un porcentaje muy significativo sobre las mujeres de la tercera edad.

\footnotetext{
${ }^{45}$ Los datos utilizados en este apartado se tomaron del informe de la Encuesta de Calidad de Vida 2010.

46 De acuerdo con la proyección sociodemográfica presentada por el Departamento Administrativo de Planeación, DANE.
} 
La pobreza y precariedad económica de este sector se evidencia en la estratificación socioeconómica $^{47}$ existente, ya que solo predominan dos estratos, el bajo bajo y el bajo. El 35,6\% de la población se encuentra en bajo bajo y el 64,5\% en bajo; el 52\% de la población clasificada en ambos estratos corresponde a mujeres. Sin duda esta situación es el resultado del alto nivel de afectación que sobre las mujeres tiene la falta de oportunidades equitativas en el mercado laboral, la marginación y exclusión que la ciudad en general hace sobre las personas que habitan en estas zonas, pero en especial sobre las mujeres, quienes tienen como casi única posibilidad entregar su mano de obra en labores domésticas mal remuneradas (Unidad Mujer y Desarrollo, 2004), y en el peor de los casos, y no menos frecuente, la falta de ingresos propios que las obliga a tener una dependencia absoluta de su compañero de turno, con quien predomina la incertidumbre de la estabilidad económica y también emocional.

El $47 \%$ de los hogares está conformado por entre 3 y 4 personas, seguido por grupos de 6 a 10 personas que representan el $17,93 \%$, casi la tercera parte del total de los hogares, el $14,71 \%$ está conformado por 5 personas, el 13,31\% por 2 personas, el 5,32\% por una sola persona y el 1,54\% por más de 10 personas. Al contrastar esta lectura con la estratificación de los hogares del párrafo anterior, se aprecia que hay un alto porcentaje de hogares que viven con unas condiciones mínimas: el $47 \%$. Es preocupante que en la tercera parte del total de los hogares habite un promedio de 8 personas por hogar, lo que puede incrementar ostensiblemente unas condiciones para nada dignas en cuanto a la calidad de vida de los hogares que habitan este sector de la ciudad.

De 37.017 hogares identificados en la C1P, en el 53,22\% sus jefes de hogar son hombres y en el $46,78 \%$ son mujeres. En cuanto al estado civil, en el caso de las mujeres jefe de hogar predomina la condición de solteras, con un porcentaje equivalente a los hombres que son casados, esto es, mientras que del total de estos hogares, 7.050 son mujeres solteras, 7.155 son hombres casados. Igualmente, se destacan los casos de las jefas de hogar que son divorciadas o viudas, en porcentajes entre el $80 \%$ y el $84 \%$. Esto muestra que si bien es más alto el porcentaje de hombres jefes de hogar, las condiciones en las que se encuentran las mujeres que ejercen el rol difieren puesto que la gran mayoría de las mujeres lo ejercen sin ningún tipo de acompañamiento formal o informal pero permanente. Otro aspecto importante en relación con la jefatura de hogares es el rango de edad en el

\footnotetext{
${ }^{47}$ Según la Encuesta Calidad de Vida, en Medellín hay seis estratos socioeconómicos: bajo bajo, bajo, medio bajo, medio, medio alto y alto. Se identifican también con clasificación numérica como estrato 1, 2, 3, 4, 5 y 6 , en su orden, respectivamente.
} 
que se encuentran, ya que el número de mujeres con edades que oscilan entre los 15 y 19 años que se encuentran asumiendo ese rol triplica el número de hombres.

El 57,56\% de los/as jefes/as de hogar trabajan ${ }^{48}$, es decir, 21.307 hogares cuentan con al menos un ingreso económico para la atención de sus necesidades básicas. De este porcentaje, el 32\% son mujeres, mientras el $68 \%$ son hombres, lo que significa que solo la tercera parte de los hogares con jefatura femenina cuentan con un ingreso básico para su sostenimiento. Un número importante de hombres se encuentran buscando trabajo, o en otra actividad, aunque no es preciso determinar cuál. Un porcentaje de hombres que doblega el de las mujeres está estudiando. Un número de 3 jefes de hogar hombres están jubilados por una mujer, y del total de jefes de hogar que se encuentran dedicados a los oficios del hogar, el 93\% son mujeres que no obtienen ningún tipo de ingresos.

En esta comuna hay alrededor de 37.017 hogares y 36.498 viviendas, lo que implica que hay más de 500 hogares sin vivienda. En consecuencia, en una vivienda puede habitar uno o más hogares. Esto sin tener en cuenta que del total de las viviendas, un $8 \%$ se encuentra en condiciones no aptas para ser habitadas.

Con respecto a la educación, aunque una parte importante de los programas de gobierno se han orientado a la cobertura educativa, con lo cual han buscado evidenciar un porcentaje de cero analfabetismo en la ciudad, casi el 6\% del total de los habitantes mayores de 15 años no saben leer ni escribir, siendo mujeres el $58 \%$ de este porcentaje.

El 2\% del total de los habitantes no cuenta con afiliación a ningún sistema de seguridad social, en porcentajes similares de hombres y mujeres, y solo el 16,7\% se encuentra afiliado a un sistema de pensiones, de los cuales el 63\% son hombres y el 37\% son mujeres, es decir, 13.237 y 7.975 , respectivamente.

La C8VH está habitada por 134.235 personas, de las cuales 64.141 (47,8\%) son hombres y 70.094 $(52,2 \%)$ son mujeres. Esta población representa el 5,73\% del total de la de la ciudad. De este número de habitantes, el 22,4\% lo constituyen niñas y adolescentes; el 25,5\%, mujeres jóvenes; el $43,8 \%$, adultas; y el 8,1\% son mujeres de la tercera edad. Al igual que sucede en la C1P, en este sector de la ciudad predomina el grupo etario de niñas, adolescentes y mujeres jóvenes, y en un

\footnotetext{
${ }^{48}$ Sin embargo no es posible determinar el nivel de formalidad e informalidad de la actividad laboral.
} 
porcentaje no distante las mujeres adultas. Esta distribución porcentual no establece puntos porcentuales significativos en relación con los grupos etarios de hombres, siendo la diferencia mínima de 2 y máxima de 4 puntos porcentuales.

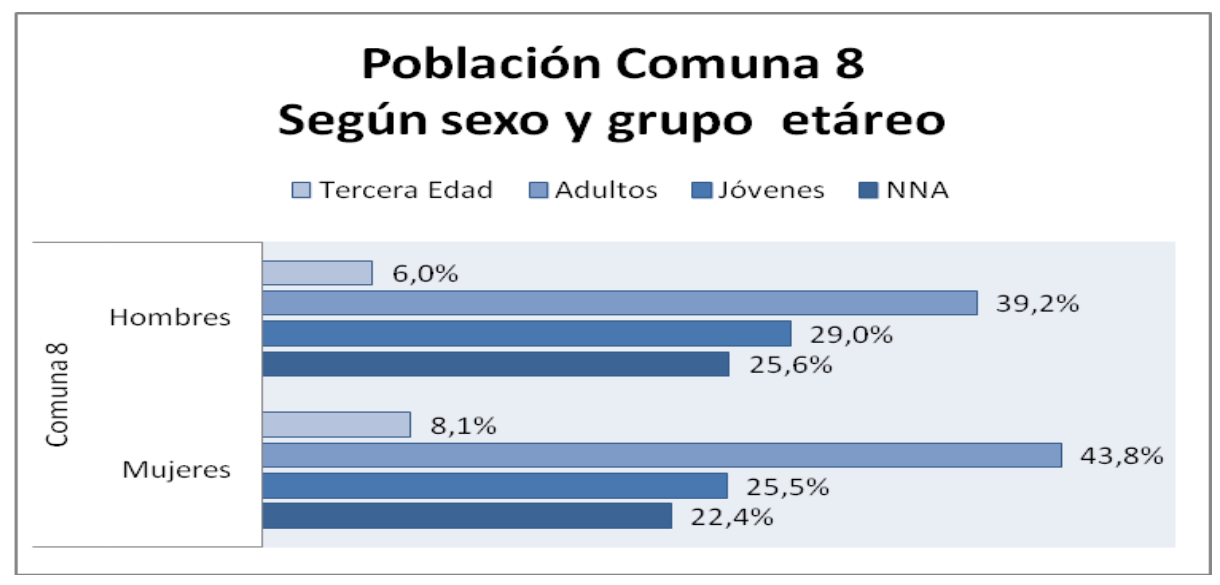

Figura 13. Población C8VH, según sexo y grupo etario. Fuente: Encuesta Calidad de Vida 2011.

De los seis niveles de estratificación socioeconómica, cuatro de ellos están presentes, dadas las condiciones de la comuna. El estrato bajo bajo tiene el 38\% y el 33\% corresponde al estrato bajo; en ambos un poco más de la mitad son mujeres. El estrato medio bajo tiene el 27\%, del cual el 43\% son mujeres. Finalmente, el estrato medio tiene el $2 \%$, del cual $57,5 \%$ son mujeres.

La mayoría de los hogares están conformados por entre 3 y 4 personas, le siguen los constituidos por entre 6 y 10 personas $(17,09 \%)$, es decir, casi la tercera parte del total de los hogares, seguido del $15,21 \%$ con 5 personas, el $12,63 \%$ con 2 personas, el $8,25 \%$ con una sola persona y el $0,94 \%$ con más de 10 personas.

En la C8VH hay identificados 44.164 hogares, de estos, el 55\% son hombres y el 45\% restante son mujeres. Sin embargo, las condiciones en que ejercen el rol de jefe/a de hogar difieren en razón de su estado civil, ya que mientras más de la tercera parte de las mujeres está soltera, viuda, separada o divorciada, es decir, aproximadamente 13.000 mujeres, solo 4.585 hombres lo están, lo que representa que por un hombre hay tres mujeres en esa misma circunstancia. De otra parte, también es mayor el número de hombres que siendo jefes de hogar cuentan con una pareja, este porcentaje casi que cuatriplica el número de mujeres que cuentan con un acompañamiento formal de una pareja estable. Este panorama permite analizar que pese a que son más los hombres quienes tienen la jefatura de los hogares, son las mujeres las que se encuentran en condiciones más difíciles a razón de la ausencia de un acompañamiento estable. En cuanto a la edad, hay una equitativa proporción 
en cuanto al número de hombres y mujeres que asumen las jefaturas del hogar entre los 15 y los 24 años de edad, con la salvedad de que en el rango de 15 a 19 años solo son mujeres quienes a esta temprana edad empiezan a ejercer ese rol.

Del total de los/as jefes/as de hogar, 25.707 (58,21\%) se encuentran trabajando, y de estos, un poco menos de la mitad son mujeres (7.294); el 21,71\% está dedicado a los oficios del hogar, en su mayoría mujeres que no reciben ningún tipo de ingreso económico; el 9,8\% son personas jubiladas o pensionadas, de las cuales un poco más de la mitad son hombres. El porcentaje restante $(10,25 \%)$ está principalmente buscando trabajo, realizando otra actividad, aunque no se específica de qué tipo, con incapacidad laboral, estudiando o recibiendo algún tipo de renta, siendo este último caso una mínima parte de la población.

En esta comuna hay 44.164 hogares y 43.328 viviendas, lo que significa que 836 hogares no cuentan con una vivienda para habitar, o en su defecto comparten una vivienda con uno o más hogares. Del total de esas viviendas, el $6,5 \%$ se encuentran en condiciones no aptas para ser habitadas.

Aproximadamente el 3\% del total de los habitantes no están afiliados a un régimen de salud, en proporciones similares hombres y mujeres. Igualmente, solo el $21 \%$ se encuentra afiliado a un régimen de pensiones, correspondiendo el $59 \%$ a hombres y un $41 \%$ a mujeres.

En las zonas donde se ubican la C1P y la C8VH hay una autopercepción de pobreza del 29\% y el $24 \%$ respectivamente, por encima del promedio de la ciudad, que tiene un $22 \%$ de la población que se autopercibe como pobre ${ }^{49}$. Esta situación se atribuye a la falta de empleo, bajos ingresos económicos y la falta de dinero para cubrir las necesidades básicas. Igualmente, como consecuencia de esto son también las zonas de mayor porcentaje de hogares donde alguno de sus miembros dejó de comer por falta de dinero: la zona nororiental en primer lugar con $19 \%$, seguida de la centrooriental con un $11 \%$.

Las características socioeconómicas que se acaban de exponer de estas comunas dan luces para determinar el contexto de pobreza, exclusión y marginación en el que vive un porcentaje importante

${ }^{49}$ Mediante encuesta se preguntan las razones por las cuales las personas se consideran pobres, y las respuestas aducen a "razones económicas, relacionadas con el empleo y el ingreso, como por ejemplo la falta de muchas cosas para vivir mejor, la falta de dinero o el dinero no alcanza para cubrir las necesidades". (Medellín cómo vamos, 2010: 6). 
de sus habitantes, aún más considerando que el mayor nivel de concentración de la población se encuentra en los barrios más periféricos de estos sectores de la ciudad.

\subsubsection{Caracterización del conflicto armado urbano en las C1P y C8VH}

Las C1P y C8VH han sido epicentro de algunas de las situaciones que han marcado la historia de violencia de la ciudad, y eso ha repercutido de manera directa en sus procesos sociales. De hecho, algunos aspectos de la violencia se instauran como característicos de dichas comunas; vaya por caso la presencia de grupos milicianos ${ }^{50}$ en la década de los ochenta, la aparición de bandas delincuenciales ligados al narcotráfico ${ }^{51}$ y posteriormente finalizando la década de los 90's la aparición y consolidación de grupos paramilitares. Sin embargo, la situación varía en cuanto a la incidencia de estos factores en la vida social, sus periodos de permanencia y las formas como se han hecho presentes.

Ambas comunas han sufrido el efecto de los conflictos territoriales entre $\operatorname{combos}^{52}$ y milicias, que han generado ciclos de violencia de acuerdo con el escalamiento del conflicto armado en la ciudad. A finales de la década de los ochenta y principios de los noventa, aparecieron las milicias en estos sectores de la ciudad "como respuesta a la proliferación de bandas ${ }^{53}$ y a la consolidación del sicariato" (Franco, 2004: 43), otros grupos de autodefensas comunitarias Los capuchos, Milicias del pueblo y para el pueblo, las Milicias Populares del Valle de Aburrá del Ejército de Liberación Nacional, Eln, y las Milicias Bolivarianas de las Fuerzas Armadas Revolucionarias de Colombia (FARC), como extensión a la ciudad del conflicto político armado que se vivía en las zonas rurales del país.

\footnotetext{
${ }^{50}$ La aparición de las milicias en las comunas de la ciudad ha tenido diversas y complejas interpretaciones desde diversos analistas. De una parte, postulan una expansión de la guerrilla en la ciudad, hasta la consolidación de grupos de autodefensas como respuesta a los altos niveles de delincuencia y la violencia indiscriminada que ocurría en la ciudad, como también unas luchas territoriales con las bandas delincuenciales. (Nieto y Robledo, 2006; Medina, 2006; Franco, 2004; Jaramillo, et al, 1998).

${ }^{51}$ El tema del narcotráfico ligado a la violencia en la ciudad está anclado a la presencia de Pablo Escobar como el actor principal, quien financia y promueve la venta de armas y droga entre los diversos grupos que operan en la ciudad, haciendo de este el mercado por excelencia que se va consolidando especialmente en las zonas más pobres, con mayores niveles de desempleo y ausencia de Estado, su principal caldo de cultivo, y, que amplía su radio de acción en diversos sectores de la sociedad, lo político, lo económico y lo social, involucrando principalmente a la población juvenil.

${ }^{52}$ Los combos son grupos armados de jóvenes en los barrios, en algunos casos presentan similitudes con las pandillas juveniles, sin embargo para el caso de Medellín, estas se articulan a estructuras criminales complejas (Jaramillo y Gil, 2014:133) generalmente ligadas al negocio del narcotráfico.

${ }^{53}$ Combos.
} 
Desde comienzos de la década de los ochenta se presentaron en la C8VH fuertes enfrentamientos por el control territorial y la venta de estupefacientes por parte de los combos que operaban en los sectores de La Sierra y La Cañada. Estos enfrentamientos empeoraron luego de que ingresaran proyectos políticos insurgentes apoyados en principio por el Ejército de Liberación Nacional (ELN), que reclutó jóvenes para la conformación de los Comandos Armados 6 y 7 de noviembre y enfrentó a combos que ya tenían presencia en la zona, como La Cañada.

Posteriormente, en la década de los noventa se produjeron procesos de negociación ${ }^{54}$ entre los grupos de milicias populares y el Gobierno Nacional, que, en el caso de la C1P, culminaron con la desmovilización y la dejación de las armas. En la C8VH, pese a la firma de los pactos, continuaron los enfrentamientos ante el incumplimiento de los acuerdos, lo que generó un mayor fraccionamiento al interior de los grupos amados.

A finales de la década de los noventa, la C8VH se convirtió en uno de los primeros escenarios donde se llevó a cabo una lucha frontal de grupos paramilitares contra grupos milicianos, entre los que se encontraban los Comandos Armados del Pueblo CAP ${ }^{55}$, las milicias del ELN, y los Comandos 6 y 7 de noviembre. Ante esta arremetida, una parte de estas milicias que tenían su principal zona de influencia en el barrio La Sierra, como fue el caso de los Comandos 6 y 7 de noviembre, a partir del 2001 se pasaron a las filas de paramilitares que por ese entonces venían haciendo su ingreso en diversos sectores de la ciudad, en un reducto del denominado Bloque Metro $^{56}$, que posteriormente también terminó cooptando los combos, como sucedió con la banda ${ }^{57}$ de La Cañada.

\footnotetext{
${ }^{54}$ En 1993 se firma el "Acuerdo de Paz con las Milicias Populares, la negociación con la Corriente de Renovación Socialista a partir de la Mesa de Trabajo del Bosque - Moravia y los Pactos de Convivencia con seis Bandas Juveniles en el Barrio Antioquia y otros procesos desarrollados en la ciudad" (Sepúlveda, 2010). En el 94 se firma el "Acuerdo para la convivencia ciudadana" que desmovilizó a las milicias Populares del Pueblo y para el Pueblo, las Milicias Metropolitanas y las Milicias Independientes del Valle de Aburrá. En el 97 se firma el "Pacto de no agresión" firmado por las bandas delincuenciales y el grupo de milicias Comandos 6 y 7 de noviembre.

55 Los Comandos Armados del Pueblo fueron un grupo de milicias urbanas que se originaron a mediados de la década de los noventa con el Ejército de Liberación Nacional, ELN. Iniciaron su accionar en la C1P para después replegarse en otros sectores de la ciudad.

${ }^{56}$ El Bloque Metro tuvo su origen en las Autodefensas Campesinas de Córdoba y Urabá (ACCU), operaron en la ciudad entre 1997 y 2003. Sus miembros establecieron fuertes relaciones con bandas delincuenciales y no se sumaron al proceso de desmovilización, por lo que fueron combatidos y posteriormente cooptados por el Bloque Cacique Nutibara.
} 
Esta adhesión al mismo bloque paramilitar por parte de bandas delincuenciales y de milicias con una tradición de confrontación entre sí, terminó en la conformación de un nuevo bloque paramilitar denominado Bloque Cacique Nutibara $^{58}$, que en el 2005 se insertó en el Proceso de Desmovilización y Reinserción que se originó en la ciudad, presentándose como integrantes del Bloque Héroes de Granada ${ }^{59}$, al igual que otros integrantes de bandas y narcotraficantes (Gil, 2009).

Este mismo proceso de reorganización por parte de actores contrainsurgentes se produjo en la C1P, en el marco del escalonamiento del conflicto armado urbano y la presencia progresiva de grupos de paramilitares, que al igual que en la $\mathrm{C} 8 \mathrm{VH}$ y del resto de la ciudad ${ }^{60}$, se vincularon al proceso de desmovilización.

\begin{tabular}{|l|c|c|c|c|}
\hline \multicolumn{1}{|c|}{ Comuna } & Bloque Cacique Nutibara & Bloque Héroes de Granada & Otros & Total \\
\hline 1 - Popular & 176 & 245 & 106 & 527 \\
\hline 3 - Manrique & 97 & 275 & 118 & 490 \\
\hline 8 - Villa Hermosa & 99 & 117 & 108 & 324 \\
\hline 6 - Doce de Octubre & 46 & 51 & 151 & 248 \\
\hline 5 - Castilla & 8 & 36 & 168 & 212 \\
\hline 1 - Popular & 21 & 68 & 90 & 179 \\
\hline 7 - Robledo & 0 & 1 & 11 & 12 \\
\hline
\end{tabular}

Tabla 2. Número de desmovilizados por comuna.

Fuente: Alcaldía de Medellín, 2007.

57 Se denomina banda en tanto es un grupo armado con trayectoria y reconocimiento en el mundo delincuencial, que tiene un amplio radio de acción y articulación a diferentes redes bien sea de microtráfico, extorsión o robo a su vez son las encargadas de la subcontratación de combos (Arbelaez y Gil, 2014: 133).

58 El Bloque Cacique Nutibara surgió en el 2001 como una organización paramilitar, liderada por Diego Fernando Murillo, alias Don Berna, quien apoyado en las redes delincuenciales y estructuras del narcotráfico logró instalarse en aquellos lugares de la ciudad donde había presencia de grupos armados de izquierda o de milicias.

${ }^{59}$ El Bloque Héroes de Granada se consolida como un apéndice del Bloque Cacique Nutibara, apoyado por la denominada Oficina de Envigado, la cual tenía toda su estructura al servicio del narcotráfico.

${ }^{60}$ El número de desmovilizados en el Valle de Aburrá es de 4.153 personas (Cf. Alcaldía de Medellín, 2007). El 79\% de ellas, 3.270 desmovilizados, se encuentran en la ciudad de Medellín. Los mayores niveles de concentración de dicha población se encuentran en la Zona Nororiental y en la Zona Centro Oriental. Específicamente, el 59\% del total de población desmovilizada de la ciudad (1.932 excombatientes) se encuentran en las Comunas 1 - Popular, 3 - Manrique, 4 - Aranjuez y 8 - Villa Hermosa. En la ciudad de Medellín también están presentes 4.250 desmovilizados de las FARC, el ELN y paramilitares que no participan directamente en el programa de reinserción de la Alcaldía (Espinal y Valencia, 2008: 19). 
La arremetida de los actores del conflicto armado bajo las distintas formas que han asumido en los últimos treinta años ha tenido profundas repercusiones sobre la población civil por cuanto esta vive sometida al fuego cruzado de los actores armados, vive con miedo e incertidumbre constantes ante la eventualidad de la muerte o herida propia o de algún pariente o persona cercana. En ocasiones los pobladores son victimizados/as o en el peor de los casos revictimizados/as en su condición de desplazados $/ \mathrm{as}^{61}$, al tener que abandonar el territorio en el que habitan a causa del desplazamiento forzado intraurbano ${ }^{62}$. En otras ocasiones viven a expensas de las condiciones y limitaciones de la vida cotidiana que imponen los combos, que incluyen vacunas ${ }^{63}$, extorsiones, fronteras invisibles, entre muchas otras (Agencia de Prensa - Instituto Popular de Capacitación, 2011). Esto repercute negativamente en las formas de relacionamiento de la población civil, que no solo se ve obligada a vivir bajo estas circunstancias, sino que además termina implementando esas formas de impartición de justicia en la solución de conflictos vecinales y familiares.

Estos antecedentes que tienen como marco explicativo el conflicto armado urbano, caracterizado por la "acumulación social de la violencia" donde convergen diversos factores (Misse, 2010: 32), repercuten en los procesos de poblamiento y repoblamiento de las comunas en la ciudad a causa del desplazamiento, como se presentó en la C1P, donde en 268 declaraciones se relacionaron 926 personas, y en la C8VH, donde en 126 declaraciones se relacionaron 557 (Encuesta de calidad de vida, 2010; García, 2011). Igualmente, estos sectores de la ciudad fueron a su vez protagonistas de algunos de los principales desplazamientos masivos y colectivos ${ }^{64}$ que se registraron durante el año 2010, como lo muestra la siguiente tabla.

${ }^{61}$ En el periodo 2000-2009 se calcula que aproximadamente han llegado a la Comuna 8 - Villa Hermosa, 9.260 personas desplazadas, distribuidas principalmente en los barrios Enciso, Caicedo, Villatina y Llanaditas, y en la C1P, alrededor de unas 13.037 personas ubicadas en Santo Domingo y Popular. Datos de recepción de encuestas Personería de Medellín.

62 Históricamente, las comunas con mayor problemática de desplazamiento forzado (expulsión) han sido en su orden la Comuna 1 - Popular, 13 - San Javier, 8 - Villahermosa, 6 - Doce de Octubre y 3 - Manrique. Las Comunas 1 - Popular y 13 - San Javier se caracterizan además por ser las mayores receptoras de población desplazada. Pero es necesario anotar que es menor la proporción de personas recibidas por desplazamiento forzado intraurbano frente al importante número de población expulsada desde dichas comunas. Una de las declaraciones recibidas por la Personería en el año 2010 correspondió a un desplazamiento masivo de 86 personas del barrio La Sierra de la C8VH, ocurrido en el mes de junio. Esta declaración hizo parte de las 126 que se recibieron durante el año, que implicaba además 557 personas. En la C1P, por su parte, las declaraciones correspondieron al doble, con 268 que implicaban a 926 personas. Un motivo frecuente de migración de estas familias es para evitar la vinculación de esta población vulnerable a diferentes ofertas ilegales.

${ }^{63}$ Las vacunas son una forma de extorsión que implementan los grupos armados sobre los territorios en los cuales ejercen dominación, para obtener recursos económicos.

${ }^{64}$ Según la caracterización que se ha hecho sobre el asunto, los desplazamientos masivos se configuran por el desplazamiento de 10 o más familias o 50 o más personas por un mismo hecho. Artículo 12 de Decreto 


\begin{tabular}{|l|l|l|}
\hline \multicolumn{3}{|c|}{ Desplazamientos masivos } \\
\hline \multicolumn{1}{|c|}{ Comuna } & \multicolumn{1}{|c|}{ Fecha } & \multicolumn{1}{|c|}{$\mathbf{N}^{\mathbf{0}}$ personas } \\
\hline 1- Popular & Agosto 3 al 18 de sep. del 2010 & 11 familias, 42 personas \\
\hline 8 - Villa Hermosa & Junio 12 del 2010 & 86 personas \\
\hline \multicolumn{3}{|c|}{ Desplazamientos colectivos } \\
\hline 1 - Popular & agosto 12 del 2010 & 25 personas \\
\hline 8 - Villa Hermosa & 30 y 31 de octubre del 2010 & 7 familias, 28 personas \\
\hline
\end{tabular}

Tabla 3. Desplazamientos masivos y colectivos.

Fuente: Personería de Medellín.

Los conflictos armados que vive la ciudad inciden además en el número de homicidios que se presentan en estas comunas, los cuales oscilan de forma similar en número al panorama general. La interpretación de esta situación debe alejarse de una simple coincidencia en la medida en que es en estos dos sectores donde se consolidan los grupos de paramilitares y bandas delincuenciales, y posteriormente donde tiene lugar el proceso de desmovilización y reinserción, particularmente en la C8VH. Por lo tanto, los resultados de estos procesos se reflejan en parte en estos elevados números de homicidios que en el 2009 y en el 2011 representan más del 15\% del total de homicidios ocurridos en toda la ciudad. Por su parte, en el año 2010 hay una diferencia sustancial en el número de homicidios que ocurrieron en la $\mathrm{C} 1 \mathrm{P}$ y $\mathrm{C} 8 \mathrm{VH}$, siendo esta última la más afectada con un número que quintuplica el dato de la C1P. Además es importante observar cómo el número de homicidios en el periodo inicial de análisis, que es casi a mediados de la década, llega a triplicarse al finalizar la misma, mostrando un descenso importantes durante el 2006 y 2007, especialmente en la C8VH, pero invirtiéndose otra vez y de una manera acelerada en esta misma comuna en el 2009, como se refleja en la gráfica siguiente.

2569 de 2000, mientras que los desplazamientos colectivos, no llegan a configurar un desplazamiento masivo, por el número de personas y de familias. 


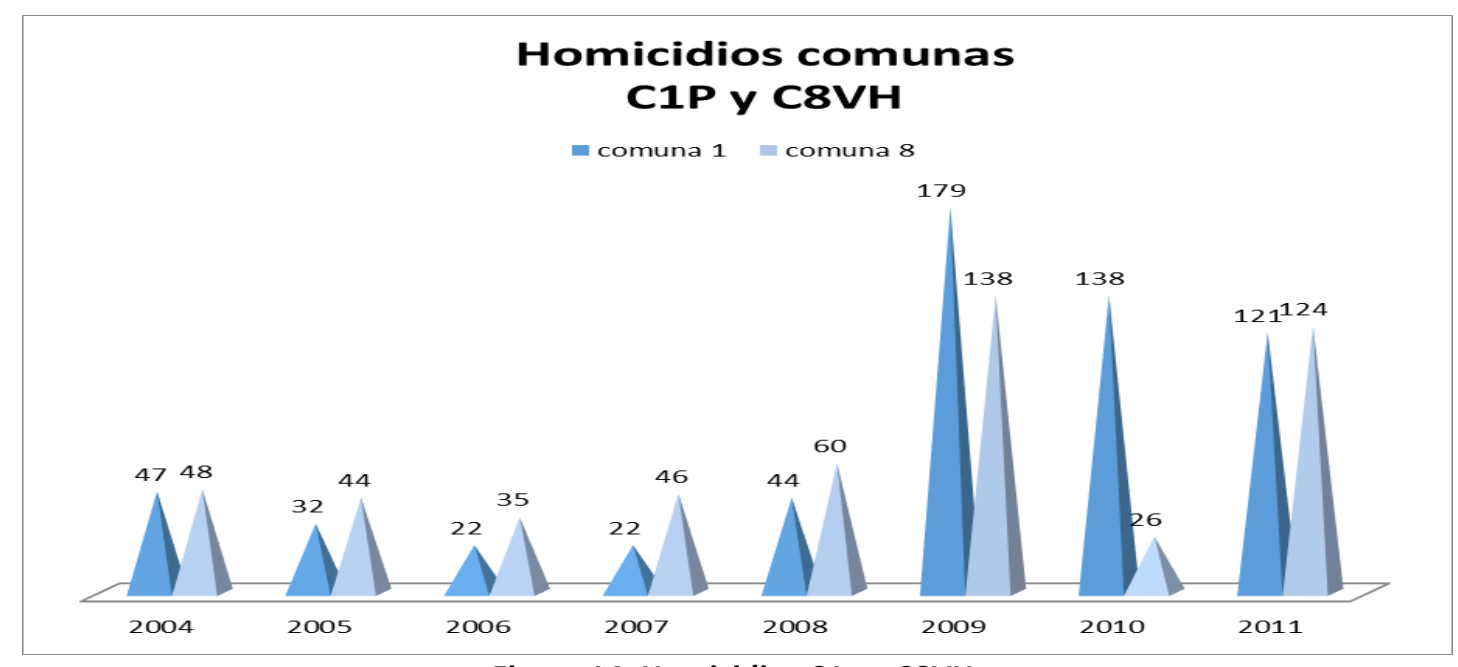

Figura 14. Homicidios C1p y C8VH.

Fuente: Secretaría de Gobierno - SISC (Datos concertados INML, SIJIN, CTI).

Un dato importante es que en los últimos cinco años ha habido una mujer asesinada, tanto en la C1P como en la $\mathrm{C} 8 \mathrm{VH}$, llegando incluso a incrementarse este número a seis mujeres asesinadas en el año como es el caso de la C8VH en el año 2008 donde, vale la pena resaltar, es la comuna donde más se presentan estos hechos.

Las explicaciones habituales sobre lo que acontece en estas zonas de la ciudad apuntan a la expansión del narcotráfico, la expulsión de la guerrilla de la ciudad y los macroproyectos de desarrollo que se van consolidando en el tiempo donde "el oeste de la ciudad está siendo objeto de un importante desarrollo de la red de carreteras, mientras que el nordeste proporciona acceso a la zona interior industrial de Medellín en el Oriente Antioqueño, una zona en la que está previsto un desarrollo industrial en gran escala" (Amnistía Internacional, 2005: 42).

De otra parte, en los últimos años el tema de la trata de personas y la explotación sexual ha venido tomando relevancia, puesto que se ha convertido en una nueva modalidad de ingresos de las bandas que operan en la ciudad y que ha tomado fuerza especialmente en la C1P. Esta nueva modalidad "esconde toda una red de comercio sexual dominada por peligrosas estructuras armadas" (Agencia de Prensa - Instituto Popular de Capacitación, 2010) en donde lo que se negocia es la virginidad de las jóvenes y adolescentes, quienes son contactadas y convencidas por otras jóvenes que tienen como misión dentro de la estructura indagar la vida sexual de las niñas en las diferentes instituciones educativas. 
En conclusión se puede afirmar que los problemas que afectan la seguridad de las personas que habitan la C1P y C8VH están relacionados con diferentes formas de violencia fácilmente asociadas a los altos niveles de desigualdad social y de pobreza en los que se encuentran inmersas, situaciones que se convierten en caldo de cultivo para la cooptación de los grupos armados ilegales que operan en la ciudad. Esto refleja el alto nivel de incidencia que tiene el tema del conflicto armado en estos contextos.

\subsubsection{Otros detonantes de la violencia y la inseguridad en las comunas}

Estos detonantes de la violencia y la inseguridad que ocurren en las comunas tienen como víctimas principales a las mujeres. Esta situación se establece desde los niveles de riesgo que enfrentan y por las distintas formas de violencia que las afectan, llegando a ser incluso su condición de mujeres la que las lleva a una forma de vulneración diferente en relación con el conflicto armado. En un diagnóstico realizado en el 2008 (Ver tabla 4) sobre la seguridad de las mujeres (Gómez, 2008) se encontró que los hombres y mujeres priorizaban la violencia contra las mujeres en sus distintas dimensiones como el problema seguritario central.

\begin{tabular}{|l|l|l|}
\hline Comuna & \multicolumn{1}{|c|}{ Mujeres } & \multicolumn{1}{c|}{ Hombres } \\
\hline C1P & $\begin{array}{l}\text { Abandono y maltrato } \\
\text { Robos }\end{array}$ & $\begin{array}{l}\text { Explotación sexual y laboral } \\
\text { Violencia intrafamiliar } \\
\text { Desplazamientos } \\
\text { Hurtos }\end{array}$ \\
\hline C8VH & $\begin{array}{l}\text { Maltrato } \\
\text { Explotación económica } \\
\text { Violación y abuso sexual }\end{array}$ & $\begin{array}{l}\text { Violación } \\
\text { Robos } \\
\text { Abuso sexual } \\
\text { Abandono mujeres mayores }\end{array}$ \\
\hline
\end{tabular}

Tabla 4. Percepción de riesgos con enfoque diferenciado por comuna.

Fuente: Gómez (2008).

Con respecto a los casos de mujeres víctimas de delitos sexuales, la C1P está entre las principales comunas de mayor ocurrencia de este delito con 74 casos reportados; un poco más atrás está la $\mathrm{C} 8 \mathrm{VH}$ con 68 casos $^{65}$. Así mismo, los casos en estos sectores de la ciudad plantean cifras importantes que invierten los datos de homicidios de la ciudad con respecto al género, es decir, se presenta casi diez veces más la ocurrencia de estos delitos sobre las mujeres que sobre los hombres. Y peor aún, en ambas comunas, en dos años, los casos se han duplicado, tal como podemos ver en el siguiente gráfico:

\footnotetext{
${ }^{65}$ Secretaría de Gobierno de Medellín, Casos recibidos en el Centro de Atención Integral a las Víctimas de la Violencia Sexual, CAIVAS, enero-diciembre (2010-2011), Sistema de Información para la Seguridad y la Convivencia, SISC, 26 de enero de 2012, Medellín.
} 


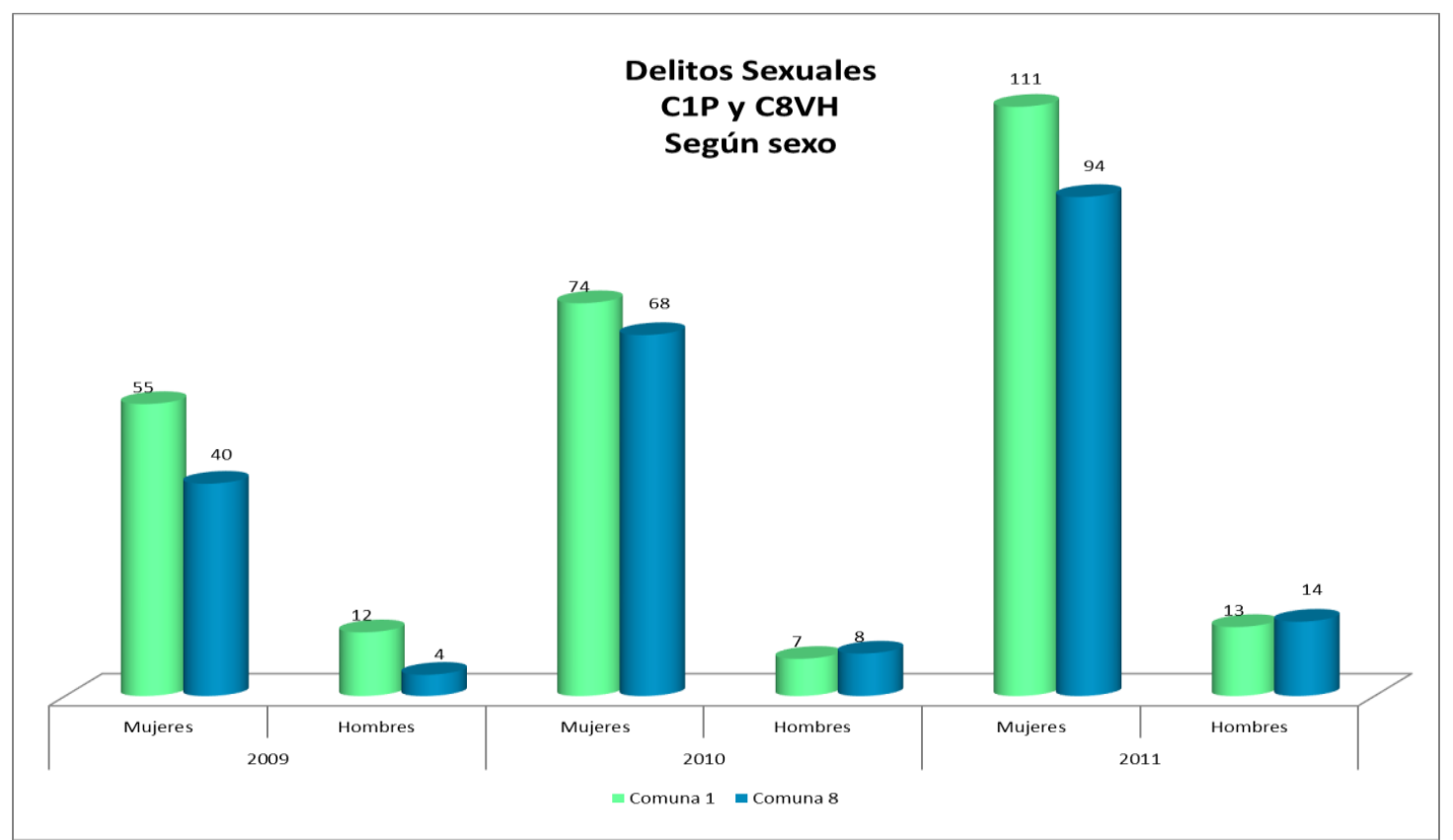

Figura 15. Delitos sexuales C1P y C8VH según sexo. Fuente. Instituto de Medicina Legal - CAIVAS - SISC.

En cuanto a la violencia intrafamiliar, en los últimos años también se han incrementado de manera constante las denuncias en la C8VH. Solo en el año 2009 se presentó un número similar de casos en ambas comunas, tanto en hombres como en mujeres. A partir de allí se refleja una leve disminución en la C1P. Igualmente, llama la atención cómo en los dos últimos años se ha incrementado los casos de hombres en la C8VH (Ver figura 16).

66 Sistema de Información para la Seguridad y la Convivencia, SISC, Dateo por comuna, resumen de criminalidad y convivencia en Medellín (datos concertados Sijin, Fiscalía, CTI, Policía, Medicina Legal), datos diferenciados del 2010 y 2011 a 30 de noviembre. 


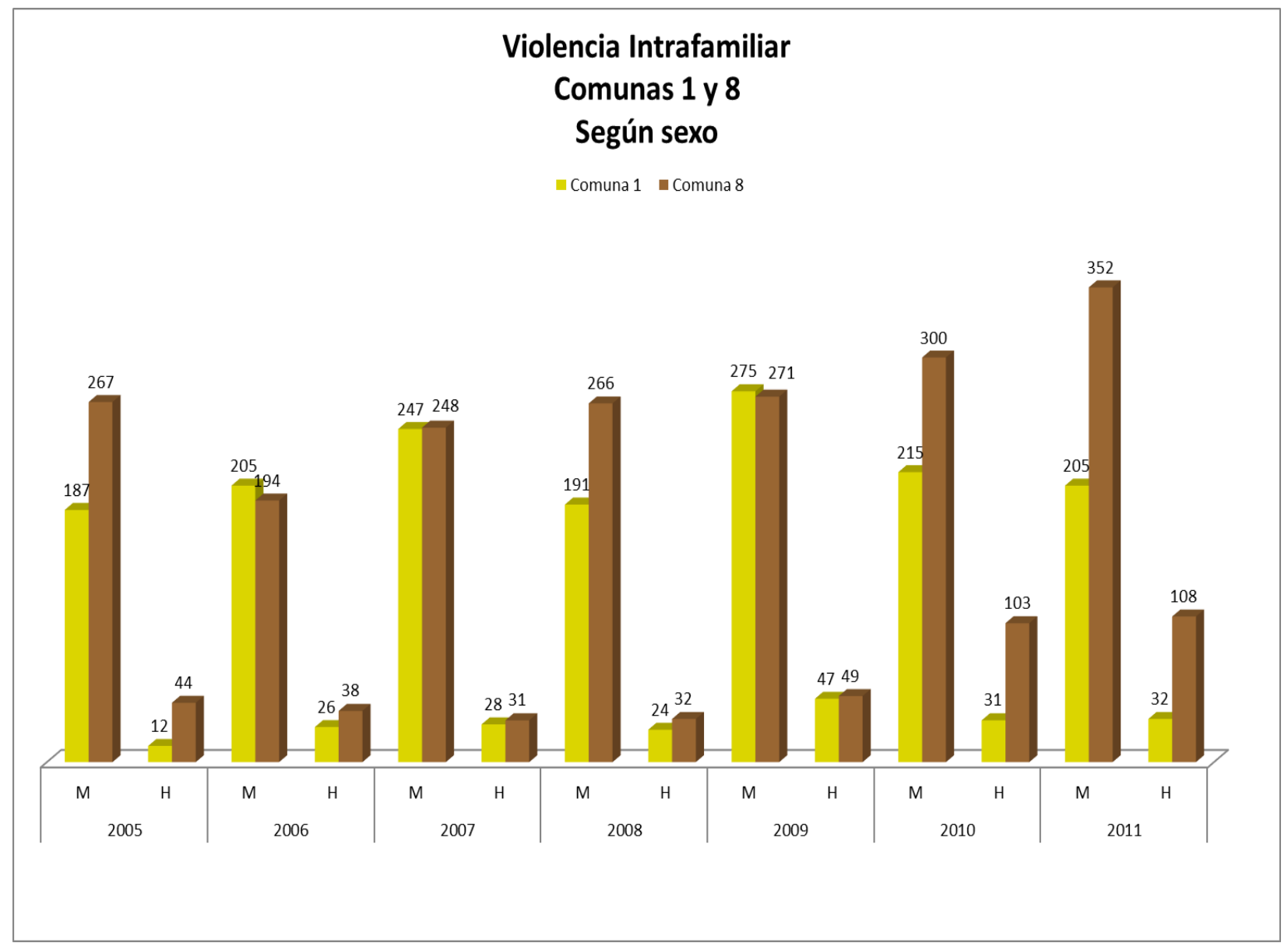

Figura 16. Violencia Intrafamiliar, C1P y C8VH según sexo. Fuente: Secretaría de las Mujeres, 2008 - Sistema THETA, Secretaría de Gobierno, SISC ${ }^{67}$

Finalmente, al analizar un panorama general en cuanto a los delitos que ocurren en las comunas, incluidos los de menor impacto, se puede ver que los delitos relacionados con la violencia intrafamiliar, son mayores a los otros tipos de delitos, duplicando la $\mathrm{C} 8 \mathrm{VH}$ a la C1P. Estos datos por comuna no alcanzan a superar el $10 \%$ de los homicidios ocurridos en la ciudad durante el mismo periodo, en ese mismo sentido estas comunas son en las que menos casos de hurtos de carros y en general se presentan en comparación con otras comunas de la ciudad. (Ver figura 17)

\footnotetext{
67 Sistema de Información para la Seguridad y la Convivencia, SISC, Dateo por comuna, resumen de criminalidad y convivencia en Medellín (datos concertados Sijin, Fiscalía, CTI, Policía, Medicina Legal), datos diferenciados del 2010 y 2011 a 30 de noviembre.
} 


\section{Delitos en General \\ Comunas 1 y 8}

Comuna 1 Comuna 8

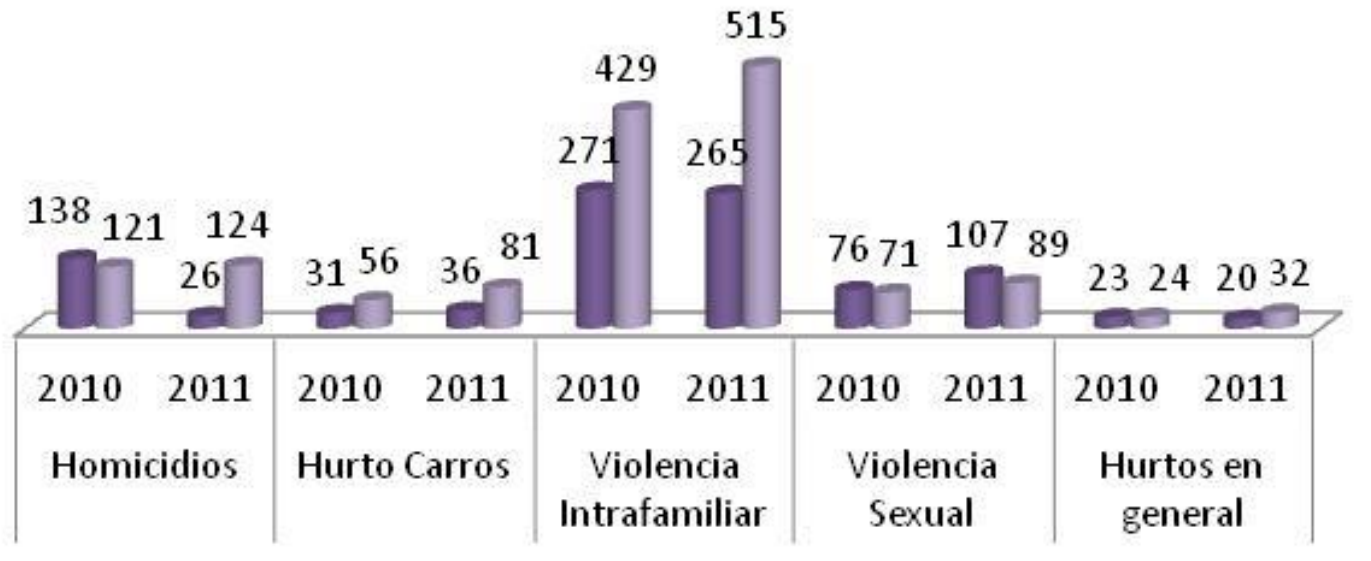

Figura 16. Delitos en General en las C1P y C8VH.

Fuente: Secretaria de Gobierno - SISC (Datos concertados INL, SIJIN, CTI).

\subsection{Un enfoque diferenciado desde las políticas públicas de seguridad}

Los lugares de ocurrencia de los delitos contra las mujeres demandan la necesidad de no considerar ningún espacio seguro per se para ellas. En ese sentido, los movimientos sociales de mujeres han abogado para que el espacio doméstico deje de ser considerado como un espacio de seguridad, ya que es allí donde pueden llegar a sentirse más vulnerables. En consecuencia, la seguridad debe incluir el espacio doméstico como objeto de sus preocupaciones, de lo contrario se caería en el eufemismo que las feministas han denominado "el continuum de la violencia contra las mujeres".

Kaminsky describe el entorno inmediato de la seguridad "elemental" "lo cerrado se ofrece como el imaginario relevo de lo seguro pero clausurado, la circulación de seres de clausura anhelada, mientras se recusa el espacio abierto porque, se dice expone al "individuo" a una violencia virtual continuada...” en el caso de las mujeres además simbólica, “...a los riesgos de la inseguridad, y lo someten a una socialidad impugnada" (Kaminsky, 2005: 22) particularmente, mientras podría pensarse como los nuevos desafíos de la seguridad, en el ámbito femenino estos han sido parte de su historia, cargada de manifestaciones de miedo y pánico, los cuales han sido potenciados bajo 
premisas morales y sociales que se han convertido en un espiral social ascendente que restringe el comportamiento.

La seguridad debe ser entendida en una relación con múltiples demandas. En particular si se piensa desde un sistema democrático, permite ubicarlas con las diferentes violencias urbanas, los actores de la misma y las políticas que en materia de seguridad se adoptan en las ciudades (Laub, 2007).

En el año 2002, la administración municipal realizó un avance importante para la reivindicación de los derechos de las mujeres en la ciudad y creó la Subsecretaría de Metromujer dentro de la Secretaría de Cultura Ciudadana. Esta iniciativa fue tomando fuerza hasta consolidarse como la Secretaría de las Mujeres a partir del 2007. Desde allí contribuye "a la igualdad de derechos y oportunidades entre mujeres y hombres, y a la disminución de prácticas discriminatorias que atenten contra el desarrollo político, social, económico y cultural de las mujeres" (Secretaría de las Mujeres, 2008). Decisión importante además porque empezó a incluir en las estadísticas un enfoque diferencial, que permite medir el impacto de las violencias sobre las mujeres.

Como parte de su propósito, esta dependencia ha planteado en la ciudad una Estrategia de Seguridad Pública para las mujeres, que aporta elementos para la elaboración de una política pública municipal de Seguridad y Convivencia. Esta se enmarca en las normas y leyes vigentes en el contexto nacional e internacional, desde las cuales, y mediante una lectura de contexto frente a las violencias que enfrentan las mujeres en la ciudad, establecen el derecho a la seguridad, tanto en los espacios públicos como privados, en la calle y en la casa, tomando como ejes orientadores la gestión del conocimiento, información, investigación y difusión; el fortalecimiento en justicia de género del sistema institucional de atención; el empoderamiento de las víctimas y la movilización social (Secretaría de las Mujeres, 2008).

Si bien es un avance importante la existencia de la Secretaria de las Mujeres y más aún el Consejo de Seguridad de las Mujeres ${ }^{68}$, el contexto de las dinámicas de violencia y conflictividad urbana que

\footnotetext{
${ }^{68}$ El Consejo de Seguridad Pública para las Mujeres es una instancia institucional que coordina el diseño y aplicación del programa de protección integral y apoyo para las mujeres víctimas de violencia y que cuenta con tres comisiones temáticas: la Comisión Primera, encargada del análisis de contexto de los derechos humanos de las Mujeres; la Comisión Segunda, encargada del fortalecimiento institucional y la Comisión Tercera, trabaja en la divulgación de la información. Entre las instituciones de orden local y departamental que participaron en este Consejo fueron la Fiscalía General de la Nación, la Unidad Atención a Víctimas, el Instituto Colombiano de Bienestar Familiar (ICBF), Profamilia, la Corporación para la Vida Mujeres de Crean,
} 
vive la ciudad demanda también acciones concretas para enfrentarlo, en este sentido existe en la ciudad un Plan Integral de Seguridad y Convivencia - PISC- ${ }^{69}$. Desde el cual se articulan acciones de la Política Nacional de Seguridad y Convivencia Ciudadana y el Gobierno Departamental con enfoque diferenciado para atender las distintas problemáticas identificadas en un diagnóstico de ciudad que da un lugar relevante al accionar de la Fuerza Pública ${ }^{70}$. En los cuales el homicidio, el hurto, el desplazamiento forzado, la violencia intrafamiliar, la violencia sexual fueron algunas de las problemáticas identificadas y que en la investigación son transversales en la construcción de representación de las mujeres.

la Secretaría de Género para la Mujeres, el Centro de Recursos Integrales para la Familia (CERFAMI), la Rama Judicial, la Policía Nacional, Medicina Legal entre otros destacados organismos (Alcaldía de Medellín, 2014). 69 El PISC tiene como objetivo el fortalecimiento de la seguridad, la capacidad operativa de los organismos de seguridad y justicia, la articulación con la política nacional y regional, así como de los actores que intervienen en ella, mediante la implementación de acciones que contribuyan a desmantelar estructuras criminales consiguiendo así, la disminución de delitos. (Alcaldía de Medellín, 2012)

${ }^{70}$ Compuesta en forma exclusiva por la por las Fuerzas Militares (Ejército, Fuerza Aérea, Armada) y la Policía Nacional; establecidas para la defensa de la soberanía, la independencia, la integridad del territorio nacional y del orden constitucional; y el mantenimiento de las condiciones necesarias para el ejercicio de los derechos y libertades públicas, y para asegurar que los habitantes de Colombia convivan en paz.(Constitución Política de Colombia, 1991). 


\section{CAPITULO II}

\section{ESTRUCTURAS RELACIONALES DEL MIEDO}

"Cuando se mantiene a un individuo o grupo de individuos en situación de inferioridad, es un hecho que es inferior, pero habría que ponerse de acuerdo acerca del alcance de la palabra ser,

la mala fe consiste en darle un valor substancial cuando tiene el sentido dinámico hegeliano: ser es haber devenido, es haber sido hecho tal cual se manifiesta; si, las mujeres, en conjunto, son hoy día inferiores a los hombres, es decir, que su situación les abre menos posibilidades: el problema consiste en saber si ese estado de cosas debe perpetuarse".

De Beauvoir, 1954, 24 
En este capítulo se analizan las representaciones que construyen las mujeres de las C1P y C8VH acerca de sus relaciones personales y de sociabilidad en sus contextos inmediatos. Estas relaciones están dotadas de un sentido de proximidad en el que intervienen algunos elementos como la confianza y el reconocimiento. Asuntos de orden simbólico, físico y emocional a partir de los cuales se construyen sus representaciones de seguridad/inseguridad. Operan, además, otros aspectos como la cercanía, la tranquilidad, el conocimiento, la intuición frente al otro/a, y aquellos que tradicionalmente ha impuesto la sociedad y que definen la manera como las mujeres deben relacionarse con los demás, en los que inciden factores como lugar y modo.

Estas representaciones son construidas a partir de una dimensión subjetiva que se sustenta en su experiencia individual y social. Mediada además por los roles y atributos de la feminidad que han identificado en sus entornos sociales y familiares, los cuales han asumido de acuerdo a las experiencias que han marcado sus vidas (Vélez, 2008: 59).

Este capítulo se elaboró en base a información recolectada en las trece (13) entrevistas y setenta y seis (76) encuestas que se realizaron, donde se pusieron en juego las categorías que se referían directamente a las representaciones del género y la feminidad. La encuesta se basó en una serie de "frases previamente elaboradas" en las que las mujeres encuestadas expresaron su conformidad o inconformidad respecto a afirmaciones normativas sobre la identidad y roles de género, como por ejemplo hasta qué punto estaban de acuerdo con frases como "la casa es para las mujeres y la calle para los hombres" o "cuando las mujeres son violentadas es porque se lo buscaron". En las respuestas emergieron elementos que permiten hablar de contrastes entre las mujeres que en algún momento estuvieron vinculadas a algún proceso organizativo social, independientemente de la naturaleza del mismo, y, quienes nunca tuvieron esta experiencia de participación.

Tradicionalmente, en nuestra sociedad se ha sostenido la creencia según la cual los entornos familiares y domésticos constituyen espacios seguros y protegidos para las mujeres, y ésta se ha basado en el supuesto de que la esencia de la familia implica la protección de sus miembros más vulnerables, entre los que se encuentran las mujeres y los niños y niñas, lo que en si fomenta una idea moral conservadora en la cual la forma de protección de las mujeres se instala a partir de la adopción de los roles tradicionales (Madriz, 2001: 117). Algo similar sucede con la creencia de que la presencia de la Fuerza Pública genera seguridad, que para el caso concreto de esta investigación hace alusión específicamente al accionar de la Policía que opera en los barrios y comunas de estudio. 
Por otra parte, se encuentran las relaciones vecinales y barriales que conforman la cotidianidad en la que habitan las mujeres. Allí opera el "conjunto de normas y prescripciones que dictan las sociedades y la cultura sobre el comportamiento femenino" (Lamas, 1986: 26), que las mujeres tienden a asumir por tradición o costumbre. A diferencia de las relaciones interpersonales, en el ámbito familiar y las relaciones que se tejen con las instituciones, para el caso de las relaciones vecinales y barriales, no existen estereotipos definidos que asocien a las mujeres con las ideas de protección y seguridad, aunque de una manera ambivalente remite a imaginarios de convivencia, en los cuales las mujeres consideran que hay menor exposición al peligro si se encuentran dentro de su ámbito doméstico.

Se debe tener especialmente en cuenta, como se dijo en el capítulo 1, que en el ámbito vecinal operan además distintos grupos armados ilegales bien sea bajo la estructura de combos o bandas delincuenciales, que para esta investigación se denominarán indistintamente. De modo que el imaginario de seguridad, aunque paradójico, se refuerza con la presencia de estos grupos, es decir, encuentra en la persistencia de estos conflictos, condiciones para reproducirse.

La mayoría de estas creencias han estado infundadas en las situaciones de dominio y control que han caracterizado las relaciones interpersonales familiares, institucionales y vecinales, que han limitado el ejercicio de las libertades de las mujeres, reproduciendo estereotipos modelados e impuestos desde el orden social que, tal como lo plantea Bourdieu, se han dispuesto de manera espontánea desde una forma de violencia simbólica (1999: 225), en los cuales cualquier comportamiento como por ejemplo salir solas a la calle a altas horas de la noche, realizar prácticas deportivas consideradas masculinas o frecuentar lugares de socialización masculina, conlleva situaciones de riesgo para ellas. Es decir, aquí subyace la idea según la cual "la seguridad puede lograrse al precio de una degradación identitaria en los espacios públicos” (Kessler, 2009: 163). Esta degradación relega el espacio público para las mujeres y las recluye al hogar, garantizando su reclusión adscrita al límite de sus libertades y expuestas a que situaciones de violencia no sean evidentes.

En este capítulo vamos a analizar de qué manera la adhesión a estas creencias o la puesta en cuestión de las mismas, inciden en las representaciones que las mujeres construyen de las relaciones que establecen en los tres ámbitos mencionados, familiar, institucional y vecinal, y, por lo tanto, en sus percepciones sobre la inseguridad o la seguridad. 
A partir de lo dicho, se construyeron cinco categorías de análisis que desarrollamos en apartados separados en este capítulo; categorías que permitieron profundizar en la construcción de las representaciones, a saber: a) la construcción y deconstrucción del género; b) los escenarios de dominación, responsabilidad o búsqueda de libertad; c) la paradoja de la inseguridad, el Estado ; d) el control social y territorial en el marco de la ilegalidad; y e) una categoría en la que se agruparon las características organizacionales de las mujeres en esas comunas que denominamos Capital Social y Problemáticas Sociales ¿construyen representaciones?

\subsection{Construcción y deconstrucción del género}

El género como construcción social que establece y distribuye los roles y funciones asignados a hombres y mujeres está sometido a un proceso constante de construcción y deconstrucción. Los roles y funciones no son universales sino que cambian de una sociedad a otra e incluso son diversos dentro de una misma sociedad. El orden de género hegemónico se consolida por medio de pautas de comportamiento mediadas por un sentido común sustentado en la naturalización de las jerarquías basadas en las diferencias biológicas. A su vez, este sentido común se refuerza mediante un proceso experiencial y de aprehensión de la realidad apoyado en la tradición social, la educación y los medios de comunicación.

Esta construcción de la realidad social mediada por el género determina unas prácticas sociales en cuanto a las relaciones que se establecen con las/os otros/as, en las que el sistema de valores, creencias y normas de cada individuo — en este caso las mujeres que participaron en el estudioadquiere un sentido relevante para la interacción social y la determinación de la representación social (Araya, 2002: 5) que sobre la seguridad/inseguridad construyen. De allí que las interacciones que se establecen en los distintos niveles - familiar, vecinal, institucional - constituyan contextos donde es posible consolidar o transformar el aprendizaje del género, lo que puede dar lugar, en ocasiones, a la elaboración de nuevas interpretaciones, llegando incluso a confrontar las interpretaciones hegemónicas sobre el orden social de género.

El proceso de aprendizaje y transformación del género no puede responder a una generalización. Según los hallazgos de la investigación, existen tres factores: percepción de sí mismas, la aceptación de las estructuras patriarcales y la representación del riesgo en relación con la adscripción al género. La clasificación de estos factores es importante en tanto inciden en este 
proceso y pasan por una construcción social que, según Lamas (2013), opera como un "filtro" cultural desde el cual se interpreta el mundo y da sentido a las relaciones desde las obligaciones sociales de hombres y mujeres. Esto, en consecuencia, influye en la representación de seguridad/inseguridad cuando se transgreden las prohibiciones simbólicas. Estos factores identificados intervienen indistintamente en las mujeres de las dos comunas estudiadas.

La percepción de sí mismas permite generar confianza en las relaciones que establecen y en los entornos en los que se desenvuelven. En ocasiones interpretan como un mecanismo de protección el hecho de que la gente confíe en ellas, lo cual se debe a que previamente conocen quiénes son, o las reconozcan por lo que dicen o la forma en como dicen las cosas (CA, C1 feb. 10), (CM, C1, mayo 11), (DQ, C1, feb. 13), (EI, C1, mayo 8), (LR, C1, abril 25) ${ }^{71}$.

Otro elemento vinculado a la confianza que destacan las entrevistadas es el temperamento fuerte, es decir, la reacción a la defensiva o en ocasiones agresiva ante las situaciones que buscan someterlas o ejercer alguna forma de dominio sobre ellas. Este es un aspecto del cual hacen alarde en sus respuestas, aunque en ocasiones también reconocen que son llevadas de su parecer, porque casi siempre responden dejándose llevar por acciones impulsivas que no dan lugar a razones. Ambas reacciones suelen aparecer cuando las mujeres confrontan situaciones de vulneración, expresiones patriarcales o límites a sus libertades que encuentran ilegítimos (CA, C1 feb. 10), (CM, C1, mayo 11), (CO, C1, abril 10), (DQ, C1, feb. 13), (EI, C1, mayo 8), (MG, C1, marzo 9), (CG, C8, feb. 29), (RD, C8, mayo 12).

El respeto constituye otro elemento a tener en cuenta en la percepción de sí mismas. El respeto se refiere al prestigio y reconocimiento que inspiran entre sus amistades y personas del barrio por la dirección que les han dado a sus vidas, por ser jefas de hogar, lideresas, estudiantes, comprometidas con las cosas que hacen. Aunque estas actividades no estén vinculadas a reivindicaciones de movimientos de mujeres, conducen a un trato particular y/o diferente por parte de las personas que están a su alrededor, caracterizado por el reconocimiento y valoración a sus acciones y respuestas en determinados contextos. Para muchas, esto marca diferencias con el resto de las mujeres que habitan esos sectores de las comunas (DQ, C1, feb. 13), (LR, C1, abril 25), (CG, C8, feb. 29), (LR, C8, feb. 24), (RD, C8, mayo 12), (RO, C8, marzo 3).

\footnotetext{
${ }^{71}$ Estos datos en paréntesis son la codificación que se asignó a las personas entrevistadas utilizando las iniciales de sus nombres como la fecha de la entrevista.
} 
La confianza, el temperamento fuerte y el respeto son palabras centrales que se repiten en las entrevistas y que dan cuenta de la percepción de sí mismas. Estas palabras además son elementos constitutivos de la seguridad y en consecuencia les permite percibirse como mujeres seguras e incidir en la relación con su entorno.

Para una parte de las mujeres entrevistadas las diferencias en esa percepción de sí mismas, se establecen en su "actitud de mujeres seguras", que la conforman la confianza, el temperamento fuerte y el respeto, que son constitutivos de su seguridad y que funcionan además como una barrera y como una alerta frente a situaciones de riesgo o de amenaza, lo que Madriz denomina una distinción entre "tener conciencia y tener miedo" (2001: 66). Una percepción que se refuerza con estrategias de autocuidado como por ejemplo no transitar solas o no hacerlo en horarios extremos por lugares que fueron referenciados por otras mujeres como sitios donde se han presentado tipos de violencias sexuales; no establecer conversaciones con desconocidos; y la autoimposición de sentirse seguras de sí mismas (CO, C1, abril 10), (AG, C8, abril 24), (CG, C8, feb. 29). Algunas de estas estrategias de seguridad de alguna manera han sido interiorizadas a través de los mensajes que los medios de comunicación han difundido y que conducen finalmente a que las mujeres limiten sus libertades de ser y circular (CAFSU, 2002 citado en Massolo, 2007: 139), pero también a formas de protección que las mujeres en el voz a voz implementan para identificar los riesgos.

Aunque en ocasiones suele producir tensiones la participación en procesos formativos generados en su mayoría por las organizaciones sociales de base de las comunas ${ }^{72}$ — ya sea desde la educación formal o no formal como los procesos organizativos de mujeres, desde donde se adquieren y consolidan posturas críticas relativas al género que inciden tanto en su vida personal y familiar como social-, lo asumen como parte del proceso importante en la coherencia de su ser y su hacer (LR, C8, feb. 24), (LR, C1, abril 25), (DQ, C1, feb. 13), (EI, C1, mayo 8), pero además confronta la sociedad patriarcal y el contrato desigual desde otros aprendizajes para entender las violencias y las inseguridades que las afectan.

En segundo lugar, otro elemento tiene que ver con la aceptación de las estructuras patriarcales que dominan la sociedad y que están claramente reflejadas no solo en los entornos familiares o

\footnotetext{
72 En la C1P la Corporación Convivamos ha generado diferentes propuestas formativas en las cuales se han articulado tanto la Coordinación de Mujeres de la Zona Nororiental como también la Corporación Cultural Diafora y la Corporación Manapaz en la C8VH.
} 
domésticos, sino también en las relaciones sociales. Las estructuras y las normas patriarcales se interiorizan mediante un proceso de aprendizaje en el que las mujeres incorporan los gestos o los comportamientos de lo que implica ser mujer, incluyendo aquellos que dentro de la lógica patriarcal se consideran útiles para tratar de enfrentar o mitigar las inseguridades o las razones de vulnerabilidad. En ese sentido, es relevante lo que plantea Bourdieu, cuando señala que "el efecto de la dominación simbólica no se ejerce en la lógica pura de las conciencias cognitivas, sino en la oscuridad de las disposiciones del habitus" (2000: 225), puesto que las mujeres que aceptan sin más las normas patriarcales adquieren habitus orientados a proveerse de seguridad, sin lugar a cuestionarlas.

No obstante, según pudimos ver en este estudio la aceptación de las estructuras patriarcales oscila entre la legitimación de las violencias y la emergencia de una conciencia emancipadora que cuestiona el orden social de género. Por un lado, la legitimación de las violencias, desde donde se terminan aceptando las formas de control y subordinación tanto en el espacio público como privado, que van desde las justificaciones de actos de violencia sexual a causa del uso de determinada ropa o ciertos comportamientos hasta las agresiones físicas y/o simbólicas en el ámbito doméstico. Pero por el otro, se puede verificar una conciencia crítica. Tal vez, ello tenga que ver con la intervención del movimiento social de mujeres y las políticas públicas de la secretaria de mujeres de la Alcaldía de Medellín que promueven campañas y talleres para visibilizar las violencias basadas en género que contribuyen a ello.

En la siguiente figura se pueden observar los resultados obtenidos en la encuesta diseñada para conocer la opinión de las mujeres respecto a las normas patriarcales. Las afirmaciones de la encuesta se elaboraron con base en algunas frases que habían surgido previamente en las entrevistas y que parecían constituir "lugares comunes" para algunas de las entrevistadas. A las 76 encuestadas se les pidió que respondieran en qué grado se adherían a las siete afirmaciones propuestas. Como se puede observar en la Figura (\#18), hay diferencias claves entre una comuna y otra. Aunque el enfoque de la investigación no pretendía ser comparativo, surgieron elementos interesantes que explican las tendencias de las respuestas, como por ejemplo la existencia de un proceso organizativo de mujeres en la C1P que tiene aproximadamente quince años de desarrollo en ese territorio $^{73}$.

${ }^{73} \mathrm{Si}$ bien no todas las mujeres entrevistadas hacen parte de los procesos organizativos, actividades que se promueven constantemente desde la Coordinación de Mujeres de la Zona Nororiental desde hace 16 años, inciden de manera indirecta en el resto de las mujeres. En cuanto a las mujeres de la Comuna 8 - Villa 


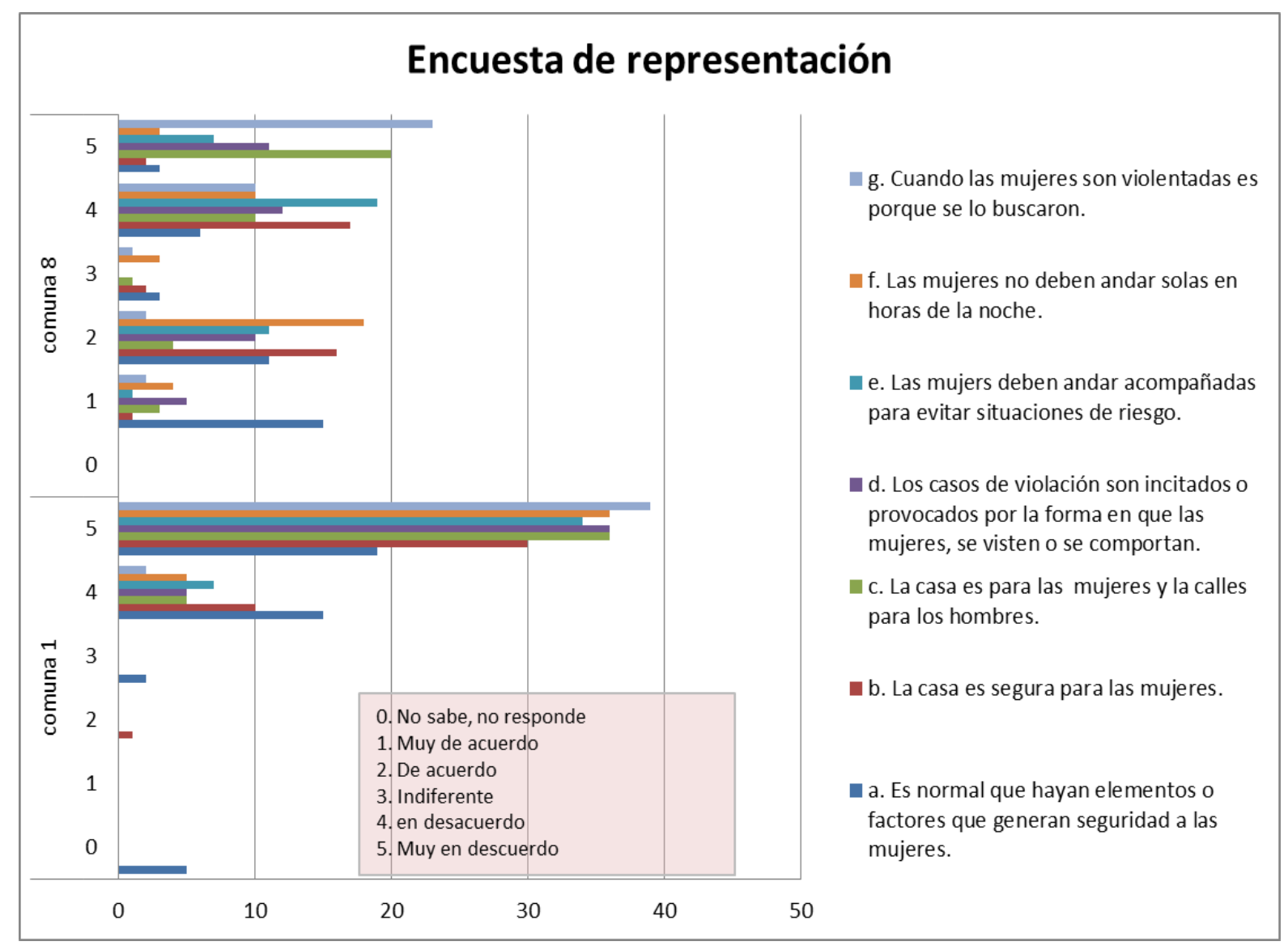

Figura 17. Encuesta de percepción.

Fuente: Elaboración propia.

Las afirmaciones incluidas en la encuesta se relacionaban entre sí y estaban dirigidas a evidenciar la opinión de las mujeres sobre diferentes aspectos relativos a la seguridad/inseguridad. El primero de éstos estaba vinculado con el lugar de las mujeres como víctimas; las afirmaciones de las frases $d$ y $g$ culpabilizan a las mujeres por las situaciones de violencia que les acontecen. Como se puede ver, en las respuestas, hay una significativa proporción de las mujeres de la C1P que están en desacuerdo, mientras que la mitad de las mujeres de la $\mathrm{C} 8 \mathrm{VH}$ comparten esta apreciación, responsabilizando a las mujeres frente a la ocurrencia de los hechos de violencia ejercidos contra ellas.

Otro conjunto de afirmaciones -las contenidas en los ítems $e$ y $f$-, hace referencia a la posibilidad de las mujeres a usar y disponer los espacios públicos de las comunas y de la ciudad sin tener que estar

Hermosa, esto se hace evidente pues los procesos organizativos de mujeres son aún incipientes y no han logrado consolidarse. 
acompañadas o tuteladas por alguien, bien sea hombre o mujer. En las respuestas de las mujeres de la $\mathrm{C} 1 \mathrm{P}$, el 50\% de ellas (38) afirmaron estar en desacuerdo en el ítem e y el mismo número dijeron estar muy en desacuerdo en el ítem $f$. En la $\mathrm{C} 8 \mathrm{VH}$, lo estuvieron un poco más de la mitad (26) y una pequeña proporción (13) de las encuestadas, respectivamente. Lo anterior da cuenta de los altos márgenes de dependencia que manifiestan las mujeres de estas comunas para sentirse seguras mientras se movilizan en sus barrios, lo cual es síntoma de una clara limitación para la movilización en los territorios de manera libre y autónoma.

Frente a los estereotipos de género relacionados con la casa como lugar seguro en las afirmaciones $b$ y $c$, variables de donde se deriva que estar fuera de ella es un elemento determinante para la inseguridad de las mujeres, encontramos que las encuestadas de la C1P están en desacuerdo o muy en desacuerdo, mientras que entre las mujeres de la $\mathrm{C} 8 \mathrm{VH}$ la proporción de las que están en desacuerdo y las que están de acuerdo es similar, existiendo también una cantidad importante que dicen ser indiferentes o estar muy de acuerdo.

Finalmente, con respecto a la última afirmación del ítem $a$ referido, tal como lo muestra el gráfico, a los factores o elementos que generan seguridad a las mujeres, encontramos que para las encuestadas de la C1P prevalece la respuesta de que no es normal la existencia de factores que generen seguridad a las mujeres (32). Aunque para unas pocas mujeres (2) es indiferente que haya o no estos factores e incluso otras mujeres (4) no manifestaron una opinión al respecto. Esto contrasta nuevamente con las posturas de las encuestadas de la $\mathrm{C} 8 \mathrm{VH}$, puesto que una proporción importante de ellas (26) considera que es normal la existencia de esos factores; pocas (9) declararon no estar de acuerdo con la afirmación anterior, y una proporción mínima (3) dijo que les resultaba indiferente.

El hecho de que se considere normal la existencia de factores externos que garantizan la seguridad de las mujeres da cuenta de la dependencia de ellas respecto a estos factores para determinar su propia seguridad y que como se evidencia en los resultados, difieren notoriamente de las mujeres de la $\mathrm{C} 1 \mathrm{P}$, en quienes han tenido mayor incidencia los procesos formativos relacionados con el género y los derechos de las mujeres.

Como se puede ver, esta encuesta da cuenta de cómo las mujeres de ambas comunas interpretan las situaciones de riesgo que enfrentan según las diferentes representaciones de género. Se puede observar que existe una marcada diferencia entre ambas comunas. Si bien, como ya se dijo, fueron encuestas realizadas de manera aleatoria, presentan un contraste interesante, tal vez marcado por la 
existencia de procesos organizativos de mujeres con trayectoria en el territorio en el caso de la C1P, a diferencia de la $\mathrm{C} 8 \mathrm{VH}$, y de la apropiación del territorio que les permite transitarlo de una manera libre y segura, o con otras certezas que le agregan mayor seguridad a su vida cotidiana.

Complementando el análisis de las encuestas, las respuestas obtenidas en las entrevistas muestran otros aspectos relacionados con la aceptación de las normas patriarcales o bien la aparición de un distanciamiento crítico frente a estas normas que sugiere la formación incipiente de una conciencia emancipadora. Entre los aspectos que denotan una mayor adscripción a los valores patriarcales se encuentran quienes afirman que las mujeres necesitan mayor acompañamiento: "Las mujeres nos sentimos más inseguras, nos hace falta más acompañamiento" (EI, C1, mayo 8), no solo para interponer denuncias ante las instituciones públicas, entendiendo este relacionamiento como el acceso efectivo a los servicios que presta el Estado, bien desde la prevención de las violencias contra las mujeres, como desde la judicialización de las mismas, pasando por las rutas de atención a las víctimas y el restablecimiento de sus derechos.

Otro aspecto para resaltar tiene que ver con la responsabilidad que se asignan las mujeres entre sí con los hechos de violencia de las que son víctimas. Afirman las mujeres entrevistadas: "Somos culpables de que los hombres barran con nosotras" (AG, C8, abril 24). De manera significativa también señalan que los hombres son más solidarios entre sí, comparados con las mujeres, debido al predominio entre ellas de la envidia y la conflictividad (AG, C8, abril 24), que puede explicarse en que su universo de relaciones sociales es más reducido, precisamente por las limitaciones sociales que impone la inseguridad ante el temor al riesgo, y a detonantes como el chisme (CG, C8, feb. 29), que no solo promueve acciones insolidarias ${ }^{74}$, sino también generan malestar y confrontación entre las mismas mujeres.

Lo anterior en términos de la definición de representación social propuesta por Abric sería el equivalente a una función justificadora (2004: 16) en tanto es desde allí que buscan dar explicación a dichas situaciones que aumentan o disminuyen las formas de violencia y en consecuencia su representación de seguridad/inseguridad.

\footnotetext{
${ }^{74}$ Como es el caso de las elecciones para Juntas de Acción Comunal y Juntas de Acción Local que son los espacios políticos de decisión de los barrios y comunas de Medellín, y donde la participación de las mujeres si bien ha avanzado de manera importante, no logra aún una incidencia importante.
} 
Ahora bien, otras entrevistadas sostuvieron posturas divergentes, algunas de las cuales coinciden con lo que Madriz plantea "las inquietudes y los temores de las mujeres no son idénticos ni irracionales; en realidad están vinculados al lugar que cada persona ocupa en la estructura social” (2001: 75). Por ejemplo en algunas de las respuestas, las entrevistadas plantearon que un componente de inseguridad es la falta de acceso a la educación de las mujeres, ya que esto genera más dependencia y menores posibilidades de autonomía ( $R D, C 8$, mayo 12) e incrementa los miedos relacionados con los entornos familiares y vecinales. En tanto la vulneración es mucho más alta dado que hay una mayor dependencia hacia un miembro de la familia generalmente hombre que ante estas circunstancias ejerce formas de control y dominación. Hay también posturas que difieren, en cuanto consideran que las relaciones cotidianas en las cuales las mujeres comparten experiencias y actividades genera lazos de solidaridad, porque encuentran situaciones similares que si bien no se solucionan por el mero hecho de compartirlas, tienen en la escucha una manera de desahogo, como señala una entrevistada de la C8VH:

“... relacionarme con mis compañeras, con las demás personas es muy rico porque una ve que el problema que a veces estoy viviendo, lo está viviendo la otra también, y que son casi semejantes, parecidos; que estamos luchando todas para salir adelante, que estamos bregando a cuidar los hijos bien, bregando a prepararnos y respondiendo por una cantidad de cosas que no pensamos que nos llegara a tocar... nos damos moral la una a la otra... el mirar que es similar la situación. Pero vamos para adelante" ( $\mathrm{RD}, \mathrm{C} 8$, mayo 12$)$.

También es importante destacar la emergencia de una postura crítica frente a la culpabilización de las mujeres por la violencia que sufren-. Como afirmaba críticamente una de las participantes:

“... legitimamos una violación porque iba vestida así, legitimamos cualquier cosa: "Para qué estaba tan tarde en la calle". Entonces yo creo que igual es ese pensamiento que no nos ha dejado avanzar y esas son las principales inseguridades que nosotras tenemos" (MG, C1, marzo 9).

En otra entrevista se hizo referencia al trato recibido por las mujeres cuando denuncian ante las autoridades dicha violencia:

“... incluso cuando van a poner denuncias, si es un hombre el que atiende, no es el mismo trato que le dan a la mujer. Siempre hay alguna cosa que le dicen: “iAh! ¿No será que usted iba mal vestida? ¿Sería que provocó con un escote muy profundo?”... Buscan si fue por algo” (EI, C1, mayo 8). 
Es decir, un análisis crítico de la manera en cómo son abordados los hechos que son denunciados por las mujeres desde la respuesta institucional da cuenta de un enfoque que victimiza y delega por cuanto no se les trata como ciudadanas sujetas de derechos y además no se abordan los casos de una manera integral, llegando incluso a posturas justificatorias, lo que genera a su vez una doble victimización (Rainero, 2008).

De otra parte, la aparición de una conciencia crítica lleva en ocasiones a que las mujeres adopten una actitud alerta frente a determinadas personas o grupos de personas, ciertos lugares y actividades, entre otras razones, por temor a una agresión física y psicológica. Las entrevistadas lo expresan en frases como estas:

"A las mujeres las abusan y las violan". "A las mujeres las violentan de muchas formas". (LR, C1, abril 25). "Siempre estamos inseguras, siempre tenemos que estar a la defensiva mirando quién está atrás, quién está adelante, cómo nos movemos, cómo caminamos rápido, y siempre hay una agresión para las mujeres siempre o de palabra o simplemente de mirarte. O sea, siempre hay una agresión". (CO, C1, abril 10).

Estas afirmaciones pueden interpretarse de manera ambigua en tanto que, por una parte, manifiestan que algunas mujeres han ido reconociendo las múltiples y distintas violencias que las afectan por el hecho de ser mujeres y en consecuencia las confrontan; mientras otras tienden a exacerbar su sentimiento de vulnerabilidad al mismo tiempo que se reconocen como personas inseguras o miedosas. De esa manera vemos que continuamente se están construyendo imaginarios de terror que ayudan a la subordinación ante la imposibilidad de considerarse capaces para enfrentarlos.

La edad es una variable que no se incluyó de manera directa para el análisis, pero sin embargo pudimos reconocerla en las entrevistas como una dimensión a tener presente. Nos dimos cuenta de que la edad de las entrevistadas era relevante para pensar las representaciones en torno a la inseguridad. En otras palabras, la seguridad/inseguridad no es percibida de la misma manera si son mujeres jóvenes o mayores. Las mujeres jóvenes sienten mayores niveles de riesgo, o el riesgo está asociado a determinadas prácticas o eventos. Mientras que para las mujeres mayores, los riesgos pueden ser otros. El miedo no siempre es el mismo miedo, no siempre está asociado a los mismos eventos aunque puede involucrar a los mismos actores. Un temor, como se verá más adelante, que está asociado al accionar de los grupos armados ilegales que operan en ambas comunas e incluso a los miembros de la Fuerza Pública. Mientras que las mujeres adultas plantean sentirse menos 
expuestas a violencias de connotación sexual ${ }^{75}$, situación que ellas explican o relacionan por la apropiación de los espacios y la participación en procesos organizativos en los cuales ejercen un liderazgo social y comunitario.

Si bien la relación con el cuerpo en relación con los miedos y las inseguridades opera para todas las mujeres -porque la predisposición a la intimidación del cuerpo es una constante (DQ, C1, feb. 13), ya sea por actos de violencia sexual o física-, es claro que, y tal como lo expresa McKinnon, "los hombres tratan a las mujeres como las ven [...] el poder de los hombres sobre las mujeres significa que la manera en que los hombres ven a las mujeres define quienes pueden ser las mujeres" (McKinnon, en Langton, 2001: 50).

Persiste entonces la consideración en las mujeres adultas acerca de que son más altas las probabilidades de una violación sobre una mujer joven:

"Una mujer joven no pasa ese sector, no tanto porque la van a matar, sino porque la van a violar o le van a hacer un daño en su sexualidad, en su ser" (CO, C1, abril 10).

Esta percepción del riesgo al que se enfrentan las mujeres en los espacios, si bien la identifican las mujeres adultas, no es tan claramente identificable para las mujeres jóvenes. Para ellas, hay lugares que se identifican como inseguros, antes que por los actores que allí se encuentran que por los hechos concretos que puedan tener lugar y que no están directamente asociados a las violencias contra las mujeres sino a las estructuras delincuenciales, como expendios de vicio $^{76}$, tráfico de armas, asesinatos.

Pasemos ahora al siguiente factor: la representación del riesgo en relación con la adscripción de género. Esta investigación está relacionada con los elementos asociados al riesgo y al tipo de violencia con que se asocian hombres y mujeres, riesgos asociados con la utilización de los espacios, los horarios, las actividades que se realizan y los estereotipos que se construyen acerca de las relaciones que establecen mujeres y hombres.

\footnotetext{
75 No se limita a violencia sexual estrictamente hablando, sino a ser cooptadas por los grupos y/o a mantener relaciones sentimentales con sus integrantes o verse involucradas en estructuras del negocio ligadas a la explotación sexual.

${ }^{76}$ Denominados también ollas porque allí se venden todo tipo de sustancias alucinógenas y tienen constante control y vigilancia por los grupos armados que operan en esos sectores.
} 
En las entrevistas pudimos reconocer cuál es la representación que tienen las mujeres de los hombres, cómo ven la amistad o las conversaciones que entablan acerca de las mujeres. Por ejemplo, dicen: "son más amigos, como más parceros, se cuentan más sus cosas" 77 (EI, C1, mayo 8) y en sus reuniones "hay menos habladurías" que busquen afectar a otros (CG, C8, feb. 29), incluso “disponen de más tiempo para socializar entre sí", "se unen más como a perder su tiempo" (RD, C8, mayo 12). A la vez, también reconocen en ellos seres superficiales, que construyen estereotipos sobre las mujeres: "cabello largo, que sean ingenuas" (RD, C8, mayo 12), "piensan en el cuerpo físico de la mujer, no en las habilidades y potencialidades que esa mujer puede llegar a desarrollar o si ella es capaz de salir delante de otra manera sin necesidad de tener un compañero al lado" (LR, C8, feb. 24).

Con todo, dichos estereotipos que los hombres construyen objetivizan y cosifican a las mujeres y contribuyen a justificar e invisibilizar las relaciones de subordinación frente a las hombres y a hacer que aquellas se sientan menos valoradas. Dando relevancia a las formas de relacionamiento entre los hombres y colocándola por encima de las solidaridades que las mujeres establecen ante distintas circunstancias.

También aparecen representaciones asociadas a la distinta apropiación del espacio público por parte de hombres y mujeres, en las cuales las entrevistadas consideran que falta mayor apropiación del espacio público por parte de las mujeres en relación con los usos y disfrute. El sentido común que impera es una segregación espacial en términos de horarios, porque se reconoce que en el día hay un mayor flujo de circulación de mujeres por razones de compromisos y deberes familiares como llevar los hijos/as al colegio, comprar el diario ${ }^{78}$ o realizar alguna diligencia, mientras que los hombres pueden hacer uso y disfrute del espacio público indistintamente del horario: "Si estás en la calle tarde de la noche, pues ya sos una mujer de la vida alegre; si un hombre está en la calle, qué verraco, oíste, es que le gusta la calle" (DQ, C1, feb. 13). Como se puede advertir, esta afirmación, que sin duda contiene una postura crítica por parte de la entrevistada sobre la situación, deja entrever la asociación del espacio público que tradicionalmente se le asocia a los hombres indistintamente del horario y/o de las formas de uso, mientras que para la mujer sucede todo lo contrario, está confrontando el orden ya instalado frente a los usos del espacio.

\footnotetext{
77 Modismo que tradicionalmente se utiliza para establecer cercanías entre personas, asociado al término de amigo/a.

${ }^{78}$ Denominación asignada a las compras que se hacen a diario para cubrir los alimentos de la familia.
} 
Otra cuestión vinculada a la anterior son las fronteras invisibles. Llamaremos fronteras invisibles a la delimitación territorial que establecen los grupos armados ilegales para ejercer el control en barrios y comunas de la ciudad, y que afecta en un porcentaje significativo más a hombres que a mujeres. Estas afectaciones van desde amenazas hasta asesinatos, pasando por extorsiones a pequeños y medianos comerciantes como por la imposición de productos de consumo ${ }^{79}$. Las delimitaciones operan en un plano simbólico, puesto que no hay trazos físicos evidentes. Más aún: las fronteras son móviles, se van corriendo con las horas del día. A medida que llega la noche el barrio se va achicando para algunos y agrandando para otros. Las delimitaciones se asumen con base en las extensiones de un sector tradicionalmente dominado por uno de los grupos armados ilegales o en disputa por la hegemonía con un actor armado emergente o proveniente de otro sector.

Se considera que en determinados lugares hay una suerte de licencia que permite a las mujeres movilizarse con mayor libertad que los hombres. Como dice una de las entrevistadas: “... inclusive uno es el puente para ir a determinado sitio porque en estos sitios los límites y fronteras que se generan son para los hombres" (CM, C1, mayo 11). De modo que el barrio no siempre es el mismo barrio, no siempre será vivido de igual manera. No todos llevan el mismo mapa. Hay una lectura diferencial del territorio que está determinada por las condiciones impuestas de los grupos armados ilegales. Aunque la exposición al riego siempre será un asunto latente, por razón del género es diferente, como también la mitigación del mismo.

Esto genera una lectura ambivalente especialmente para los hombres en la medida en que por lo general las fronteras invisibles limitan los privilegios masculinos en relación con el uso de los espacios públicos. Para los hombres vivir en un sector específico puede traer como consecuencia la idea de vinculación con el bando opuesto bien sea como integrantes o colaboradores, que puede ser otro barrio u otra comuna. Mientras que los riesgos para la mujer son diferentes, como por ejemplo cuando se les asocia como madres, esposas, novias y/o amigas de hombres que hacen parte de los bandos en conflicto, lo que implica que sean más susceptibles de ser atacadas en las fronteras interiores de las comunas (RO, C8, marzo 3), es decir en su mismo barrio.

Si bien transitar una frontera invisible puede conllevar a los hombres a la muerte, las mujeres por su parte están expuestas a una agresión o abuso sexual, ya que "las mujeres son el blanco solo por el

79 La imposición de productos de consumo de canasta básica hace referencia a la prohibición de comercializar productos de determinadas marcas y obligar a la población a consumir determinados productos, esto es lo que se denomina el "cartel del huevo", el "cartel de la leche" o el "cartel de la arepa". 
cuerpo, por el hecho de ser mujer, esos hombres quieren satisfacerse físicamente con ellas" (LR, C8, feb. 24). Esto deja de manifiesto la manera en que mujeres y hombres perciben la seguridad, difiere notoriamente. Mientras que los hombres son asesinados, las mujeres son violadas, trasgrediendo su ser tras las lógicas de la estructura machista que instalada en los referentes sociales "que tienen los hombres de que ellos son dueños del cuerpo de las mujeres y de que si ellos son los duros del barrio tienen derecho a todo, incluso a las mujeres, a sus cuerpos, a sus vidas" (CO, $\mathrm{C} 1$, abril 10). Esta es la manera como la objetivación se hace presente, las mujeres se convierten en objetos con base en las percepciones, deseos y creencias que los hombres han construido en las relaciones desiguales de poder (Vélez, 2008: 50).

Estos factores inciden en las representaciones de seguridad/inseguridad de las mujeres en tanto parten de la percepción de sí mismas que determina las formas de relacionamiento con los demás como su rol y función en la sociedad, no siempre como un acto consecuente con las relaciones de géneros instituidas socioculturalmente. De allí su respuesta a las normas establecidas en las estructuras patriarcales y la identificación de situaciones de riesgo. Esto conlleva a unos comportamientos mediados más por la conciencia que previene que por el miedo que paraliza y limita. Así mismo y como se verá en los siguientes apartados inciden en las relaciones familiares, institucionales y vecinales.

\subsection{Escenarios de dominación, responsabilidad o búsqueda de libertad}

La familia constituye el marco de referencia tradicional a partir del cual se ha enmarcado el universo de relaciones de la mujer. Esto hace que las relaciones que se analizan sean uno de los asuntos más complejos, en parte por la gran susceptibilidad que genera, especialmente cuando la trayectoria personal de la entrevistada está atravesada por situaciones traumáticas en este entorno y porque el mensaje que se ha transmitido de generación en generación está sustentado en los límites en su vida y sus actividades relegadas al hogar como la esfera de las mujeres (Madriz, 2001: 51, 29). Este apartado busca identificar los actores y los factores que al interior de la familia median en la construcción de esas representaciones de seguridad/inseguridad que construyen las mujeres y que las determina en un rol de subordinación ante el miedo o de protección confrontando los roles establecidos en la sociedad.

En la familia se establecen formas de interacción, como por ejemplo, la división sexual del trabajo, el ejercicio de la autoridad y la estructura familiar (Camarena, 2003). En este sentido, Pateman 
(1988) establece en el contrato sexual dos dimensiones, cada una de las cuales postula roles diferentes para los miembros de la familia: una pública, fraternal, política y constituida por lazos igualitarios; y la otra, privada, patriarcal y no política, constituida por lazos naturales de sujeción. Sobre esta segunda dimensión se hará hincapié para explorar las representaciones de la familia en la (in) seguridad de las mujeres, ya que es en esta esfera que tradicionalmente se ha atribuido un espacio por excelencia para ellas. Sin embargo, analizando las cifras de violencia contra las mujeres y los escenarios en los cuales ocurre, desde una perspectiva de género, constituye todo lo contrario: convirtiéndose en un escenario de vulneraciones soterradas e invisibilizadas. De allí la necesidad de insistir en una de las principales luchas del feminismo radical "lo personal es político", en tanto lo que ocurra en la esfera privada en este caso, circunscrito a la familia, tiene consecuencias en el orden social, pero además que el espacio privado no es per se el más seguro para las mujeres.

En esta dimensión privada tienden a naturalizarse algunas formas de violencia doméstica que surgen a partir de las relaciones que se establecen en el núcleo familiar. En estas relaciones la afinidad o desapego con miembros de la familia, en particular con hermanos/as; la cercanía o lejanía en términos de distancia física; la llegada de nuevos miembros a la familia ${ }^{80}$ o el lugar donde colocan sus miedos e inseguridades que trascienden su ser, pasa a ser transferido sobre sus hijos/as y conlleva a que la representación de inseguridad esté ligada a algún miembro del grupo familiar en particular, desde el cual se tiende a generalizar la concepción de la dimensión privada o el espacio doméstico como inseguro para las mujeres. Esta concepción, según la cual la inseguridad puede estar representada en alguien cercano no solo hace parte del componente subjetivo de la seguridad de las mujeres, sino que además se encuentra perfectamente evidenciado en estudios que han dado cuenta que los principales victimarios de las violencias contras las mujeres en el espacio doméstico forman parte del núcleo familiar (Caicedo, 2013), tal como se demuestra en el desarrollo de éste apartado.

En esta misma dimensión se encuentran roles muy diferentes. Por un lado, están las mujeres que tienen que tener miedo, que les está permitido tener miedo, porque esa es una condición importante para que el compañero asuma su rol protector y cuidador sobre la mujer reverente y sumisa que encuentra en esa relación de poder su zona de confort y tranquilidad, en la que la violencia estructural actúa como un elemento estabilizador para la convivencia, pero además se logran imponer las ideas obteniendo beneficios (Lorente, 2001: 43), que de otra manera con una mujer segura y altiva no sería posible.

${ }^{80}$ Nuevo compañero sentimental de la madre y/o de las hermanas u otra pariente con la cual habiten. 
Luego está la mujer proveedora de seguridad, cuyo rol consiste precisamente en proveer seguridad al interior de las familias, lo que la inhibe de manifestar inseguridad o miedo, aunque en su interior sea esa la sensación que prevalezca. Generalmente este rol contradice y confronta el tradicionalmente asignado a los hombres de garantes de seguridad y protección. En gran medida esto se debe a los procesos de aprehensión y compromiso que estas mujeres generan dentro de la estructura familiar, porque hacen conciencia de su rol de mujeres protectoras que va en contra de la estructura patriarcal o por la ausencia incluso de la presencia masculina, ellas se apropian de la discusión y análisis del contexto, frente a lo que sucede en sus barrios o entornos cercanos para tomar decisiones, tanto para la seguridad de los miembros de la familia como de ellas mismas (CG, C8, feb. 29), 1legando incluso a ocultar situaciones que las afectan directamente, como amenazas y señalamientos, con el fin de no alterar la tranquilidad de padres, hermanos/as e hijos/as (LR, C1, abril 25).

En esta dimensión privada, dos representaciones contradictorias se confrontan. Una es negativa que está hecha de miedo, y la otra positiva hecha de admiración y respeto. La primera nos habla de la sensación de miedo que inspira la figura paterna. El padre no es el proveedor de seguridad sino una fuente constante de temor y violencia. La sola referencia a él ya produce miedo (CG, C8, feb. 29) toda vez que aparece asociada a reiterados actos de violencia, abandono y abuso contra las mujeres.

La segunda representación, por el contrario, está dotada de admiración y respeto. Acá no se confronta el rol del padre sino que se aprende de él, asumiendo en consecuencia su rol protector (DQ, C1, feb. 13) sobre la familia, el cual en estos casos estuvo mediado por otro tipo de comportamientos contrarios a los tradicionales, es decir, sin formas de subordinación o de violencia sobre las mujeres. Estas representaciones aportan insumos morales para construir una sensación de seguridad. La figura paterna inspira seguridad.

De acuerdo o en desacuerdo con esta representación que se tenga del padre, cambia el rol de la mujer, pasando de mujeres protegidas a mujeres protectoras. Ello no excluye que aún al interior de las familias haya una marcada influencia de figuras patriarcales desde las cuales históricamente se han determinado relaciones de dominio y se han aceptado las posturas machistas $(\mathrm{RO}, \mathrm{C} 8$, marzo 3), (DQ, C1, feb. 13). Esto ha incidido en que los patrones de violencia se repitan con más frecuencia entre los hijos varones que entre las mujeres. Esta situación no es recurrente en las mujeres que salen de sus hogares de origen y asumen la jefatura de su propio hogar, lo que 
evidencia que estas representaciones se instauran por los roles tradicionales de género que de manera simbólica se instalan en los hogares (Segato, 2003: 14).

Todo ello también repercutirá en los demás miembros de la familia, y será fuente de disputa, sobre todo cuando las mujeres trasgreden los comportamientos asignados. También los hijos, hermanos, primos o tíos quienes se sienten dueños y poseedores de las mujeres, es posible que se sientan aludidos e incluso las mismas mujeres de la familia que suelen conformarse con ese papel, pueden terminar confrontando a las otras mujeres que se salen del esquema y evidencian un ejercicio de autonomía. Así lo plantea una de las entrevistadas: "Porque incluso la idea de que yo tuviera un novio en el colegio fue para ellas motivo de dejarme de hablar: 'No me volvás a hablar, aquí no volvés"” (RO, C8, marzo 3).

En otros casos, cuando hay un nuevo compañero sentimental, la situación puede empeorar. El nuevo miembro masculino de la familia, sin ser reconocido como tal, asumirá el rol de "padrastro" y por añadidura se tenderá a arrogarse el lugar de la autoridad, afectando el entorno de confianza del núcleo familiar, generando desconfianza y miedo, especialmente en las hijas (CG, C8, feb. 29). En este contexto se desestimarán las preocupaciones y desconfianzas de las mujeres que hacen parte de ese núcleo familiar, y se valora por encima de ellas los intereses y actitudes del nuevo integrante.

En ocasiones, la imposición de figuras autoritarias externas no solo abarca a los miembros de una familia que habitan la misma casa, sino que además puede afectar a personas que, siendo del mismo núcleo, se encuentran en lugares distantes. Todo eso pone en evidencia las diversas formas de ejercer dominio y control sobre las mujeres, por ejemplo, mediante el vínculo natural de los tíos, primos o hermanos, quienes través de la articulación con los grupos armados ilegales, sean combos o bandas que operan en estos sectores de la ciudad, transmiten los mensajes de advertencia.

Otra situación que incide en la trayectoria personal de las entrevistadas en esta dimensión privada es la experiencia en el matrimonio o la convivencia en pareja. La cual marca la proyección de sus vidas, con un cambio importante en la representación de estas relaciones de poder, transformando el lugar de sumisión al de control de sus vidas, en los cuales si bien inicialmente atravesaron momentos de inseguridad y de miedo para "enfrentar" la vida, lograron pasar ese umbral y reencontrarse a sí mismas, ratificando incluso sus capacidades: 
"Le tenía miedo a la soledad, le tenía pavor a la soledad. Yo decía que sin mi esposo no podía vivir y ese hombre se fue: “¡Yo qué voy a hacer! ¡No voy a ser capaz de pagar unos servicios, la comida! ¿Con qué le voy a dar el estudio a mi hija?”. Pues te digo: a mí ahora me mencionan el matrimonio y yo me quedo sola, no quiero volver ni a cocinar ni a aplanchar. Me daban las 11:00 de la noche haciendo una bendita sopa... atendiendo al rey de la casa. ¡Eso se acabó! porque llevo seis años sola, pero los primeros cuatros años me fue muy mal, seguía con ese miedo, pero ahora me le mido a todo ya, hasta a la soledad" (RD, C8, mayo 12).

Este aprendizaje se instala en un proceso personal en el cual se deconstruye la representación de seguridad en el otro y desde ahí, se reconstruye la seguridad sobre sí misma. Pero podría decirse sin lugar a equivocaciones que no son muchos los casos en los que las mujeres toman estas decisiones, pues hay asuntos como el económico, es decir las posibilidades de manutención o de ingresos que son determinantes y que hacen que su representación de seguridad esté condicionada a los ingresos económicos de la pareja, aunque no es fácil encontrar los argumentos que soporten esta tesis.

Muy ligadas a los contextos de las comunas analizadas están las relaciones que se establecen con hombres que hacen parte de los grupos armados, que en un contexto de conflicto armado urbano están demarcados por la violencia (Sánchez, 2011: 87) y transforman sus comportamientos fuera y dentro del hogar. Ellos muestran un rol de poder y de dominio sobre la mujer ante los miembros del grupo al que pertenecen y otro en la privacidad del hogar:

"Ella nunca se pudo separar de él, ella me decía: “A mí me da mucho miedo porque él cuando está conmigo en la casa es bien, es amoroso, es superpendiente. Pero llegan los muchachos y ahí se pone todo brusco, que tráigame eso, que esta boba, y me empuja y todo, y a mí me da mucho temor". Entonces cuando estaban solos, era la dulzura y llegaban los amigos y él se convertía en un hombre supremamente violento" (LR, C1, abril 25).

El desenlace fatal de esta situación se da luego del asesinato del compañero, es la única forma de desligarse de esos comportamientos bipolares en contextos relacionales diferentes, entre las dimensiones pública y privada, en donde el patrón cultural de hombre dominante prevalecía, negando cualquier posibilidad de cercanía que pudiera conducir a transformar su representación al interior del grupo armado del cual hacía parte. 
Otros argumentos se sostienen en las posturas críticas sobre la convivencia con otro ${ }^{81}$, por el aprendizaje propio, o bien sea del entorno familiar o del entorno cercano, estas experiencias marcan unas respuestas que niegan cualquier posibilidad de volver a compartir el mismo techo con otra persona. Así, al menos, lo dijeron nuestras entrevistadas: "Como amo mi libertad, entonces me separé, afortunadamente" (DQ, C1, feb. 13). Aunque también sin haber tenido la experiencia de la convivencia en pareja, lo interpretan como un camino hacia la inseguridad y en consecuencia la infelicidad,

"yo he visto cosas las experiencias de mi mamá que mi mamá sufrió mucho con los hombres y que le han pagado muy feo", "para qué uno se va a casar si después uno cuando le den los primeros años una buena vida después lo empiezan a humillar" (CG, C8, feb. 29), "El maltrato, el doblegarse a esa persona por depender de ellos" (RD, C8, mayo 12).

De esta manera, y particularmente para estos casos que tienen un profundo arraigo en nuestra sociedad, hay una fuerte noción de sentido de la realidad en relación a la convivencia, pues estas vivencias propias o ajenas solo tienen importancia cuando son vividos de forma única y plena, en los procesos de objetivización e individuación de la realidad (Berger, P. y Luckman, T., 2008), que incide en la toma de decisiones de las mujeres.

Finalmente están los puntos de vista de algunas mujeres que niegan la posibilidad de construir representaciones de inseguridad en sus hogares, dado el rol de cuidadoras, garantes y proveedoras de seguridad dentro de sus núcleos familiares:

"La diferencia es que uno asume más un rol de estar ahí para la familia que ellos estar para uno. Entonces, más que generarme seguridad es un compromiso de generarles seguridad a ellos" (CG, C8, feb. 29), "De todas maneras mis papás viven ahí. Cuando a mí me pasan ese tipo de $\operatorname{cosas}^{82}$, yo generalmente no les comento" (LR, C1, abril 25).

Acá es claro ese comportamiento "altruista" que denomina Dammert y que se vincula más a la preocupación por sus hijos y padres u otros miembros de la familia que por sí mismas (2007: 93). Pues como se pudo establecer en este apartado, de manera general se ha tenido la creencia de que el fracaso o descuido de la familia es responsabilidad de la mujer en su rol de madre y protectora y

\footnotetext{
${ }^{81}$ Hablo específicamente de un otro masculino porque no encontré referencias distintas de convivencia.

82 "Ese tipo de cosas" alude a amenazas directas de los grupos armados de las cuales la mujer ha sido víctima por el liderazgo que ejerce en la comuna.
} 
que en consecuencia el lugar seguro por excelencia es el hogar donde habita el núcleo familiar, sin embargo la mayor parte de las violencias contra las mujeres ocurren es allí, y más aún la probabilidad de ser víctimas de un de un delito cometido por un conocido es mucho mayor (Madriz, 2001: 33). Pero la respuesta a estas situaciones está supeditada a la aceptación o negación de las mujeres del rol asignado en la estructura patriarcal en la esfera doméstica y de la cual el Estado ha decidido marginarse, restándoles garantías a las mujeres para que no sean violentadas y/o evadiendo su responsabilidad de brindar protección.

\subsection{La paradoja de la inseguridad, el Estado}

Hasta ahora, las representaciones en torno a las inseguridades fueron abordadas desde la dimensión privada, en donde la construcción social del género ha demandado un rol determinado para las mujeres en las familias. Esos roles condicionan las representaciones sobre la inseguridad. En este apartado nos abocaremos ahora a explorar el lugar que tiene el Estado, en tanto dimensión pública-, en las percepciones sobre la seguridad. Se trata de explorar en qué medida la interpretación que se tiene del Estado en tanto garante de seguridad, incide o no en la representación de (in)seguridad de las mujeres.

La representación del Estado está mediada por la estructura institucional, en donde hay una marcada influencia y reconocimiento negativo o positivo en el ejercicio de la Fuerza Pública, las respuestas institucionales frente a las necesidades y demandas de las mujeres frente a la garantía de sus derechos y la provisión de seguridad.

La pregunta que subyace en este punto es la siguiente: ¿qué representaciones tienen las mujeres del Estado y cómo estas influyen en las percepciones sobre la seguridad y la inseguridad? En el trabajo de campo se reconocieron dos representaciones sobre el Estado. Por un lado, una representación Estatal (con mayúscula), donde el Estado aparece asociado a la respuesta institucional eficaz o no que ensaya desde la estructura central. Por el otro, una representación estatal (con minúscula), donde el Estado está vinculado al ejercicio concreto de la Fuerza Pública en el ámbito barrial, donde la Fuerza Pública responde o no a los problemas de "convivencia", sobre todo a partir de las formas de dominación y el poder que ejercen los grupos armados ilegales que operan en los sectores donde las mujeres habitan. 
En cuanto a la primera representación- la Estatal-, todas las entrevistadas coincidieron acerca de la poca o nula existencia de una acción efectiva desde diferentes instancias que constituyen el sistema estatal que es la que debería garantizarles a las mujeres medidas de protección y justicia frente a situaciones que vulneren su seguridad y sus derechos. Por ejemplo, manifestaron la dificultad para hacer denuncias; la falta de formación de los/as funcionarios/as públicos para su recepción; la falta de apoyo concreto de las instancias institucionales creadas con el fin de atender y orientar las mujeres en el tema relativo a su seguridad; y la ausencia de un debate real y efectivo para la construcción de políticas públicas con perspectiva de género ${ }^{83}$, que pese a que Colombia se ha acogido a normas y decretos internacionales, aún no parecen hacerse efectivos.

Si bien es importante destacar en la ciudad de Medellín la existencia de una Secretaría de Mujeres ${ }^{84}$, cuyo objetivo es desarrollar políticas públicas desde una perspectiva de género y desde la cual se han liderado diversas líneas de atención focalizadas en cada comuna ${ }^{85}$, algunas de las mujeres entrevistadas manifestaron que el trabajo de esta dependencia parece mínimo, y lo dicen por varias razones, entre otras porque:

\footnotetext{
${ }^{83}$ En las últimas décadas, luego de arduas luchas por parte del movimiento social de mujeres se han logrado instrumentos internacionales, regionales y nacionales, tales como la ratificación de la Conferencia por la Eliminación de Todas las Formas de Discriminación contra la Mujer, CEDAW (1979), y la posterior conquista del Protocolo Facultativo. La Convención de Belém do Pará (1994), convocada por la OEA, fuente de inspiración a la primera serie de legislación contra la Violencia hacia las Mujeres en los 90. Las Plataformas de Acción y compromisos expresados en las Conferencias de Naciones Unidas, tales como la de Medio Ambiente y Desarrollo (Ecco 1992), Hábitat II ( Estambul, 1996), la Declaración Mundial de IULA sobre las Mujeres en el Gobierno Local (1998), la Declaración del Congreso Fundador de "Ciudades y Gobiernos Locales Unidos" (París 2004), así como la Carta Internacional por el Derecho de la Mujer a la Ciudad, elaborada por la Red Mujer y Hábitat de América Latina, y otros instrumentos tales como la "Carta Europea de la Mujer en la Ciudad" (1995) y la "Declaración de Montreal sobre la seguridad de las mujeres" (2002).

${ }^{84}$ En su condición de entidad rectora de las Políticas Públicas para las Mujeres Urbanas y Rurales de Medellín, mediante el Acuerdo 022 de 2003, la Secretaría de las Mujeres contribuye a la igualdad de derechos y oportunidades entre mujeres y hombres y a la disminución de prácticas discriminatorias que atentan contra el desarrollo político, social, económico y cultural de las mujeres del municipio de Medellín a través de la transversalización del enfoque de equidad de género en el diseño, implementación, coordinación, monitoreo y asesoría de las políticas, planes y programas de la Alcaldía Municipal. El Acuerdo 52 de 2011 "por medio del cual se crea en el Municipio de Medellín el Programa Integral de Protección a Mujeres Víctimas de Violencia" crea las posibilidades jurídicas para que la Secretaría de las Mujeres actúe de manera articulada con la Defensoría del Pueblo, con el que además se da cumplimiento a la ley 1257 de 2008 en su art. 8, literal b.

${ }^{85}$ La Secretaría de las Mujeres opera con profesionales distribuidas en las distintas comunas y corregimientos de la ciudad, con las cuales implementa los programas y fortalece los colectivos de mujeres en cada sector.
} 
“...Van una o dos veces al barrio, pero no están inmersas en las necesidades, no saben qué es lo que pasa $[\ldots]$, lo desconocen totalmente y la gente empieza ahí a perderle credibilidad y por eso es que tampoco las llaman" (MG, C1, marzo 9).

Incluso, algunas manifiestan que los programas no tienen resultado o no cuentan con un espacio institucional donde las mujeres se sientan identificadas o que verdaderamente puedan atender las situaciones que las afectan (LR, C1, abril 25; CG, C8, feb. 29).

Lo anterior no hace más que confirmar lo que han señalado Rainero y Massolo, para las políticas públicas existentes sobre la violencia y la inseguridad. Estamos ante políticas asistencialistas, ante la ausencia de programas preventivos; victimistas, toda vez que proponen un trato de las mujeres solo como víctimas y no como ciudadanas autónomas; delegativas, en la medida que las instancias institucionales rotan su responsabilidad ante los hechos y desgastan las rutas de atención y el acceso a la justicia; y donde además se enfatiza la violencia en los espacios privados como un asunto de la esfera personal e interna de las mujeres sobre las cuales ellas tienen control (Rainero, L., 2008: 11; Massolo, 2007).

Para el caso de la ciudad de Medellín la división territorial establece adscripciones o pertenencias de sus habitantes a los barrios y comunas para acceder a servicios de administración de justicia. En estas circunstancias, es posible determinar la falta de idoneidad de los funcionarios, y la falta de claridad en el ejercicio de las funciones de quienes atienden las solicitudes y demandas de las mujeres. Pero sin duda alguna el aspecto más grave a resaltar tiene que ver con la pérdida de credibilidad en estas entidades públicas:

"Confiaba más en la gente, era más confiada y creía que todo el mundo le guardaba a uno la espalda y hoy en día creo que no, y menos la policía porque a mi hija la mataron con la fiscalía" (CA, C1 feb. $10)$.

"No siento como: “¡Ay, llegó la policía! estoy segura”. No, pues no porque por ejemplo pasa que en una casa están maltratando a una mujer, el marido le está pegando, uno llama a la policía, para cuando lleguen la mujer puede estar muerta" (CG, C8, feb. 29).

Estas apreciaciones son análogas a la crítica formulada por la Asamblea de Naciones Unidas cuando plantea que las respuestas institucionales se caracterizan por la falta de voluntad política, hecho que se verifica en la asignación insuficiente de recursos y en la incapacidad para crear y mantener 
entornos políticos y sociales estables para poner en crisis la violencia contra las mujeres (Asamblea General de Naciones Unidas, 2006: 11).

Pasemos ahora a la segunda dimensión estatal, esto es las representaciones que se tienen sobre las fuerzas públicas locales, en caso concreto la Policía. Directamente todas las entrevistadas coinciden en que no son seguras, no le agregan certidumbre, no contribuye a garantizar entornos seguros. Su existencia en el territorio no garantiza seguridad. Se las percibe no sólo como un actor pasivo sino como fuente de conflictos constantes. Lejos de agregar seguridad, le imprimen mayor inseguridad a la vida cotidiana en los barrios:

"Para mí que haya mucha policía o que haya mucho ejército eso no significa seguridad" (DQ, C1, feb. 13).

"Identifico que ellos aumentan el pie de fuerza, creen que aumentando la policía se aumenta la seguridad pero para mí eso no es seguridad" (EI, C1, mayo 8).

De modo que las fuerzas públicas son percibidas directamente como factor de inseguridad. Específicamente, en la C1P existen acusaciones contra ella, la señalan de abusar del uso del uniforme y seducir niñas y adolescentes para llevarlas al comando de Policía que queda cerca de una Institución Educativa:

“En los barrios que hay más Fuerza Pública hay como más desorden. Lo digo porque no todas, pero sí hay muchas mujeres que las atrae el uniforme o las armas... o no sé si es que las chantajean, pero siempre cuando existe más Fuerza Pública hay más desorden en los barrios" (EI, C1, mayo 8).

"No es lo más seguro que esté la Fuerza Pública en un sector, porque también ellos han accedido a nuestras mujeres violándolas o maltratándolas y bueno... sabemos que las armas no son para darles besos o abrazos a las mujeres" (LR, C8, feb. 24).

En este sentido, las mujeres entrevistadas nos cuentan acerca de las violencias simbólicas que diariamente ejercen contra ellas. Vaya por caso los piropos obscenos, los maltratos, y las violencias de las que son objeto las mujeres por parte de los policías cuando realizan recorridos en las motos por los barrios (LR, C8, feb. 24). Estas mujeres incluso, llegan a ubicarlos en el mismo nivel que los miembros de los grupos armados ilegales (MG, C1, marzo 9). 
Esta percepción deslegitima a la Fuerza Pública, la que además es referenciada como ineficaz y corrupta, por las relaciones de connivencia que tiene con los grupos armados ilegales que operan en el sector. Así lo han dado a conocer diversas investigaciones sobre el tema y artículos periodísticos ${ }^{86}$, y se ratifica en esta afirmación que hace una de las entrevistadas:

"Hay en la ciudad un imaginario de Fuerza Pública que no cumple, para la sociedad no cumple, es una Fuerza Pública que está siendo todo el tiempo mirada con lupa, porque se está involucrando más en el tema de delincuencia, de sobornos, de ser blanda con los delincuentes, de ser pasiva en el momento de actuar con las violencias callejeras, reacciona poco a temas de la ciudad [...] es una Fuerza Pública parcializada, subjetiva, que mira más sus intereses que la sociedad, que no está haciendo un ejercicio de protección de ciudad ni está haciendo un ejercicio de seguridad en la ciudad, sino que simplemente está haciendo una panorámica, en vez de involucrarse y tratar de transformarla. La veo muy lenta frente a problemas de ese tipo, no opera para hacer un cambio. Me imagino que debe ir más allá, se quedó en una figura de años 20,30 y no evoluciona. La ciudad va más adelante y es más propositiva, y ella se está quedando en el discurso y no está generando ni cambios. (RO, C8, marzo 3).

La situación empeora cuando la Fuerza Pública en lugar de responder a las denuncias de la comunidad, la pone en riesgo con los grupos armados ilegales, cuando por diferentes razones les hacen saber quién o quienes han realizado denuncias en su contra y por cuales motivos(AG, C8, abril 24). De hecho las denuncias por connivencia de la Fuerza Pública con los grupos armados ilegales es una constante en los casos de corrupción y falta de garantías a la población, o peor aún cuando su respuesta es tan poco efectiva que se terminan generalizando y promoviendo formas de justicias "alternativas" ilegales, pero eficaces: "La policía no sirve para nada y los ilegales se han legitimado por la misma ineficiencia de los legales, en este caso la policía" (CM, C1, mayo 11). Se ha terminado remitiendo a los grupos armados ilegales para resolver los conflictos:

"Llamé a la estación de policía de aquí del parque, pues ellos tienen que subir... ¿sabe cuál fue la respuesta de ellos? "Hable con los muchachos, ¿ustedes no están cerquita de los muchachos?, llámenlos a ellos, para qué nos van a hacer subir a nosotros hasta allá”. ¿Seguridad? ¡Cuál seguridad! "Llame a los muchachos". ¿Qué hizo la señora de enseguida? "Mija, ¿ya llamó a la policía y qué le dijo?" Que hable con los muchachos. El muchacho de enseguida dijo: “Ah. Entonces yo voy a hablar con los muchachos" Se fue y habló con los muchachos y ahí mismo bajaron tres...” (LR, C1, abril 25).

\footnotetext{
${ }^{86}$ Al respecto ver: Gómez Ramírez et al (2012), Control territorial y resistencias, una lectura desde la seguridad humana, editorial La Carreta, Medellín. Restrepo E. Juan Diego (2013). "Sectores de Fuerza Pública generan inseguridad". En: Revista Semana. 01 de abril de 2013.
} 
El campo de acción de la Fuerza Pública se restringe en cuanto a las personas que demandan sus servicios y a los sectores donde ocurren los hechos. Esto se da por dos factores: Primero por una delimitación institucional que establece las zonas de atención demarcadas por inspecciones de policía y seguridad por cuadrantes ${ }^{87}$; segundo por la restricción de los grupos armados ilegales que operan en algunos sectores de ambas comunas, en los cuales hay un control absoluto: "La policía no entra allá, la policía no va, llegan hasta las escalitas pero por allá no se meten, no ve que los devuelven a bala" (DQ, C1, feb. 13). Ante la incapacidad de impartir "orden" de manera general, abusan del ejercicio del poder y enfocan su acción en jóvenes con características de pertenecer a grupos como punkeros, hoppers, rockeros entre otros:

"La policía en el sector es nada, es nada. Son simplemente los que están molestando todo el tiempo: 'Usted no se puede hacer acá, usted no se puede hacer acá'” (MG, C1, marzo 9).

Todo esto nos lleva a sostener que existen razones suficientes para entender que el desdibujamiento del Estado, el deterioro de la credibilidad en el Estado, se da en relación a las respuestas que a nivel Estatal y estatal se brindan para garantizar la seguridad de las mujeres. La ineficacia del Estado para atender las demandas concretas y la incapacidad para dirigir la Fuerza Pública a nivel local, le agrega mayor vulnerabilidad a las mujeres. Por un lado genera expectativas con las políticas públicas que después frustra cuando se implementan en el territorio. Por el otro, la violencia de la Fuerza Pública, violencia que se verifica no solo en la portación y uso de la fuerza letal sino en ostencibilidad de las masculinidades propias de su formación, contribuyen a reforzar la sensación de vulnerabilidad o desprotección en las mujeres.

\subsection{Control social y territorial en el marco de la ilegalidad}

Como dijimos en el primer capítulo, la existencia de grupos armados ilegales, actores del conflicto armado urbano, es un fenómeno que históricamente ha caracterizado a la ciudad, especialmente a las comunas del presente estudio. Conflictos con formas de accionar e intensidad que varían de

87 La comuna 1 cuenta con una inspección de policía y siete cuadrantes de seguridad, mientras que la comuna 8 tiene dos inspecciones de policía y seis cuadrantes de seguridad. Los cuadrantes de seguridad obedecen a una estrategia institucional para la seguridad ciudadana desde la cual se busca asegurar las condiciones de seguridad y convivencia ciudadanas desde la asignación de policías en áreas específicas que operan bajo un modelo integral de servicio. 
acuerdo con los territorios donde se establezcan y el control territorial que ejerzan, el cual no se determina solo por el espacio físico, la cantidad de hombres en sus grupos y la geografía de las comunas, sino también por otras formas de control como el económico, social y político que imponen (Gómez, Ramírez H., et al, 2010: 49). Aunque en años recientes se ha incrementado la participación de mujeres en estas estructuras, no hay aún estudios que permitan determinar su relevancia dentro de las mismas.

En consecuencia, dichos grupos forman parte del entorno social donde las mujeres se relacionan. La pregunta que nos hacemos ahora es la siguiente: ¿Cómo impactan estos conflictos, y sobre todo estas organizaciones en la vida de las mujeres? ¿Cómo son percibidas estas organizaciones y qué influencia tienen en la percepción de la inseguridad?

Los grupos armados ilegales son importantes en las representaciones sociales de seguridad/inseguridad de las mujeres, dado la hegemonía que han logrado construir en los últimos 25 años que ha incidido en la convivencia y la vida social en distintas zonas de la ciudad (Gómez, 2012). Algunas de sus acciones tienen una repercusión directa sobre las mujeres como son la explotación de niñas y adolescentes con fines de prostitución y trata de personas, las violencias sexuales y el desplazamiento forzado intraurbano, como se explicó en el capítulo 1.

Pero como si esto no fuera suficiente y tal como se planteó en el apartado anterior sobre la impartición de justicia, los grupos armados ilegales operan además como agentes de "limpieza social”, estableciendo una suerte de "orden” que incluso será percibido como más eficaz frente a la incapacidad de las fuerzas públicas. Éstos se encargan de perseguir a los protagonistas de los robos y atracos o procuran que este tipo de delitos no tengan lugar en el barrio. Por ejemplo:

"La seguridad ha mejorado muchísimo. [...] En el centro se dice que si le roban a uno, se grita y salen los de las Convivir ${ }^{88}$. Si por la casa pasa algo, se llama a los muchachos de la esquina y ya. Es más seguro los muchachos que la misma policía" (CM, C1, mayo 11).

En ocasiones se cuestionan los medios que utilizan por considerárselos extremos:

\footnotetext{
${ }^{88}$ Las Convivir son grupos que operan en la ciudad de Medellín y se definen como Cooperativas de Vigilancia y Seguridad Privada, legalizadas en 1994 y conformadas en su mayoría por personas desmovilizadas de los grupos armados ilegales, inicialmente milicias y posteriormente grupos de paramilitares.
} 
"Si es para la seguridad ¿entonces por qué matan?, ¿cierto? Es que la seguridad no es matar al que robó, sino pues darle una lección, pero no quitarle la vida" (CG, C8, feb. 29).

Nos parece que existe una relación entre el descreimiento hacia el Estado y estas afirmaciones, entre la desconfianza (del estado) y la confianza (a los grupos armados). Si el Estado está ausente o estando presente le agrega más incertidumbre, los vecinos empezaron a buscar otros actores que puedan resolver conflictos, que le agreguen certidumbre a la vida cotidiana. Es decir la seguridad como "la defensa de lugar" se convierte en un asunto de la comunidad ante el fracaso del Estado, así sea que las personas que habitan un territorio sean quienes se provean su propia seguridad desde un sentido amplio (Zygmunt, B., 2003: 134) y a través de diversas estrategias.

Generalmente estos grupos están conformados por habitantes de la comuna que se han vinculado a las estructuras armadas por diversas razones, lo cual no los margina de la vida social y personal de las mujeres que habitan estos sectores, dado que también en muchas ocasiones hacen parte de los núcleos familiares, en lugar de padres, hermanos e hijos:

"Conozco los de mi cuadra porque son pelados que han crecido conmigo. Unos se han involucrado por cuestiones económicas, otros por cuestiones de poder. Niñas, mujeres, también” (MG, C1, marzo 9).

Los grupos armados ilegales llegan a tener un nivel de control territorial tal que abarcan grandes extensiones de las comunas, en especial cuando se asocian con "combos" o bandas de sectores aledaños, que para el caso de esta investigación se denominan grupos armados ilegales:

"Más o menos hasta la mitad del Popular son de los mismos, entonces están divididos por todos los barrios en todas las esquinas" (MG, C1, marzo 9).

Esta situación genera cierta sensación de tranquilidad que solo se verá alterada cuando los grupos empiecen a disputarse el control territorial y a establecer los límites que ya definimos como "fronteras invisibles".

Mediante estas formas de control territorial los grupos acceden a recursos económicos importantes por medio de distintos mecanismos como la extorsión a viviendas, locales comerciales y transporte público, entre otras. También recaudan vendiendo servicios de vigilancia, una suerte de seguridad paradójica o protección coercitiva, toda vez que se impone a través del uso de la violencia. Una 
protección violenta que se consolida en protección racket cuando la extorsión se convierte en una acción permanente que no demanda esfuerzos porque ya la mayor parte de la población la ha asumido (Bedoya, 2010: 50), pero que llega a un punto de saturación cuando se conoce que son los mismos miembros de los grupos armados quienes pueden hacer el daño, así se cumpla con el pago:

“iNo, señor, uno de pronto puede pagar si a uno lo están cuidando, pero si antes miran cuando quedan las casas solas... entonces uno cómo les va a pagar!” (EI, C1, mayo 8).

Por lo tanto hay unos límites difusos en las dinámicas que imponen estos grupos. Grupos referenciados al mismo tiempo como generadores de seguridad y de inseguridad. Producen seguridad cuando resuelven determinados conflictos (robos, por ejemplo) y generan inseguridad cuando amenazan con acciones violentas o cometen castigos ejemplarizantes ${ }^{89}$ para controlar mediante el miedo a la población.

Estas situaciones tienen un impacto sobre las representaciones de (in) seguridad que tienen las mujeres. Algunas apelan a su propia experiencia y otras hablan a partir de experiencias ajenas, lo que puede denominarse un miedo por transferencia. Acciones violentas contra otras, relaciones que establecen con los miembros de los grupos armados (quienes son hijos o hermanos de sus amigas y/o amigos de infancia) o por comportamientos arbitrarios y violentos contra ellas, sin mediar relación alguna. Es así una construcción que se hace de la seguridad/inseguridad, como un asunto individual y anclado también en el aprendizaje colectivo (Vargas, 2007: 30).

Los grupos armados ilegales instalan una serie de centros de operaciones en lugares específicos y estratégicos de las comunas, como lugares cercanos a instituciones educativas, canchas deportivas, zonas comerciales y esquinas, donde alcanzan a hacer un monitoreo de las dinámicas barriales con sentido espacial y social:

"Sí, los actores se están yendo para otros lugares que frecuenta la masa: la ciudad, una discoteca. Casualmente, en estos días estaba en un centro comercial y me senté cerca a un tipo que cobra gota a gota $^{90}$. Inicialmente no sabía, yo solamente vi a un tipo con un computador, pero vi que allá llegaba

\footnotetext{
${ }^{89}$ Estos castigos ejemplarizantes van desde arrastrar a una persona por las calles atada a un carro hasta asesinarla en frente de varios testigos.

90 La denominación "gota a gota" hace referencia a una modalidad de préstamo de dinero que realizan miembros de los grupos armados ilegales en los barrios, con elevadas tasas de intereses que se pagan a diario hasta cubrir el valor total de la usura.
} 
mucha gente y más que todo son mujeres, entonces ahí hay otro tema de seguridad" (RO, C8, marzo $3)$.

Los grupos armados ilegales "administran" los escenarios deportivos públicos cobrando para su uso. Su interés en estos espacios se justifica además porque esos lugares son espacios de encuentro de niños y jóvenes. Los grupos armados muchas veces reclutan a sus miembros en estos espacios que administran, ofreciéndoles posibilidades de ganar dinero de forma "fácil", es así como a los niños y adolescentes hombres les proponen realizar labores de apoyo (IPC, 2012) con el fin de cooptarlos para la estructura criminal bajo diferentes modalidades como "carritos"91:

"En la cancha hay una administración, entonces en la cancha vos necesitás permiso para entrar, pues ahí hay una dificultad y es que mirá las placas: van niños y niñas, pero también van los actores que tienen otros intereses en los niños y las niñas" (DQ, C1, feb. 13).

Las esquinas han sido históricamente lugares de referencia y de ocupación por parte de personas ligadas a grupos armados ilegales, que en la actualidad hacen parte del conflicto armado urbano. En ellas se establece mayor control de acceso y salida en los territorios, como se establecerá en el siguiente capítulo y como lo afirma una de las entrevistadas:

"En los barrios hay actores armados. Es histórico que en las comunas de Medellín, sobre todo en los sectores populares, ha habido muchísimos actores armados, cada uno con su nombre dependiendo de la época. Entonces las mujeres tienen miedo de salir a la calle en la noche, de pasar por determinada esquina porque ahí están parados no se sabe quiénes" (DQ, C1, feb. 13).

Otros lugares, como por ejemplo los restaurantes y cafeterías, ubicados en cercanías de instituciones educativas, sirven para monitorear el acceso de las/os estudiantes al plantel, establecer relaciones con ellas/os y a partir de allí vincularlas con mayor facilidad los grupos, a las niñas y adolescentes las utilizan para hacer seguimiento a sus compañeras de manera que puedan insertarlas en el negocio de prostitución y trata de personas:

"Las mujeres son "utilizadas" por los actores armados para un montón de cosas, para venta, para consumo de sustancias, para venta del cuerpo, para trata, para muchos episodios de violencia que

${ }^{91}$ Denominación dada a los niños/as para que transporten drogas y armas, además de estar vigilantes y dar aviso de recorridos de patrullas de la policía. 
ocurren en la comuna, y a los hombres los invitan para que estén en estos grupos, si ellos no aceptan, o los matan o los hacen ir, es que esas son las opciones que ellos tienen no más" (LR, C1, abril 25).

Esta es una de las principales vulneraciones que enfrentan niñas y adolescentes y en la representación de inseguridad las mujeres adultas que tienen madres adolescentes, ven en este tipo de acciones una amenaza constante para la integridad de sus hijas, de hecho esta es una de los principales razones que afecta el desplazamiento forzado intraurbano. Nuevamente los grupos armados ilegales no solo marcan el cuerpo de las mujeres a partir de los actos de violación sino como objetos de propiedad de los cuales disponen.

Como se puede ver, la trata de personas es uno de los principales problemas de seguridad que preocupa en la C1P, y son los miembros de los grupos armados ilegales quienes han consolidado el negocio de trata con fines de explotación sexual (EI, C1, mayo 8).

"Muchas mamás que trabajan, que tienen que salir a conseguirse el pan diario no están tranquilas porque saben que si sus hijos salen de la casa están en un alto riesgo cierto de ser vinculados a cualquiera de esos asuntos que les generan tanto miedo a las mujeres, cierto?, que los hagan consumidores, que los hagan transportadores o transportadoras, que les muestren ese mundo fantástico que no existe, sobre todo a las niñas y a las mujeres jóvenes, y las vinculen a las redes de prostitución, a las redes de trata de personas, que es un negocio que ahorita está generándoles muchísimo dinero a esos personajes que son los que tienen el mango por sus manos" (DQ, C1, feb. 13).

Esta situación no se establece tan claramente en la $\mathrm{C} 8 \mathrm{VH}$, aunque es un problema que ha ido aumentando y llamando la atención de las autoridades y la ciudad en general, en el trabajo de campo realizado no hubo ninguna alusión sobre el particular.

Poner en la discusión pública la trata de personas con fines de explotación sexual que enciende las alarmas en la $\mathrm{C} 8 \mathrm{VH}$, que se propaga no solo en el ámbito familiar, sino escolar y social, pone en riesgo a las mujeres que lo hacen, quienes han llegado incluso a recibir amenazas. Lo que ha impedido paradójicamente que las amenazas se materialicen son los lazos establecidos desde la infancia con quienes hoy hacen parte de estas estructuras.

"Pero de todas maneras ahí está como la amenaza. Yo estuve los primeros meses después de la amenaza con mucho miedo. Después de salir de la universidad me iba de una vez para la casa, hacía cosas para cuidarme" (LR, C1, abril 25). 
Se presentan intervalos de tranquilidad o tensa calma entre las acciones de estos grupos armados que operan en estas comunas, pero no disminuyen los problemas de seguridad ( $\mathrm{RO}, \mathrm{C} 8$, marzo 3). Los vínculos personales, familiares y sociales que se conjugaron en algún momento se convierten en una "alteridad amenazante", en la que las relaciones siempre son complejas y nada transparentes, ya que la mayoría de las inseguridades percibidas en estos territorios tienden a ser directamente asociadas con estos actores considerados los directos responsables del deterioro social (Reguillo, 2006: 36), y en no pocas ocasiones las razones de los conflictos familiares, ya que como se planteó antes, quienes hacen parte de estos grupos son hijos, padres y hermanos de mujeres que habitan estos territorios.

Los propósitos de las mujeres en las relaciones sentimentales que establecen con miembros de los grupos armados son diferentes. Algunas buscan el poder y el reconocimiento en el entorno social, y otras con fines de captación para la consecución de dinero se articulan al negocio de trata de personas mediante el reclutamiento de adolescentes y jóvenes en las instituciones educativas. En ambos casos se presentan situaciones de violencia sexual y riesgo de niñas, adolescentes y jóvenes que no son denunciados por la "imposición estructurada del silencio” (Sánchez, 2011: 210).

La alteridad amenazante, como el otro generador de miedo, es el punto de culminación de las relaciones sentimentales, allí mediante actos de conquista que en este contexto están representados por regalos (MG, C1, marzo 9), salidas a bares y paseos, se van construyendo estrategias de sometimiento por parte del dominante, por medio de la violencia simbólica que ejerce (Bourdieu, 2000: 6).

"Es una relación de poder, igual que como tienen el arma, como tienen el control de la plaza, las tienen... las mujeres son cosas para ellos tener el control” (CO, C1, abril 10).

De allí que incluso se establezcan fijaciones de los miembros de grupos armados ilegales sobre niñas y adolescentes desde edades tempranas a las cuales van monitoreando constantemente y ejerciendo cierto tipo de presiones soterradas que en principio pasan desapercibidas hasta que se convierten en imposiciones tanto para los padres como para la niña y de las cuales las mujeres difícilmente logran desvincularse, otras incluso llegan a legitimar ese tipo de acciones por razones amorosas, justificando en razones sentimentales ese tipo de comportamientos: 
“Algunas se ven amedrantadas porque se enredan con ellos a nivel sentimental. Entonces cuando ya se quieren despegar no pueden porque son amenazadas: “iSi te conseguís otro, te hago daño!”. Las pistean, las llevan al colegio" (RO, C8, marzo 3).

En otros niveles y a partir de confianzas para lograr propósitos o fines ligados con el poder, se construyen relaciones que buscan desempeñar un rol que refleje niveles de poder en el entorno social, generalmente entre mujeres jóvenes, es así como inicialmente:

“... establecen con ellos contactos muy cercanos, de amistad, de ser la novia, de ser las mejores amigas, salir con ellos de rumba, de estar siempre en función de la diversión, de pasar bueno con ellos" (LR, $\mathrm{C} 1$, abril 25).

"Las chicas sí se dejan seducir por este poder porque no sé si ven en eso un estatus, una posibilidad de también ser temidas, porque el hecho más que estar con él, también es ser temidas y manejar cierto poder. Pero sí, hay un ejercicio en el que ellas se sienten importantes siendo la pareja del que manda" (RO, C8, marzo 3).

"Las chicas se están involucrando no solamente como parejas, sino que están ingresando en los aparatos delictivos, hacen de campaneras, son quienes guardan las armas, las entregan, las transportan de un lado a otro. Se están involucrando más, de una manera más pasiva dentro de toda la estructura, pero eso se ve cambiar todo el tiempo, de pronto ahora hay bandas de mujeres atracadoras y sencillamente hacen de su debilidad una fuerza, ellas son supuestamente las víctimas y terminan siendo las ladronas" (RO, C8, marzo 3).

En este contexto se generan también relaciones de poder que algunas mujeres utilizan para tener lugar a cierto prestigio y reconocimiento en el entorno inmediato, pero se convierte a su vez en una camisa de fuerza que limita sus formas de comportamiento, el precio de este reconocimiento prestigio es la subordinación total a la estructura patriarcal del miembro del grupo armado ilegal, buscar desmarcarse de éste tipo de situaciones puede conllevar en ocasiones a hechos de violencia sexual "ejemplarizante" que impongan el terror sobre las otras mujeres o transmitan el mensaje de control y dominación e incluso la muerte.

Los casos de violencias sexuales principalmente dirigidas a mujeres jóvenes ( $\mathrm{AG}, \mathrm{C} 8$, abril 24) llegan al punto de mayor incidencia en la representación de la inseguridad construida de quienes hacen parte de los grupos armados. Las posibilidades de ser víctimas de este tipo de delitos es una constante que ronda en tiempo y espacio. Algunas veces las han ubicado en la posición de 
espectadoras obligatoriamente pasivas, como lo relata una entrevistada que conoció un caso cercano de una mujer que fue testigo de un caso de violación en un sector de la C1P:

"Ella vio cuando entraron a la niña y que la niña estaba gritando, y empezó como a que la vieran, empezó a caminar de arriba para abajo para que vieran que ella los estaba viendo, como una especie de... ¿cómo se le dice a eso?, como una especie de alerta para ellos para que la soltaran o algo. Lo que hicieron los chicos que estaban cuidando ese suceso fue empelotarse, quitarse todos la ropa y decir: “¿Es que usted también quiere?, es que para usted también hay...”. Las mujeres adultas sienten mucho miedo de pasar por ahí, primero porque les ha tocado ver y no han podido hacer nada, porque siempre hay el que viola y los que vigilan, que nadie haga nada, pues es como el cordón que hacen. (LR, C1, abril 25). Y en el peor de los casos son asesinadas cuando no pueden violarlas" (CG, C8, feb. 29).

La pregunta que subyace ante esto es cómo evitar lo inevitable, cuando son estos comportamientos el patrón general que determina las relaciones de grupos armados y niñas, adolescentes y jóvenes ${ }^{92}$ en las comunas de la ciudad, que cada vez queda más en evidencia la "incapacidad creciente para ponerle freno a una espiral de violencia que encuentra su justificación en el temor a ese otro que amenaza la norma" (Reguillo, 2006: 39), pero que bajo el poder y el reconocimiento genera estrategias de legitimación en gran parte de la comunidad, que en muchos casos termina justificando los actos de violencia sexual, física y simbólica contra las mujeres.

Las acciones que ejercen los grupos armados ilegales en los territorios, no solo generan unas formas de control social y territorial, sin que consolidan su poder y dominio en el cuerpo de las mujeres el cual es objetivizado, primero como una fuente de ingresos en un negocio que cada vez se consolida más como es la trata de personas y segundo en las relaciones que determinan la subordinación de las mujeres ante la implementación de formas violentas para obtener obediencia y ante las cuales las formas de aceptación o las acciones de resistencia entran en juego.

Si bien los grupos armados ilegales como ya se vio en este apartado construyen representaciones de inseguridad para las mujeres a través de las formas de dominación y control, también es necesario destacara la existencia de los otros; los otros conocidos o desconocidos, establecidos o recién llegados, los otros que suelen ocupar el espacio público y no se reconocen como miembros de los

\footnotetext{
92 En el trabajo de recolección de información no hubo casos que dieran cuenta de violencia sexual contra mujeres adultas por parte de los actores armados ilegales.
} 
grupos armados ilegales, reconocidos legalmente como Fuerza Pública, Policía, o como pertenecientes a combos o bandas delincuenciales que históricamente han operado en el sector:

"Ver un grupo de jóvenes reunidos en la esquina que yo no los conozca me azara" $(\mathrm{CO}, \mathrm{C} 1$, abril 10); "Cuando yo veo gente extraña rondando de pronto por los lares del asentamiento donde yo estoy, de pronto gente que llega y se sientan...” (IQ, C8, feb. 16).

Los otros, son los extraños, porque sus rostros no son conocidos o familiares en la cotidianidad de habitar el barrio, los que alteran la "seguridad" del vecindario, de la comunidad, a la que ya se está acostumbrada, una seguridad garantizada por el cobro de vacunas por parte de los grupos armados ilegales, que implementan una forma de extorsión que se ha ido naturalizando y que "garantiza" que personas desconocidas no ingresen al barrio, en consecuencia, se puede llegar a la creencia de que hay menor probabilidad de riesgo, sin embargo esto es la forma de protección violenta o protección rackets (Bedoya, 2010: 51), donde los vecinos a quienes se dice proteger son sus clientes, sobre los cuales no se determina género ni condición social.

La existencia de hombres desconocidos genera mayor preocupación y cuestionamiento que los mismos miembros de los grupos armados ilegales ${ }^{93}$, cuyos actos de violencia han pasado a ser actos que se instalan en la cotidianidad de la vida de los barrios y comunas y que obedecen a un gueto voluntario, en palabras de Bauman (Zygmunt, B., 2003: 137). Los otros aumentan las incertidumbres y los temores, por tanto, son una amenaza que afecta la comunidad y en especial a las mujeres, quienes desconocen las nuevas formas de actuación y las violencias que traen consigo.

La exposición al riesgo ante la existencia de un extraño aumenta los niveles de incertidumbre, en tanto que se reconocen las violencias que sobre las mujeres ejercen los miembros de los grupos armados ilegales y los miembros de una misma familia, pero el extraño no se conoce y mucho menos de lo que puede ser capaz.

\footnotetext{
${ }^{93}$ Que en los barrios se posicionan como combos o bandas delincuenciales y adquieren nombres que los caracterizan y hacen reconocibles en el sector, no solo por parte de la comunidad en general sino incluso también por parte de la Fuerza Pública, es así como en la C1P se destacan: 1). "La Silla". 2). "El Hoyo de San Pablo". 3). "La 29". 4). "La Avanzada". 5). "Los Triana" *. 6). “La 38". 7). "Los Terranovas". 8). "El Filo". 9). "Los Chicos Malos" (de la vía a Guarne). 10). "La Torre" o "La 107". 11). "La Galera" (reducto). Y en la C8VH están: 1). "La Roja" *. 2). "La Libertad". 3). "La Mansión". 4). “Los Conejos"*. 5). "Los Praga". 6). "Villa Hermosa". 7). "13 de Noviembre". 8). "San Antonio". 9). "La Sierra" *. 10). "Villatina". 11). "Caicedo". 12). "La Cañada" o "Tres Esquinas". 13). "Las Granjas". 14). "La Torre". 15). "La Bombonera". 16). "La Arenera". 17. "Morro Chispas". 18). "Los Negritos". (El inspector: 2014).
} 
Este contexto asociado a las formas de dominación y control por parte de grupos armados ilegales constituye un escenario importante para la representación de la seguridad/inseguridad de las mujeres en las comunas de estudio en tanto su existencia es un fenómeno ligado al conflicto armado urbano que ha vivido la ciudad. Sin embargo aunque este es el común denominador de ambas comunas sería errado plantearlo dejando la idea de mujeres víctimas y pasivas, por el contrario esto ha hecho que algunas mujeres también consoliden acciones como se verá en el apartado siguiente que contribuyen de manera concreta a la representación de seguridad.

\subsection{Capital Social y Problemáticas Sociales, ¿construyen las representaciones?}

Como hemos visto en el transcurso del capítulo, se han logrado identificar diversos aspectos que inciden en la representación de seguridad/inseguridad de las mujeres, algunos asociados a la construcción del género durante su trayectoria personal, del cual se desprende además la relación que se establece en la familia y en las funciones asignadas a los miembros que la constituyen, como también la representación asociada a la institucionalidad garante de la seguridad de la ciudadanía como en este caso es la Fuerza Pública, y a la existencia de grupos armados ilegales que predominan en la ciudad de Medellín y específicamente en las comunas donde se centra el estudio.

Es necesario ahora dar cuenta de otros aspectos sociales que inciden en la construcción de las representaciones que tienen las mujeres sobre la seguridad. Para ello hemos construido dos categorías de análisis. La primera la tomamos de la noción de Capital Social propuesta por Bourdieu (1986). Con ella queremos aprender la trama organizacional de las comunas, los recursos sociales, reales o potenciales, con los que cuenta una comunidad para encarar y resolver determinados conflictos. El Capital Social es el resultado de las relaciones sociales que establecen sus miembros entre sí. A mayor sociabilidad, mayor Capital Social. Los contactos se multiplican si la vida cotidiana se vuelve fluida. Por el contrario, cuando la vida cotidiana se retrae, el Capital Social disminuye. Estas tienen que ver con el conocimiento de las personas que habitan el territorio y las organizaciones sociales y comunitarias existentes.

La segunda categoría de análisis la llamaremos Problemáticas Sociales. Con esta queremos aludir a las acciones que ejercen las personas en lugares o territorios determinados que tienen la capacidad de alterar las relaciones sociales, conllevando con ello a situaciones que afectan la seguridad de las personas, incluyendo en este marco de situaciones las condiciones económicas de las mujeres. 
El Capital Social que se identificó está vinculado a los procesos organizativos existentes ${ }^{94}$, ya que desde allí se fortalece el trabajo comunitario enfocado en la comunidad en general y de manera específica hacia las mujeres. En este sentido hay una marcada diferencia entre ambas comunas. De una parte, en la C1P existe un referente de más de una década de un grupo de mujeres denominado Coordinación de Mujeres de la Zona Nororiental ${ }^{95}$, que aparece en las entrevistas realizadas a algunas de las participantes, tanto pertenecientes o no al mismo.

Por su parte, en la $\mathrm{C} 8 \mathrm{VH}$, los procesos de organización del movimiento social de mujeres son aún incipientes, y son promovidos por iniciativa de la Secretaría de Mujeres con el objetivo de crear Colectivos de Mujeres en todas las comunas, pero sin dar cuenta de una continuidad en el proceso, lo cual ha generado posiciones encontradas frente al asunto:

"Está dividido el concepto, algunas quieren que la Secretaría esté constantemente ahí con el tema de los recursos y de la profesional, y otras desean que el colectivo sea autónomo, de la comuna, y que no tengan ningún logo [...] Pero es bastante interesante que la mitad del grupo piense que pueden andar solitas" (LR, C8, feb. 24).

De otra parte, en esta misma comuna hay una apuesta interesante de un club de lectura de mujeres denominado Litera, que desde ejercicios de lectura feminista motivan la reflexión sobre el género, especialmente con mujeres jóvenes.

Frente al trabajo organizativo de base, en ambas comunas hay trabajos enfocados a los planes de desarrollo local ${ }^{96}$ y la participación que han tenido las mujeres en él, así como la incidencia en el desarrollo de las líneas temáticas que se han promovido desde un enfoque diferencial:

\footnotetext{
${ }^{94} \mathrm{Si}$ bien es importante reconocer que en la comuna existen otras formas de organización de mujeres que pueden estar ligadas a estructuras religiosas, comunitarias o políticas, nos centraremos en aquellas que aparecieron en las respuestas de las entrevistadas.

${ }^{95}$ Este grupo se consolida hace aproximadamente 15 años como un espacio para el manejo y la elaboración de duelo. Denominado inicialmente Semillas de amor, allí las mujeres que participaban eran quienes a causa del conflicto de los 80 y 90 habían perdido un familiar o una persona cercana. Estas mismas mujeres, en su mayoría de la tercera edad, son quienes lo componen en la actualidad.

${ }^{96}$ Los planes de desarrollo local son los documentos que exponen las necesidades más sentidas de las comunidades, son ejercicios realizados por las mismas comunidades donde se proyecta el trabajo a realizar en un periodo de 10 años.
} 
"Un plan de desarrollo que se elaboró fue con las necesidades de las comunidades. Se elaboró con líderes de la comunidad, se elaboró fue con personas que están pantaniando, que tienen hambre, que no tienen energía, que no tienen luz" (IQ, C8, feb. 16).

A partir de allí se han generado procesos identitarios y de pertenencia en los territorios, además de consolidar espacios de participación de hombres y mujeres. Pese a ello aún falta mayor sensibilidad frente al tema de las mujeres, desde las mismas mujeres que hacen parte de las juntas comunales, y eso sin duda genera gran preocupación porque,

“...en la junta administradora local quedó una mujer que tampoco se reconoce como mujer y los demás hombres reconocen que hay un proceso en la comuna, pero no conocen del tema ni tampoco lo defienden y muy seguramente no lo apoyarán” (LR, C8, feb. 24).

Ser conscientes de estas limitaciones sin duda da cuenta de un paso inicial en los procesos que pueden conllevar a ejercicios de reflexión más profundos sobre los problemas que afectan a las mujeres en estos sectores de la ciudad. Si bien aún no alcanzan a resolver problemas de convivencia y a generar estrategias alternativas de resolución de conflictos, sí cuestionan otras formas de solución de conflictos que legitiman el accionar de los grupos armados o las confrontaciones armadas:

"La convivencia aquí no es que sea muy buena que digamos, entonces no se sabe qué es más difícil, si uno tener esta convivencia que hay acá en Los Mangos o que nos estemos dando bala. Mirá que es silencioso pero a la vez... claro que no pasa pues de amenazas y todo eso.” (AG, C8, abril 24).

Este entorno cercano aún no satisface la necesidad de seguridad, mucho menos cuando al interior de las mismas comunidades se generan situaciones de inseguridad, que ante la debilidad institucional reinante y los aprendizajes propios, establecen la forma en que se resuelven los conflictos en la lucha por la supervivencia generalmente mediante expresiones de violencia y abuso del poder, en condiciones tan hostiles en las que pareciera que mostrar signos de debilidad justificaran la derrota (Zygmunt, B., 2003: 133).

Sin embargo, otras formas de lucha por la supervivencia han generado transformaciones importantes, en especial para las mujeres adultas, quienes desde su experiencia personal difieren del comportamiento de otras, especialmente de mujeres jóvenes, pero reconocen también que es una etapa de grandes transformaciones socioculturales, con una circulación de imágenes que matizan los 
discursos y los comportamientos influenciando sobre todo a niños, jóvenes y mujeres (Reguillo, 2002: 73), desde donde además se abren otros campos y posibilidades a las mujeres:

"Eso les ha abierto la mente a que ellas no dejen que se les vulneren sus derechos y saber que ya no son solo para la cocina, para atender un marido. Ya tienen más posibilidades en lo académico y en lo laboral" (CM, C1, mayo 11).

"Ya saben que ellas no están oprimidas" (CG, C8, feb. 29).

Pero también hay que destacar la incidencia que tiene la información en el comportamiento de las mujeres. Algunas entrevistadas consideran que el alto flujo de información a la que han accedido las ha puesto más arriesgadas ( $\mathrm{AG}, \mathrm{C} 8$, abril 24) porque logran avanzar en la apropiación de los espacios, de sus cuerpos de las mujeres ( $\mathrm{CO}, \mathrm{C} 1$, abril 10), pero a su vez puede convertirse en un sinónimo de peligro porque pueden aprovecharse de esa apertura y generar abusos justificados en esas actuaciones (AG, C8, abril 24) trasgrediendo el ejercicio de sus derechos y de las demás, porque pueden ser acciones que sobrepasan los límite de lo que las mujeres han aprendido. De esta manera pueden exponerse de una manera más abierta al peligro, ya que aunque la experiencia personal las haya abocado a un mundo de conocimiento y conciencia de derechos, la sociedad en general no ha asumido los principios de equidad e igualdad de hombres y mujeres.

El Capital Social acumulado en los entornos sociales con los cuales se afirma la conciencia de género en algunas mujeres, se convierte en una Problemática Social que las coloca en riesgo, pues constituyen una amenaza para la estructura patriarcal, porque atentan con los comportamientos históricamente aceptados de las mujeres, confrontar los grupos armados ilegales a través de manifestaciones como "Mi cuerpo es mío" o "ser mujer antimilitarista", trabajar para el fortalecimiento del ejercicio de derechos de las mujeres en sus comunas, confrontar los actos de corrupción y connivencia de la Fuerza Pública con los grupos armados ilegales entre otras, y que son interpretados por las personas como formas de pensamiento y acción "diferentes" como lo expresa una de las entrevistadas:

"Precisamente por las diferencias de pensamiento, entonces me he sentido muchas veces atemorizada, amedrentada, mucha gente se me ha venido encima solo por pensar distinto" (MG, C1, marzo 9). 
Y es allí en las acciones que promueve el Capital Social cuando los efectos duraderos del orden social que ha imperado sobre las mujeres desde la violencia simbólica (Bourdieu, 1999: 225) salen a la luz y cuestionan sus comportamientos y justifican los actos de agresión hacia las mismas. "Una mujer sola en la noche es vetada y estigmatizada" (CM, C1, mayo 11) y aumentan no solo las inseguridades en tanto que,

“...no tenemos como una vida plena, una vida segura, todavía seguimos siendo inseguras porque todavía hay patriarcados, eso todavía no se ha acabado y eso siempre va a estar como ahí, la inseguridad de las mujeres siempre van a estar ahí" (CG, C8, feb. 29).

Pero ello no logra acabar con el Capital social que se ha consolidado en el transcurso del tiempo, por el contario el aprendizaje adquirido, el "tener conciencia", las ayuda a identificar mejor los riesgos a los que están expuestas, a mirar en mayor detalle su entorno y a no naturalizar las violencias que siempre están presentes en su vida cotidiana y que no son fácilmente percibidas por la sutileza con que ellas ocurren.

Como se dijo antes, las Problemáticas Sociales están determinadas por las acciones que ejercen personas en determinados lugares y que logran alterar las relaciones sociales, pero también inciden en ellas las condiciones económicas. Es así como las posibilidades de ingreso económico con que cuentan las mujeres en una ciudad evidencia altos niveles de desigualdad ${ }^{97}$, que como ya se vio en el capítulo 1, no son ajenos a los sectores donde se hace la investigación y se refleja en las fuentes de ingreso de quienes habitan estos sectores. De allí que las representaciones de seguridad/inseguridad también estén mediadas por los recursos que disponen para la satisfacción de sus necesidades básicas para una vida digna:

"La falta de una economía o sea de un sustento económico para un cierto hogar también está generando inseguridad porque una madre de ver que sus hijos o un padre de ver que sus hijos tienen hambre que no tienen nada que echarle a la olla, de ver que no tiene un trabajo si a este o sea si en un momento de desesperación vienen a este señor y le dicen ve vamos a hacer tal cosa vamos a hacer tal daño él en su desespero puede acudir a hacer lo que no quería pero por qué? por sus hijos” (IQ, C8, feb. 16).

\footnotetext{
${ }^{97}$ De acuerdo con la Misión para el Empalme de las Series de Empleo, Pobreza y Desigualdad (Mesep), la capital antioqueña es la que registra la mayor desigualdad del país, con un coeficiente Gini de 0,53. Adicional a esto, según Isvimed (El Instituto Social de Vivienda y Hábitat de Medellín) las comunas 1 y 8 se encuentran entre los puntos más críticos de pobreza y vulnerabilidad, junto con la comuna 3.
} 
Estas limitaciones en el ingreso económico y la falta de oportunidades laborales median para que algunas mujeres se expongan a situaciones de riesgo que vulneran sus derechos:

"La mayoría de las chicas a las que las están insertando en esos asuntos tienen hermanos menores y eso es otra menores que ellas, $[\ldots]$ uno se pone a mirar y ellas dicen no es que mi hermanito no tiene por qué salirse de estudiar, porque mi mamá no tiene con que darle el estudio, yo tengo que hacer algo. Entonces ese no saber qué va a pasar con mi hermano no va a poder estudiar, si yo no algo mi mamá no tiene con qué. $\mathrm{Y}$ otro asunto y bien grave es que es que hay mujeres que ni siquiera tienen la posibilidad de decidir, sino que tienen que hacer lo que otros dicen porque ese cuerpo ya lo negociaron. $\mathrm{Y}$ es que las que ya han vivido la experiencia, ellos las contratan para que traigan a otras, entonces a la que ven que es muy seriecita que es muy callada entonces se hace amiga de la otra a esa le pagan para que se haga amiga de ella porque también si no lo hace también corre mucho peligro su vida" (DQ, C1, feb. 13).

Incluso el vincularse con miembros de los grupos armados se convierte en una estrategia para salir de la pobreza:

"El llamativo de las motos, que ese es el vacán, ese es el que da, el que me da la plata, el que esto, muchas veces es también debido a la pobreza, a la necesidad que tienen en la casa, muchas veces eso es también lo que genera" (AG, C8, abril 24).

Lo anteriormente expuesto sobre el control territorial se convierte en una constante como Problemática Social, tal como lo expresa claramente una de las entrevistadas:

"La situación de la comuna es muy compleja por el tema. Puede que la presencia de los grupos sea socialmente problemática en los relacionamientos y las relaciones de amistad que uno genere y lo pongan a uno en riesgo, pero igual los enfrentamientos que hay en la comuna, todo el tiempo te van a poner en riesgo, el pasar entre fronteras, entre un barrio y el otro, ese es un tema de inseguridad indiferente de quiénes son tus amigos, de pronto con las amistades uno puede decir: "Yo llamo y si algo pasa...", pero eso nunca va a evitar que vos estés en una situación de riesgo como las que se presentan ahora." (RO, C8, marzo 3).

Esto da cuenta de que si bien hay un Capital Social que ha logrado consolidarse, desde el cual se establecen unas relaciones que promueven y buscan garantizar el derecho de las mujeres a una vida libre de violencias y se generen las condiciones para que se sientan seguras en sus territorios, la 
Problemática Social existente que pasa por el accionar de grupos armados ilegales que ejercen formas de control no solo sobre el territorio sino también sobre el cuerpo de la vida de las mujeres; las características socioeconómicas que prevalecen de pobreza y exclusión; así como el orden social dominante que se instaura bajo las formas de subordinación de la mujer, generan un brecha cada vez más distante para que las representaciones de inseguridad disminuyan.

Para concluir este capítulo es importante poner en consideración el aprendizaje de los miedos que median las relaciones sociales y familiares de las mujeres, de los cuales el Estado en lugar de generar garantías a las mujeres en el ejercicio libre de su derecho a una vida libre de violencias que les permita estar seguras, se vuelve cómplice y se convierte a su vez en una fuente adicional de inseguridad en el mismo nivel que los grupos armados ilegales que operan en los territorios de estudio. Sin duda desde las relaciones sociales y personales que las mujeres establecen están las bases para que su seguridad sea una realidad dotada de sentido.

El aprendizaje que se instala desde la estructura patriarcal que determina los roles y funciones que se asignan a hombres y mujeres, se enmarca en espacios diferentes asignando la connotación de seguro a la esfera privada o doméstica a las mujeres con un alto precio que son los límites a la movilidad y al acceso, uso y disfrute de los espacios públicos, como se verá en el siguiente capítulo. 


\section{CAPITULO III}

\section{ESPACIOS DE INSEGURIDAD Y MIEDO}

La perspectiva de género aplicada a la ciudad significa mucho más que tomar en cuenta a las mujeres y reconocer su existencia:

implica detectar y analizar las diferencias (no biológicas, sino sociales y culturales) entre hombres y mujeres, así como las relaciones de poder entre los géneros.

Es una forma distinta de mirar y pensar los procesos sociales, las necesidades y demandas, los objetivos de la planificación del desarrollo urbano. Massolo, 2007. 
En este capítulo se describe la relación que establecen las mujeres de las Comunas Uno (C1P)Popular y Ocho -Villa Hermosa (C8VH) con los espacios públicos de comuna ${ }^{98}$ y de ciudad, a partir de un análisis de espacio. Los lugares de encuentros pero en ocasiones ajenos y extraños por las personas que transitan, los usos que hacen del espacio denominado como público y su disfrute y acceso a ellos. Territorios que ratifican la tradición que demarca un uso diferenciado de hombres y mujeres denotando tiempo, modo y lugar, plasmando allí una segregación espacial marcada por el género. Así mismo se analizan los entornos de ciudad, comuna, barrio y casa, y la manera como estos se configuran y re configuran en las trayectorias personales y sociales, a partir de las cuales han construido las representaciones de (in) seguridad demarcadas por fronteras que, invisibles o no, reducen o amplían las posibilidades de movilidad en el territorio.

Algunos factores describen aspectos históricamente inherentes al territorio que lo caracteriza y aquellos que se han ido transformando en el tiempo incidiendo negativamente en la seguridad de las mujeres. En particular nos interesan los que están relacionados con los hechos que han dotado de un significante negativo a algunos lugares de la ciudad, por lo que en consecuencia se censura o limita su tránsito, debido a que marcan la memoria de las mujeres con las violencias que contra ellas se han generado y que han sido difundidas por diferentes medios y de distintas maneras.

La ciudad es un universo complejo atravesado por diversos estilos de vida, donde se puede reconocer la concepción que tienen hombres y mujeres de sí mismos/as y sobre los otros/as, la cual es, aprehendida por los ámbitos sociales y culturales. En este estudio, conceptos como urbs, civitas y polis, que desarrolla De Manuel (2010), son importantes para comprender el contenido de las representaciones de seguridad desde la perspectiva de género que se conjugan en la ciudad vivida y alimentan dos de las cuatro categorías de análisis Geoespacial y Socioespacial.

En primer lugar con la urbs, se identifican las condiciones físicas (mobiliarios, arquitectura, infraestructura y extensión), que nos permitirá pensar cuáles son los criterios que orientan los ejercicios de planificación de las ciudades y que se analizan bajo la categoría Geoespacial. En segundo lugar el civitas, la raíz de la civilización que se expresa a partir de la producción social, cultural y la producción económica, que nos posibilitará explicar las estructuras de la sociedad y las

\footnotetext{
${ }^{98}$ Es importante tener presente que la Comuna Uno - Popular cuenta con 333.04 hectáreas para 116.312 habitantes, lo que implica una densidad de 349 personas por hectárea, mientras que la Comuna Ocho - Villa Hermosa tienen 577.7497 hectáreas para una población de 139.725 personas para una densidad de 241 personas por hectárea.
} 
relaciones marcadas por el género. Finalmente la polis, donde se establecen las relaciones de poder, así como el ejercicio de los derechos y las libertades públicas, que conlleva a entender los espacios públicos de participación política y el rol que las mujeres desempeñan en ellos (De Manuel Jerez, 2010: 16). Estas dos últimas aportan insumos importantes para el análisis para la lectura de la categoría socioespacial ya que desde esta concepción de lo público, se han generado los puntos de tensión para un acceso equitativo en el ejercicio de la ciudadanía para hombres y mujeres.

Teniendo en cuenta estos tres conceptos es posible explorar las formas de violencia y de inseguridad, en tanto como problemática alcanza de manera no siempre visible a las políticas urbanísticas, las relaciones sociales y de género, reduciendo los campos de acción, aumentando los riesgos de inseguridad e impactando los usos y costumbres del espacio tradicionalmente conocido como público, obligando a que sea lo cerrado la representación de lo seguro, porque lo abierto expone al ciudadano/a una violencia incontrolable (Kaminsky, 2005: 22).

Desde la colectividad que constituyen los seres humanos hay circunstancias que demandan una lectura diferenciada de estos tres conceptos Urbs, civitas y polis. Un ejemplo de ello es la forma en que hombres y mujeres desde sus universos simbólicos se apropian de los espacios de ciudad, que ha conllevado a que desde los movimientos feministas se demande el reconocimiento de las diferencias, pero no en un plano de desequilibrio y desigualdad como ha sido la constante en los procesos de planificación propuestos con un sesgo masculino (Massolo, A., 2007: 6), sino equitativo en tanto oportunidades como sujetas de derecho en todos los ámbitos.

Tradicionalmente, la ciudad se organizó desigualmente. La mujer y el hombre no ocupaban los mismos lugares, no podían estar de la misma manera en la ciudad. Los horarios eran diferentes, pero también los itinerarios. Ya en la antigua Grecia existía una concepción de ciudad en relación al cuerpo humano, donde los espacios urbanos eran concebidos y asimilados de acuerdo a la diferenciación de derechos y estos a su vez coincidían con la división de los sexos, en cuanto que los cuerpos poseían diversos grados de calor, de ahí que se pensaba que las mujeres eran versiones frías de los hombres, por lo tanto ellas no podrían andar por la ciudad, lo que las llevaba a permanecer en las casas, como si este fuera su lugar de pertenencia por naturaleza. Por su parte, los hombres se identificaban con lo cálido y lo activo, lo que los ubicaba en una posición de dignidad y superioridad frente a las mujeres, conllevando con esto a la contrastación de lugares dentro de la sociedad, ubicando al hombre como único portador de la condición de ciudadano (Sennett, R., 1994: 47) y en consecuencia sujeto del derecho de habitar y transitar la ciudad. 
Esta situación se ha manifestado como una consecuencia de una larga historia social que tiene sus cimientos en la exclusión de los espacios de participación en la racionalidad griega, el señalamiento de la mujer en el judeo cristianismo, su segregación en el siglo de las luces y la revolución francesa, hasta las disputas actuales por el reconocimiento y la reivindicación de sus derechos. Esto además de la historia personal, que se establece en los procesos de aprendizaje en las trayectorias espaciales $\mathrm{y}$ en las relaciones sociales, laborales $\mathrm{y} / \mathrm{o}$ emocionales.

Si bien los conceptos de urbs, civitas y polis son importantes en tanto nos permiten entender la manera como se establecen las relaciones sociales entre hombres y mujeres, encontramos dos categorías que son centrales para pensar la relación entre ciudad e inseguridad. La noción de espacio, es un eje central en la estructura de éste capítulo. El espacio se construye por elementos reales y simbólicos desde los cuales la alteridad amenazante devela una relación de riesgo en donde interactúan campos de sentido compuestos por los lugares de mayor o menor tránsito, las practicas que allí se realizan y las acciones de sociabilidad urbana que se establecen. En la noción de espacio hay que distinguir a su vez tres dimensiones, con las cuales se negocia su inclusión: 1) el cuerpo, autonomía, derechos reproductivos y sexuales, la maternidad y la oposición a la violencia y a la opresión sexual, vinculada además a la comunidad y el espacio público, mediador de experiencias de relaciones sociales y culturales vividas; 2) el hogar, identidades y roles sociales y políticos que giran en torno al espacio privado y público; 3) el medio ambiente, que se convierte en el entorno cotidiano, la infraestructura de la ciudad y la comuna, y es especialmente sobre esta última que éste análisis hace referencia.

El espacio público, y en términos generales, la calle, el afuera, la exteriorización de los espacios que circundan la casa, es lo que por antonomasia define la ciudad en sí misma; allí donde se establecen, de manera diferenciada, técnicas, prácticas y símbolos que la organizan, transforman espacial y temporalmente, en ella interactúan los seres humanos de acuerdo a las exigencias de cada situación (Delgado, 1999: 36).

Estos espacios, representan certezas y seguridades otorgadas por un referente simbólico que se construye a través de redes y relaciones de sentido (Lindon, A., 2007) en las que si bien los objetos que conforman el lugar tienen cierta autonomía entre sí, "no tienen autonomía de significados pues cada día nuevas funciones sustituyen las antiguas" (Santos, M., 1996: 51), también varían de acuerdo al género, pues es evidente que el espacio difiere entre hombres y mujeres de acuerdo a los 
usos y prácticas que en él se realicen. Además hay una fuerte importancia en la dimensión espaciotiempo, lo cual es el resultado de la multiplicidad de dinámicas que se configuran en una sociedad donde las relaciones de género están claramente establecidas, lo que conlleva a que los espacios domésticos, públicos, ya sea de barrio o de ciudad, se conjuguen de distintas maneras con el tiempo (Vargas, 2007: 48).

Esta relación de las mujeres con los espacios de la ciudad contiene una dimensión analítica, que es la conciencia del peligro, desde las cuales se construyen las representaciones, allí tal como lo manifiesta Reguillo el peligro disminuye o aumenta, según el grado de conocimiento del territorio, generando entonces más seguridad frente a lo conocido y más inseguridad con lo desconocido (Reguillo, 2002: 74). Esta interpretación de la realidad espacial de la ciudad se constituye inicialmente mediante elementos externos que posteriormente se interiorizan (Berger y Luckman, 1986: 170) y se refuerzan en las trayectorias personales, que bajo ciertas condiciones transforman el sentido común.

En la búsqueda de estas representaciones espaciales de (in) seguridad en la ciudad, se construyeron para este estudio cuatro subcategorias de análisis que se aplican en la variable de ciudad y de comuna, las cuales fueron identificadas en las 13 entrevistas, que se complementaron con un ejercicio gráfico en los cuales se establecían puntos de relacionamiento con espacios de ciudad y comuna donde los trazos de cercanía permitieron la construcción de los atributos que se exponen en el cuadro de análisis, expresados de manera positiva o negativa y algunos umbrales que no se identificaron como seguros o inseguros se establecieron como zonas neutras por parte de las entrevistadas.

Las representaciones de (in) seguridad que las mujeres entrevistadas han construido con relación a espacio, coinciden con los datos reportados de diversas instituciones (Defensoría del Pueblo, 2013; Personería de Medellín, 2013) encargadas de trabajar en el tema de seguridad y derechos humanos y con el análisis de prensa. Las situaciones de mayor relevancia que afectan la seguridad de las mujeres están ubicados en su mayoría en sectores de la Comuna 10 - La Candelaria, la cual tradicionalmente ha sido el centro de la ciudad donde convergen distintas actividades y dinámicas de ciudad como comercio, transporte público, entidades bancarias, entre otras.

De estas respuestas se precisaron las siguientes subcategorías: 1) socioespaciales, 2) geoespaciales, 3 ) institucionales y 4) emocionales con sus respectivos atributos, desde los cuales se plantean una 
serie de relaciones articuladas o desarticuladas por las características que definen los espacios y que encierran todo el sentido de apropiación, pertinencia y/o negación de las personas con ellos en la ciudad que, con base a los hallazgos, es posible determinar de la siguiente manera:

a. Socio espaciales: en ella se consideran las condiciones sociales que determinan los lugares, de acuerdo a atributos particulares como son los actores sociales que allí se destacan, las dinámicas sociales que se realizan y la tendencia del estrato socioeconómico. Atributos: actores sociales, dinámicas sociales y estrato o clase social.

b. Geo espaciales: estas están determinadas por unas condiciones físicas del lugar en las que se incluyen atributos relacionados con la disposición física (infraestructura), el entorno, la infraestructura vial y la temporalidad de sus usos. Atributos: disposición física del espacio, entorno, infraestructura vial y temporalidad.

c. Institucionales: Se caracterizan porque su acceso y uso de lugar está determinado por la presencia de instituciones de distinta índole entre las que se encuentran, las religiosas, educativas, estatales o públicas y las privadas. Atributos: públicas y privadas.

d. Emocionales: se establecen de acuerdo a una experiencia vivida o por algún hecho social negativo o positivo que haya ocurrido en un lugar determinado de la ciudad y que haya incidido notablemente sobre una sociedad determinada, aquí imperan las relativas al miedo, seguridad, inseguridad o libertad. Atributos: seguridad, in seguridad, miedo, libertad.

\begin{tabular}{|c|c|c|}
\hline \multicolumn{3}{|c|}{ Variables y atributos en la representación de (in) seguridad } \\
\hline Subcategorias & \multicolumn{2}{|l|}{ Atributos } \\
\hline \multirow{8}{*}{ Socio espaciales } & \multirow{3}{*}{ Actores sociales } & Transeúntes \\
\hline & & Residentes \\
\hline & & Temporales \\
\hline & \multirow{4}{*}{ Dinámicas sociales } & Culturales \\
\hline & & Deportivas \\
\hline & & Recreativas \\
\hline & & Educativas \\
\hline & \multicolumn{2}{|c|}{ Estrato o clase social } \\
\hline \multirow{6}{*}{ Geo espaciales } & \multirow[t]{2}{*}{ Disposición física del espacio } & Equipamiento \\
\hline & & Aseo \\
\hline & \multicolumn{2}{|l|}{ Entorno } \\
\hline & \multicolumn{2}{|c|}{ Infraestructura vial } \\
\hline & Temporalidad & Día \\
\hline & & Noche \\
\hline \multirow{6}{*}{ Institucionales } & \multirow[b]{3}{*}{ Públicas } & Educativas \\
\hline & & Salud \\
\hline & & Justicia \\
\hline & \multirow{3}{*}{ Privadas } & Religiosas \\
\hline & & Educativas \\
\hline & & Salud \\
\hline & \multicolumn{2}{|l|}{ Seguridad } \\
\hline
\end{tabular}




\begin{tabular}{|l|c|}
\hline Emocionales & In seguridad \\
\cline { 2 - 2 } & Miedo \\
\cline { 2 - 2 } & Libertad \\
\hline
\end{tabular}

Tabla 5. Relaciones y atributos del espacio.

Fuente: Elaboración propia.

A partir de estas definiciones se construye la estructura del texto partiendo de una lectura macro de ciudad en donde la segregación espacial es un elemento importante desde el cual se interpretan las relaciones de género existentes y su articulación con el espacio, hasta llegar a los escenarios cercanos como comuna y barrio desde los cuales las fronteras invisibles determinan las representaciones asociadas con los factores y condiciones expuestos en el capítulo anterior. Finalizando con el análisis de los medios de comunicación y la manera como abordan los hechos de violencia contra las mujeres que acontecen en la ciudad. Información que sin lugar a dudas refuerzan las representaciones de la seguridad/inseguridad de las mujeres y que tal como lo plantea Surette "los delitos que dominan la conciencia pública y los debates políticos no son los más comunes sino los más raros" (1994: 131. Citada en Madriz, 2001: 140) aunque las violencias sean diversas y ocurran en la cotidianidad, las que despliegan los medios de comunicación se convierten en los referentes inmediatos del espacio.

\subsection{La ciudad, lo urbano, el centro... lo ajeno, lo extraño...lo distante}

La ciudad constituye un punto de encuentro en donde convergen diversos aspectos en una sociedad, allí se establecen diferencias que permean todas las áreas o ámbitos de interés de las personas, estos van desde lo político, social, cultural hasta lo familiar etc., las cuales funcionan de la misma manera y con la misma lógica. Sin embargo las particularidades están dadas por los actores o "agentes" que en ellas intervienen (Bourdieu; 2007). Como dice Augé "la organización del espacio y la constitución de lugares, son las apuestas y modalidades prácticas colectivas e individuales" (2000: 57), eso significa que los espacios y lugares de la ciudad son marcados por las actividades y dinámicas que en él se desarrollan, en su mayoría por los conglomerados sociales.

En los últimos 10 años la ciudad de Medellín se ha ido transformando para responder a las demandas que la globalización exige, bajo un criterio construido de urbanismo social, enfocado principalmente en los territorios reconocidos tradicionalmente como marginados y con menos desarrollo, buscando intervenirlos física y socialmente. Asunto que se convierte en un campo de controversia entre quienes legitiman la propuesta y quienes deciden marginarse de ella buscando otras perspectivas de ciudad $\mathrm{y}$, por qué no, de modus vivendi que son difíciles de integrar y 
controlar, toda vez que a partir de allí buscan resistir a las formas de dominación frente a los modelos impuestos de los usos de los espacios, ya sea a través de comportamientos que contradicen lo establecido o la negación de la utilización de los mismos. Incluso algunas de estas transformaciones importantes se han implementado so pretexto de que las mujeres se sientan más seguras:

\footnotetext{
"La ciudad está pensada para que las mujeres estén más seguras en la ciudad, yo siento que claro que la infraestructura si ha cambiado y la ciudad se ve muy distinta. La ciudad hay lugares en los que se ve muy agradable, y hay lugares en que se ve muy saturada, hay lugares en que a uno no le provoca estar" (LR, C1, abril 25).
}

Pero también con una clara transformación de ciudad industrial a ciudad de servicios, con nuevos equipamientos y amoblamientos, que le dan un gran vuelco a su infraestructura con el fin de satisfacer su nueva proyección.

Estas transformaciones marcan en el campo de las representaciones sociales unas respuestas activas o pasivas que median en el uso de los espacios. Algunas mujeres dejan de lado los factores negativos como una estrategia para contrarrestar la inseguridad que les genera pero a la vez, porque supeditar las trayectorias o los recorridos a la inseguridad que les genera implica desperdiciar las ventajas que trae el acceso a lugares como bibliotecas y parques, y dejar que el miedo domine sus vidas (Madriz: 2001).

Aunado al proceso de transformación de la ciudad, las medidas de seguridad que se han venido implementando, por ejemplo con la proliferación de cámaras de vigilancia, inciden no siempre positivamente, en la manera como son apropiados los espacios, ya que crean la sensación de estar en un panóptico puesto que las personas son constantemente vigilados/as. Estas medidas de seguridad generan controversia en tres sentidos: el primero porque a algunas mujeres pueden generarles seguridad y en consecuencia mayor tranquilidad para el acceso y uso de los escenarios de ciudad. En el segundo porque están las mujeres que se niegan a dejar de acceder a estos espacios leídos como espacios de control y vigilancia, dejando de lado este factor negativo, porque ponen en riesgo también el ejercicio de sus libertades para acceder al espacio público. Tercero, están las mujeres que por el contrario, son renuentes a continuar accediendo a esos escenarios, conllevando a 
un distanciamiento con algunos lugares de la ciudad, especialmente en aquellos frecuentados por población joven.

"Con el perio" 99 también pues con las cámaras mucha gente que dejo de caer, porque sentían ese espacio tan de ellos tan bacano para ir a conversar a charlar a hacer sus cosas pero con las cámaras todo el mundo como que pereza uno sentirse vigilado todo el tiempo o sea es como mero cambio, entonces siento que para algunas personas puede ser ese espacio para entrar y para apropiarse de él pero en otras no" (MG, C1, marzo 9). "Uno se siente es como más que conforme con la ciudad uno se siente es como perseguido, observado, vigilado, en la ciudad y yo siento que esa es una estrategia también par que las personas no lleguen a muchos espacios de la ciudad, que supuestamente son espacios abiertos para la ciudad, pero cerrados, pues yo los concibo como espacios cerrados porque no todo mundo puede estar ahí" (LR, C1, abril 25).

Algunos espacios impregnan la ciudad de sellos característicos que la determinan y le crean una identidad mediada de actos y/o símbolos. En estos espacios se concentran grupos o conglomerados sociales que invitan a la dispersión por las variadas actividades que allí se desarrollan. Esto, si bien genera propuestas identitarias alrededor de un espacio por las actividades que allí se llevan a cabo, promueve a su vez acciones segregacionistas y de exclusión hacia quienes no comparten o representan dicha identidad. La ciudad, entonces, se va conformando de acuerdo a los usos de los espacios, no es una estructura orgánica mediada por determinados comportamientos o relación de los sujetos entre sí y hacia el espacio, aquí no opera la identidad sino la necesidad de tránsito y movilización.

Así mismo, la relación espacio-tiempo, tiene una fuerte carga establecida por los parámetros de un aprendizaje cultural en el que, y tal como afirma una de las entrevistadas:

“...Nos han enseñado que por una calle oscura es muy miedoso pasar o que por una calle estrecha es muy miedoso pasar, cierto? le sale a uno el coco por ahí cierto eh desde pequeñas nos metieron muchos miedos cierto fuimos criadas en una cultura de tenerles que tener miedo a todo a la sombra así sea de un perro" (DQ, C1, feb 13).

\footnotetext{
99 Así se le denomina coloquialmente al Parque del Periodista, un lugar del centro de la ciudad frecuentemente transitado por población joven, pero además reconocido por el tráfico y consumo de sustancias sicoactivas.
} 
De ahí que siempre la relación de las mujeres con la noche este marcada por la inseguridad y el peligro, pues desafía los cánones temporales impuestos por la sociedad. Pero que es imposible evitar ya que en muchos casos forma parte de las trayectorias que las mujeres tienen por cuenta de sus jornadas laborales, académicas o cotidianas:

"Hay lugares en la ciudad que una siente que son incómodos sobre todo por ejemplo en el centro, Bolívar de noche, yo hace rato que no salgo pero cuando yo trabajaba en el centro, Bolívar de noche era tenebroso porque era muy oscuro" (DQ, $\mathrm{C} 1$, feb 13). "A las 8 de la noche no hay nadie entonces es muy sola para pasar, y preciso el bus que me toca coger para ir a Robledo Aures para ahí" (MG, C1, marzo 9).

La representación de (in) seguridad con relación a los espacios de la ciudad, de la cual dieron cuenta las mujeres de las $\mathrm{C} 1 \mathrm{P}-\mathrm{C} 8 \mathrm{VH}$, contiene factores similares, aunque no es posible determinar con certeza entre la comuna y la ciudad cuál de ellas está más asociada al peligro, según las respuestas obtenida. El siguiente cuadro da cuenta de esta situación, en el coinciden lugares según las variables y atributos construidos:

\begin{tabular}{|c|c|c|c|}
\hline \multicolumn{4}{|c|}{ Variables $v$ atributos en la representación de (in) seguridad en la ciudad } \\
\hline Subcategorías & & tos & Lugar \\
\hline \multirow{8}{*}{ Socio espaciales } & \multirow{3}{*}{$\begin{array}{l}\text { Actores } \\
\text { sociales }\end{array}$} & Transeúntes & $\begin{array}{l}\text {-La ciudad es más insegura porque cuando uno va por } \\
\text { diferentes partes y ve bastantes personas uno no sabe } \\
\text { quién es esa persona que está allí (EI, C1, mayo 8). }\end{array}$ \\
\hline & & Residentes & \\
\hline & & Temporales & $\begin{array}{l}\text {-el (parque) de los Deseos y dije: ¡que es este } \\
\text { desorden!... grupos de toda clase...unos pelaos con esa } \\
\text { forma de vestir, de ver la vida...como que le estresan a } \\
\text { uno (RD, C8, mayo 12) }\end{array}$ \\
\hline & \multirow{4}{*}{$\begin{array}{l}\text { Dinámicas } \\
\text { sociales }\end{array}$} & Culturales & \\
\hline & & Deportivas & \\
\hline & & Recreativas & \\
\hline & & Educativas & \\
\hline & \multicolumn{2}{|c|}{ Estrato o clase social } & $\begin{array}{l}\text {-Sectores como los altos estratos es decir el tema de la } \\
\text { Aguacatala en el Poblado hacia abajo el parque de la } \\
\text { calle } 88 \text { por toda la calle } 8 \text { (LR, C } 8 \text {, feb } 24)\end{array}$ \\
\hline \multirow{5}{*}{ Geo espaciales } & Disposición & Equipamiento & \\
\hline & & Aseo & \\
\hline & \multicolumn{2}{|c|}{ Entorno } & $\begin{array}{c}\text {-Parque de San Antonio } \\
\text {-Parque Berrio } \\
\text {-Centro de prostitución hay muchas y se presta para } \\
\text { que uno lo molesten los hombres (RO, C8, marzo 3) }\end{array}$ \\
\hline & \multicolumn{2}{|c|}{ Infraestructura vial } & \\
\hline & Temporalidad & Día & \\
\hline
\end{tabular}




\begin{tabular}{|c|c|c|c|}
\hline & & Noche & $\begin{array}{l}\text {-Bolívar de noche era tenebroso porque era muy oscuro } \\
\text { (DQ, C1, feb 13). } \\
\text {-Si me da miedo Niquitao, para esos lados, es } \\
\text { complicado pero creo que son miedos, mas mentales } \\
\text { infundados (CG, C8, feb 29) } \\
\text {-Cúcuta con Colombia }\end{array}$ \\
\hline \multirow{7}{*}{ Institucionales } & \multirow{4}{*}{ Públicas } & Educativas & $\begin{array}{c}\text {-Universidad Nacional en la Minorista que uno pasa un } \\
\text { puente (CG, C8, feb 29) }\end{array}$ \\
\hline & & Salud & \\
\hline & & Culturales & $\begin{array}{c}\text {-Museo de Antioquia en la parte de abajo (RO, C8, } \\
\text { marzo 3) }\end{array}$ \\
\hline & & Justicia & \\
\hline & \multirow{3}{*}{ Privadas } & Religiosas & Detrás de la de la iglesia San José (RO, C8, marzo 3) \\
\hline & & Educativas & \\
\hline & & Salud & -SaludCoop \\
\hline \multirow{4}{*}{ Emocionales } & \multicolumn{2}{|c|}{ Seguridad } & \\
\hline & \multicolumn{2}{|c|}{ In seguridad } & \\
\hline & \multirow{2}{*}{\multicolumn{2}{|c|}{$\begin{array}{l}\text { Miedo } \\
\text { Libertad }\end{array}$}} & \\
\hline & & & \\
\hline
\end{tabular}

Tabla 6. Variables y atributos en la representación de la seguridad en la ciudad.

Fuente: Elaboración propia.

De acuerdo a este cuadro, muchas de las representaciones de inseguridad manifestadas por las entrevistadas de ambas comunas, tienen en común que tanto los atributos de actores sociales como de temporalidad, específicamente actores sociales y noche, son los que más se destacan al momento de identificar situaciones de riesgo y amenaza en la ciudad. Los lugares expuestos en el cuadro se encuentran localizados principalmente en la Comuna 10 - La Candelaria, zona que se conoce como el centro de la ciudad, y que además se caracteriza por presentar las más altas estadísticas de delitos que afectan la seguridad de las personas, según datos reportados por el Sistema de información para la Seguridad y la Convivencia de Medellín SISC.

La información obtenida en este estudio, en relación a las representaciones de inseguridad que tienen las mujeres de las $\mathrm{C} 1 \mathrm{P}$ y $\mathrm{C} 8 \mathrm{VH}$, no ha tenido variaciones importantes en los últimos cinco años. Las respuestas conservan ciertas coincidencias en relación a los espacios de ciudad, así por lo menos lo demuestra un estudio de orden cuantitativo realizados en el $2008^{100}$, en el que las calles de la ciudad eran las que representaban mayor inseguridad, seguido de los barrios pobres, las plazas de mercado y los parques y plazas. Igualmente en este estudio de referencia están presentes las zonas bancarias y los puentes peatonales.

${ }^{100}$ Secretaria de las Mujeres - Instituto de Estudios Regionales, Diagnóstico de Seguridad Publica para las Mujeres y una Encuesta de percepción realizada por el Centro de Estudios de Opinión de la Universidad de Antioquia CEO. Ambos realizados en el 2008. 
Ahora bien, las respuestas acerca de la temporalidad en la contextualización de los espacios son de la misma manera determinantes, una clara situación es la noche, que se percibe como una variable directa e indefectiblemente relacionada con el peligro, ese que moviliza, limita y encierra, y que por tanto debe ser tenido en cuenta en mayor proporción por las mujeres que por los hombres al momento de transitar la ciudad. A veces no hay situaciones específicas a las cuales atribuirles la inseguridad, pero la representación se establece en un sentido general y abstracto, así lo plantea una entrevistada de la C1P: "Hay muchas partes de la ciudad que uno en realidad no quisiera pasar o porque son muy oscuras, a veces tiene uno que pasar de noche y eso da temor" (EI, C1, mayo 8).

Esta situación se remite a estructuras culturales en las que la noche es re-semantizada como tiempo de "bajos instintos", de emergencia del "espíritu violento", de la trasgresión al orden y al autocuidado, incluso se identifican horarios específicos hasta los cuales las mujeres pueden transitar tranquilamente hasta las 7:00p.m. u 11:00p.m. (CO, C1, abril 10) (RO, C8, marzo 3). Distinto sucede con las horas de día, en las que sin distinción de edad, genera mayores posibilidades para el tránsito en tanto que la luz genera confianza y tranquilidad.

La ciudad es un espacio de tránsito donde convergen dinámicas y actores. Las mujeres acceden a ella en la medida en que encuentran condiciones que favorezcan o garanticen su seguridad, estas posibilidades de acceso van más allá de la infraestructura o el equipamiento como ciudad de servicios, ya que se requiere un uso consciente de la misma ligado al reconocimiento en el acceso equitativo de hombres y mujeres a los espacios de ciudad, que deje de lado los atributos que determinan un riesgo en las subcategorías construidas, sociespaciales, geo espaciales, institucionales y emocionales.

\subsubsection{Un asunto de segregación espacial}

El uso de los espacios está atravesado por la connotación de lo público, es decir, de libre acceso. Los espacios públicos pertenecen a todas las personas, sin embargo, los modos de uso organizados en función de las pautas formales o informales, y de las representaciones que tenemos, determinan en última instancia el carácter que tendrán. No basta que los espacios tengan ese destino, si las personas no pueden ocuparlos. Escuchemos que decía una de nuestras entrevistas:

“La gente no se puede apropiar del espacio público porque aquí el espacio público no es público es del Estado entonces vos te sentás en una cera y llega un policía y te dice que ahí no podes estar 
porque es espacio público pero vos ahí no podes estar, las escalitas del metro para subir a las taquillas del metro son públicas y vos ahí no podes estar porque viene la policía y dice que tu no puedes estar ahí, pero eso es un espacio público, pero usted no puede estar ahí porque son del metro, entonces son públicas o son del metro, aquí en el espacio público antes los vendedores ambulantes, que tienen esa alternativa de buscar su sustento económico, vos los encontrabas en cualquier parte, ahora entonces no, ahora se tienen que ubicar donde el gobierno dice que se ubiquen o sea no en el espacio público donde era que se comercializaban muchas cosas que la gente o hacia o compraba para revender ahora no, ahora están hacinados en unos lugares que fueron definidos para esas personas que están ahí en su economía informal, entonces yo creo que aquí el espacio público no es público (DQ, C1, feb 13).

El acceso a los espacios públicos es desigual en razón del género como también de las actividades que en este se realizan. No todos los hombres tienen la posibilidad de acceder a él pero sucede aún más con las mujeres. De una parte hay una segregación institucional en los espacios que se construyen bajo la categoría de públicos pero a los cuales se puede acceder bajo determinadas circunstancias especialmente transitorias, y de otra, hay una segregación que la constituyen los propios actores que se instalan, apropian y generan formas de control y dominio en esos espacios públicos.

El proceso de transformación urbana que ha vivido Medellín en los últimos diez años, ha tenido un fuerte impacto en la conformación y adecuación de los espacios públicos. A esto se suma la relevancia que se la ha dado a los eventos de talla internacional que se han realizado en la ciudad y que buscan consolidarla como destino de eventos internacionales ${ }^{101}$, en estos se busca proyectar la imagen de ciudad innovadora. Sin embargo esta imagen de ciudad innovadora contrasta con el sentido de lo público, ya que ha implicado una segregación espacial en la cual se propician estrategias para las cuales el estrato social, el género y/o la edad funcionan como las contraseñas para acceder a esos espacios o hacerlo a determinadas horas del día, o determinados días o solo o acompañados:

101 Juegos Suramericanos en el 2010, la Asamblea del BID en el 2009, el Congreso 19 de la Federación Iberolatinoamericana de Cirugía Plástica (Filacp), el noveno International PGPR Workshop, el octavo Simposio Suramericano de Geología Isotópica -SSAGI, la edición 16 del Latin American Congress of Sexology and Sexual Education (Clases), la décima tercera Latin American Conference on the Applications of the Mössbauer Effect (Lacame) y el décimo cuarto Congreso Latinoamericano de Desarrollo de la Gestión Humana y la Responsabilidad Social (Clade), entre otros eventos. 
"Es una estrategia también para que las personas no lleguen a muchos espacios de la ciudad, que supuestamente son espacios abiertos para la ciudad, pero cerrados, pues yo los concibo como espacios cerrados porque no todo mundo puede estar ahí. La ciudad pues en cuestión de infraestructura si ha cambiado muchísimo pero yo siento que los espacios que se están abriendo no son acordes para todo tipo de público. Yo siento que se están abriendo pero en algunos sectores de la ciudad pero no en todas, hay lugares que si vos los ves, pues cuando uno los visita uno no se siente conforme en esos lugares porque uno siente que son lugares más o para jóvenes o para personas adultas, pues no son para todo tipo de público y siento que todos están estratégicamente pensados y no son pues solamente para las mujeres (LR, C1, abril 25).

En el espacio público se determinan una serie de comportamientos que desencadenan situaciones concretas que se condensan en órdenes que se instauran en el cuerpo de las mujeres como son por citar algunas, unas formas de vestir específicas y modelos que promocionan productos a través de su figura. Son el resultado de las relaciones de poder que se hacen invisibles a la otredad y que se han fortalecido en la historia de la ciudad, en la que en palabras de Augé "el cuerpo siempre ha sido un espacio compuesto y jerarquizado" (2000: 65). En este caso las mujeres comercializadas y exhibidas bajo los cánones de belleza que la sociedad ha impuesto y que se refuerzan en el afán de la ciudad por venderse y proyectarse como ciudad de servicios a partir de transformación de su infraestructura y espacio físico, pero relegando las posibilidades de acceso de sus mismos/as habitantes.

En el comportamiento de las mujeres se encierran ciertas contradicciones, las manifestaciones de cohibición y libertades para las mujeres, su rol de maternales o guerreras que las ha caracterizado desde tiempo atrás. Siempre hay una ley social que medie y controle la expresión de su corporalidad, su vestimenta, su uso y todo lo que el cuerpo emane y quiera pronunciar, prueba de ello se evidencia en las limitaciones existentes para transitar algunos espacios hasta las 8:00, 9:00 o máximo hasta las 11:00 p.m. ( $\mathrm{AG}, \mathrm{C} 8$, abril 24), ( $\mathrm{RD}, \mathrm{C} 8$, mayo 12), o las permisividades para exhibirlas.

Allí no se tiene en cuenta el miedo soterrado que prolifera en la ciudad, que alimenta además "las formas de agregación y desagregación social, en los procesos de inclusión y exclusión, en las nociones de orden y caos" (Villa Martínez, M. I., Sánchez Medina, L. A., \& Jaramillo Arbeláez, A. M., 2003: 13) que se imponen por el modelo de ciudad que demarca espacios de transito libre y restringido, por la multiplicidad de actores que en ella convergen y que inciden en la apropiación de los mismos que convierten el derecho a la ciudad en utopía, especialmente para las mujeres. 
Pero en algunos casos, estas situaciones que limitan el ejercicio de derechos de las mujeres, es lo que suele fortalecer su actitud para confrontar los imaginarios de miedo e inseguridad, que aunque pocas, se enfrentan a ellos buscando acallar la tradición hegemónica del deber ser de las mujeres que les impide hacer uso y disfrute de la ciudad en cualquier hora y lugar y que incluso tiene una construcción tan fuerte desde sí mismas, que les permite pasar por alto situaciones de riesgo o peligro cotidianos "Yo camino tranquila entre ellos, por cualquier lugar" (RO, C8, marzo 3), o de manera consiente reforzando el sentido de autonomía, como lo expresa una entrevistada de la C1P:

\footnotetext{
"Será por terca, yo pienso que soy hábil y como lo hice desde pequeña, yo siento que me conozco muy bien el centro, yo sé está callecita por donde sale, yo sé cómo se llaman las calles del centro, yo sé cómo encontrar una dirección, sé en cuál lugar andar y cual no, yo sé dónde sacar plata en el centro, donde puedo ir y a donde no puedo ir, y como me meto en los centros comerciales para evitar riesgos de que de pronto me atraquen, se donde venden las cosas baratas y las caras, las cosas buenas y baratas" (CO, C1, abril 10),
}

Esta percepción de sí mismas, pero también el conocimiento de la ciudad, ratifica posturas de confianza y seguridad, las cuales están atravesadas por una trayectoria personal que orienta el proceso de aprendizaje de la ciudad y de su ser como mujeres. De allí que la manera como las mujeres construyen sus relaciones con los espacios de ciudad está, como ya se ha dicho, mediada por la representación que tienen de los espacios que habitan, utilizan o simplemente transitan. En esto incide no solo la valoración subjetiva que reproduce la experiencia vivida sino también la estigmatización que sobre algunos sectores se construye socialmente y que en ocasiones constituye parte de la representación de peligro que se fundamenta en la información construida especialmente desde los medios de comunicación que además alcanza altos niveles de popularidad, aunque algunas de estas situaciones nunca más vuelvan a repetirse, pero es suficiente para crear las ideas y representaciones hacia un espacio.

En la mayoría de las ocasiones los usos de los espacios suponen una división sexual, en la cual, como lo expresa Falú $(2009,28)$, se jerarquiza los territorios, determinando un uso concreto por parte de hombres y mujeres. Para un ejemplo de esta afirmación se acude al siguiente gráfico y la representación que a razón del género se establece para su uso: 

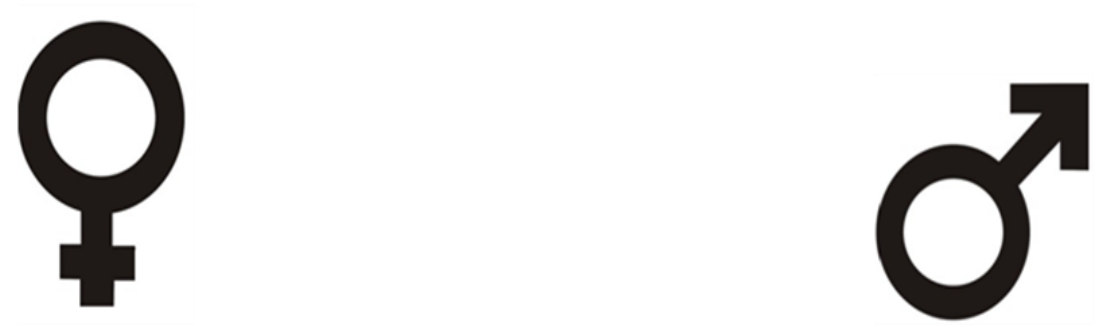

A no ser que sea una espectadora, su significado va a estar en estrecha relación con su


Jugador o espectador, sentido normalizado condición sexual Relación a la prostitución
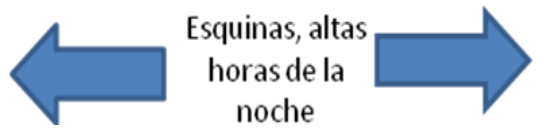

Uso del espacio, sentido normalizado

Figura 18. Usos del espacio. Fuente: Elaboración Propia.

En este gráfico se toman como ejemplo espacios que tradicionalmente han sido asociados a hombres y mujeres y la representación que genera controvertir la norma. En este caso el sentido normalizado de que sean los hombres quienes hagan uso de escenarios deportivos especialmente canchas de futbol y el sentido estigmatizante que cuestiona la condición sexual de las mujeres que lo hacen. De igual manera el sentido normalizado de que sean los hombres quienes hagan uso de las esquinas y del espacio público inclusive en altas horas de la noche y el cuestionamiento que se hace a las mujeres que trasgreden esta norma socialmente impuesta. De hecho esta trasgresión de la norma en el caso de que ocurra un acto de violencia contra ellas se convierte en un argumento justificador del acto.

El género no solo actúa como factor que establece diferencias y divide el comportamiento en la estructura social, sino que asigna espacios en la ciudad según el rol y la función social que tradicionalmente la sociedad desde su concepción patriarcal ha construido. Los espacios se constituyen en espacios de segregación donde el hombre que accede indistintamente a los escenarios públicos adquiere un sentido naturalizado porque ese ha sido su lugar por excelencia o porque su condición de género le atribuye ciertas libertades para acceder a todos los espacios, por tanto no entra en confrontación o estigmatización por estar allí. Mientras que la mujer es confrontada y hasta puesta en cuestionamiento cuando accede a sitios socialmente "no permitidos". 
Las mujeres que acceden a espacios segregados por el género, adquieren connotaciones negativas que, o cuestionan su condición sexual o la relacionan con prácticas ligadas al ejercicio de la prostitución. Sin embargo hay ocasiones en que la mujer "trasgresora" de la norma social impuesta, consciente del ejercicio del derecho a la igualdad en términos de acceso a la ciudad, pero también de la participación en la esfera de lo público optan por asumir un actitud más activa no solo en cuanto a los usos de los espacios decisorios y de representación:

"Nos hemos venido sensibilizando nos plantamos ahí, de ahí no nos movemos y ese espacio público es espacio público y también nos pertenece" (DQ, C1, feb 13).

La mujer que busca hacerse a los espacios públicos, está expuesta a la estigmatización y a la revictimización. De un aparte porque se cuestiona el comportamiento que contradice la norma social del rol de la mujer en la sociedad, y en consecuencia es rechazada por algunos sectores de la sociedad y negándole sus derechos y de otra parte porque los actos de violencia que se generen contra las mujeres serán asociados a sus comportamientos, dando razón al victimario.

La apropiación del espacio público pone en discusión la hegemonía masculina del espacio público. Pero al mismo tiempo, pone en debate el sentido que tiene lo privado. Lo privado (la mujer) es una amenaza porque está fuera de su sitio (en el espacio público), la mujer se sale de quicio, se corre del lugar que le "corresponde". Pero además, siguiendo a Delgado, "se produce un doble juego de rechazo de la mujer en tanto sujeto que pretende asumir un rol distinto del asignado, pero también de fascinación, de atracción, como objeto del deseo masculino" (2007: 110). Sin embargo, en los espacios públicos de la ciudad la toma irreverente por parte de algunas mujeres, abre una posibilidad de liberación del dominio masculino y se construyen unos nuevos referentes frente a la ciudad.

\subsection{De la comuna al barrio y del barrio a la cuadra}

Para entender la dinámica de la comuna como una división geopolítica de la ciudad, el barrio como el entorno cercano y la cuadra como el sector que se habita, es necesario reconocer: la forma como éstos fueron planeados en relación a la ciudad y a los territorios de los cuales hacen parte, la implementación de vías y de acceso del transporte público, aunque además hay otros elementos que resultan relevantes. Se plantea un análisis conjunto de ellos, aunque no en un mismo nivel, por la familiaridad que encontramos en algunas de las respuestas obtenidas. 
La historia de las comunas que componen la ciudad, ha sido la historia de quienes han llegado allí "metiendo el hombro". Eso implica que su consolidación no ha sido planificada, antes bien fue una construcción improvisada. Al menos esa ha sido la lógica que ha predominado en las comunas estudiadas, en donde, a medida que iban surgiendo las necesidades, se iba desarrollando la infraestructura. De ahí que existan tan pocos espacios reservados para el deporte y la recreación. Para decirlo con una de las entrevistadas:

\footnotetext{
"el barrio fue un barrio loteado y de ahí para ahí para arriba son barrios de mucha invasión entonces ahí no hubo ninguna planeación, si no que las cosas fueron apareciendo en relación a la necesidad, por ejemplo, necesitamos conectar este barrio y llevar el transporte hasta San Pablo, entonces ampliemos un poquito la vía para que quepa la buseta, pero entonces no habían aceras, amplían la vía para la buseta pero entonces se perdía el espacio para transitarlo, ahí no había ningún tipo de planeación, no hay espacios, hay muy pocos espacios verdes, para la recreación y el encuentro no los hay" $(\mathrm{CO}, \mathrm{C} 1$, abril 10).
}

Estas trayectorias espaciales en la consolidación de las comunas, las cuadras y los barrios ha generado asuntos que implícitamente se fueron constituyendo como relevantes pese a la infraestructura compleja que compone el entramado de estos sectores de la ciudad, calles pendientes y estrechas, algunas con procesos de pavimentación a partir de convites en las décadas de los 70's y 80 's, propiciaron una relación particular con el espacio y con sus habitantes, de eso da cuenta lo que plantean una de las entrevistadas:

“en los barrios no se ha pensado en vías o en calles, ellos están las casas muy juntas y eso desde mi perspectiva es por seguridad entre mayor sea la población entre ellos se cuidan y se quieren y en caso de que suceda algo pues ellos mismos lo solucionan" (LR, C8, feb 24),

Acá las condiciones sociales y espaciales, articulan elementos simbólicos, vivenciales, y materiales, donde confluyen memorias e identidades (Echeverria R., M. C., et al., 2011: 6) desde las cuales la necesidad de un lugar donde habitar establece el origen de las relaciones. Este es el punto de articulación con los espacios del barrio que son representativos para ilustrar la seguridad/inseguridad y como un ejemplo particular esta un sector de la C1P en donde la transformación del espacio público re adecua unos nuevos usos del espacio tendientes a la privatización del mismo, bajo la aparición en escena de personas de vigilancia privada o rondas policiales para garantizar la protección y seguridad más que de las personas del espacio, negando el 
uso histórico de grupos de jóvenes que convergían allí para el disfrute de la noche y de la compañía (MG, C1, marzo 9).

En los entornos cercanos como el barrio y la cuadra, se construye o de construye en el tiempo el sentido de pertenencia y adscripción a los mismos. La cuadra es un punto de referencia que se establece más para los hombres que para las mujeres, debido a que ellos quienes hacen más uso de ese espacio, juegan futbol, comparten con los amigos, se ubican en las esquinas donde pasan generalmente las tardes y parte de la noche.

Aunque la dimensión geoespacial barrial es importante, en tanto los espacios físicos determinan la posibilidad de uso, acceso y tránsito, lo es aún más la dimensión socioespacial dado que la trama social que allí se establece marca profundamente la representación de in seguridad/seguridad de estos entornos, tal como se estableció en las relaciones sociales expuestas en el capítulo anterior. En este sentido el barrio en general aparece referenciado como un espacio importante de sociabilidad para las mujeres, en este se construye y consolidan estrategias de acogimiento, que se presentan por la temporalidad de la habitabilidad del lugar, que redundan en sensación de protección y bienestar. El barrio es un espacio físico en el que se conjuga el sentido de las relaciones sociales afianzadas en las historias de vida construida con vecinos/as y amigos/as.

Cuando se transita el barrio, inconscientemente se tiene un mapa en la cabeza. El barrio no es una página en blanco o una página cuadriculada. Es una página que se fue punteando entre todos. Un mapa confeccionado en base a historias previas. Historias vividas en carne propia o historias ajenas. Ese mapa orienta los modos de recorrer el barrio, de habitar los lugares (Reguillo, 2000). Los espacios que hacen parte de la comuna, que están en el barrio (la tienda, la escuela, la iglesia, el parque), hacen que predomine una sensación de confianza y seguridad sustentada entre otras razones por el conocimiento de los trayectos y de la distribución espacial a través de los recorridos realizados durante largo tiempo como parte de su cotidianidad (RO, C8, marzo 3), (EI, C1, mayo 8):

\footnotetext{
“uno, en los barrios, conoce más o menos las personas y los lugares por dónde uno pueda pasar... pues si me siento con miedo de pasar por algún lugar me voy por otro lado, si allí está oscuro me voy para otra parte", (CO, C1, abril 10).
}

Sin embargo esta sensación de seguridad y confianza a partir del reconocimiento del barrio, esta mediada también por la identificación de los espacios que no cuentan con una adecuada 
infraestructura (ya sea en términos de iluminación y/o mantenimiento de sectores aledaños, ya que aún hay algunos sectores con lotes baldíos inundados de maleza y basuras y espacios boscosos) (LR, C8, feb 24) como también por los actores armados que se establecen en determinados sectores del barrio y de los cuales no es posible abstraerse, pues hay casos en los que con algunos de ellos se compartió la infancia ( $\mathrm{MG}, \mathrm{C} 1$, marzo 9) o se tienen algún vínculo familiar ( $\mathrm{RO}, \mathrm{C} 8$, marzo 3), tal como se describió en el capítulo de relaciones sociales. Para confrontar esta situación se genera la necesidad de establecer rutas alternas que se identifican como zonas o sectores acondicionados para el tránsito a cualquier hora del día o de la noche.

Los barrios se desagregan en cuadras que se convierten en un referente importante en el que las mujeres ubican espacios, personas y situaciones que detonan seguridad/inseguridad. En la geografía de las comunas estudiadas estas cuadras tienen unas especificidades espaciales como la existencia de una quebrada ${ }^{102}$, una calle ciega o sin salida y una terminal de buses, entre otras. Estás, de acuerdo a las condiciones del entorno tanto físico como social, se convierten en una alarma natural (Reguillo, 2000) que indica la pertinencia o no de transitar en ella.

\subsubsection{Puntos de referencia en la representación del barrio y la comuna}

El espacio desde el cual se construye la relación con la comuna, la cuadra y el barrio, no está claramente definidas en las respuestas obtenidas por las mujeres entrevistadas, esto se puede establecer con base en las trayectorias, pues independiente de su representación de inseguridad hay una historia de vida que atraviesa varios sectores de la comuna, situaciones de infancia en el colegio, etapas de la adolescencia en las que la permanencia en parques fue una constante, incluso las viviendas de amigos y compañeros hacen que su concepción del barrio sea uno solo, pues en ella no existen las nominaciones que el mapa geopolítico de la ciudad establece para diferenciar un barrio de otro en el que los límites son difusos, así mismo como sucede en los límites de una y otra.

En ambas comunas además de identificarse una ausencia notable de espacios para la recreación y el esparcimiento, se comparten otras características generales en relación a la infraestructura de la ciudad que podemos expresar de la siguiente manera: a menor distancia de la periferia, es decir, de los límites del entorno urbano, mayor dificultad en relación a las vías de acceso a ciertos sectores. Son procesos de expansión habitacional que no se detienen debido a que el desplazamiento persiste no solo del campo a la ciudad sino dentro de la misma. Esto repercute en la representación de

\footnotetext{
${ }^{102}$ Es un afluente pequeño de río dado la composición montañosa que conforma la ciudad.
} 
seguridad/inseguridad, en tanto que son otro tipo de situaciones las que constituyen una fuente de peligro, mientras que en las mujeres que habitan barrios centrales predominan los actores del conflicto armado urbano, en las mujeres que habitan las laderas son las condiciones físicas del terreno lo que las hace estar en situación de riesgo inminente ante avalanchas o deslizamientos de tierra dada la pendiente de su geografía. Este tipo de contrastes se pueden identificar en barrios que hacen parte de una misma comuna.

Ambas comunas tienen puntos de referencia con base a las intervenciones hechas por la administración municipal en el propósito de recuperar espacios públicos para la educación, esparcimiento y recreación de sus habitantes a través del urbanismo social ${ }^{103}$, como son en la C8VH, la biblioteca La Ladera, el parque de Boston, alrededor de 55 instituciones educativas y el cerro Pan de azúcar. Por su parte en la C1P se encuentra la Biblioteca España, el parque de Villa de Guadalupe y más o menos 35 instituciones educativas y el cerro Santo Domingo, en ninguna de las dos no fue fácil determinar un número específico de canchas deportivas o parques infantiles.

Aunque hay un sistema de transporte masivo en la C1P (en la C8VH está en etapa de construcción), alimentada por el servicio del metro cable ${ }^{104}$ y el metroplus. En la C8VH, presenta unos deficientes niveles de conectividad, además de pocas vías de acceso (LR, C8, feb 24), por lo empinado de la geografía y por la estrechez de las calles. Caracteriza la infraestructura de estas comunas unas vías deficientes pero además consideradas como peligrosas.

La existencia de estos puntos de referencia que se han ido construyendo en los últimos 10 años, no significa que las mujeres puedan acceder de manera libre y autónoma, pues las condiciones físico espaciales no lo permiten, o porque quienes acceden a ellos son fuentes de inseguridad, entonces la opinión de las entrevistadas se enfoca a la no existencia de los mismos,

\footnotetext{
"no hay los espacios...faltan parques y lugares de esparcimiento para las mujeres” (EI, C1, mayo 8), “espacios actuales para la mujer en la comuna así físicos no hay" ( $\mathrm{RO}, \mathrm{C} 8$, marzo 3).
}

\footnotetext{
${ }^{103}$ El urbanismo social se define en Medellín como un conjunto de acciones dirigidas por el gobierno municipal para promover el desarrollo en territorios marginados, generando transformaciones físicas y sociales, especialmente en territorios que han ido rugiendo de manera informal es una idea que empieza a promoverse desde el año 2004 y que toma forma en el Plan de Desarrollo Municipal 2004 - 2007 (Quinchía Roldán y Arrieta Neira, 2012: 7).

${ }^{104}$ El metro cable es un sistema de cable aéreo dispuesto por el sistema de transporte masivo METRO al igual que los buses integrados al sistema de metro plus.
} 
Pero además los espacios que adquieren la connotación de públicos están referidos a bares y tabernas, que por un lado están intervenidos en su mayoría por los grupos armados ilegales o son de uso masivo de población joven especialmente en la C1P "aquí los espacios públicos son mínimos, los espacios públicos que hay aquí son entonces las tabernas" (LR, C1, abril 25), incluso se va más allá al afirmar que los espacios para el esparcimiento de las mujeres termina reduciéndose nuevamente a sus casas en los frentes o aceras (AG, C8, abril 24).

Lugares emblemáticos de ambas comunas, como los parques biblioteca y la adecuación de espacios representativos, no son suficientes para garantizar su uso y apropiación,

\footnotetext{
"porque el interior de la biblioteca pues obviamente, hay muchas personas y eso, pero en las afueras de la biblioteca, hay muchos caminos que se prestan para muchas cosas vos por los caminos te encontrás a los pelados organizando ahí sus negocios, entonces no me genera confianza o sea adentro si, pero vos no siempre tenés con que pagar un taxi que te deje en toda la puerta de la biblioteca, sino te toca subir a pie" (DQ, C1, feb 13).
}

Los aspectos ligados a los atributos del espacio público como iluminación, lotes baldíos y falta de representación institucional, dejan a la deriva las posibilidades de la libre movilización,

\footnotetext{
"Hay lugares muy poco iluminados, hay muy poca presencia del Estado con la Policía, con vigilancia, sectores muy abandonados se evita transitar por esos lugares" (CM, C1, mayo 11), "eso por ahí se mantiene muy solo y las calles están oscuras, eso genera inseguridad más que todo para las mujeres y porque de pronto puede salir un hombre y la puede violar o le puede hacer daño porque ahí se presta, vea es solo, oscuro y por ahí para arriba, hay monte" (CG, C8, feb 29).
}

Esta percepción del entorno como amenazante obviamente conduce a limitaciones en el uso y disfrute de los espacios de las comunas; así lo demuestra la evidencia empírica, que muestra que los espacios públicos del barrio como las calles y los parques, son más usados por los hombres, mientras que los espacios que suponen ciertas formas de control y vigilancia, son más usados por las mujeres (Vargas, V., 2007: 18) como los parques biblioteca, las iglesias y hasta el mismo espacio de la casa. Incluso la existencia de actores institucionales que proveen seguridad en el espacio público no constituyen una prenda de garantía para las mujeres.

\subsection{2 ¿"Fronteras invisibles"?, urdimbre de las representaciones}


Las comunas y los barrios adquieren una delimitación territorial la cual es asignada en la planeación política de la ciudad desde las instancias gubernamentales desde las cuales se define su extensión territorial. Sin embargo en los últimos años, otras formas denominadas "fronteras invisibles" han venido imponiéndose por parte de los grupos armados que operan en los distintos sectores de la ciudad en la disputa por el control territorial. Esto puede generar unas formas de asociación en tanto en los trayectos que las mujeres recorren en sus barrios construyen también unas fronteras imaginadas que determinan la relación con el espacio o la adscripción a los recorridos que cotidianamente realizan y que están caracterizados por la familiaridad no solamente del espacio sino también con las personas que hacen parte de éstos.

Las "fronteras invisibles" tienen una connotación particular y especial, dentro de la subcategoría socioespacial en tanto tienen atributos de inseguridad porque son establecidos por personas o grupos ligados a una estructura criminal. Pero a su vez están dentro de la subcategoría ge espacial porque crean límites del espacio barrial y/o comunal estableciendo nuevos márgenes, los cuales dotan los espacios de un significado para los habitantes demarcados por la violencia (Sánchez Gómez, G. \& Wills, M. E., 2011: 87).

Se construye una representación de inseguridad, en la que se limita el tránsito de las personas, allí no opera el derecho a la libre movilización, allí opera la sectorialidad, la exclusión de los territorios, la delimitación geográfica impuesta en las calles públicas, donde elementos naturalmente constituidos como parte del espacio público (postes, lámparas de luz, estaciones de teléfono), son utilizados de forma macabra para delimitar el acceso, tránsito y uso. En algunos casos más radicales, las fronteras se trazan en el imaginario social mediante actos de terror, como la exposición de cuerpos de personas asesinadas, que son utilizados como transmisores de un mensaje de prohibición que son difundidos a través del voz a voz para demarcar, alarmar y prevenir.

Estas fronteras que delimitan territorialmente las comunas generan un gran desconcierto para quienes lo habitan, pues afectan todas las dinámicas sociales, la vida cotidiana y el sentido de comunidad gestado en los largos años de habitar los barrios, pues el mensaje que se transmite no discrimina a razón de género, sin embargo trae consigo un mensaje implícito para los hombres en relación a la muerte y a las mujeres jóvenes, aunque el mensaje no es claro para ellas el temor a la vulneración de sus cuerpo, hace que establezcan ciertos límites: 
"las mujeres se cuidan de no pasar por ciertos...pues las mujeres jóvenes, las mujeres adultas como te dije si lo transitan, pero las mujeres jóvenes después de que saben, se cuidan de no hacerlo" (CO, C1, abril 10).

Las condiciones espaciales se complementan con los factores sociales Los atributos de las subcategorías geoespaciales se complementan con los atributos de las subcategorías socioespaciales existentes en cada una de las comunas determinando una representación de (in)seguridad a partir de un ejercicio de memoria que queda instalado en los/as habitantes. Sin embargo para las mujeres el caso de los feminicidios y los casos reiterados de violaciones, hurtos o atracos se convierten en elementos determinantes para la construcción de rutas alternas con las que evaden ciertos sectores. Así ocurrió con un puente construido en la C1P para comunicar dos barrios separados por un arroyo y que fue posteriormente demolido por fallas en la infraestructura:

“aparte de que está ubicado en un lugar que es camino, es más trocha que camino, no le hacen mantenimiento a las escalitas entonces eso es monte que se presta para cualquier cosa, para violaciones, para atracos, para lo que vos queras, el puente como tal es inseguro, o sea por ese puente pasa quien se arriesgue, ese puente no está, no fue construido con las especificaciones técnicas que soporte el peso para que las personas puedan transitar, aparte del lugar en el que está ubicado, me genera mucha desconfianza" (DQ, C1, feb 13). "las mujeres que van por el lado de la terraza, la violan, o cualquier cosa, pues me parece como una parte insegura, yo nunca he pasado por allá, porque me da miedo" (CA, C1 feb 10).

El continuum de hechos que atentan contra la vida y el bienestar de las mujeres como violaciones y asesinatos en ambas comunas y en la ciudad en general, son relevantes en la construcción de representaciones. Además de la violencia que ejercen los grupos armados, las deficientes características de los atributos de los espacios propician la ocurrencia de los mismos, pero además contribuyen a su estigmatización como espacios vetados, son marcados con actos violentos. Así ocurrió en un sector conocido como el Cerro Pan de Azúcar en Villatina en la C8VH, en donde pese a que recientemente había habido una intervención importante por parte de la administración municipal, para mejorar las condiciones físico espaciales no fue suficiente para evitar que allí fueran encontrados los cuerpos sin vida de dos mujeres adolescentes afrodescendientes, situación que instala una representación de lugar asociada a la inseguridad como lo manifiesta una de las entrevistadas: 
"En si querían era tener ese sitio como un sitio inseguro y poner ese sitio como algo tenebroso, también para ellos sentirse que tienen el poder y que están empezando a manejar parte de la ciudad, porque es un referente de ciudad y por qué ahí hacia muy poco había tenido una intervención de infraestructura" (LR, C8, feb 24).

Igualmente sucede con espacios destinados al deporte y al esparcimiento que, en horas de la noche, se convierten en sitios propicios para abusos y violencias sexuales, con el agravante de que, dada la inoperancia de la justicia, no son denunciados. Así lo relata una mujer:

\footnotetext{
"De vergüenza se han quedado calladas, entre esas una primita mía, a ella la cogieron entre cuatro y creo que gritaba... eso era horrible... ella dice que eso era horrible, [...] En la plazoleta, hay una canchita ahí y por ahí las meten. Ella de vergüenza se quedó callada, pero uno que sabe la historia uno la mira y uno dice ¡hay Dios mío que es esto!” (RD, C8, mayo 12).
}

La violación sexual, sigue siendo un crimen que por el estigma que persigue y marca a sus víctimas, conduce más al silencio que a la denuncia, y si bien cuando sucede en los barrios se conoce de su ocurrencia no trascienden al ámbito institucional y se convierten en un tema de manejo público pero clandestino. Es decir todos/as saben de él, en ocasiones incluso se sabe de la víctima y el sector de ocurrencia del hecho es marcado en el referente simbólico pero se limita a ser un lugar de prohibición al que la justicia nunca llega.

En ciertos contextos como el colombiano, más que existir las condiciones propicias para la denuncia, se presenta "la imposición estructurada del silencio" (Sánchez Gómez, G. \& Wills, M. E., 2011: 210). Los espacios en vez de ser intervenidos para evitar que estos hechos ocurran son señalados como peligrosos y negados para el acceso de las mujeres, no se hace honor a la justicia y mucho menos al derecho a la libre movilización de las mujeres, por el contrario no solo cabe la posibilidad de ser víctima de este tipo de delitos sino también de revictimizarse en tanto que consiente del riesgo se expuso a transitar el espacio prohibido. La negación del espacio es un acuerdo implícito que es establece en las normas sociales que operan en la sociedad y con muchas más fuerza en las comunas de estudio.

Estos espacios, sórdidos, abandonados, oscuros, controlados, desde donde se originan las representaciones de (in) seguridad en las comunas están asociados a las siguientes relaciones y atributos de acuerdo a las respuestas obtenidas y en relación a sectores del barrio y de la comuna y de una manera que no se expone en el cuadro también son determinados por una dimensión 
temporal, desde la cual los horarios, la tarde, noche o madrugada al igual que días de semana o fines de semana tienen incidencia.

\begin{tabular}{|c|c|c|c|c|}
\hline \multicolumn{3}{|c|}{$\begin{array}{c}\text { Relaciones y atributos } \\
\text { Representaciones de (in) seguridad }\end{array}$} & $\begin{array}{l}\text { Comuna Uno - } \\
\text { Popular }\end{array}$ & $\begin{array}{c}\text { Comuna Ocho -Villa } \\
\text { Hermosa }\end{array}$ \\
\hline Subcategorías & Atril & & & \\
\hline \multirow[t]{4}{*}{$\begin{array}{l}\text { Socio } \\
\text { espaciales }\end{array}$} & \multirow[t]{4}{*}{ Actores sociales } & Transeúntes & $\begin{array}{l}\text { "la terminal de buses } \\
\text { bueno el parche me } \\
\text { parece muy inseguro" } \\
\text { (MG, C1, marzo 9). }\end{array}$ & $\begin{array}{l}\text { "Otro lugar maluquito es de } \\
\text { colinas una parte que hay } \\
\text { para atrás por la Normal por } \\
\text { esos pinos... es horrible han } \\
\text { tirado mucho muerto y se } \\
\text { mantiene muchos vicioso } \\
\text { ahí... se van a tirar vicio ahí. } \\
\text { Lo que se llama Villa } \\
\text { Mercedes ipor ahí una } \\
\text { pelada no se puede meter } \\
\text { sola!" (RD, C8, mayo 12). }\end{array}$ \\
\hline & & Residentes & $\begin{array}{c}\text { "en segundo plano lo } \\
\text { de los lotes baldíos y } \\
\text { los lugares de la } \\
\text { periferia, en esos } \\
\text { extremos que viven } \\
\text { con mucha gente; creo } \\
\text { que es Carpinelo, ellos } \\
\text { que vienen } \\
\text { desplazados, que les } \\
\text { toca compartir con } \\
\text { gente que viene con } \\
\text { diferentes culturas y } \\
\text { maneras de vivir. Para } \\
\text { ellos si puede ser } \\
\text { inseguro" (CM, C1, } \\
\text { mayo 11). }\end{array}$ & \\
\hline & & Temporales & $\begin{array}{l}\text { "Hay muchas partes en } \\
\text { que la mujer, no solo } \\
\text { yo, sino todas nos } \\
\text { sentimos atemorizadas } \\
\text { de pasar, por ejemplo } \\
\text { hubo una época en que } \\
\text { pasar para Bello } \\
\text { Oriente por la parte de } \\
\text { la Y era bastante } \\
\text { tedioso" (EI, C1, mayo } \\
\text { 8). }\end{array}$ & \\
\hline & & $\begin{array}{c}\text { Grupos } \\
\text { armados }\end{array}$ & $\begin{array}{l}\text { "comuna San Pablo, } \\
\text { ahí los paramilitares } \\
\text { tienen una sede de } \\
\text { ellos y yo siento que } \\
\text { ellos ahí se mueven } \\
\text { como quieren, y pasan } \\
\text { cosas muy feas los } \\
\text { fines de semana" (LR, } \\
\text { C8, feb 24). }\end{array}$ & $\begin{array}{l}\text { “pero también han matado, o } \\
\text { sea que son Llanadas, los } \\
\text { Mangos, Golondrinas, } \\
\text { Colinas de Enciso, } \\
\text { Villahermosa, colinas de } \\
\text { enciso parte baja, acá está el } \\
\text { trece de noviembre, la } \\
\text { Libertad, el Pinar, Villatina, } \\
\text { villa Lilia parte alta, la }\end{array}$ \\
\hline
\end{tabular}




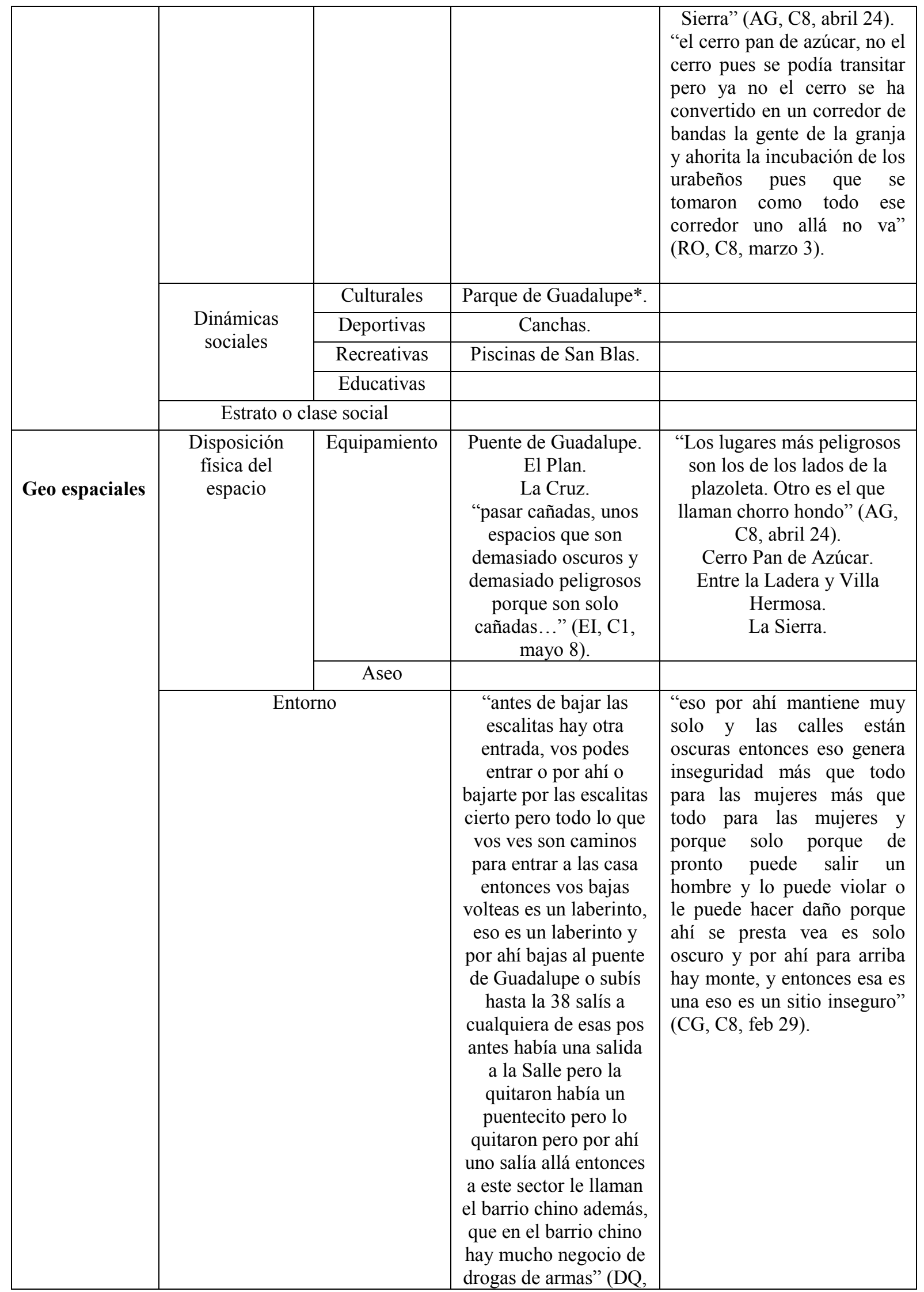




\begin{tabular}{|c|c|c|c|c|}
\hline & & & $\begin{array}{c}\text { C1, feb 13). } \\
\text { Puente de Guadua. } \\
\text { Biblioteca España. }\end{array}$ & \\
\hline & \multicolumn{2}{|c|}{ Infraestructura vial } & $\begin{array}{l}\text { "las personas no } \\
\text { miraban donde } \\
\text { ubicarse cierto y } \\
\text { cuando vino } \\
\text { planeación disque a } \\
\text { lotear planeación lo } \\
\text { que hizo fue, no abrir } \\
\text { calles sino caminos } \\
\text { porque son pocas las } \\
\text { calles que hay en la } \\
\text { comuna son pocas las } \\
\text { calles que realmente } \\
\text { sirven para el } \\
\text { transporte de buses de } \\
\text { taxis de camiones, } \\
\text { entonces lo que } \\
\text { abrieron no fue calles } \\
\text { abrieron caminos y } \\
\text { entregaron lotes a } \\
\text { algunas personas" } \\
\text { (DQ, C1, feb 13). }\end{array}$ & $\begin{array}{l}\text { "hay muchos callejones y la } \\
\text { sierra tiene un solo eje pues } \\
\text { una sola vía y ahí está como } \\
\text { todo el tema de los bares de } \\
\text { la terminal entonces ahí yo } \\
\text { me siento insegura" (RO, } \\
\text { C8, marzo 3). } \\
\text { "por aquí } 2 \text { s muy difícil } \\
\text { porque son callejones, las } \\
\text { vías con como más } \\
\text { estrechas, porque hay } \\
\text { sectores donde no hay sino } \\
\text { una sola vía por donde uno } \\
\text { puede pasar, pues no hay } \\
\text { como desvío, mientras que si } \\
\text { uno ve que alguien lo está } \\
\text { como siguiendo, uno se mete } \\
\text { o se puede meter a una } \\
\text { tienda, un almacén, puede } \\
\text { despistar, mientras que acá } \\
\text { en la comuna no es lo } \\
\text { mismo" (AG, C8, abril 24). }\end{array}$ \\
\hline & \multirow[t]{2}{*}{ Temporalidad } & Día & $\begin{array}{c}\text { "cuando vengo de } \\
\text { Guadalupe de noche si } \\
\text { me da miedo" (CA, C1 } \\
\text { feb 10). }\end{array}$ & \\
\hline & & Noche & $\begin{array}{c}\text { "San Blas a ciertas } \\
\text { horas" }(\mathrm{CO}, \mathrm{C} 1 \text {, abril } \\
10) .\end{array}$ & \\
\hline \multirow{4}{*}{ Institucionales } & \multicolumn{2}{|c|}{ Religiosas } & & \\
\hline & \multicolumn{2}{|c|}{ Estatales } & & \\
\hline & \multicolumn{2}{|c|}{ Educativas } & $\begin{array}{l}\text { "en San Pablo es que } \\
\text { ellos se adueñaron de } \\
\text { una parte del colegio } \\
\text { que nunca pudo ser } \\
\text { demolido, entonces } \\
\text { ellos ahí tiene todo el } \\
\text { espacio, ellos ahí le } \\
\text { dicen la oficina, } \\
\text { entonces en el primer } \\
\text { piso tienen un } \\
\text { deshuesadero, en el } \\
\text { segundo piso es la sala } \\
\text { donde se reúnen, en el } \\
\text { tercer piso es un salón, } \\
\text { pues esos salones ellos } \\
\text { los utilizan como a } \\
\text { ellos les da la gana" } \\
\text { (LR, C1, abril 25). }\end{array}$ & $\begin{array}{l}\text { "el ITM, yo lo veo como } \\
\text { más o menos porque el lugar } \\
\text { como lugar lo transita uno } \\
\text { pero con sus prevenciones ya } \\
\text { me ha tocado ver hay gente } \\
\text { que la han apuñalado ahí por } \\
\text { atracarla" (RO, C8, marzo } \\
\text { 3). } \\
\text { "La normal superior de } \\
\text { Medellín ninguna mujer por } \\
\text { empoderada que este se } \\
\text { atrevería a ni de día ni de } \\
\text { noche a pasar por estos } \\
\text { sitios" (LR, C8, feb 24). }\end{array}$ \\
\hline & \multicolumn{2}{|c|}{ Privadas } & & \\
\hline \multirow{2}{*}{ Emocionales } & \multicolumn{2}{|c|}{ Seguridad } & & \\
\hline & \multicolumn{2}{|c|}{ In seguridad } & & "a mí el lugar que en este \\
\hline
\end{tabular}




\begin{tabular}{|c|c|c|c|}
\hline & & $\begin{array}{c}\text { momento me parece un } \\
\text { riesgo para las mujeres es la } \\
\text { sierra (RO, C8, marzo 3). } \\
\text { (hay una calle en la comuna } \\
\text { que yo no me acuerdo el } \\
\text { nombre y esa calle por ahí } \\
\text { han matado varias mujeres" } \\
\text { (CG, C8, feb 29). }\end{array}$ \\
\hline & Miedo & $\begin{array}{c}\text { Los Charcos. } \\
\text { Santa Lucía. }\end{array}$ \\
\cline { 2 - 4 } & Libertad & $\begin{array}{c}\text { Cañada de la Salle. } \\
\text { Santo Domingo. }\end{array}$ & \\
\cline { 2 - 4 } & & \\
\hline
\end{tabular}

Tabla 7. Representaciones de inseguridad en el barrio y la comuna.

Fuente. Elaboración propia.

* Ambas representaciones como sitios seguros o inseguros en la comuna.

Los atributos de las subcategorías de análisis de la comuna tienen puntos en común con los hallazgos de la ciudad y lo que se ha descrito a lo largo de este capítulo en relación con los espacios. Los espacios públicos que son utilizados como sitios de esparcimiento, deporte y recreación tienen una carga de representación de (in) seguridad para las mujeres en ambas comunas. En particular para las mujeres de la $\mathrm{C} 1 \mathrm{P}$ hay una carga negativa para los parques y plazas, los cuales también están marcados por atributos de temporalidad.

Comuna, barrio y cuadra son los espacios analizados hasta el momento y que se establecen dentro de lo que se concibe como espacio público, podrían haber razones asociadas a la construcción social del género desde las cuales se conciben como naturales las representaciones de (in) seguridad expuestas hasta ahora, sin embargo, el debate sobre lo público no concibe estas argumentaciones como válidas porque sería continuar aceptando el acceso desigual e inequitativo por parte de las mujeres. Además como se verá en el siguiente apartado el espacio privado (la casa) también entra a cuestionarse como espacio inseguro.

\subsection{La casa ¿espacio seguro por excelencia?}

Una de las principales denuncias del movimiento feminista ha estado orientado a que se reconozca el espacio doméstico como el espacio donde se anidan gran parte de las violencias, así lo demuestran los datos presentados en el primer capítulo, donde más del $80 \%$ de los casos de violencia intrafamiliar afectan a las mujeres. Pero no es posible asociar las violencias que generan inseguridad únicamente a las agresiones físicas, ya que situaciones como la pobreza a la que se ven constantemente expuestas en especial algunas de las entrevistadas, hace que las condiciones de la vivienda en que habitan las exponga a situaciones de vulneración. 
La pobreza y las condiciones de la vivienda inciden en tanto que están más expuestas a situaciones que afectan su seguridad, como la falta de ingresos que no les permita acceder a las necesidades básicas tanto a ellas como a su núcleo familiar. Además pueden enfrentar situaciones de riesgo para su salud al no tener los mínimos requeridos, como servicios públicos, ubicación en un terreno estable y un material para la vivienda que las proteja en condiciones climáticas difíciles. Así pudo constatarse en una de las cuatro entrevistadas que habitaban en casas de madera y plástico, así describe una de las mujeres en situación de desplazamiento su vivienda:

\footnotetext{
"Mi casa es un ranchito de tabla, en este momento está malísimo porque tiene el agua que baja de un solar más arriba y toda pasa por mi casa ¡es un pantanero horrible! cada vez que me arrimo al fogón me dan corrientazos porque eso permanece húmedo" (EI, C1, mayo 8).
}

Dos de ellas compartían la vivienda de dos habitaciones con núcleos familiares mayores a cuatro personas, mientras que las siete mujeres restantes habitaban en casas con una buena adecuación en cuanto a la infraestructura de la vivienda y el número de habitaciones proporcional al número de personas que allí habitaban.

La representación de (in) seguridad también está asociada al tiempo de permanencia en el barrio, en tanto la temporalidad adscribe un proceso de identidad y apropiación con el entorno socioespacial, en donde quienes tradicionalmente habitan un territorio se convierten en un grupo cerrado que interpreta la llegada de "nuevos" como un grupo de intrusos (Elias, 1998: 116).

En el contexto de la ciudad de Medellín, esto implica además los riesgos a los cuales se aludía en el primer capítulo en relación con las fronteras invisibles pero también de la historia de violencia sociopolítica que ha generado el desplazamiento forzado del campo a la ciudad. De las trece mujeres, cuatro de ellas fueron afectadas por el desplazamiento forzado en los últimos 10 años, dos por causas de la violencia y las otras dos por razones económicas, aunque en su totalidad llevan un periodo de tiempo importante en el barrio y en las viviendas en que habitan. Sin embargo hay que reconocer que coincidencialmente el desplazamiento es un asunto que afectó a gran parte de las entrevistadas pues fueron sus familias quienes llegaron a la ciudad y se ubicaron en los territorios de ladera que compone las comunas de estudio en busca de mejores oportunidades y calidad de vida, así lo narra una de las entrevistadas: 
“...mucha gente dejo sus tierras, se vino, y paró cuatro palos en cualquier parte, sin importar que pasara la quebrada, sin importar que no sé qué y planeación no volvió a reubicar, a decir mire es que aquí no se puede construir pero pueden construir acá e ir ubicando las personas en otros lotes no, sino que cuando nos dimos cuenta cuando ya crecimos nos dimos cuenta lo mal que estábamos lo mal ubicados que estamos" (DQ, C1, feb 13).

Pese a la ubicación de las viviendas, en su mayoría en zonas reconocidas como de alto riesgo, se sienten mucho más seguras y tranquilas en sus viviendas, barrios y comunas que en la ciudad, en tanto que conocen su entorno y las personas que habitan a su alrededor, así lo expresa una de ellas:

“...por lo menos a mí la gente me conoce mucho saben que vivo en la comuna, saben quién soy y una se da eh... como esa confianza de decir que ya me conocen mucha gente si a mí me va a pasar algo imposible que alguien no salga y diga un momentico es que nosotros la conocemos cierto, es como un mecanismo de protección que lo conozcan mucho a uno también” (DQ, C1, feb 13).

Contrariamente a lo que dicen algunos datos estadísticos e informes de violencias contras las mujeres ${ }^{105}$ cuando señalan a la casa como uno de los lugares más inseguros para la mujer, algunas de las mujeres entrevistadas identificaron la casa como un lugar seguro ( $\mathrm{CO}, \mathrm{C} 1$, abril 10), (AG, C8, abril 24), (CM, C1, mayo 11). Sin embargo es importante subrayar que esta representación de seguridad, esta mediada por dos situaciones, la primera es el rol de jefa de hogar, donde ella es quien ingresa los recursos económicos y administra el hogar, la segunda es una relación emocional con la pareja y los demás miembros de la familia mediada por el respeto y la tercera está dada por la convicción política de la mujer como sujeto de derechos que determina las relaciones familiares. A partir de allí se desarrolla y se consolida un sentido de apropiación y de pertenencia del ámbito privado.

En esta representación incide de manera notable los hechos de inseguridad y de violencia que afectan mayoritariamente a los varones adultos y jóvenes, además del incremento de la percepción

105 Este es un dato reiterativo en los informes que la Corporación Mujeres que Crean y Vamos mujer presenta en los informes anuales sobre la situación de ddhh de las mujeres. "Las mujeres víctimas de la violencia en un alto porcentaje tienen como principales agresores a la pareja afectiva, a familiares, amigos y vecinos; sus casas, hogares no son espacios que garanticen la protección de sus vidas". (Informe 2003: 16). "De cada 100 casos que atiende diariamente la sala de atención al usuario de la Fiscalía por violencia intrafamiliar, 90 son mujeres" (Informe 2004: 26). En el 2008, según datos de Medicina legal, de 378 casos de agresiones sexuales, 228 ocurrieron en la vivienda de las afectadas. (Informe 2008: 22). El 48\% de los asesinatos de mujeres son cometidos en la vivienda (Bedoya, 2008: 139). 
de inseguridad en la ciudad ${ }^{106}$ que contribuye a que las mujeres se adhieran a esta percepción generalizada en los espacios públicos, pasando por alto los registros de violencia contra las mujeres en los espacios privados (De la Cruz, C.: 2007) y en lo cual el aporte de los medios de comunicación es importante, en tanto que, desde la información que allí se despliega se le da relevancia a ciertos hechos de violencia contra las mujeres pero se dejan de lado las múltiples violencias que se naturalizan tanto en el espacio público como privado de allí la importancia de tenerlos en cuenta para el análisis como se aborda en el siguiente apartado.

\subsection{Los medios de comunicación median las representaciones}

Sin duda los medios de comunicación tienen una alta incidencia en la construcción de las representaciones de (in) seguridad de las mujeres, en tanto que como productores y reproductores de sentido, son determinantes en el momento de entender la manera como se han construido las condiciones de desigualdad y de inequidad entre los géneros (Gómez, 2008), aportando con ello a la reproducción de los estigmas sociales que justifican los abusos y violencias que se cometen, además de generar una lectura parcial y reduccionista sobre el tema, con lo cual

"ofrecen determinadas representaciones de la realidad de las mujeres y los hombres; explican los motivos de dichas construcciones basándose en estereotipos tan obsoletos y repetidos, que reproducen noticias y narraciones clónicas que impiden distinguir unos medios de otros, y presentan una iconografía elaborada para dicha realidad, basada en presupuestos tradicionales de dominación y subordinación entre hombres y mujeres” (López, 2002: 27, citado en Gómez, 2008).

La afirmación de López permite tener un marco de referencia para entender las representaciones sociales de las mujeres de las $\mathrm{C} 1 \mathrm{P}$ y $\mathrm{C} 8 \mathrm{VH}$, a partir de la interpretación de la información de los medios de comunicación. Para tener un panorama general del tipo de violencias que afectan a las mujeres en la ciudad pero especialmente en las comunas de estudio, se realizó un seguimiento de prensa de dos medios de comunicación escrita de mayor circulación como son el periódico El Colombiano y el Q'Hubo, ambos pertenecientes a la misma casa editorial, pero con diferencias notables en el manejo de la noticia, llegando el segundo incluso a ser identificado como un medio "amarillista", por la forma en que elabora la noticia y transmite el mensaje.

106 De acuerdo al informe de percepción ciudadana del 2010, entre el 2009 y el 2010 disminuyo la percepción de seguridad tanto en el barrio como en la ciudad, lo que implica que la inseguridad estuvo en aumento durante ese periodo de tiempo (percepción de seguridad en la ciudad 2009: 49\% / 2010: 23\%. En el barrio 2009: 59\% / 2010: 49\%). 
Este seguimiento se realizó con el fin de tener un registro, como punto inicial para el análisis de las noticias que afectaban a mujeres en la ciudad durante el año 2011. Los hechos que predominaron fueron referidos en su mayoría a la muerte de mujeres principalmente ocasionadas por asesinato y en una mínima proporción por accidentes de tránsito, y a mujeres desaparecidas.

La ficha de registro de las noticias, establecía algunos datos precisos del hecho como el medio donde se publicaba la noticia, la fecha y el lugar de ocurrencia del hecho, la edad de la víctima, el nombre, el hecho, los sindicados para conocer el nivel de impunidad de los delitos y finalmente un apartado referido a las observaciones acerca de la noticia, en el cual se hacía una breve síntesis.

\subsubsection{Una aproximación al análisis de medios}

En el rastreo de prensa realizado durante el año 2011, se encontró que el medio que más información reporta de hechos de violencia ocurridos contra las mujeres es el periódico Q'Hubo con 109 noticias registradas durante el año, cifra que duplica los reportes realizados por El Colombiano con 48. Ambos periódicos registran asesinatos ${ }^{107}$ ocurridos por medio de arma de fuego y arma blanca, principalmente, seguidos de balas pérdidas, accidentes de tránsito y asfixia, y en una pequeña proporción no presentan datos del mecanismo utilizado para lograr la muerte de la víctima.

En este registro aparece el reporte de 119 mujeres asesinadas, de las cuales ocho fueron en la C8VH y cuatro de ellas en la C1P, la mayoría de los autores perpetradores del crimen se desconocen, presentándose un alto nivel de impunidad de los casos reportados. Igualmente tampoco es posible establecer un rastreo de los casos de mujeres violadas durante este mismo periodo de tiempo. Como se ha planteado, ello obedece a la invisibilización de los medios hacia este tipo de delitos, que pueden ser sustentados entre otros motivos primero por la falta de interés para hacer el respectivo registro, segundo por la falta de denuncias ante las instituciones responsables y tercero por la falta de consulta y solicitud de información a las fuentes institucionales.

Es importante destacar además que de los casos de asesinatos de mujeres reportados por los dos medios impresos, 44 de las víctimas eran mujeres menores de 20 años, 40 de ellas tenían entre 20 y

\footnotetext{
107 No se recurre en este caso a denominar los casos como feminicidios, por dos asuntos, el primero porque no se hace un análisis detallado de los casos que conlleve a determinar el asesinato como tal y segundo porque la lectura se hace con base al análisis de la prensa escrito esto incluye la forma como son nombrados los hechos.
} 
30 años de edad y 20 estaban entre los 30 y 40 años de edad. 21 no reportan edad y el resto son mujeres mayores de 41 años. Con lo que se puede inferir que la población joven es la más afectada por este tipo de delitos.

Frente al tema de mujeres desaparecidas El Colombiano registra tres mujeres, dos de ellas menores de 30 años y una sin datos de edad. Por su parte el Q'Hubo, da cuenta de 49 casos, el alto número de registros en comparación con el otro medio impreso, obedece en parte a que este último tiene una sesión destinada a reportar casos de personas desaparecidas en la que incluso se registra un número telefónico para obtener información, y en algunos casos les realiza seguimiento.

De los datos de mujeres reportadas en el Q'Hubo tres de ellas habitaban en la C1P y solo una en la $\mathrm{C} 8 \mathrm{VH}$, y en 16 de los casos no está reportado el barrio o comuna de procedencia. Es relevante el hecho de que las mujeres reportadas como desaparecidas en la $\mathrm{C} 1 \mathrm{P}$, son menores de edad, lo que coincide con una preocupación que se ha generalizado en este sector de la ciudad en los últimos años, ante el incremento de casos de trata de personas que se han registrado, caracterizado por la venta de la virginidad de niñas y adolescentes por parte de miembros de los grupos armados ilegales que allí operan ${ }^{108}$.

\subsubsection{Una fuente ambigua de información}

Los medios de comunicación relegan los aspectos relativos a las violencias sexuales como un asunto de menor importancia, de ello da cuenta una de las entrevistadas:

“el tema de seguridad de calle, pues yo lo pongo así porque no se cómo nombrarlo, [...] los medios manejan esto de una manera muy liviana, a mi me parece que hacen una diferencia y creo que ni los periodistas están manejando ni siquiera la dimensión de todo lo que significa el trato a la mujer en tema de seguridad porque es que una cosa es esa violencia que se hace ancestral, otro es esa violencia que da la dinámica de ciudad y otra es esa violencia que hace como el manejo de la mujer el cuerpo de la mujer como botín de guerra" (RO, C8, marzo 3),

\footnotetext{
108 Sobre el asunto la UNDOC ha hecho investigaciones recientes que buscan dar cuenta del crecimiento de este problema en la ciudad y los niveles de afectación que predominan en unos sectores de la ciudad. Así mismo algunas agencias de noticias de organismos no gubernamentales han encendido las alarmas por el incremento de casos que en muchas ocasiones no son denunciados por los riesgos que implica para las familias afectadas, además de la desconfianza institucional.
} 
El abordaje de los casos en los medios de comunicación, contribuyen en la concepción del cuerpo de la mujer como un objeto sexual, al no darle un análisis de contenido a los hechos que ocurren y en los cuales la forma como se aborda el tema tiene una gran incidencia en la construcción de estas representaciones. Pero de otro lado, ocultan algunas situaciones que para las mujeres que habitan los territorios son evidentes, y que en reiteradas ocasiones aparecen en las respuestas de las entrevistadas en las que hacen alusión a asuntos que se abordan en el capítulo dos, como son la connivencia de la Fuerza Pública con los grupos armados ilegales en los barrios de las comunas, y la impunidad que reina frente a las denuncias de violación, violencia sexual y acoso sexual, por parte de todos los actores armados incluyendo la institucionalidad. Así lo plantea una de las mujeres de la C8VH:

\footnotetext{
"Uno se pone a ver y tapan cosas por todos los lados... disimulan por todos los lados y no lo difunden como debe ser, ahora por donde te metas hay esa inseguridad y pasan cosas raras, cosas extrañas y la gente se queda callada, como que no le hace conocer al otro...mira lo que está pasando o mucho cuidado con esto" (AG, C8, abril 24),
}

Allí, no solo se establece un riesgo importante para la percepción de ciudad alimentada por lo que difunden los medios, sino también y es podría decirse que más grave aún, la naturalización de la violencia, pues muchos hechos no son tenidos en cuenta como noticia porque ya han llegado a concebirse como normales, lo que da cuenta de que las violencias, simbólicas y físicas, o que acontecen en la esfera privada, pierden relevancia y sentido para ser expuestas.

En este sentido en algunas de las afirmaciones de las mujeres entrevistadas, se planteaba que los medios de comunicación no difunden ni la mitad de los hechos que ocurrían en las comunas y que afectaban directamente a las mujeres, "lo que pasa en el barrio, no se cuenta en los medios de comunicación, nunca, es más el feminicidio que hubo en la Salle nunca se contó, las violaciones que ha habido en la cañada tampoco" (CO, C1, abril 10). Estas situaciones logran de alguna manera primero reproducir los imaginarios de que a las mujeres no les pasa nada grave y segundo que no tiene sentido la denuncia.

Se ha establecido que solo el 10\% de los crímenes de carácter sexual son denunciados a la Policía, y los casos que conocen las mujeres que habitan las $\mathrm{C} 1 \mathrm{P}$ y $\mathrm{C} 8 \mathrm{VH}$, se dan es por información de voz a voz que solo llegan a hacerse público cuando llegan al movimiento social de mujeres, es por esto que las violencias contra las mujeres no quedan reflejadas completamente en las estadísticas 
oficiales para establecer las tasas de criminalidad. Al respecto no entran en consideración los tipos de delitos que afectan a las mujeres según edad, estrato social, orientación sexual, jóvenes de la calle, drogadicción, explotación sexual, ni mucho menos si son los atributos del espacio los que facilitaron la ocurrencia del hecho (De la Cruz, C., 2007: 37).

El abordaje de la información por parte los medios de comunicación masiva, genera lecturas parciales frente tema, si bien de alguna manera la difusión de algunos de los hechos que afectan a las mujeres, ha incidido en actuaciones del movimiento social de mujeres, repercutiendo en la visibilización de las vulneraciones de las cuales son víctimas, también ha generado una respuesta negativa en tanto no le dan una "dimensión política a los hechos" (CO, C1, abril 10). Peor aún los actos de violencias contra ellas son justificados por los redactores de la noticia, en razón de que el comportamiento de las mujeres suscita dicha respuesta violenta, lo que de alguna manera termina ratificando los patrones sociales que indican que deben y que no deben hacer las mujeres, $\mathrm{y}$ determinando además los espacios por los cuales pueden transitar, para que puedan estar y sentirse seguras tanto en el espacio público como el privado, en este sentido lo plantea una de las entrevistadas:

"los medios de comunicación como pueden hacer bien, también han hecho mucho daño en las personas, porque generan como conciencia de que está permitido y que no está permitido, de que se puede hacer y que no se puede hacer, y en muchas ocasiones los medios de comunicación normalizan los episodios de inseguridad, de violencia" (LR, C1, abril 25).

Los alcances en la forma en que se construye la noticia son de tal magnitud que en las entrevistas se pudo constatar cómo se construyen las representaciones del espacio, y se reproducen comportamientos de rechazo y estigmatización a quienes habitan en los territorios y que marcan la idea de comuna que se tiene de ellas, es así como en la $\mathrm{C}_{1} \mathrm{P}^{109}$, fue fácil encontrar rechazo hacia la Comuna 13 - San Javier por las noticias generadas sobre este sector, como también sucedió de manera contraria con el sector de la Sierra ubicado en la $\mathrm{C} 8 \mathrm{VH}$, como lo plantea una de las entrevistadas:

\footnotetext{
109 Ubicada en la zona nororiental, $x$ distante de la Comuna 13 - San Javier, pero con características socio económicas similares y problemas de seguridad y violencia asociados a la existencia de grupos armados ilegales.
} 
“nosotros tenemos es la Sierra, la Granja esas partes, pero no vaya a creer, a la final allá no son ni tan peligrosos, porque esos son los referentes, pero los que yo veo que los que son los más silenciosos son más peligrosos" (AG, C8, abril 24).

Para quienes habitan la C8VH es un poco más fácil entender el contexto de violencia en el barrio la Sierra, mientras que el contexto de la Comuna 13 San Javier y el rechazo y miedo que produce este sector de la ciudad esta mediado por la representación que los medios de comunicación han construido. Y en este sentido también es posible interpretarlo desde quienes no habitan la C8VH.

\subsubsection{Otros recursos, otros medios de información}

Ante los vacíos en la información que presentan los medios masivos de comunicación, se implementan estrategias para la difusión de los hechos, algunas de ellas a través de redes de mujeres que utilizan el voz a voz entre mujeres cercanas y/o vinculadas al movimiento social, redes sociales, mensajes de texto y llamadas telefónicas entre ellas, para poner al tanto de las múltiples violencias que siguen afectando a las mujeres y establecer de esta manera estrategias de protección y de denuncia, de esta manera lo describe una entrevistada de la C1P:

\footnotetext{
"si una a una le pasa algo o la vecina y esa llama a cualquiera de las mujeres del movimiento y nosotras empezamos a comunicarnos y a contarnos que es lo que está pasando cierto ya decirle a la otra que hacemos que hay que hacer nos vamos para allá donde nos encontramos que tenemos que hacer como te podemos apoyar cierto pero nosotras las mujeres del movimiento porque la mayoría de las mujeres pues por ejemplo a mí en mi barrio muchas mujeres me dicen no se vaya por allá que por allá la van a matar fue como por allá que mataron a esa muchacha si usted se va por allá pues se mueren del susto muchas cierto yo si voy porque yo tengo otro otra forma de pensar y de ver las cosas" (DQ, C1, feb 13).
}

Incluso las redes sociales se han constituido como una de las más efectivas formas para difundir la información, llegando incluso a construir noticia. Contrastando información con la publicada en los medios masivos y generando estrategias para su difusión bien sea mediante las organizaciones sociales y comunitarias, agencias de prensa de organismos no gubernamental que se consolidan como las fuentes de información veraz para la elaboración de informes anuales de derechos humanos de las mujeres.

Estas estrategias complementan la información producida por las organizaciones del movimiento social de mujeres, sobre las violencias que afectan a las mujeres, que si bien no alcanza a tener una 
cobertura suficiente en tanto hacen parte de la literatura gris y no alcanza a tener la difusión que en este caso logran los medios de comunicación masiva, si constituye un avance importante para la visibilización y denuncia de las vulneraciones a los derechos humanos de las mujeres y que en consecuencia afectan su seguridad. 


\section{CONSIDERACIONES FINALES}

El concepto de seguridad tal como se ha entendido tradicionalmente, ligado al campo de acción de la Fuerza Pública, deja de lado otros campos de interpretación para entender las representaciones sociales que las mujeres han construido, en tanto que no permite un ejercicio pleno de sus derechos, que es hacia donde deben enfocarse las acciones emprendidas mediante la política pública. Sin embargo en la representación de (in) seguridad que las mujeres tienen median elementos ligados a la adscripción a algún proceso social sea del movimiento de mujeres o no, lo que ayuda a que se puedan determinar de una manera más amplia los factores de (in) seguridad, como también a identificar las diferentes violencias que las afectan.

En el contexto de la ciudad, se pasan por alto los hechos que afectan la seguridad de las mujeres como las violencias sexuales o la violencia intrafamiliar, estos casos representan en las estadísticas asuntos de menor atención frente al tema de los homicidios. Sin embargo, la reflexión frente a las violencias que conducen a la muerte de las mujeres, no alcanzan a tener un contexto de análisis suficiente para entender la gravedad de las mismas. La "pobreza" del dato en tanto el número de mujeres asesinadas frente al número de hombres asesinados, no es analizado en el contexto de ocurrencia del hecho. La cifra está por encima del lugar y la situación que conllevo al desenlace fatal, es decir, que sea en el ámbito del hogar, la vivienda donde ocurran este tipo de hechos, es una cuestión que no se alcanza a resolver porque no se ha trascendido la esencia misma del dato.

La construcción de la representación de (in) seguridad ligada a la familia se justifica en la trayectoria personal que cada una ha tenido, en estos resultados es erróneo entrar a un proceso clasificatorio y generalizador considerando los mundos que operan en esta construcción, sin embargo es en esta diversidad donde muchas mujeres pueden sentirse identificadas y no como seres extraños y particulares, que es finalmente lo que permite este tipo de investigaciones con orientación feminista ${ }^{110}$, que no tiene un fin comparativo en sí mismo, solo dar lugar a algunos aspectos relevantes que pueden ser comunes o distanciarse entre una comuna y otra, como también entre una mujer y otra.

\footnotetext{
110 Asumiendo las consideraciones que aporta la Teoría del Punto de Vista, que permite destacar el conocimiento de las mujeres desde su propia experiencia (Blazquez, Graf. N., Flores, Palacios. F., \& Ríos, Everardo. M., 2012)
} 
La representación de (in) seguridad en el espacio domestico está asociada no solo a lo que les pueda pasar a las mujeres o a los factores de riesgo a los cuales puedan estar expuestas por las personas con quienes habitan sino por el riesgo al que pueda estar expuestos las personas con las cuales habitan especialmente los hijos, pero este riesgo se maximiza cuando es la mujer la jefe de hogar. Allí opera el miedo y la inseguridad por transferencia, que es central en la construcción de las representaciones de (in) seguridad, pues la ocurrencia de hechos violentos a otras mujeres o la posibilidad de que un hecho violente afecte a los miembros de su núcleo familiar pasa por el cuerpo de las mujeres y asumen esa experiencia negativa en el otro/a, como algo propio.

Algunas respuestas asociadas a la representación de género mujer, que dan cuenta de unas relaciones entre mujeres caracterizadas negativamente por situaciones de envidia y conflicto, aparecieron de una manera más contundente en las mujeres entrevistadas de la $\mathrm{C} 8 \mathrm{VH}$, una causa posible de esta situación puede ser el tiempo de consolidación de los procesos de mujeres, que si bien en la C1P han tenido algunas dificultades y no se podría dar cuenta de un avance sustancial en el tema, hay unas ligeras manifestaciones que se asoman en las respuestas que dan cuenta por lo menos de una incipiente formación en relación con la $\mathrm{C} 8 \mathrm{VH}$, claro está que esta apreciación no es posible generalizarla en todas las entrevistadas, puesto que como se planteó en la metodología el proceso de selección fue aleatoria.

Las representaciones sociales de (in) seguridad marcan los comportamientos y las relaciones que las mujeres construyen con sus entornos sociales y espaciales, aunque en ocasiones pareciera haber contradicciones en la forma como asumen su seguridad pero también en los comportamientos dependientes de otra persona, sea mujer u hombre para sentirse seguras. La naturalización de este tipo de comportamientos da cuenta de que aún falta mucho para que las mujeres puedan no solo estar libres y seguras sino sentirse libres y seguras.

Si bien ha habido avances importante en las transformaciones sociales en relación al rol de las mujeres, esto no excluye que al interior de las familias se reproduzcan las figuras patriarcales desde las cuales se han determinado las relaciones de dominio, instalando privilegios sobre los hijos varones, y mayores niveles de dependencia con ellos que con las hijas mujeres, atribuyendo una mayor seguridad a la existencia de un hombre en el hogar, situación que se destaca que suceda incluso luego de que las mujeres hayan enfrentado un proceso de separación anterior. 
Las mujeres han establecido unos marcos de referencia a través de los cuales construyen su representación de la institucionalidad con la Fuerza Pública, en los cuales predomina una relación de desconfianza en sus capacidades para proveer la seguridad, ya que por el contrario son generadores de miedo y de inseguridad por múltiples razones entre las que están, su forma de relacionamiento con las mujeres jóvenes, las relaciones con los grupos armados ilegales que operan en los sectores y su ineficacia para responder a denuncias y necesidades de la población.

En el escenario de una ciudad como Medellín se complejiza la existencia de diversos actores que se constituyen como generadores de inseguridad, entre ellos actores institucionales que contradicen la función delegada por el Estado para brindar seguridad a las personas, en especial las mujeres jóvenes enfrentan riesgos asociadas a la violencia simbólica, pero particularmente no son plenamente reconocidos o identificados de manera general sino por mujeres que han construido una conciencia de género asociada a la naturalización de las violencias. Esta situación empeora cuando además no garantizan la administración de justicia sino que por el contrario conniven con actores ilegales, minando la confianza institucional y las posibilidades de denuncia de violencia contra las mujeres.

El Capital Social que se logra identificar con las mujeres es importante en tanto desde allí se establecen unas relaciones que promueven y garantizan el derecho de las mujeres a una vida libre de violencias, desde las cuales se generen las posibilidades para que se sientan seguras en sus territorios. Sin embargo el contexto para que este Capital Social exista y se consolide, sin dudas está atravesado por la existencia de grupos armados ilegales, cuyos miembros son cercanos a las mujeres, bien sea porque crecieron con ellas o porque incluso hacen parte de su núcleo familiar. Así mismo, las características socioeconómicas que prevalecen de pobreza y exclusión, así como el orden social dominante que se establece bajo las formas de subordinación de la mujer, generan una brecha cada vez más distante que hace difícil pensar que las representaciones de (in) seguridad disminuyan.

En particular la mayor parte de las mujeres entrevistadas consideraron la casa como un lugar seguro, esto en ningún caso puede conllevar a generalizaciones en tanto que hay unos componentes subjetivos que dan cuenta de esta representación que contradice los datos que desde las diferentes instancias de registros estatales, dan cuenta del elevado número de casos de violencia intrafamiliar, sin incluir allí los casos que no se denuncian. Esta situación puede considerarse como un caso particular, dado el universo de la muestra, incluso, es importante destacar el enfoque cualitativo del 
estudio que profundiza más allá del dato estadístico, lo cual es de alta relevancia en el enfoque de la investigación con perspectiva de género.

Para entender esta asociación de la casa como un lugar seguro que contradice la información objetiva, hay un elemento importante en el análisis y es las personas que conforman el hogar, el rol que dentro de esta conformación ocupan las mujeres y las relaciones de dependencia emocional y económica. Allí generalmente se destacan como jefas de hogar o con relaciones igualitarias en el acceso de ingreso, en los casos en los que esto no se presentaba las mujeres hacían parte de un proceso organizativo en el cual habían adquirido las herramientas para confrontar los escenarios de poder íntimos buscando la igualdad.

Aunque en ocasiones las representaciones de (in) seguridad en el espacio de ciudad y comuna se tornaran ambivalentes. Sin duda son el barrio y la comuna los referentes de proximidad que generan sentido de pertenencia y adscripción, hay una relación construida en la trayectoria personal de las personas que está sustentada en el tiempo que llevan habitando allí. Estos son escenario de sociabilidad que adquiere gran relevancia por encima de la ciudad, en la cual si bien su dotación física e infraestructura debería generar mayor seguridad se convierte en lo opuesto dado que su lejanía y extrañeza la dotan de una carga negativa desde la cual construyen su representación de (in) seguridad.

La difusión de la información de los hechos de violencia contra las mujeres, como los lugares de ocurrencia marcan de manera contundente los límites en la actuación de las mujeres, esto se da principalmente por la estigmatización que se construye en relación a los espacios y en la naturalización de comportamientos vetados que son castigados si van en contravía de la norma social. Allí los medios de comunicación tienen en parte una alta responsabilidad en tanto que la forma como presentan la noticia llega a mitigar la culpabilidad del delincuente como también a legitimar las acciones de violencia contra las mujeres cuando los argumentos están construidos a partir de los actos de las mujeres que "provocaron" el hecho. 


\section{BIBLIOGRAFIA}

Angarita C., P. E. \& Domínguez, Vial. A. (2006). Derechos humanos, seguridad ciudadana y fortalecimiento de la sociedad civil. Sistematización de experiencias. San José de Costa Rica: Corte Interamericana de DDHH.

Alonso Espinal, M. A. et al (2007). "Medellín: el complejo camino de la competencia armada". En: Mauricio Romero (edit). Parapolítica. La ruta de la expansión paramilitar y los acuerdos políticos. CEREC y Corporación Nuevo Arco Iris.

Araya, Umaña S. (2002). Las representaciones sociales, ejes teóricos para su discusión. (1 ed.). San José de Costa Rica: Flacso.

Arrieta Neira, E. B. y Quinchía Roldán. S. M. (2012). Urbanismo social: del discurso a la especialización del concepto. Caso Medellín - Colombia. Ponencia presentada en la $9^{\text {a }}$ Bienal del Coloquio Transformaciones Territoriales. Huellas e incertidumbres en los procesos de desarrollo territorial. Tucumán, Argentina

Augé, M. (2000). Los "no lugares", espacios del anonimato: una antropología de la sobremodernidad. España: Gedisa.

Auyero, J. y Berti, M. F. (2013). La violencia en los márgenes. Una maestra y un sociólogo en el conurbano bonaerense. Katz, Editores.

Bedoya, J. (2019). La protección violenta en Colombia. El caso Medellín desde los años noventa. Instituto Popular de Capacitación. Medellín.

Bedoya Vallejo, M. P. (2008). Feminicidios en Medellín, expresión de la violencia extrema basada en género. Texto inédito. Medellín, Secretaria de las mujeres.

Blair, Elsa et al. (2008). De memorias y de guerras. Informe final de Investigación. Medellín, INER, COLCIENCIAS, Alcaldía de Medellín.

(2012), Un itinerario de investigación sobre la violencia: contribución a una sociología dela ciencia. Medellín: Editorial Universidad de Antioquia.

Bedoya, J. (2010). La protección violenta en Colombia. El caso de Medellín desde los años noventa. IPC. Medellín.

Berger, P., \& Luckman, T. (2008). La construcción social de la realidad (1 ed.). Buenos Aires: Amorrortu.

Bourdieu, P., \& Kauf, T. (1999). Meditaciones pascalianas (Vol. 1). Barcelona: Anagrama. . (2000). La dominación masculina. España: Anagrama. . (2007). El sentido práctico (1 ed.). Buenos Aires: Siglo XXI. 
Camarena Córdova, R. M. (2003). Repensando a la familia: algunas aportaciones de la perspectiva de género. En: Estudios Demográficos y Urbanos. México. Vol. 18, No. 02, May.-Ago. p. 255-297.

Caicedo, L. P. (2013). Mujeres en territorios urbanos de inseguridad. Corporación Humanas. Bogotá.

Carrión Mena, F. (2008). "Sicariato" Boletín Ciudad Segura 24. Sicariato en el Ecuador 1. Available at: http://works.bepress.com/fernando_carrion/234

Ceballos Melguizo, R. (2000). "Violencia reciente en Medellín. Una aproximación a los actores." En: Colombia Latin American Perspectives. Ed: v. fasc. P, 2000. "Bloque Metro a punto de salir de justicia y paz". Disponible en: http://www.verdadabierta.com/component/content/article/44-procesos-judiciales-justicia-ypaz/3942-bloque-metro-identro-o-fuera-de-justicia-y-paz/. [Consultado el 20 de marzo de 2012].

Cobo, Rosa y Luisa Posada (2006). "La feminización de la pobreza" Disponible en: http://www.mujeresenred.net/spip.php?article620. [Consultado el 29 de junio de 2011].

Dammert, L. (2007). Entre el temor difuso y la realidad de la victimización femenina en América Latina. En: Ciudades para convivir: sin violencias hacia las mujeres. (Ediciones SUR., pp. 89-107). Santiago de Chile.

De Certeau M. (2000). La invención de lo cotidiano 1: artes de hacer. México: Universidad Iberoamericana.

De la Cruz, C. (2007). Espacios ciudadanos, violencia de género y seguridad de las mujeres. En: Ciudades para convivir: sin violencias hacia las mujeres. Debates para la construcción de propuestas. Chile: Ediciones Sur. pp. 203-216.

De Manuel Jerez, E. (2010). "Construyendo triángulos para la gestión social del hábitat". En: Habitat y Sociedad. Universidad de Sevilla. No 01. 1 de noviembre de 2010. pp 13-37

Delgado Ruiz, M. (1999). Ciudad líquida, ciudad interrumpida, Medellín: Editorial Universidad de Antioquia.

. (2007). Sociedades movedizas: pasos hacia una antropología de las calles. Barcelona, España: Anagrama.

Echeverria R., M. C., et al. (2011). Horizontes de sentido en la construcción social del habitat. Proyecto de investigación aplicada: Capacitación para la construcción social del hábitat en las comunas 1-Popular y 8-Villa Hermosa. Universidad Nacional de Colombia, sede Medellín, Facultad de Arquitectura, Escuela del Habitat-CEHAP. 
Espinal, M. A. y Valencia, G. (2008, julio-diciembre). Balance del proceso de Desmovilización, Desarme y Reinserción (DDR) de los bloques Cacique Nutibara y Héroes de Granada en la ciudad de Medellín. Estudios Políticos, 33, Instituto de Estudios Políticos, Universidad de Antioquia, 11-34.

Elias, Norbert (1998). La civilización de los padres y otros ensayos. Santa Fe de Bogotá: Editorial norma.

Franco R. V. L. et al (2004). Conflictos urbanos en las comuna 1, 3 y 13 de la ciudad de Medellín. Universidad Autónoma Latinoamericana.

Gil Ramírez, M. Y. (2009). Paramilitarismo y conflicto armado urbano. Relaciones entre el conflicto político armado nacional y las violencias pre existentes en la ciudad de Medellín: 1997 - 2005. Tesis de maestría en Ciencia Política. Instituto de Estudios Políticos, Universidad de Antioquia.

Gomez Osorio, D. (2008). Seguimiento a medios de comunicación. Una aproximación a la representación mediática de los hechos que afectan la seguridad pública de las mujeres, en tres medios de comunicación impresos de Medellín. Informe final de investigación. Documento inédito.

Gómez Ramírez, H. C. et al. (2008). Diagnóstico de Seguridad Pública para las mujeres de Medellín. Alcaldía de Medellín, Instituto de Estudios Regionales, Universidad de Antioquia. Documento inédito.

Gómez Ramírez, H. C:. et al (2012). Control territorial y resistencias, una lectura desde la seguridad humana, editorial La Carreta, Medellín.

Insuasty Rodríguez, A. et al. (2010). Las víctimas en contextos de impunidad, Caso Medellín.

Jaramillo, Arbeláez, A. M. et al. (1998). En la encrucijada. Conflicto y cultura política en el Medellín de los noventa. Corporación Región, Secretaria de Gobierno y Programa para la Reinserción - Red de Solidaridad Social. Medellín.

Jaramillo, Arbeláez, A. M. y Gil Ramírez, M. Y. (2014). "Medellín en su laberinto, criminalidad y violencia en los comienzos del siglo XXI”. En: Jaramillo, Arbeláez, A. M. y Perea, C. M. (Editores). Ciudades en la Encrucijada: violencia y poder criminal en Río de Janeiro, Medellín, Bogotá y Ciudad Juárez. Medellín.

Jean-Claude, A. (2001). Prácticas sociales y representaciones. México: Editorial Coyoacán.

Kaminsky, G. (2005). Tiempos inclementes, culturas policiales y seguridad ciudadana. Ediciones de la UNLa. Buenos Aires.

Kessler, G. (2009). El sentimiento de inseguridad: sociología del temor al delito. Argentina: Siglo Veintiuno Editores. 
Lamas, M. (1986). La antropología feminista y la categoría "género". En: Nueva Antropología. Revista de Ciencias Sociales, (30), 173-198.

— M. (2013). El género es cultura. Disponible en: http://www.oei.es/euroamericano/ponencias_derechos_genero.php. Consultado el 05 de julio de 2014.

Langton, R. (2001). “El feminismo en la epistemología: Exclusión y objetualización”. En: Fricker M. y Hornsby J. (2001). Feminismo y filosofía. Barcelona: Ideas Books.

Laub, C. (2007). Violencia urbana, violencia de género y políticas de seguridad ciudadana. En: Ciudades para convivir: sin violencias hacia las mujeres. Debates para la construcción de propuestas. Ediciones SUR. Santiago de Chile.

Lindon, A. (2007). El constructivismo geográfico y las aproximaciones cualitativas. En: Revista de Geografía Norte Grande, 37, 5-21.

Lopez, Diez. Pilar (2002). La violencia contra las mujeres en los medios de comunicación. En Dossier Mujer, violencia y medios de comunicación. Instituto de la mujer, Secretaria General de asuntos sociales, Ministerio de trabajo y asuntos sociales y Grupo RTVE. Madrid España, Pág. 27.

Lorente Acosta, M. (2001). Mi marido me pega lo normal, Barcelona: Ares y Mares, Editorial Crítica.

Madriz, E. (2001). A las niñas buenas no les pasa nada malo, Argentina: Siglo XXI editores.

McDowell, L. (2000). Género, identidad y lugar. Un estudio de las geografías feministas. Universidad de Valencia: Catedra.

McKinnon, Catherine (1995). Hacia una teoría feminista del Estado, Madrid: Ediciones Cátedra.

Massolo, A. (2007). Análisis y propuestas para la acción de los gobiernos locales en la seguridad de las mujeres en las ciudades. En: Ciudades para convivir: sin violencias hacia las mujeres. Debates para la construcción de propuestas. Chile: Ediciones Sur, pp. 133-153.

Medina, F. G. (2006a). Historia sin fin...Las milicias en Medellín en la década del noventa, Instituto Popular de Capacitación IPC. Medellín.

. (2006b) Una historia de las milicias de Medellín. Instituto Popular de Capacitación IPC. Medellín.

Misse, M. (2010). La acumulación social de la violencia en Rio de Janeiro y en Brasil: algunas reflexiones. En: Revista Co-herencia Vol. 7, No 13 Julio - Diciembre 2010, pp. 19-40. Medellín, Colombia.

Naranjo, G. (1992). Medellín en zonas, Monografia, Medellín: Corporación Región. 
. (2009a). Caracterización del desplazamiento forzado y el desplazamiento forzado intraurbano, asociado al territorio, el conflicto, la población afectada, la institucionalidad y las políticas públicas, Medellín: 2000 - 2008, Monografía, Comuna 1: El Popular, Instituto de Estudios Políticos - Universidad de Antioquia.

. (2009b). Caracterización del desplazamiento forzado y el desplazamiento forzado intraurbano, asociado al territorio, el conflicto, la población afectada, la institucionalidad y las políticas públicas, Medellín: 2000 - 2008, Monografía, Comuna 8: Villa Hermosa, Instituto de Estudios Políticos - Universidad de Antioquia.

Nieto Lopez, J. R. et al (2008). Resistencia civil no armada al conflicto armado y la exclusión social, casos comunas 8, 9 y 13 de Medellín. 2002 - 2006. Medellín: Universidad de Antioquia.

Pateman, C. (1995) El contrato sexual. Barcelona: Anthropos Editorial.

Prats Ferret, M. (2006). “Sexo, género y lugar”. En: Noague J. y Romero J. (2006). Las otras geografías, Valencia, España: Editorial Tirant Loblanch.

Rainero, L. (2007) "Las ausencias en las políticas urbanas y de seguridad ciudadana”. En: Revista de la Red Mujeres y Ciudad, Más Mujeres Más Democracia, No. 5, abril, Quito, Diputación de Barcelona, Red Mujeres y Ciudad, FLACSO Ecuador, AMUME.

Reguillo, R. (2002). La construcción social del miedo en la ciudad. En: Comunicación No 117, 8287.

. (2006). Los miedos contemporáneos: sus laberintos, sus monstruos y sus conjuros, en: Pereira G. José Miguel y María Villadiego Prins (Editores académicos). Bogotá. Editorial Pontificia Universidad Javeriana.

. (2002). Los laberintos del miedo. En: Revista de estudios sociales, Facultad de ciencias sociales, No 05. Uniandes. Bogotá (2000).

Rodriguez Salazar, T. (2007). Sobre el estudio cualitativo de la estructura de las representaciones.

In Representaciones sociales, teoría e investigación (1 ed., p. 334). Universidad de Guadalajara: CUCSH-UDG.

Salazar J., A. y Jaramillo, A. M. (1992). Medellín: las subculturas del narcotráfico, colección Sociedad y conflicto, CINEP, Bogotá.

Sánchez Gómez, G. (1991). Guerra y política en la sociedad colombiana, Bogotá: El Ancora. . (1995). “los estudios sobre violencia. Balance y perspectivas”. En: Sánchez Gómez, Gonzalo y Ricardo Peñaranda (comp.), 1995 [1986] [1991], Pasado y presente de la violencia en Colombia, Bogotá, IEPRI, CEREC, pp. 19-44. 
Sánchez Gómez, O. A. (2010). ¿Será que a las mujeres nos matan porque nos aman?, Feminicidios en Colombia 2002 - 2009. Casa de la Mujer, Funsarep, Ruta Pacífica, Vamos Mujer. Bogotá.

Sánchez Gómez, G. y Wills Obregón, M. E. (2011). Mujeres y guerra: víctimas y resistentes en el caribe colombiano. Bogotá: Comisión Nacional de Reparación y Reconciliación (CNRR).

Santos, M. (1996). Metamorfosis del espacio habitado (1 era.). Barcelona, España: Oikos Tau.

Segato, R. L. (2003). Las estructuras elementales de la violencia, Buenos Aires, 1ra edición, Universidad Nacional de Quilmes - Prometeo.

(2006). La escritura en el cuerpo de las mujeres asesinadas en Ciudad Juárez.

Territorio, Soberanía y Crímenes de Segundo Estado, México, DF: Ediciones de la Universidad del Claustro de Sor Juana.

Sepúlveda Arroyave, J. G. (2010). Vivencias urbanas de paz. Medellín, década de los 90a Fundación CIDOB, Fundación Casa América Catalunya, Human Iberoamérica.

Sennet, R. (1994). Carne y piedra, el cuerpo y la ciudad en la civilización oriental. Madrid, Alianza Editorial.

Vargas, V. (2006-2007). Espacio público, Seguridad ciudadana y violencia de género. Reflexiones a partir de un proceso de debate. Cuaderno de diálogos. UNIFEM Brasil y países del Cono Sur. $75 \mathrm{p}$.

Vélez, G. (2008). La construcción social del sujeto político femenino. Un enfoque identitariosubjetivo. México D.F: Miguel Ángel Porrúa y Universidad Autónoma del Estado de México. Facultad de Ciencias Políticas y Administración Pública.

Velez-Guzman, Y. (2012). Feminicidios en Medellín 2010-2011: Conceptualización, caracterización y análisis. En: Revista Criminaliad y Análisis. Volumen 54 No 2. Julio Diciembre de 2012, pp13-26.

Villa Martínez, M. I., Sánchez Medina, L. A., \& Jaramillo Arbeláez, A. M. (2003). Rostros del miedo: una investigación sobre los miedos sociales urbanos. Medellín: Corporación Región.

Unidad Mujer y Desarrollo (2004), "Entender la pobreza desde la perspectiva de género", Serie Mujer y Desarrollo, No. 52, Santiago de Chile, Comisión Económica para América Latina y el Caribe (CEPAL).

Zygmunt, B. (2003). Comunidad. En busca de seguridad en un mundo hostil. Madrid, España: Siglo XXI. 


\section{Fuentes institucionales}

Agencia Presidencial para la Acción Social y la Cooperación Internacional. Disponible en: http://www.accionsocial.gov.co/Estadisticas/publicacion\%20diciembre\%20de\%202009.ht m[Consultado el 28 de junio de 2010].

Alcaldía de Medellín (2008). Plan de Desarrollo 2008 - 2011, Medellín es solidaria y competitiva. Línea 4. Hábitat y Medio Ambiente para la gente. Disponible en: http://www.medellin.gov.co/alcaldia/jsp/modulos/P_desarrollo/obj/pdf/pplandllo/Plan\%20d e\%20desarrollo\%202008-2011\%20linea4.pdf. [Consultado el 9 de mayo de 2011].

Secretaria de Gobierno, sistema de información para la Seguridad y la Convivencia SISC. Boletín 2010 seguridad y convivencia en Medellín, marzo de 2011. (2011). Medellín en cifras No 2, Medellín. (2012). Plan de Desarrollo 2012-2015 "Medellín un hogar para la vida". (2012). Plan Integral de Seguridad y Convivencia. "Medellín un Hogar para la Vida". (2014). "En Medellín se realizó el primer Consejo de Seguridad para las Mujeres".

Disponible

en: https://www.medellin.gov.co/irj/portal/ciudadanos?NavigationTarget=navurl://2eeefc7ef3e c4a0101469d7acd6dc37a. [Consultado el 3 de julio de 2015]

Amnistía Internacional. Colombia Los paramilitares en Medellín: ¿desmovilización o legalización? Septiembre de 2005. Tomado de la página Web: http://web.amnesty.org/library/Index/ESLAMR230192005.

Asamblea General de Naciones Unidas (2006). Estudio a fondo sobre todas las formas de violencia contra la mujer. 6 de julio de 2006. A/61/122/add.1. 157

Coomaraswamy, Radhika (2002). Informe de la Relatora Especial de Naciones Unidas sobre la violencia contra la mujer, sus causas y consecuencias. Comisión de Derechos Humanos, $58^{\circ}$ período de sesiones, E/CN.4/2002/83/Add.3.

Comisión Nacional de Reparación y Reconciliación (2007). Disidentes, rearmados y emergentes. ¿Bandas criminales o tercera generación paramilitar? Área de Desmovilización, desarme y reinserción. Informe No 01.

Corte Constitucional. República de Colombia. Auto No 092 de 2008.

Defensoría del Pueblo. (2013). Informe de riesgo No 008-13. (Sistema de Alertas Tempranas - SAT No. 008-13) (p. 38). Medellín: Defensoría del Pueblo, Defensoría delegada para la prevención de riesgos de violaciones de ddhh y dih.

Departamento Administrativo Nacional de Estadística. (DANE) (2005). Boletín Censo General.

Disponible

en: 
http://www.dane.gov.co/files/censo2005/PERFIL_PDF_CG2005/05001T7T000.

[Consultada el 16 de septiembre de 2010]. . (2009). Encuesta de calidad de vida. Medellín. Alcaldía de Medellín.

Fiscalía General de la Nación, Instituto Nacional de Medicina Legal y Ciencias Forenses, Forensis 2000, 2001, 2002, 2003, 2004, 2005, 2006, 2007, 2008, 2009, 2010. Datos para la vida. Herramienta para la intervención y prevención del hecho violento en Colombia. Centro de referencia nacional sobre violencia. Bogotá.

García Alejandra (2010). "Situación de desplazamiento forzado intraurbano". Personería de Medellín. Presentación en Power Point.

Martínez Lavid, I. C. (2011), Violencia contra las mujeres "Por el hecho de ser mujer". En: Informe Semestral, Situación de los derechos humanos en Medellín. Personería de Medellín. Junio de 2011.

Medellín como vamos (2009). Informe de calidad de vida. Disponible en: http://www.fundacioncorona.org.co/descargas/publicaciones/gestion/GL_74_MCV_Inform e2009. [Consultada el 17 de mayo de 2010].

(2010). Situación económica de los hogares. Disponible en: http://medellincomovamos.org/informe-de-percepci-n-ciudadana-sobre-situaci-n-econmica-de-los-hogares-2010. [Consultada el 12 de febrero de 2011].

Personería de Medellín. (2013). Informe sobre la situación de los derechos humanos en la ciudad de Medellín (p. 146). Medellín: Personería de Medellín.

\section{Otras fuentes}

CORPADES (2009). Plan de Desarrollo Local Comuna 82008 - 2018 ¡Construyo, siento y vivo mi comuna! Medellín: Alcaldía de Medellín.

Corporación Con-vivamos (2009). Plan de Desarrollo Comuna 12005 - 2015. Medellín: Alcaldía de Medellín.

Corporación para la vida Mujeres que crean y Corporación Vamos mujer (2011). Entre resistencias $\mathrm{y}$ re insistencias, las violencias sexuales: en los andamios del patriarcado. IX informe sobre la situación de violación de los derechos humanos de las mujeres de Medellín, con énfasis en las violencias sexuales contra las niñas y las jóvenes, 2010.

INDEPAZ, Unidad Investigativa (2011), VII Informe sobre presencia de grupos narcoparamilitares en el 2011. 
Mujeres que crean (2005). Entre Resistencia y Re Insistencias. Violación de los derechos humanos de las mujeres en Medellín y el Área Metropolitana. Disponible en: http://www.mujeresquecrean.org/textos/INFORME\%20CMQC\%202005.pdf. [Consultado el 14 de junio de 2011].

Nowak, M. (2012). Femicide: A global problema. En. Research notes, Armed violence. Small Arms Survey. Numbre 14. February 2012. Disponible en: http://www.smallarmssurvey.org/fileadmin/docs/H-Research_Notes/SAS-Research-Note14.pdf . [Consultado el 10 de noviembre de 2012].

Secretaria de las Mujeres (2008). Situación de las mujeres de Medellín. Alcaldía de Medellín.

\section{Medios de comunicación}

Agencia de prensa del Instituto Popular de Capacitación IPC (2009a). "Pesadilla de víctima de trata de personas aún no termina", miércoles 18 de noviembre. Disponible en:http://www.ipc.org.co/agenciadeprensa/index.php?option=com_content\&view=article\&i d=348:pesadilla-de-victima-de-trata-de-personas-de-medellin-aun-notermina\&catid=78:general\&Itemid=176. [Consultado el 28 de junio de 2011].

(2009b). "Preocupación en la comuna 1 de Medellín por casos de explotación sexual" jueves 9 de septiembre de 2010. Disponible en: http://www.ipc.org.co/agenciadeprensa/index.php?option=com_content\&view=article\&id= 439:preocupacion-en-la-comuna-1-de-medellin-por-casos-de-explotacionsexual\&catid=37:general\&Itemid=150. [Consultado el 29 de junio de 2011].

(2010a). "Conflicto armado y violencia sexual: amenazas para mujeres de Medellín". Disponible

en: http://www.ipc.org.co/agenciadeprensa/index.php?option=com_content\&view=article\&id= 391:conflicto-armado-y-violencia-sexualamenazas-para-mujeres-demedellin\&catid=78:general\&Itemid=176. Jueves 22 de abril de 2010. [Consultado el 28 de junio de 2011].

(2011). "Pobladores ya no aguantan al guerra que se libra en la comuna 8 de Medellín”. Miércoles 02 de febrero de 2011. Disponible en: http://www.ipc.org.co/agenciadeprensa/index.php?option=com_content\&view=article\&id= 434: [Consultado el 28 de julio 26 de 2011].

(2012). "Reclutamiento de niños y jóvenes, un problema latente en Antioquia". Sábado, 26 de mayo de 2012. Disponible en: http://www.ipc.org.co/agenciadeprensa/index.php?option=com_content\&view=article\&id= 591. [Consultado el 03 de julio de 2015]. 
El inspector (2914). "El listado de combos que azotan a Medellín”. Junio 27 de 2014. Disponible en: http://www.ecbloguer.com/revelacionesdelbajomundo/?p=7180. [Consultado el 03 de julio de 2015].

Restrepo E. Juan Diego (2013). “Sectores de Fuerza Pública generan inseguridad”. En: Revista Semana. 01 de abril de 2013.

\section{Fuentes Primarias}

CA, Comuna Uno - Popular, febrero 10 y marzo 3 de 2012. (CA, C1 feb 10)

DQ, Comuna Uno - Popular, febrero 13 de 2012. (DQ, C1, feb 13)

MG, Comuna Uno - Popular, marzo 9 de 2012. (MG, C1, marzo 9)

CO, Comuna Uno - Popular, abril 10 de 2012. (CO, C1, abril 10)

LR, Comuna Uno - Popular, abril 25 de 2012. (LR, C1, abril 25)

EI, Comuna Uno - Popular, mayo 8 de 2012. (EI, C1, mayo 8)

CM, Comuna Uno - Popular, mayo 11 de 2012. (CM, C1, mayo 11)

IQ, Comuna Ocho - Villa Hermosa, febrero 16 de 2012. (IQ, C8, feb 16)

LR, Comuna Ocho - Villa Hermosa, febrero 24 de 2012. (LR, C8, feb 24)

CG, Comuna Ocho - Villa Hermosa, febrero 29 y marzo 7 de 2012. (CG, C8, feb 29)

RO, Comuna Ocho - Villa Hermosa, marzo 3 y 13 de 2012. (RO, C8, marzo 3)

AG, Comuna Ocho - Villa Hermosa, abril 24 de 2012. (AG, C8, abril 24)

RD, Comuna Ocho - Villa Hermosa, mayo 12 de 2012. (RD, C8, mayo 12) 